\title{
Stepping over the boundary: An exploration of educational psychologists' work with families
}

\author{
by
}

Claire Louise McGuiggan

This thesis is submitted to Cardiff University

for the Degree of Doctorate in Educational Psychology

July 2017 


\section{ABSTRACT}

Despite wide ranging literature (e.g. Systems Theories) supporting the need for practitioner educational psychologists (EPs) to work with families as central to good practice, there is very limited evidence of the ways in which EPs involve families, or how EPs conceptualise their role in work with children's families. This research set out to address this gap in evidence, and in doing so inform EP practice in this area.

A small-scale study was conducted to explore EP practice in relation to work with families and the EPs' perceptions of their role within this. Nine EPs from educational psychology services (EPSs) in four Local Authorities (LAs) were interviewed using semi-structured interviews that were then analysed using inductive thematic analysis. Four overarching themes were identified: Pre-school work, school based work, EP role and context. Within these themes, barriers and facilitators to EP work with families were highlighted, and the EPs' perceptions of their role explored.

The findings highlight both the range of practice, and the variance between participants' perceptions of the EP role with families. The impact of a traded model of service delivery was identified as limiting EP involvement with family systems and reinforcing a perception of the EP role being primarily school focused rather than child and family focused.

A number of implications for both individual EPs and EP services were identified in considering the profession's position in ensuring the needs of children and families are met within current service delivery models. The findings should provoke 
discussion for the EP community, in considering the profession's role in the area of EP work with families. 
signed... Claine MCEuigar

(candidate)

Date ...21/07/17 


\section{ACKNOWLEDGEMENTS}

My sincere thanks go to Andrea Higgins, tutor at Cardiff University, for her guidance, advice and support throughout this research study.

My thanks also go to those EPs who gave up their time to participate in this study, and share their experiences of their work. 


\section{DEDICATION}

For Huw.

Without whom, in so many ways, it would never have been done. 


\section{CONTENTS}

Page

CHAPTER ONE: INTRODUCTION

$\begin{array}{lll}1.1 & \text { Context } & 1\end{array}$

1.2 Literature Review 2

1.3 Empirical Research 3

1.4 Issues Relating to Definition 4

CHAPTER TWO: LITERATURE REVIEW 6

$\begin{array}{lll}2.1 & \text { Introduction } & 6\end{array}$

2.2 A Joint Systems Approach 9

2.2.1 The Joint Systems Approach and the Development of the EP Profession 10

2.2.2 Influence of the Family and the School 12

2.2.3 Linking the School and the Family 13

$\begin{array}{lll}2.3 & \text { A Systems Perspective } & 16\end{array}$

$\begin{array}{lll}\text { 2.3.1 Concepts within Systems Theory } & 17\end{array}$

2.3.2 Systemic Family Thinking 20

2.3.3 The EP Role in Systemic Approaches 22

2.3.4 Systemic Consultation 26

2.3.5 An Ecological-Systems Perspective 29

2.3.6 Bronfenbrenner Ecological Systems Theory 30

2.3.7 EP Role in Ecological Systems Work 32

2.3.8 Ecological Systems Approach in EP Assessment
and Intervention

2.3.9 Systems Work in Schools 36

2.4 The Influence of the Family System 38

2.4.1 Influence on Educational Achievement 39

2.4.2 Child and Family Well-being 41 
2.5 EPs, Family Collaboration and Intervention 45

2.5.1 Direct Family Support $\quad 47$

2.5.2 Joint Family School Consultation $\quad 50$

2.5.3 Parent Training Programmes 52

2.6 Criticisms of the EP Role in Family Work 54

$\begin{array}{lll}2.7 & \text { Summary of the Chapter } & 60\end{array}$

CHAPTER THREE: METHODOLOGY 62

$\begin{array}{lll}3.1 & \text { Overview } & 62\end{array}$

3.2 Epistemological and Ontological Assumptions of the Research 62

3.3 Methodological Position 66

3.3.1 Qualitative Approaches $\quad 66$

$\begin{array}{ll}\text { 3.3.2 Thematic Analysis } & 68\end{array}$

$\begin{array}{ll}\text { 3.3.3 Semi-Structured Interviews } & 70\end{array}$

$\begin{array}{lll}3.4 & \text { Method } & 72\end{array}$

$\begin{array}{lll}3.4 .1 & \text { Sampling } & 73\end{array}$

$\begin{array}{ll}3.4 .2 \text { Participants } & 73\end{array}$

$\begin{array}{ll}\text { 3.4.3 Data Collection } & 74\end{array}$

3.4.3.1 Semi-Structured Interviews $\quad 74$

$\begin{array}{ll}\text { 3.4.3.2 Pilot } & 76\end{array}$

$\begin{array}{lll}\text { 3.4.4 Data Analysis } & 77\end{array}$

3.4.4.1 Thematic Analysis and Thematic Networks 77

3.4.4.2 Interpretations and Reporting of the Findings 83

3.4.5 Reliability, Validity and Generalisation 84

$\begin{array}{ll}3.4 .6 & \text { Reflexivity } \\ 3.4 .7 & 87\end{array}$

3.4.7 Ethical Considerations 88 
$\begin{array}{lll}4.1 & \text { Introduction } & 90\end{array}$

4.1.1 Overview of Overarching Themes 93

4.2 Overarching Theme: Pre-School Family Work 94

4.2.1 Main Theme: Assessment 94

4.2.1.1 Sub-theme: Statutory Work 95

4.2.1.2 Sub-theme: Multiagency 100

4.2.1.3 Sub-theme: Context and Frequency 101

4.2.1.4 Sub-theme: Parent Voice 106

4.2.2 Main Theme: Intervention 107

4.2.2.1 Sub-theme: Advice and Signposting 108

4.2.2.2 Sub-theme: Counselling Role 111

4.3 Overarching Theme: School Based Family Work 114

4.3.1 Main Theme: Assessment/Formulation 114

4.3.1.1 Sub-theme: Formulation 115

4.3.1.2 Sub-theme: Use of Parental Meetings 119

4.3.2 Main Theme: Intervention 126

4.3.2.1 Sub-theme: Limitations $\quad 126$

4.3.2.2 Sub-theme: Direct Work 134

4.3.3 Main Theme: School Role $\quad 145$

4.3.3.1 Sub-theme: Referrals $\quad 145$

4.3.3.2 Sub-theme: School Expectations 148

4.3.3.3 Sub-theme: School Ethos 151

4.4 Overarching Theme: EP Role in Family Work 153

4.4.1 Main Theme: Strengths 153

4.4.1.1 Sub-theme: Child Focused 154

4.4.1.2 Sub-theme: Professional Role $\quad 156$

4.4.1.3 Sub-theme: Skill Base $\quad 157$ 
4.4.2 Main Theme: Restrictive Factors

4.4.2.1 Sub-theme: School Focused

4.4.2.2 Sub-theme: Professional Role

162

4.4.2.3 Sub-theme: Family Expectations

4.4.3 Main Theme: Ideal Role

4.5 Overarching Theme: Context of EP Role in Family Work 174

4.5.1 Main Theme: Service Delivery

4.5.1.1 Sub-theme: Trading

4.5.1.2 Sub-theme: Organisation of Service

4.5.2 Main Theme: Legislation

4.5.3 Main Theme: EP Training

5.1 Key Findings

5.1.1 Research Question 1: What are EPs' experiences of their work with families?

Pre-School Based Findings

5.1.2 Research Question 1: What are EPs' experiences of their work with families?

School Based Findings

5.1.3 Research Questions 2 and 3: What do EPs experience as the barriers and facilitators to their work with families?

5.1.4 Research Question 4: What do EPs feel their role should be in family work?

5.2 Methodological Reflections and Research Limitations

5.3 Future Research 200

5.4 Concluding Comments 201 


\section{APPENDICES}

Appendix 1: Gatekeeper Letter to Principal EPs 223

Appendix 2: Overview of Research Aims and Design Provided to Participants 224

Appendix 3: Indicative Interview Schedule 226

Appendix 4: Examples of Notes Made During Data Familiarisation 227

Appendix 5: Examples of Codes Identified on a Transcript 232

Appendix 6: Examples of Codes Grouped to Form Themes 239

Appendix 7: Thematic Map $1 \quad 246$

Appendix 8: Thematic Map 2 247

Appendix 9: Approved Ethics Committee Information 248 


\section{LIST OF TABLES}

Page

Table 1 Key features of the ecological systems theory (Bronfenbrenner, 1979, 2001)

Table 2 Ecological-systems perspectives for school based consultants

Table 3 Forms of intervention in a joint systems approach (Dowling and Osborne, 1995)

Table 4 The strengths and weaknesses of semi-structured interviews, adapted from Chris Livesey: Sociology Central, 1995-2017 (www.sociology.org.uk)

Table 5 15-point checklist of criteria for good Thematic Analysis (Braun and Clarke, 2006)

\section{LIST OF FIGURES}

Figure 1 Thematic Map Overview 


\section{ABBREVIATION LIST}

BPS British Psychological Society

CAMHS Child and Adolescent Mental Health

CWB Child Well-Being

DECP Division of Educational and Child Psychology

EHCP Education, Health and Care Plan

EP Educational Psychologist

EPS Educational Psychology Service

FSW Family Support Worker

FWB Family Well-Being

GST General Systems Theory

HCPC Health and Care Professions Council

LA Local Authority

PEP Principal Educational Psychologist

SA Statutory Assessment

SEN Special Educational Needs

SENCo Special Educational Needs Coordinator

SEND Special Educational Needs and Disabilities

SFBT Solution Focused Brief Therapy

TA Thematic Analysis

TEP Trainee Educational Psychologist

VIG Video Interactive Guidance 


\section{CHAPTER ONE}

\section{INTRODUCTION}

This study aims to explore Educational Psychologists' (EPs') experiences of their work with families within Local Authority (LA) Educational Psychology Services (EPSs). The rationale for choosing this area of study developed from my own 20 years' experience of working as an EP, and reflections over this time, both personally and with colleagues and teams within LAs, on the role of EPs within family based work. A review of the literature revealed that no studies had specifically examined EPs' experiences of family work, and also that the literature more generally around EPs and their work with families was limited in nature. The aim of this study is therefore to build evidence of EPs' reported experiences of their work with families, and from this develop an insight into EPs' understanding and assumptions about their role in this area of work, and what influences this, in order to inform EP practice in family work.

\subsection{Context}

The context in which Local Authority EPs work, has undergone a number of significant changes within the past seven years, the most significant of which are: a change in service delivery to a traded/part traded model in many services, and changes within SEN (Special Educational Needs) legislation.

In June 2010, following the formation of the Coalition Government, a national agenda to shift public services towards a 'traded' or commissioned position was put in place (Islam, 2013). This occurred within the context of significant cut backs in government 
funding as part of the comprehensive spending review (HM Treasury, 2010). As a result of this, many EP services took steps to move into a position of sustainability; where Local Authority funding could not be guaranteed to maintain an EP service to schools, and the budgetary powers to choose and purchase support services were being moved to schools. In these circumstances, a traded model of EP service was seen by many EPSs as the most sustainable route for the profession (Fallon, Woods and Rooney, 2010).

The Children and Families Act (2014) reviewed the legislation around children with special educational needs or disabilities (SEND), and the LA role, function and duty within this context. The SEND Code of Practice (DfE, 2015), issued following the Children and Families Act (2014), provided guidance for local authorities which described the provision of psychological advice, staff training, specialist support, identification of and review of strategies and interventions, as some of the EP duties within their statutory role in SEND assessments. The statutory role for EPs in the assessment of children with special educational needs has been in place since the 1981 Education Act, but the 2014 changes have focused on a more person centred, collaborative approach to the statutory assessment process, with guidelines within the Code of Practice for both LAs and EPs on how to achieve this aim.

\subsection{Literature Review}

Chapter Two provides a review of the literature. A systematic search of the literature using the databases Psychinfo, ERIC and ETHoS were utilised to identify relevant studies and papers. Using Boolean logic and search terms 'educational psychology' or 'educational psychologist' AND 'families' or 'family' or 'parents', AND 'systemic' were completed. Additional searches were also conducted on Google, Google 
Scholar and government websites, applying a snowball technique of referring to identified citations and references in order to expand the search and ensure the breadth of literature relevant to the research domain was examined.

The literature review examines systems theories and how these inform the work of EPs within family work. Considering systemic theories from family systems work, alongside eco-systems theories, and the ways in which the literature indicates these are used within EPs' work with families.

The literature review also considers the theories around the impact and influence of the family system on a child's development and well-being, to provide a further rationale for EP work within the family system. A joint systems approach of the EP joining the family and school is explored, and examples from the literature of EPs' work with families are then examined in relation to the theories considered.

\subsection{Empirical Research}

Chapter Three describes the empirical research, and the ontological and epistemological assumptions underpinning this research. The research aims to explore EPs' own views, beliefs and experiences, and therefore a qualitative design was adopted which assumes a social constructivist ontological position, that reality is complex and multi layered, and an epistemological assumption that knowledge arises out of a construction between the researcher and the researched (Tindall, 1994). A qualitative research design utilising the methods of semi-structured interviews and thematic analysis was used to construct meaning and understanding from the complex and dynamic social world in which EP family work takes place. 
Chapter Four presents the findings alongside a discussion of these in relation to the literature, presented within themes arising from the analysis of the data set, and with extensive use of quotations directly from the data to allow for a rich narrative and illustration of the themes, within individuals' experiences and across the data set.

Chapter Five then provides a summary of the findings, with implications for EP practice, service delivery and EP training considered. A critique of the research methodology is presented and possible areas of further research in this area discussed.

\subsection{Issues Relating to Definition}

The term 'family' is used within this study to indicate the significant people within a child's life who may:

- have parental responsibility for a child

- live with a child

- be related to a child

- be rearing a child

These relationships will be significant to the child, and will exist outside the school system and within a family system.

The term 'parent' may occasionally be used within this study in place of 'family', where that is the specific term used within the literature, or by a participant, or where the adults with parental responsibility are specifically being referred to. 
A definition of the term family was not provided to EPs participating within this study, as their personal construction of what this means within their own work experiences was allowed to develop through their personal narratives within the interviews. 


\section{CHAPTER TWO \\ LITERATURE REVIEW}

\subsection{Introduction}

'The central function of both schools and families is the nurture and education of children, a common task which should ensure their close cooperation and mutual support' (Dowling and Pound, 1994, p. 69).

Dunsmuir, Cole and Wolfe (2014) argued that it has been widely acknowledged that practitioner psychologists working with parents is central to good practice, and has become accepted as appropriate to the psychologist's scope of practice. However, they state that the nature of involvement is evolving as a result of professional, social, economic and legal shifts. They postulate that understanding the context in which families exist remains at the heart of assessment and adopting a critical approach to formulation is important to ensure that interventions are relevant, meet service users' needs and can be delivered with available resources.

The same authors further argued that in order for practitioner psychologists to engage effectively in work with families, they need a clear rationale for developing systems that support collaborative work with families. They also suggest that it is necessary to identify the factors that facilitate best practice, and challenge the barriers to collaboration and the delivery of effective interventions.

The rationale for EPs involving parents and families in their work, in linking the home and school systems to understand and intervene in children's difficulties, and working to strengthen families to promote best outcomes for children is clear within the literature, and will be considered within this chapter. The way in which EPs focus 
on collaborative family work and intervention within their practice, however, is less clear from the literature. Literature searches using educational psychologists and/or educational psychology and family and/or families identified very few articles within the UK context. Those which were identified were largely around families' experiences of specific SEN, and parental involvement in promoting academic outcomes. Searches using educational psychologist/psychology and parents generated a larger scope of literature with again a high focus on parental views and experiences of SEN. No articles specifically on EP practice in family work or on EPs' perceptions of their role in family work were found, indicating a paucity of research into an area of work widely acknowledged as central to the EP role (Dunsmuir et al., 2014). The search focused primarily on literature relating to the UK context, although some examples from international contexts have been included to highlight particular relevant areas.

The importance of engaging and involving parents within education has been highlighted by prominent EP practitioners, for example Sheila Wolfendale (Wolfendale, 1983, 1999; Wolfendale and Topping, 1996; Wolfendale and Cook, 1997; Wolfendale and Bastiani, 2000). However, there is limited evidence to demonstrate how EPs involve parents and families, alongside schools, in identifying needs and providing support for children, or the ways in which EPs construct and perceive their role in family work.

The aim of this research study is to address this gap in the literature and the assertion of Dunsmuir et al. (2014) that it is necessary to identify the factors that facilitate best practice, and challenge the barriers to collaboration, in order to inform effective EP practice in the area of family work. 
This research study will explore the experiences of Local Authority based educational psychologists, and their reported experiences of working with families. Within this it will be possible to explore and reflect upon the EP role in joining the two systems of home and school, how EPs involve families in this process, factors which may mitigate against, or support EPs in doing so, and the EPs own conceptualisation of their role within this.

I will begin by introducing the concept of a joint systems approach between family and schools in addressing the needs of children presenting with difficulties, how this has been approached in the development of the EP profession, and the relevance of this to current EP practice. I will then explore in more depth the theories underpinning 'systems' approaches, looking at systems theories, the development of systemic thinking in work with families, systems work with schools and families, and the development of an ecological systems framework for understanding children's development and difficulties, and how this relates to EP work with families. The role of the EP in utilising these theories within their practice in work with families will be considered.

I will then review some aspects of the literature around the family system's role, and impact on the development of a child, and the rationale that this provides for a joint systems approach in EP work. Examples from the literature of the ways in which EPs work with families will be considered, and criticisms of EP practice in family work and barriers to this work will be reviewed, to provide further context and rationale for this area of study. 


\subsection{A Joint Systems Approach}

The focus on a joint systems approach between home and school was first clearly stated in The Family and the School (Dowling and Osborne) published in 1985, and since updated in 1994 and 2003. This book brought together the separate developments in the application of systems theory to family therapy, and consultation in schools. It was viewed as a seminal text at the time of first publication for psychologists working in schools, and retains this status more than 30 years after publication. Its unique contribution has been the way in which it considers how the family and school systems merge and interact. The Family and the School aimed to provide a link between theory and practice and to connect the systems theory of family therapy to consultative work in schools.

Dowling and Osborne (1985) argued that although most professionals in the mental health field would recognise that two of the most influential systems in an individual's development are the family and the school, not enough has been done to bring these two systems together as part of a therapeutic strategy to address presenting difficulties for children. Their aim was that The Family and the School would clearly identify the need to link these two systems together, to bring about positive change for children, and would provide a framework for doing so. However, although the importance of their work was widely recognised, the impact on change in practice in linking the systems of home and school was slow. When they revised the book in 1994, Dowling and Osborne stated "in spite of an increasing use of systems orientation in many areas ... we think there is still a considerable need for this linking work to be done" (p. xv). 


\subsubsection{The Joint Systems Approach and the Development of the EP Profession}

The development of the educational psychology profession, and the changing perspective, roles, guidance, legislation and structures, was examined by Dowling and Osborne, and considered widely by other authors exploring the role of EPs in joint systems work (Frederickson, 1990; Gillham, 1978; Fine and Holt, 1983; Fox, 2009).

When the child guidance movement started in Britain before the Second World War it aimed to provide a service that took into account not only the potential and limitations of the children themselves, but also the two principal parts of their environment; their family and their school. To achieve this, a team, including a psychiatrist, psychologist and social worker, was established, which would take all the recognised variables into account and from there plan a relevant intervention for the child (Jones, 2003).

Although initially this may appear to be a joint systems approach, the practice of the child guidance teams did not take into account that simply sharing information from the different areas of a child's development did not provide an opportunity to see how the parts of the system interact and influence each other. Without this perspective it was not possible to intervene in the system itself with a view to changing the pattern of interaction for the better (Bowlby, 1994, in Dowling and Osborne).

MacKay (2006) discusses the creation of the educational psychology profession, and reports that Cyril Burt, as the first EP in Britain, in London City Council in 1913, expressed a clear commitment to understanding the families of children referred to 
the Child Guidance Centres, and immersed himself in the social and community settings of the children he worked with. He wrote:

'I recommended every educational psychologist, to start by actually living with his cases and their families' (in Hearnshaw, 1979, p. 39).

And he did so, in areas of socio-economic disadvantage in East London. However, as viewed through the modern lens of integrative practice principles, his work would be seen as being the practice of individual applied psychology within a community setting (Burton and Kagan, 2003), but he did at least see the profession as not being constrained, and limited to, the institution to which it belonged, and understood the importance of EPs working with families as well as schools.

Reconstructing Educational Psychology (Gillham, 1978) sought to challenge the traditional child guidance model of practice which had developed, and sought to reposition the EP profession away from the individualised deficit based model of the Child Guidance Centres, towards an emphasis on organisation, policy and structure of schools, the attitudes and behaviour of adults towards children, and an increased emphasis on preventative work. Educationalists moved on from the belief that all problems reside within the individual, to consider how pupils' behaviour is affected by the particular educational establishment of which they are part (Burden, 1981a, 1981b; Gillham, 1978, 1981; Rutter, Maughan, Mortimore and Ouston, 1979).

Part of the reason suggested for the lack of a systems approach linking home and school, by professionals working with children's difficulties, was thought to be that despite the reconstruction movement within educational psychology (Gillham, 1978), the strongly held belief by many families and schools, that children can be 'treated', and change, without any undue interference within the social system of which the 
child is a part, had persisted. Stoker (1992) looked at the forces mitigating against change in the role and practice of educational psychologists and suggested that to challenge such a belief is to challenge a very entrenched power structure which would not readily welcome change. In the original child guidance model the starting point was usually the child, based around a deficit model, and the intervention which followed focused therefore on the child. Within a systems approach, however, the child is no longer regarded as the primary focus for investigation or intervention, and a referral is more likely to be regarded as providing a point of entry into a number of relevant systems. Usually the most important of these will be the family and the school (Dowling and Osborne, 1985).

\subsubsection{Influence of the Family and the School}

At the time of writing The Family and the School, the notion of the importance of cooperation between teachers and parents was not new, and it was generally accepted that families and schools cannot operate in isolation without detrimental effect to the children (Kaplan, 1971). However, Dowling and Pound (1994) stated that there were few reported attempts at a multi-systems intervention even though the contextual complexity of school related problems for children was broadly understood by professionals. They highlighted those of Hobbs (1975) who applied ecological strategies, Tucker and Dyson (1976), who applied family systems theories, Aponte (1976), and Freund and Cardwell (1977) who reported interventions taking account of a complex web of interactions. All these writers expressed some commonalities in the reporting of their interventions: that facilitating collaboration between home and school is the mainstay of a successful approach, professionals should resist identifying the child as the problem at the outset, and should elicit 
commitment from staff and parents to a joint problem solving approach. Through working together, school staff and families can try to find solutions rather than identifying causes.

The vital context for a child is the family and the school, with the neighbourhood community implicit in both (Taylor, 1982). The relative importance of the influence on the child of family and school has been much debated by professionals. Reports by Coleman (1966), Jencks, Smith, Acland, Bane, Cohen, Gintis, Hayns and Michelson (1972) and Plowden (1967) all concluded that the family and the neighbourhood subculture was the decisive influence, with the implication that school could only ameliorate, but not make a comprehensive contribution to a child's development; which questioned the work of consultants for children with problems which focuses solely, or primarily, on the school. Other studies, however, attempted to tease out the factors of within school experience which could be seen to affect outcome, such as behaviour, learning, and personal satisfaction. Importantly, Rutter et al. (1979) found that schools have a greater effect on children than children do on schools, which brought about a focus on schools as systems and those factors which bring about successful outcomes, central to organisational psychology, when applied in schools.

The different approaches of 'systemic thinking', and systems work as applied in organisational contexts by EPs, and often the confusion between the two, will be explored further in this research study.

\subsubsection{Linking the School and the Family}

For four decades within the literature there has been an appreciation of the effects of home, school, and home school relationships on the life of a child (Anderson, 1983; 
Gilmore, 1974; Lombard, 1979; Pfeiffer and Tittler, 1983). Parental involvement in the education of children has long been regarded as an important element of effective education (see DES, 1967), and an extensive body of research supporting this view has developed (Cox, 2005; Desforges and Abouchaar, 2003; Eccles and Harold, 1993; Epstein, 2001). The importance of the link between home and school has therefore become a widely accepted fact for education professionals (Fine, 1985).

There have been numerous studies which identify that the influence of parents is not limited to the close family context but extends to the school environment (Casanova, Garcia-Linares, de la Torre and de la Villa Carpio, 2005), with various family factors highlighted as exerting influence, including the educational style of parents, parental involvement and parental expectations.

Parallel to this, much legislation, many initiatives and much political discourse has sought to empower parents, increase participation and focus on the importance of the family. Examples of this have been the Troubled Families Programme (2012), and the parent training voucher scheme (2012), both initiatives of David Cameron's Coalition Government. The generalised use of the term 'hard working family', first used by Gordon Brown in the 2005 election, also illustrates the importance placed on being seen to support the family unit across the political discourse.

The most recent and significant legislation, The Children and Families Act (2014), sought to give power to parents, define their rights and give them increased choice and control around special educational provision for their child. Political decision making has been influenced by the growing body of research that stresses the value of parental involvement in children's education. When it comes to children's 
outcomes, parents' behaviours and attitudes are more important than any other often cited factors, such as child care arrangements (Belsky, Vandell, Burchinal, ClarkeStewart, McCartney and Owen, 2007).

The effectiveness of both home based and school based parental involvement in improving academic attainment has been reported by several reviews and metaanalyses of the literature (Fan and Chen, 2001; Henderson and Mapp, 2002; Jeynes, 2005, 2007; Pomerantz, Moorman and Litwack, 2007). Other benefits of parental involvement which emerged from these reviews included improved parent teacher relationships, teacher morale and school climate, improved attendance, attitude, behaviour and mental health of children, and increased parental confidence and satisfaction in their child's education.

However, Hornby and Lafaele (2011) argued that despite the widespread acknowledgement of the benefits of parental involvement, there are clear gaps between the rhetoric found in the literature and the practices found in schools. This view is supported by findings from two surveys; one based in the USA, which limits direct parallels with UK schools, but which has some relevance due to the overlaps in the literature on increasing parental involvement, where of 1035 secondary school teachers, $83 \%$ felt that parental involvement in their school should be increased (Binns, Steinberg and Amorosi, 1997). Another UK based survey of parents found that $72 \%$ of mothers wanted more involvement in their child's education (Williams, Williams and Ullman, 2002).

Bevington (2013) looked at home and school communication and found over a third of parents wanting more communication, but that staff felt they were unable to provide this, which may relate to the findings of Hancock (1998) around the 
constraints and demands of the school day restricting staff levels of communication. Bevington (2013) argued that despite the growing knowledge and practice on engaging and supporting parents in education, there was a need for school staff development in maintaining effective home-school relationships and that there was a role for a Community Educational Psychologist in facilitating this support.

Whilst the literature on the influence of parents and the family on a child's education is clear and consistent, and the role of an EP has been widely acknowledged to necessitate joining the home and school systems, both as part of an integrated assessment process moving away from a child deficit intrapsychic focused model of practice, and in widening intervention strategies. However, the ways in which, or the extent to which, EPs achieve this within their practice has been less clear within the literature. This study will therefore provide a deeper reflection of the ways in which EPs work with families and schools to join the child's systems and how they perceive their role within this.

I will now move on to consider in more depth systems theories, and concepts within systems theories which underpin the assumptions informing a joint systems approach to EP practice, and which provide further rationale for EP work with families.

\subsection{A Systems Perspective}

Systems theory stems from General Systems Theory (GST) within the physical sciences (Bertalanffy, 1968), which are more exact and predictable than the social sciences, where boundaries around physical systems are more clearly defined than social systems. From GST, the use of organismic systems as a metaphor was 
developed and extended to many different kinds of science and social science (Frederickson, 1990).

A second strand of systems thinking developed around the use of computers (systems analysis) (Jenkins, 1969), and engineering, which utilised a more mechanistic metaphor than the organismic metaphor of the biological organism.

In general, a systems way of thinking when applied to human behaviour refers to the view that individual behaviour occurs within a context, and the behaviour of an individual within various contexts, or systems, will therefore affect and be affected by the behaviour of others. Both the organismic and the mechanistic conceptualisations of systems have been utilised to some extent within educational psychology, with the family the focus within the organismic system, and the school as an organisation the focus within the mechanistic system (Frederickson, 1990).

\subsubsection{Concepts within Systems Theory}

One of the basic tenets of general systems theory is the emphasis on the context in which the phenomenon occurs:

'Living systems, whether biological organisms or social organisations are acutely dependent on their external environment and so must be conceived as open systems ... open systems (which) maintain themselves through constant commerce with their environment i.e. a continuous inflow and outflow of energy through permeable boundaries' (Katz and Kahn, 1969, p. 91).

This means a move away from an intrapsychic perspective of a problem, to an interpersonal perspective; from an individual to an interactional view of behaviour. Within an interactional model, behaviour is viewed in terms of cycles of interaction. Instead of a linear perspective where A causes $B$, the behaviour of $A$ will be seen as affecting and being affected by $B$ and $C$ in circular causality: 
'any action is therefore seen as also a response and a response is also an action' (Dallos and Draper, 2005, p. 25).

This view implies a different epistemology; the question 'why' (linear, cause-effect model) is replaced by 'how' the phenomenon occurs, and attention is paid to the sequences of interaction and repetitive patterns which surround the event.

Plas (1986) suggested that the term recursive, identified by Bateson (1979) as a recursive phenomenon, is the product of multidirectional feedback, is not linear, and there is mutuality of influence. This notion of circularity, or recursive influence, is intimately linked with the concept of punctuation; that is the point at which a sequence of events is interrupted to give it certain meaning. The meanings ascribed to behaviours, and the causes of behaviour will depend on the point within an interactions cycle that reality is 'punctuated' or viewed.

The biological term homeostatic, which refers to the tendency of living organisms towards a steady state of equilibrium (Cannon, 1939), has been used in family therapy to view family systems as maintaining internal conditions or 'homeostasis'. Some family theorists such as Dell (1982) and Hoffman (1981) preferred the notion of 'coherence', referring to how the pieces of a system fit together in a balance internal to itself and external to its environment. The notion of the self-regulating properties of the family system have been developed within family therapy in understanding the purpose of a presenting problem, and the resistance to change due to the tendency to maintain the current equilibrium.

The concept of the self-regulating of dysfunctional behaviour, noted within the context of family systems, can also be transferred to a school setting where problem behaviours of certain individuals may maintain the status quo of an institution, which 
could find the suggestion of a different view or response to the problem behaviours to be a challenge to the school system, e.g. teachers can feel under pressure because they are working with children whose behaviour and cognitive skills are unacceptable to the whole system (Barrett and Trevitt, 1991).

Schools are like other systems in that they attempt to preserve equilibrium by encouraging conformity; those who do not conform create stress within the system and there may be pressure from within the system to remove them or isolate and reject them. Stability is a factor in maintaining a healthy system, but self-generated change is very difficult even within a healthy, open system. One result of this drive for equilibrium in both families and schools is that they can collude successfully to maintain this equilibrium at the expense of symptomatic children (Dowling and Osborne, 1985). System theory extends our understanding of the child in this context as the focus of a constantly developing and shifting web of relationships and interactions.

Within clinical psychology, the shift from the individual to the family as a system had a tremendous impetus in the development of clinical strategies with families; within the education context, however, although the interactional and systems approach has been recognised, theorised and discussed, there seems to have been less of an impact in practice for EPs (Pellegrini, 2009):

'It has alerted them to the dangers of labelling behaviour, but it has fallen short of equipping them with specific interventive strategies to deal with the problems they encounter' (Dowling and Osborne, 1985, p. 12). 


\subsubsection{Systemic Family Thinking}

Systemic family therapy grew out of the need to explain the complex patterns of interaction between family members, which intrapsychic psychodynamic approaches might not address successfully. This developed from General Systems Theory (GST) (Bertalanffy, 1968), which focused attention on the nature of interactions between elements of a system, also known as Cybernetics.

Within family systems work it was identified that a linear causal explanation of the problem was not helpful or realistic and it was more useful to identify the cycles of interaction within the family which contribute to the sustaining of a problem.

The 'system' within a family context became widely used in the 1970s within family therapy literature:

'A family is a system in the ways that parts of the family interact. Each family member takes on a role, has certain relationships with other family members, and performs certain activities in relation to the family' (Fine, 1979, p. 151).

Behaviour patterns evolve within a family and a pattern is set to which family members conform to maintain this. Family therapy literature supports the idea that understanding someone requires understanding their relationships and the character and functions of the system in which they are operating.

Some psychotherapists and social workers within child guidance centres became concerned with the individual pathologising of the child, and began to work with the family system rather than just with individual children. This family work, underpinned by systems thinking, fundamentally changed problems from focusing on the individual child, onto focusing on the interpersonal interactions within the child's 
family system. Understanding interactions, relationships and communication within the family became central to understanding the child (Fox, 2009).

'First order' systemic therapies, including Structural, Strategic and the Milan family therapies (Minuchin, 1974; Haley, 1976; Watzlawick, Weakland and Fisch, 1974), viewed families as systems that require homeostasis to function, and the therapist remains 'outside' the system and maintains an 'expert' role in guiding and influencing the family system. However, developments in post-modernist and social constructionist thinking (Carr, 2006; Dallos and Draper, 2005), influenced strands of systemic therapy known as 'second-order cybernetics'. The second-order school of systemic therapy was influenced by the social constructionist school of thought, and the principle that reality is subjective and co-constructed. Narrative therapy developed from this (White and Epson, 1990) which focuses on problem saturated narratives that are used to describe individual's identities. It externalises problems and aims to create and amplify alternative less problematic narratives (Morgan, 2000). The therapist maintains a 'not knowing' position and through questioning coconstructs alternative understandings. Solution focused brief therapy adopts this approach in shifting clients thinking from problem focused to exceptions, or times, when the problem is less evident or absent (Ajmal and Rees, 2001; de Shazer, 1985; George, Iveson and Ratner, 1990).

The second-order systemic therapies adopted the thinking that the therapist becomes part of the system within their role, and therapist and families influence each other, and they adopt a 'collaborative not-knowing approach' which engages families in conversations that co-construct alternative meanings about their lives (Maturana and Varela, 1980; Watzlawick, 1978; Selvini-Palazzoli, Boscolo, Cecchin and Prata, 1980). Cecchin (1987) adapted the state of 'neutrality' of the therapist, to 
one of 'curiosity' where the therapist maintains an interest in looking for explanations and resists traps of linear causality explanations.

\subsubsection{The EP Role in Systemic Approaches}

Throughout the 1970s and 1980s, following the publication of Reconstructing Educational Psychology (Gillham, 1978), there was a recognition of the need for EPs to move away from individual child focused work, but the focus that developed was primarily around developing systems work in schools using an organisational psychology approach as a basis for intervention, rather than the systemic approach being developed in clinics by family therapists. This led to the detachment of EPs from the systemic thinking which was developing in family therapy in the child guidance clinics, from which EPs were structurally and theoretically detaching (Fox, 2009).

Dowling and Osborne's (1985) recommended joint systems approach therefore was one of the first clear attempts to provide a systemic rationale to professionals within the context of family and school, with a focus on the interactions between these two systems, with the aim being to facilitate and co-construct understanding of the presenting difficulties. This approach joins the two principal systems of the child, and then facilitates them jointly working together to understand how the child's difficulties occur across both systems and how they can work together to address these. This approach not only brings the two systems together, but places the school based consultant in the role of facilitating their exploration of co-constructing their understanding of the presenting difficulties utilising systemic theories. 
When a child is referred to the EPS by a school, the 'problem' may be viewed in a number of different ways by the school and the family. The parents may view the problem as being school based and therefore explicitly or implicitly place responsibility with the school for the existence of the problem and the solution. Campion (1984) in a study of 72 children who received family therapy reported that parents usually see the child's problem as the school's responsibility.

Alternatively, the child's presenting difficulty may be viewed by school staff as caused by family situations at home. Staff may attribute the difficulty to home based events, or attitudes. This can lead to assumptions that the school can do very little, and the change needs to occur within the family, resulting in staff resisting school based intervention as it is viewed as futile (Dowling and Osborne, 1994).

Another view of the child's 'problem' may be that the school and family are united in recognising the problem in the child, and in demanding that something must be done (Dowling and Osborne, 1994). They collectively perceive the problem as being located within the child themselves, and they may seek a diagnostic label which will identify the 'problem' as neurological or developmental. When this view is taken, the context is played down or dismissed, and the focus is on supporting the child and 'management' of their 'problem'.

Dowling and Osborne (1994) suggested that whilst EPs need to take seriously the presenting problem, and it will almost certainly be the case that the referrer will see the child as having or being the problem, the aim should not be to go through a chain of possibilities in order to find whoever, or whatever, is the real cause of blame for the child's problem. The focus should instead be on the interaction between the 
various people concerned, adopting a systemic approach to school based consultancy.

Pellegrini (2009) considered different schools of systemic therapy and their usefulness and compatibility with EP practice in working directly with families whose children have been referred to EP services. Structural family therapy examines the family structures, such as the hierarchies and alliances between family members and sees dysfunction as stemming from inappropriate family organisation (Cottrell and Boston, 2002). It aims to support families in identifying boundaries that may have become over rigid or blurred, e.g. an ineffective parental subsystem failing to provide leadership, and a child taking on this role. Pellegrini (2009) suggested this approach can provide a useful theoretical perspective for EPs to help reframe 'within-child' behaviour problems as part of a problematic behaviour management style of the parents (Smith, Cowie, and Blades, 2004).

Strategic family therapy takes a more solution focused approach, in which behaviour can be viewed as a symptom which has meaning within the functioning of the family, and that it is often maintained by the behaviours that seek to prevent it. It aims to change interactions through a reframing of the meanings ascribed to the symptoms. Reframing is a central technique in this approach (Watzlawick et al., 1974), and through reframing the practitioner gives new meaning to the situation. Bowman and Goldberg (1983) described how school psychologists can use reframing to offer families alternative perspectives about children's difficulties that focuses on interactions and removes blame. They suggest:

'The function of reframing is to offer a different perspective that simultaneously validates the family's difficulties, while also providing insight and possible new ways of interacting within a supportive environment' (Bowman and Goldberg, 1983, p. 211). 
Questions are also a major systemic intervention in EP consultation (Ugazio, 1985). Questions are essential tools that therapists use to investigate and understand clients' functioning and beliefs. Different types of questions will serve different purposes at different stages of an intervention process, and through questioning an EP can also explore the beliefs of the client or system, and facilitate healing or change (Pellegrini, 2009).

Tomm $(1985,1987 b, 1988)$ analysed questions according to whether they intend to gather more information, or influence others and trigger change. Tomm's (1987a, $1987 b, 1988)$ ideas of the therapeutic potential of different types of questioning led him to develop the term 'interventive interviewing' to describe how therapists can use questioning to facilitate change. This type of systemic questioning can be used by EPs in work with adults, staff and family, when a child is referred with a 'problem', and moves formulation away from linear assumptions of cause and effect explanatory thinking, towards circular assumptions which seek to identify connections within the system, family and/or school.

Pellegrini (2009) used a case study to illustrate how systemic thinking and interventive questioning can be used to enhance EP practice, and bring about change for a child in the family and school system. He described his questioning of a mother, about her concerns over her child's eating habits and his use of exploration of family scripts and trans-generational family meaning and beliefs (Byng-Hall, 1995). He also described use of reframing, 'less of the same' and paradoxes (Watzlawick et al., 1974), interventive questioning (Tomm, 1987a, 1987b, 1988), including linear questioning to gather information, circular questioning to explore patterns of behaviour between members of the system and the impact on 
relationships, strategic questioning to influence behaviour and reflexive questions to enable the mother to reflect on patterns of interaction.

Pellegrini (2009) reflects on the very limited literature published at that time on the use of systemic thinking within educational psychology. He suggested that while EPs are often interested in applied systemic therapy, they are often unaware when approaches they are using are grounded in systemic thinking, such as solution focused brief therapy (SFBT), which has a more extensive literature on its use in educational psychology (Ajmal and Rhodes, 1995; Burns and Hulusi, 2005; Fogell, 1999; King and Kellock, 2002; Redpath and Harker, 1999; Rhodes, 1993; Stobie, Boyle and Woolfson, 2005; Thorne and Ivens, 1999; Young and Holdorf, 2003). Pellegrini suggests that SFBT is favoured by EPs as it is easily incorporated into EP work due to the time limited nature of its approach and its application with individuals. He cautions, however, that whilst systemic approaches can be used with individuals, the focus needs to remain systemic or there is a danger of being drawn back into 'within child' or 'within person' narratives. For an EP the systemic approach is a way of thinking which is in tune with the wish to avoid putting people, and children in particular, into categories and labelling them. A further important result of shifting the focus from the individual to the interactions they have is that the possibilities for intervention are immediately widened. Instead of putting all our energies into changing the individual, the emphasis is on attempting to change the situation.

\subsubsection{Systemic Consultation}

The use of consultation in EP practice has developed significantly since the 1990s and has been viewed as a crucial way in which EPs have moved away from focusing 
assessment and intervention on the individual child, towards working with the adults who hold the problem, and help them find solutions (Wagner, 2000). Consultation as a model of EP service delivery originates from a social construction psychological perspective (Kelly, 2008), where the emphasis is placed upon understanding that behaviour is intrinsically linked to the context in which it occurs, thus in order to fully comprehend an action, it needs to be viewed in relation to the social circumstances that impinge on an individual. When used in this way it is grounded within systemic theories (Kelly, 2008).

Different models and approaches to consultation can be used, and some approaches to consultation utilise systemic theories, although arguably this link is not always made explicit. However, the term 'consultation' can have implications for viewing the EP as the expert who holds the knowledge which allows them to identify issues and impart information to address these; akin to diagnosing an illness and then prescribing a treatment (Kelly, 2008). This relates back to the 'traditional' EP role of an individually-focused approach to practice, where EPs used the deficit model to assess children and provide advice (Farrell, 2010).

Much of the literature around EPs' use of consultation is focused on work with school staff, who refer children due to problems in school, and there appears to be very little published literature on EPs' use of consultation with families. This suggests that even where EPs may be using systemic consultation, it is still primarily being utilised with only one of the child's systems; the school, who refer, hold the problem, and receive the intervention. Peake (1999) argued that psychological services had increasingly become distant from children and families, and were more and more viewing themselves as services for schools. If a consultation model is used with school staff, around a child they have referred, where children and their families are 
not involved in the process, then the profession could be open to such a criticism. Turner, Randall and Mohammed (2010) argued that EPs can become distanced from the child due to only consulting with the adults supporting the child; the same can be said of families, unless they are involved in the consultation process.

Systemic consultation, however, can be used with families directly, or in joining the home and school system, when used with school staff and parents together. Nolan and Moreland (2014) discussed the process of joint consultations with schools and families. They described utilising a systemic approach of collaborative exploration to build a shared understanding between family and school, which brought about a more open dialogue, and collaborative working, reported by parents and teachers, than they had previously experienced when discussing the child's difficulties.

The aim of systemic based consultation is an awareness by all the adults involved that children's problems are at least partially maintained by the actions of the adults. If children's difficulties are seen as signs of individual pathology or neurological development, then consultation can only be of limited usefulness. If, however, adults believe that context, settings and relationships are always part of a problem, then consultative work can be of significant value (Conoley and Conoley, 1982).

Dawson and McHugh (1986) suggested that in historical terms, using systemic principles as a basis for thinking about problems was a relatively recent phenomenon at that time, and although those ideas had started to have increasing influence in the psychiatric and social work fields, the application of systemic principles to work with families and schools, particularly in an educational context had been even more recent; a view that is supported by the relative absence of relevant literature in this area, as discussed by Pellegrini (2009). 


\subsubsection{An Ecological-Systems Perspective}

An ecological systems perspective integrates concepts and techniques from systems theory and ecological psychology. This framework underscores the systemic nature of a child's relationships within and across settings and widens the possibilities for interventions (Fine, 1984). Whilst systemic theories developed to understand the interactions within the family system, an ecological-systems perspective extends this approach to consider the development of an individual within all the systems in which they operate, from their immediate relationships to their cultural context (Bronfenbrenner, 1979).

Fine (1984) stated that this framework has a particular usefulness for school psychologists, whose work necessarily involves the relationships of home and school settings in the context of a child's 'problem'. Fine wrote that a systems-ecological approach is particularly useful for school based mental health consultants, as these professionals have a psychological orientation, and therefore an understanding of the many influences on behaviour.

The historical use of the term ecological is in relation to the natural environment; the collection of reciprocal and interrelated forces around us. The use of the term ecological within a psychological perspective is to refer to the environment and the interrelated relationships which reciprocally influence and surround individuals.

Bronfenbrenner's ecological systems framework can be a useful means for furthering our understanding of the child within their environment. 


\subsubsection{Bronfenbrenner Ecological Systems Theory}

Bronfenbrenner's original ecological systems theory (Bronfenbrenner, 1979) and its further development within his bio-ecological theory of human development (Bronfenbrenner, 2001), recognises a child's development within the systems of relationships that form the nested layers of his or her environment, and provides a useful means for understanding the child. The various systems of a child (described in Table 1), include the influence of the people closest to them, their wider community and the cultural and political landscape in which these are situated. Their microsystem refers to their relationship to people and environment in their immediate setting such as the classroom, clubs and home. Their mesosystem refers to the interrelationships between the child's microsystems. The exosystem refers to the institutions or social structures, and the macrosystem refers to the overall cultural context the child is part of, such as the economic, political and educational systems.

Microsystems are embedded within and influenced by the structures that comprise the macrosystem, such as social, cultural, political and community structures ( $\mathrm{Ho}$, 1997). Factors such as the value placed upon, and investment in, education influence the macrosystem of a culture and impact upon educational systems within which EPs work, thus psychological assessment and intervention should take into account micro-, meso- and macrosystems (Fernandez, 2011). 
Table 1: Key features of the ecological systems theory

(Bronfenbrenner, 1979, 2001)

\begin{tabular}{|l|l|}
\hline Name of system & Key features of the system \\
\hline The Microsystem & $\begin{array}{l}\text { The features of the individual, family or } \\
\text { classroom. The systems in which the child lives: } \\
\text { including family, peers etc. This is the system in } \\
\text { which most direct social interactions take place. The } \\
\text { individual is not a passive recipient of experiences in } \\
\text { these settings. }\end{array}$ \\
\hline The Mesosystem & $\begin{array}{l}\text { Two microsystems in interaction with one } \\
\text { another. For example, interaction between their } \\
\text { parent and their teacher. }\end{array}$ \\
\hline The Exosystem & $\begin{array}{l}\text { External environments which indirectly influence } \\
\text { development, e.g. community based resources. } \\
\text { Exosystems are essentially any setting which affects } \\
\text { the individual, although the individual is not required } \\
\text { to be an active participant. This refers to community } \\
\text { level influence, including social norms and } \\
\text { standards. }\end{array}$ \\
\hline The Macrosystem & $\begin{array}{l}\text { The larger socio-cultural context. These are the } \\
\text { cultural values, customs and norms as well as social } \\
\text { and political contexts in which the child is situated. }\end{array}$ \\
\hline
\end{tabular}

The more recent bio-ecological theory of human development (Bronfenbrenner, 2001), also included the Process-Person-Context-Time (PPCT) model which presented development as a process of increasingly complex reciprocal interactions between an active and evolving person and people and objects within their environment. It also emphasised the synergistic interactions between heredity and environment (Bronfenbrenner, 2001). The model proposes that interactions (proximal processes) must occur regularly over an extended period of time in order to be effective. The chronosystem was added to the framework to encompass the pattern, duration and timing of experiences over a life span (Bronfenbrenner, 2001) to his original (1979) framework. 
The updated framework, including the chronosystem, suggests that subjective forces which exert a particularly strong influence over the proximal process, could lie within relationships with close family members and wider family networks, friends and neighbours. At a superordinate level, development is mediated by more distal, but powerful influences from the exosystem and macrosystem of an individual child.

\subsubsection{EP Role in Ecological Systems Work}

Anderson (1983) identified professional activities that can occur in each of the systems within the total ecological framework of a school; but acknowledges that most school based consultation is likely to be at the micro and mesosystem level, as these are the systems which are accessible for intervention and where producing change is more possible. Anderson (1983) also acknowledged, however, that in order for school based consultants to bring about greater and more lasting change, for the greatest number, change at the exo and macrosystems level would need to occur.

Fine (1985) identified that many school consultants probably use an ecologicalsystems perspective without calling it that. They may think in terms of 'understanding the whole picture'. What he believed can be missing from this, however, is the appreciation for the reciprocal and interactive nature of the child and their environment and the range of possible interventions this can point to.

Fine (1985) points to a number of factors relating to an ecological-systems perspective which need to be considered by consultants using this approach within schools: 
Table 2: Ecological-systems perspectives for school based consultants

\begin{tabular}{|l|l|}
\hline Ecological-systems perspectives for school based consultants: \\
\hline 1. & $\begin{array}{l}\text { There is no standard procedure. It is not a programme or operating } \\
\text { procedure, but is a framework within which a wide range of techniques and } \\
\text { interventions can be used selectively. }\end{array}$ \\
\hline 2. & $\begin{array}{l}\text { It is not synonymous with 'family therapy'. Although some concepts from a } \\
\text { systemic approach are applicable, the framework is primarily focused on } \\
\text { understanding patterns of behaviour and interactions, as this can lead to } \\
\text { opportunities for disrupting the sequence, thereby giving a wider scope for } \\
\text { intervention. }\end{array}$ \\
\hline 3. & $\begin{array}{l}\text { It concerns the material effect of the environment upon the child, which can } \\
\text { present opportunities for interventions within the environment rather than } \\
\text { the child as the focus. }\end{array}$ \\
\hline 4. & $\begin{array}{l}\text { The child exists in overlapping systems, and change in one system can } \\
\text { influence change in another. The exchange of information between the } \\
\text { home and school system can alter perceptions of the child's 'problem' within } \\
\text { one system and alter the patterns of interrelation within another system. }\end{array}$ \\
\hline 5. & $\begin{array}{l}\text { There is recognition that systems seek stability and may resist change in } \\
\text { order to maintain a homeostatic balance. This means that home and school } \\
\text { may exercise influence to maintain their own status quo, but may also } \\
\text { attempt to influence the other system to assume a similar perception in } \\
\text { relation to the child. }\end{array}$ \\
\hline 6. & $\begin{array}{l}\text { It considers that the systems based procedures and processes can } \\
\text { exacerbate or define a 'problem'. A frequent example of this is application of } \\
\text { labels that represent a static view of the child and which places the problem } \\
\text { as a within-child factor, giving a stimulus value to the child's influence on } \\
\text { interactions. }\end{array}$ \\
\hline 7. & $\begin{array}{l}\text { Within an ecological-systems perspective a school based consultant is able } \\
\text { to take into account the broad spectrum of interactions that influence, and } \\
\text { are influenced by the child, and the consultant is able to initiate conferences } \\
\text { and interventions that involve teachers, parents and the child (Aponte, } \\
\text { 1976; Fine and Pitt, 1980). }\end{array}$ \\
\hline
\end{tabular}

Psychological research examines mediating and explanatory variables that can provide specific and generalisable explanations for human behaviour, whereby specific explanations can lead to the implementation of targeted changes within a given microsystem, and generalisable explanations can be applied as part of a whole school approach to raise achievement and promote inclusion (Cameron, 2006). Interventions may also be implemented at a local authority level thus influencing micro-, meso-, exo- and macrosystems that impact upon child development, in 
addition to mediating the impact of chronosystemic factors. However, as noted by Anderson (1983) much EP work will be focused at the micro and meso level, the child's family, class and school, as these are the levels most readily accessible for intervention.

\subsubsection{Ecological Systems Approach in EP Assessment and Intervention}

Ecological theories are an example of a social constructionist approach - an approach which is reflected in current legislative frameworks regarding SEN. For example, the Special Educational Needs and Disabilities (SEND) Code of Practice (2015) promotes an holistic approach to take account of the many complex factors and differing contexts that may influence children's development. According to ecological-systems theory, developmental outcomes are influenced by dynamic interactions between the processes, values and characteristics associated with the individual child, their home, school and community (Kelly, 2008).

EPs' work, particularly assessment and intervention, may be focused on within-child explanations for behaviour resulting from individual differences at a biological, cognitive or behavioural level (Frederickson and Cline, 2009). Alternatively, EPs may adopt an interactionist perspective, viewing behaviour as a result of both within-child and situational factors, such as the influence of children's home and school environments and the cultural or socio-political context (Cunningham, 2016). EPs can gain an understanding of complex systems through a dynamic process of assessment involving information gathering from across systems, analysis, interventions across systems and review (Wood, 2015). 
Greater consideration of the varied systems and wider societal influences on development represented a move away from the more rigid, scientific and decontextualised approach previously espoused in psychological practice, towards ecological approaches. The Woolfson Integrated Framework, for example, which was developed to support EPs with assessment and intervention work, incorporates Bronfenbrenner's (1979) social ecology model to ensure a holistic understanding of the child across multiple contexts (Woolfson, 2008). Application of this framework by EPs can help to ensure professional standards, ethical practice and measured outcomes (Eodanable and Lauchlan, 2009). An ecological-systems perspective supports EPs to create a multi-layered understanding of a problem situation, thus reducing bias and stereotyping (Cameron, 2006). Arguably, it therefore supports anti-oppressive practices by increasing awareness of, and sensitivity to, the social, economic, cultural and political diversity of relevant parties and contexts, including the family.

EPs have a varied range of roles and responsibilities, one of which is to challenge 'common-sense' explanations by encouraging consideration of alternatives (Cameron, 2006). This may involve the EP using collaborative consultation and positive re-framing techniques to help parents and teachers move from a childcentred explanation for behaviour at the micro level, to a contextually-based explanation at the macro level (Kennedy, Cameron and Monsen, 2009). EPs are responsible for the co-ordination of proposed interventions and can advise on potential implications for the child in question (Fernandez, 2011). Intrinsic to this is the need to consider the differential impacts of, and work within, the systems around the child to support exploration of alternative, contextual explanations for behaviour, and ensure the effective implementation of interventions. 
An interdisciplinary approach to planning and intervention has been described as "the most logical from an ecological perspective" (Ho, 1997, p. 35) development whereby the role of EPs is to ensure the most effective maximisation of, and interconnections between, family, school and community resources which contribute to the child. Resources identified within the family microsystem include the provision of basic needs and support with the development of positive self-concept and attitude to learning (Ho, 1997). As such, EPs direct work with families can help to improve the context within the home microsystem, creating a foundation for further learning and development within the school system.

An example of this is how EPs can facilitate collaboration between the home and school, and may adopt a particular important bridging role where the relationship between home and school has broken down. The EP can work with both of these microsystems to draw out beliefs and attitudes that may be exacerbating the child's difficulties, and identify areas for improvement within each. Ho (1997) proposed that the formation of effective connections between resources is assisted by the nurturing of collaborative relationships, forming partnerships, setting goals, establishing mutual respect, sharing knowledge, structured and frequent interactions, and reciprocal empowerment - activities which the EP may be involved in whether working within a specific system or alongside wider systems.

\subsubsection{Systems Work in Schools}

The reconstruction movement in educational psychology which occurred in the 1970s and 1980s (Gillham, 1978; Burden, 1978a, 1978b, 1982) argued for the benefits of moving away from dealing with individual referrals to becoming 'school based consultants'. Burden (1982) described a team approach to working with 
school staff at the 'systems level' to bring about organisational change in schools. This 'systems work' can be seen as the beginning of some confusion within the EP profession between, 'systemic' thinking and approaches, and 'systems' work with the school as an organisation.

Burden's work drew on Georgiades and Phillimore's (1975) seminal paper on the difficulties of the hero innovator in making changes in a system. This systems work was about organisational change based on an Organisational Development Model (Fox, 2009). A number of EPs at this time wrote about, and promoted, work with schools as organisations (Hart, 1979; Topping, 1979; Miller, 1980) and the term 'system' was used interchangeably with 'organisation', blurring the lines between a systemic interactional approach, and organisational or whole school work (Fox, 2009). Fox (2009) suggests that the confusion between systemic thinking, and systems work linked to organisational development, which developed in the 1970 s and 1980s, has persisted within EP literature since that time.

Throughout the 1980s and 1990s many psychologists were describing systems interventions in schools (Gersch and Noble, 1991; Stoker, 1987; Stratford, 1990), using management and organisational psychology as central to their thinking. EPs were then using a number of strategies to promote change in schools including INSET training, Action Research, Organisational Development and consultancy (Fox, 2009). A few EPs were beginning to bring together the process led model of organisational change and an ecological systems perspective, which recognised the importance of the child within a range of complex organic systems (Thomas, 1987), but it was the seminal text of Dowling and Osborne (1985) that highlighted that the family and the school are two separate but interrelated systems, and who provided the link between using systemic approaches, and bringing the two systems together 
to create positive change for children. They provided the first detailed and practical examples of how systemic family thinking could be applied by EPs in schools. In 1999, Burden reflected that his biggest regret within systems/organisational work in schools was the absence of the paradigm shift to second order cybernetics that occurred in systemic thinking, but which was not incorporated into systems work for EPs (Fox, 2009).

\subsection{The Influence of the Family System}

As noted previously, the influence of the family on a child's development has long been recognised as the most significant and influential factor (Belsky et al., 2007). This recognition goes back to ancient thinking about society and family in the West and in the East. Plato's Republic postulated that the unity of the state depended on the unity of the family (translations by Jowett, 2000), and Confucius postulated that until, and unless the family unit is 'in order', the nation and the world cannot be 'in order' (Confucius, in Whaley, 1938).

Modern research and theories have sought to explore and explain the long recognised importance of the family, and political discourse focusing on the family unit, around 'troubled families' and 'hard working families' has placed the family as central to societal stability.

Good practice recommendations for all professionals who work with children are to involve and support parents, and schemes such as parenting programmes and family interventions have continued to grow (Moran, Ghate and ver der Merwe, 2004). 
Dunsmuir et al. (2014) suggested that in order to meet the demands for family focused intervention, practitioners need to have a clear rationale for developing systems that support collaboration with families, as well as identifying factors that facilitate best practice, and factors which challenge or create barriers to collaboration and intervention with families. They argued that although it was widely acknowledged that working with parents was good practice for EPs, and that the planning and delivery of interventions was accepted as appropriate to the scope of psychologists' practice, the nature of involvement was evolving due to professional, social, economic, and legal shifts.

The influence of the family system on a child's development, and the rationale this can provide for EP work with families, will now be considered. This will, by necessity, be a broad overview of some key areas which could be considered in providing a rationale for EPs' work with families, as an in depth consideration of the family influence on all areas of development cannot be fully addressed here due to the word limitations and the breadth of the theories and research in this area.

\subsubsection{Influence on Educational Achievement}

Within the literature there has been an appreciation of the effects of home, school, and home school relationships on the life of a child (Anderson, 1983; Gilmore, 1974; Lombard, 1979; Pfeiffer and Tittler, 1983) which prompted a call for greater parental involvement in education and the need for a family orientation within education (Fine, 1985).

Parental involvement in the education of children has long been regarded (see DES, 1967), as an important element of effective education, and an extensive body of 
research supporting this view has developed (Cox, 2005; Desforges and Abouchaar, 2003; Eccles and Harold, 1993; Epstein, 2001). The effectiveness of both home based and school based parental involvement in improving academic attainment has been reported by several reviews and meta-analyses of the literature (Fan and Chen, 2001; Henderson and Mapp, 2002; Jeynes, 2007; Pomerantz et al., 2007). Other benefits of parental involvement which emerge from these reviews include improved parent teacher relationships, teacher morale and school climate, improved attendance, attitude, behaviour and mental health of children and increase in parental confidence and satisfaction in their child's education.

There have been numerous studies which identify that the influence of parents is not limited to the close family context but extends to the school environment (Casanova et al., 2005) with various family factors highlighted as exerting influence, including the educational style of parents, parental involvement and parental expectations.

The link between parental expectations and children's academic achievement has been consistently shown across numerous studies (Frome and Eccles, 1998; Singh, Bickley, Keith, Trivette and Anderson, 1995; Steinburg, Lamborn, Dombusch and Darling, 1992; Wang and Wildman, 1995).

Christenson, Hurley, Sheridan and Fenstermachor (1997) argue that variables related to parental attitudes and behaviour are more important in improving academic results than social class or family make up. They argue that it is through attitude and behaviour that parents transmit positive educational experiences to their children, and these are the factors which influence academic outcomes. Deslandes, Potvin and Leclerc (1999) also conclude that parental variables, such as parental style and parental involvement are stronger predictors of academic achievement 
than family characteristics, and students with problems report their parents display a lower level of supervision, support and affection, as well as higher levels of conflict, in comparison to students with no achievement problems.

Casanova et al. (2005) argued that students may benefit from programmes directed at parents which aim to increase the support and acceptance parents demonstrate, increase parental interest and involvement and raise levels of parental expectation. Their findings indicate that it is necessary to consider the role of parents and the influence of family variables when tackling low achievement in schools. Furthermore that knowledge of which family and parental practices are most beneficial to children's achievement should be used as a preventative measure through promotion of these practices.

This strong body of evidence for a significant parental influence on academic achievement, and an understanding of the ways in which family and parental factors influence the development of a child allows EPs to apply this knowledge within the ecological systems frameworks already discussed, within both their assessment and intervention practice.

\subsubsection{Child and Family Well-being}

Children are referred to educational psychology services, due to concerns around aspects of their development or well-being. The Scottish Division of Educational Psychology in the BPS refers to a number of EP services who highlight promoting psychological well-being as being central to the practice of EPs. The DECP professional practice guidelines state the EP role should always be around achieving positive outcomes for young people, with the primary focus being on the well-being 
and needs of young people. The AEP in their 2017 manifesto for all children and young people argued that EP work should not only be in supporting those children with Special Educational Needs and/or Disabilities, but should address the wellbeing of all young people.

The literature already considered, around the significant impact of parents and families on a child's emotional and cognitive development, and a child's academic performance, has been considered as a rationale for EPs involving families in bringing about positive change for children who have been referred; here I will consider the wider scope of family well-being and the impact this has on a child's development and individual well-being, and the further rationale this provides for EP consideration of this within assessment and intervention when a child has been referred.

Family well-being (FWB) is one of the strongest and most consistent predictors of child well-being and resilience (Newland, 2014). Aspects of FWB, including adult health and well-being, family self-sufficiency, and family resiliency, have been shown to impact child well-being through parent child interactions. However, risk factors for families such as poverty, limited resources, poor adult health, and inter family conflict can threaten family and child well-being. Newland (2014) argued that strategies for reporting FWB through supporting family resilience will impact positively on child well-being and resilience.

If FWB is identified as one of the strongest predictors of child well-being, then promoting family well-being must be considered by EPs in order to promote child well-being, if this is viewed as the aim of their practice. Family well-being is a broad construct capturing individual and family level variables, but is generally considered 
to include physical and psychological well-being, strong family relationships, financial security, protective factors and interdependence between these components (Buehler and O’Brien, 2011; Chien and Mistry, 2013; McKeown, Pratschke and Haase, 2003). Parental well-being influences FWB because of the influence of their decisions on all family members, and the effect of their behaviours across the whole family system, all of which impact family well-being, family resiliency and family selfsufficiency, identified as the core aspects of FWB (Buehler and O’Brien, 2011).

Parental physical and mental health are important components of FWB and can have a lasting impact on the family system (Sawyer, Gale and Lambert, 2006). Mental health problems such as depression and anxiety can lead to poor family relationships, dyadic conflict, unhealthy behaviour patterns and poor work productivity and satisfaction (Carlson, Kacmar and Williams, 2000; Edwards and Rothbard, 1999).

Family resiliency is vital to FWB, and is defined as a family's ability to strengthen family relationships and enhance personal growth through positive management of conflictual or stressful situations (Walsh, 2003). If positive family functioning in the areas of communication, role satisfaction, problem solving and strong connected relationships can be strengthened, then parent child interactions and child outcomes are improved (Carr, 2013; Newland, Chen, Coyl-Shepherd, Liang, Carr, Dykstra and Gapp, 2013).

Family resiliency can be bolstered through improving family leadership skills, increasing optimism, strengthening relationships within families and broader social networks (Bandura, Caprara, Barbaranelli, Regalia and Scabini, 2011).

The literature on child well-being and family resilience is clear: 
'Children need supportive and close relationships with at least one parent or caregiver to optimise their outcomes, and parenting quality may be threatened by multiple interactive factors that exacerbate family stress and dysfunction' (Newland, 2014, p.1341).

Extensive research has linked a lack of early nurturing experiences and relationships to a wide variety of risk factors in later childhood, adolescence, and into adulthood, such as anxiety, depression conduct disorders, language development difficulties, cognitive development difficulties and difficulties in forming relationships (Landry, Smith, Millar-Loncar and Swank, 1997; Murray and Hornbaker, 1997; Sung and Hsu, 2009; Taylor, Anthony, Aghara, Smith and Landry, 2008; Carr, 2006). The research in all areas points to the crucial determinant in the child's outcomes being the quality of parent child interactions during the first three years of life (Murray, Arteche, Fearon, Halligan, Goodyer and Cooper, 2011).

The disruption of healthy attachments due to mental health difficulties within a family has been widely explored, particularly the impact of maternal postnatal depression on infant and child development. The risks are well documented and long term, including increased risk for future depression (Murray et al., 2011), lower expectations in academic achievement at GCSE level (Murray, Halligan and Cooper, 2010), and negative impact on attention (Hay, Pawlby, Sharp, Asten, Mills and Kumar, 2001). Newland (2014) recommended that practitioners involved in promoting child well-being should evaluate the context in which the family system is embedded and identify unique contextual factors which may be barriers to FWB and supportive parenting, evaluate parenting practices, evaluate well-being and resilience, and consider overall FWB. The practitioner will then be in a position to create an individualised family intervention plan which builds upon strengths and mitigates risks, and therefore promote well-being for the individual child. 
Newland's (2014) recommendations for practitioners to promote family well-being through evaluating the family context, and identifying contextual factors which may be barriers to FWB, can further be viewed as part of an ecological systems framework which can be used by EPs to inform assessment, and structure intervention plans, to bring about positive changes for the child who has been referred. In this way the ecological systems framework is not used to only assess the child within their own systems, but also to assess the strengths and needs of the systems themselves, namely here the family system and its context, to promote best outcomes for the child. This approach therefore opens up wider opportunities for interventions across the child's systems. As parenting capacity, family well-being and family relationships have been identified as strong predictors of child well-being and resilience, they are therefore valid focus areas for EP practice given child well-being is seen as the driver of that practice.

\subsection{EPs, Family Collaboration and Intervention}

The rationale for involving parents and families in their child's education, in linking the home and school systems to understand and intervene in children's difficulties, and working to strengthen families to promote best outcomes for children is clear within the literature. The way in which EPs focus on collaborative family work and intervention within their practice is, however, less clear.

Dowling and Osborne made it clear that a joint systems approach is a general framework for conceptualising problems, and that decisions on how to work collaboratively or intervene can take several forms and are dependent on many factors. 
Table 3: Forms of intervention in a joint systems approach

(Dowling and Osborne, 1995)

\begin{tabular}{|c|c|}
\hline 1. & A joint family school intervention with an individual referral. \\
\hline 2. & $\begin{array}{l}\text { Initial contact with family and school but focus on treatment of } \\
\text { the family alongside consultation with school staff. }\end{array}$ \\
\hline 3. & $\begin{array}{l}\text { An ongoing school based consultation for parents and } \\
\text { teachers, geared to dealing with the problems in the school } \\
\text { context and to build skill levels of school staff. }\end{array}$ \\
\hline 4. & A family system based model in an education context. \\
\hline 5. & A family consultation in the school setting. \\
\hline 6. & $\begin{array}{l}\text { An intensive consultative service to a school which may or } \\
\text { may not include interviewing families. }\end{array}$ \\
\hline
\end{tabular}

The decision for an EP on how to proceed following a referral will depend on who is concerned, what the concern is and what the expectation of the EP involvement is.

A themed edition of Educational and Child Psychology Volume 31, Number 4, December 2014, Working with Families: Collaboration and Intervention, generated the widest examples of practitioner work reflecting the collaboration and intervention approaches already discussed. This edition presented family work carried out by professionals in this area, including clinical and educational psychologists, to provide a flavour of the diverse nature of family work currently taking place.

Some of the ways that EPs' work can reflect the collaborative rationale discussed within this chapter will now be reviewed, through a consideration of examples within the published evidence, and with reference back to the joint approaches postulated by Dowling and Osborne (1985).

It is not possible here to consider the full scope of EP family work in depth or detail due to the wide variety of forms this may take, therefore examples within the areas of 
direct family support, joint family and school consultation, and parent training and workshops will be considered, as the majority of EP family work will fall into one of these categories.

\subsubsection{Direct Family Support}

The use of therapeutic approaches by EPs working directly with parents reflects the use of systemic theories explored earlier in this chapter. McQueen and Hobbs (2014) described how they utilise narrative therapy to try and redress the differential power that exists between parents and EPs, and enhance the value of parents' experiences. Through the use of 'genuinely curious' questioning they describe how it is possible to consider what parents believe to be important for them and their children, how those beliefs have formed, and how they might put this into practice in their family life. The case study they described consisted of five meetings, or 'conversations' between the psychologists and the parents, the use of outsider witnesses, and a therapeutic letter. McQueen and Hobbs (2014) reported that in this case study the conversations moved away from the focus of the 'problem child', to wider discussions about their strengths as family, and how these had formed. At the end of the sessions the parents reported that they felt more confident in managing their family life.

McQueen and Hobbs argue that in their experience, parents' conversations with professionals are often based around information gathering, problem solving and solution finding with the expectation that the professional will offer some strategies or solutions (Annan, Chua, Cole, Kennedy, James, Markusdottir, Monsen, Robertson and Shah, 2013; Todd, 2007). The approach where parents are information givers to the professional, who is the problem solver, often involves a repetition of the "known 
and familiar', a factual account of what is happening to them, what they have tried and the success or otherwise. McQueen and Hobbs (2014) suggest this approach prevents true collaborative working with parents as the power is given by the parent to the professional. Using narrative therapy, they argue, can change the dynamic between parents and professionals to one of collaboration, away from a practitioner led intervention, to one that is co-constructed. Broad generalisations from this single case study cannot be made, and the assertions by McQueen and Hobbs that narrative therapy provided a space for parents to examine and reflect, could be brought about in other ways using other approaches. However, the issue raised of exploring what is important to families, and time and space given to parents to develop understanding of the problem within their own context, is worth EPs considering within their own practice.

The use of Video Interactive Guidance (VIG) within a group intervention for mothers seeking support for post-natal depression was described by Rackett and Macdonald (2014) to increase attunement and pleasure in mother infant relationships. VIG is a relationship based approach to enhance attunement, empathy and well-being, and there is growing evidence that it can be highly effective for improving relationships in a wide range of contexts (Fukkink, 2008; Kennedy, Landor and Todd, 2011). The intervention reported by Rackett and Macdonald (2014) consisted of a group of six to eight mothers and their babies, who attended seven sessions focusing on parentbaby interactions, with VIG shared reviews after each session. Results indicated that mothers reported a marked decrease in depression, and improved mindfulness and enjoyment in their relationships with their babies. Given the clear risk factors for children of depressed mothers and children who do not have secure attachments, these findings could indicate promotion of positive outcomes for these children. This 
intervention was jointly led by an EP and a social worker and was a community based initiative. No long term impact on the children's development was indicated within this study, and the measures taken were of the mothers' self-reported improved mood and enjoyment of their babies; objective measures of improved mother child interactions were not reported. The impact of this intervention must therefore be viewed through the causal links established between maternal depression and infant development within the literature, and therefore the potential benefits that improving mothers' mood and enjoyment of their babies may have provided.

Guishard (1998) described a project developed with the aim of evaluating the viability of time limited family work within a school setting. They worked in multidisciplinary teams within the school context focusing on families' perceived difficulties following self-referral. This service operated in ten schools within a London borough. The project focused on self-referral by families; as it was argued that families are mainly referred to EPs because of school's concerns about a child, and as a result most parents who meet EPs in school are seen because of the school's needs, and school's perceptions of the child's difficulties (Guishard, 1998).

The aim was therefore to focus this project on self-referral so that a population that could not normally access EP services had opportunities to do so.

The professionals running the surgeries used systemic family therapy approaches (Weakland, 1982; Jones, 1993; Jenkins, 1995) alongside cognitive behavioural therapy (Shapiro and Cole, 1994) and a humanistic counselling model (Egan, 1990). The interviews at the surgery aimed to support families to clearly identify their 
concerns, explore with them some hypotheses around their concerns and identify possible solutions.

The drawback of this project was time limitations, and it was therefore suggested that rotating the surgeries throughout a patch of schools would be a more feasible approach and would also avoid an over dependence by families on using the surgeries for individual counselling. Parents and families expressed a high level of satisfaction with this service and they reported that it helped them approach their relationship with their child from a different and fresh viewpoint whilst also maintaining authority and control. Parents felt listened to and not judged. However, adolescents who were involved in the service alongside their parents, in the secondary school context, were less positive, and felt that the service did not provide the confidentiality and freedom to express their views without their parents present that they sought.

\subsubsection{Joint Family School Consultation}

Dowling and Pound (1994) described examples of joint intervention work by EPs with families and schools. They explained that within this type of intervention the natural role of parents is often to identify with their children and therefore their often fierce defence of their offspring should be viewed as a sign of love which requires respect and which can be put to good therapeutic use in the child's interests. They also suggested that where there is conflict between school and home, some children may contribute to this discord by criticising the school to the family, or vice versa, creating wider gulfs between the position of each of the child's systems. While this type of behaviour may reduce inner conflict within the child as they identify with, and reject, one system, it creates a position where presenting difficulties cannot be resolved due 
to the weakness of the authority figures. In this way broken relationships between school and family can lead to future behaviour issues within school and a wider persistent and perhaps paranoid attitude towards authority and systems outside the family.

Dowling and Pound (1994) illustrated a case where joint family consultations within school brought about change with a reception age child facing potential exclusion for behaviour problems, and an attitude of suspicion and mistrust existed between school and parents. Through a joint family school consultation, the psychologist was able to build understanding of the position and experiences and feelings between school and family, and raise school's awareness of the family situation. This led to the school taking a supportive position of the family, and the parents and teacher agreeing to meet weekly to discuss the child's progress. This joint family school consultation brought about a change from suspicion and mistrust to one of optimism and goodwill, resulting in a reporting of improvement in the child's behaviour over the next few weeks.

Nolan and Moreland (2014) discussed the process of joint consultations with schools and families, with consultations carried out by two EPs. The sessions were presented as being collaborative in nature to all involved, and it was found that the EPs were able to facilitate effective communication between the family and school that often continued after the consultation session. The consultations did not constitute a formal referral to the EPS, detailed notes were not taken during the sessions, EPs were not given prior information of the problems, and the explicit purpose was to build shared understanding, and shared plans. Follow up reviews were offered. Following the sessions, parents commented that they felt that school staff had been more open during the consultation than they had previously been, and 
sometimes teachers commented similarly of parents. Nolan and Moreland (2014) suggested this may represent a shift in the dynamic between home and school, created through the collaboration of the consultation process.

As EPs in this study were not given information about a child before a joint consultation, this supported the position of 'not knowing' (Anderson and Goolishian, 1992), and therefore allowed the EPs to be genuinely inquisitive about what was happening for the child. Techniques involving questioning, wondering, challenging, demonstrating empathy, deep listening, summarising, and reformulating were utilised by EPs during the consultations, to encourage the consultees to see the situation differently, perhaps from a different perspective. Used in this way, consultation brings together home and school systems in an ecological systems approach, through joining two of the child's systems, and utilises systemic theory and approaches within the consultation to support those systems in co-constructing an understanding of the child's problems across the systems and therefore supporting collaborative intervention strategies.

These case examples illustrate the permeability of the school and family systems through the psychologist creating a third system within the joint consultation where the integrity and respect for both systems, in their concern for the child, is held.

\subsubsection{Parent Training Programmes}

The use of manualised parenting programmes has been widely promoted and utilised by professionals working to support families (NICE, 2013), with the focus of most parent training programmes being for families with children with behavioural problems. Examples of parenting training programmes delivered by EPs within the 
literature include: The Confident Parenting Programme for parents of children with learning disabilities (Hames, Rollings and Janes, 2009), the Mellow Parenting Programme, devised to improve the psychosocial functioning of vulnerable infants (Puckering, Connolly, Werner, Toms-Whittle, Thompson, Lennox and Minnis, 2011), the Incredible Years Programme devised to reduce behavioural problems and promote social, emotional and cognitive competence (Webster-Stratton, 2006), Triple P for managing children's behaviour (Sanders, Mazzucchelli and Studman, 2003), Pillars of Parenting (Cameron and Maginn, 2009).

There is an extensive and growing evidence base for the effectiveness of parent training programmes as an intervention for families with children with behavioural problems (Hutchings, Bywater, Daley, Gardner, Whitaker, Jones, Eames and Edwards, 2007), with evidence that programmes not only reduce child behaviour problems, but also reduce parental stress and increase parental confidence (Barlow, Coren and Stewart-Brown, 2002).

Parenting programmes, however, do pose a tension for both professionals in delivering them, and governments in promoting them; between providing parents with support, and being seen to intrude into the private world of the family (Pugh, De'Ath and Smith, 1994). Additionally, this model of intervention is based around 'upskilling' parents, which implies a judgement of a lack of knowledge, or lack of understanding or information (Todd, 2007), and therefore retains a power differential where most of the power resides with the professional expertise. The referral route for parenting programmes is often not self-referral, and there can be external pressure on parents to attend which may mitigate against full engagement, or lack of ownership of the problem as discussed previously. 
Despite this, parenting programmes remain the single most successful treatment approach for reducing externalising behaviour problems in young children (Brestan and Eyberg, 1998). The biggest impact has been shown for group based programmes which last for at least eight weeks, which targets the parents of preschool children, and are delivered by well trained staff (Moran et al., 2004).

\subsection{Criticisms of the EP Role in Family Work}

The examples above from the published literature consider some of the ways in which EPs work with families in joining the systems of home and school, using systemic approaches and ecological systems frameworks to intervene within the family system to bring about positive changes for children. As noted, the literature search on EPs and work with families did not elicit extensive results, so the degree to which these types of interventions are commonly utilised by EPs within their practice, or perceived as core to the EP role, is not clear. As this research study is a qualitative design, the question of the extent of this type of work by EPs nationally will not be addressed, but through exploring in depth with a small number of EPs their own experiences of working with families, and the themes which emerge from this, the aim of building the knowledge base of EPs' work with families, and how EPs perceive their role in this will be addressed.

Peake (1999) argued that psychology services had become increasingly inaccessible to families, with only children with demonstrative SEN receiving a service, and that EP work is focused almost entirely on assessments of need, review systems, and consultation work with teachers. She suggested that these factors had meant that EP work had become more driven by LA and school procedures and as a 
result the EP profession had become more removed from the everyday needs of children and families. She stated that:

'We have become a school's psychological service rather than services for children and families who use schools. Schools and teachers have begun to define what we have to offer and see themselves as the prime recipient of our services' (Peake, 1999, p. 1).

Peake argued that EP practice in schools reflects this position. She suggested that EP practice would often exist where EPs would frequently see the child before they see the parents so that they can tell parents what they think; the message being that the EP is there to tell, not listen. EPs would often talk to the teacher, the SENCo, the TA, or other support agencies, before they talk to the parent, and also that EPs frequently have contact with parents through review meetings in schools, which have a structure and agenda defined by the school or the LA. Peake stated her position that the EP profession had 'deserted parents and families', and had evolved instead as a profession focused upon schools' needs and LA procedures.

She went on to recommend ways that this could be readdressed within the profession, and how systemic theory could be used for EPs to work with families to address the needs of children. She challenged the EP profession to readdress this imbalance through ensuring that:

- Parents have access to EP services; with a proportion of EP time available for parental, and not just school, referral.

- EPs use their time to demonstrate that listening to parents is a priority and fundamental to their practice. 
- EPs provide detailed advice and intervention for parents, to empower them to solve their own problems, such as use of parental consultation services, and parent groups.

- EP services should ensure a balance of statutory work with children and families work.

- EP services should create, and offer, intervention services for families to meet local need.

- EP services need to prioritise offering psychological services to vulnerable children and families such as LAC, homeless families, those who have experienced domestic violence, women who live in poverty, those who have experienced abuse and those where addiction and mental health needs exist within the family (Peake, 1999).

Jones (2003) presented a personal reflection on the contribution of child and family guidance within the EP profession, and argued for a return to a child and family orientation within practice to ensure that there is a better focus on children's needs. He argued that although the prophecy of those contributing to Reconstructing Educational Psychology (Gillham, 1978) that EPs would move away from child guidance had been to a large degree fulfilled (he suggested that EP involvement in child guidance type services still existed in 2010 in approximately only six services), the actual presence of multidisciplinary child guidance like services has mushroomed. Jones (2003) suggests that as EPs have moved out of this area, health provision has expanded, and child clinical psychologists have in the past 30 years risen from an almost non-existent professional group to being a sizeable profession. 
The focus now placed on 'child mental health' together with a considerable increase in funding linked to this has already stimulated a number of EP services to start considering improving child and family consultation, e.g. Barking and Dagenham (Bickford-Smith, 2003). As the role of parents and families is validated in the national working party report on the role of the EP (Department for Education and Employment, 2000) Jones argued for a move for the EP profession away from resource gatekeepers, or report writers, towards a multiagency child and family guidance model.

Alternatively, some EPs and EP services have argued for a shift in service delivery towards a community educational psychology approach to address a perceived narrow focus in the profession on bureaucratic procedures, and narrow SEN issues.

Hampshire Educational Psychology Service moved to a community educational psychology orientation in an attempt to escape the bracketing of EPs with SEN and associated statutory work which had occurred in several government papers (DfES, 2005a; DfES, 2005b), and assist the profession in more effectively communicating about what it has to offer children, young people and families. Stringer, Powell and Burton (2006) in their paper 'Developing a community psychology orientation in an educational psychology service' explained that they wanted to better reflect the range of work they did for the community beyond that simply defined by the school. They also intended to convey the message that as a service paid for by council taxpayers they were not owned by schools. Stringer et al. (2006) were writing at a time before many educational psychology services had moved to a traded model with schools, yet they describe the time allocation system they used at that time as creating an 'illusion' among head teachers that they 'owned' the EPS, and could demand of it what they would. They described what they saw as some ethical 
dilemmas for EPs in the time allocation model, such as challenges to an EP's requirements to see parents if the school thought it unnecessary, potential disputes over work with excluded pupils, and potential disputes over requests from parents for EP involvement.

Examples of the activities of EPs arising from this change of structure, which are provided within their paper, and which relate to work with families includes the use of Video Interaction Guidance (VIG) with parents in their homes, intervention work with parents whose children were at risk of exclusion, parents' problem solving sessions held in community centres, workshops for parents of children in the early years, and those with adolescents, and informal discussion groups for parents on aspects of child development, work with health colleagues on contributions to antenatal sessions on communication, play and attachment.

Stringer et al. (2006) argued in conclusion that a community educational psychology orientation can ensure the effective application of psychology to improve outcomes for children and families.

MacKay (2006) makes the case that the aims of educational psychology services can only be achieved by moving away from the narrow boundaries of special educational needs and the servicing of bureaucratic educational functions and towards an embracing of a community psychology orientation, where applied psychology can contribute to meeting the key outcomes for all children and their families and not just a subset who have been labelled as having 'special educational needs'.

Optimistically MacKay suggests: 
'The EP is uniquely placed, in collaboration with others, to provide generic child psychology services, and that it is time for the profession to claim its natural heartland of holistic services to children and young people across the settings of home, school and community' (MacKay, 2006, p. 14).

Prilleltensky and Nelson (2000) suggested a vision whereby school psychologists could promote child and family well-being, create school change and develop strong community infrastructures for children and families. They argued, however, that in order to do so shifts in the paradigms of school psychology would need to take place, and this would not be an easy task, as the barriers are significant.

How EPs and other professionals view the role of EPs may be a barrier that prevents EPs from applying systemic theory in their work. Ashton and Roberts (2006) elicited the views of 28 SENCos and eight EPs about EPs unique contribution. Whilst four EPs expressed an interest in systemic approaches, most SENCos saw 'advice giving', 'statutory assessment work' and 'individual assessment' as the unique contributions that EPs make to their schools. This suggests that it may be difficult for EPs to promote a systemic approach in schools which may not be valued by SENCos, who are seeking individual child assessments and advice giving.

Pellegrini (2009) suggested that his findings, that UK EPs have limited engagement with systemic thinking and practice, could in part be due to receiving limited training in systemic theories and practice in their initial training, as well as further training being lengthy and expensive if self-funded and opportunities for systemic supervision being rare.

Peake's sharp critique of EPs' role in family work, and her challenge to the profession to restructure, and reorganise to address this, points to the aims of this research study. 
Through the exploration of EPs' own experiences, and reflections on their work with families, it will be possible to consider the extent to which her criticisms have any basis in the current EP role, and in service delivery today, and to what extent the challenges she posed in 1999 may, or may not, have been addressed.

\subsection{Summary of the Chapter}

This chapter has reviewed the literature around EPs' work across a child's systems to provide a rationale for EP work with families when addressing the presenting difficulties of children referred to EP services. The joint approach, as espoused by Dowling and Osborne (1985), focused on the EP role recognising the interactions between the home and school systems and directing interventions at the point of interaction and across both systems. The system theories which underpin a joint home and school approach have been considered, alongside the application of these theories into EP practice over the changes and development of the profession (Fox, 2009).

An overview of some key influences of the family system on child development and well-being have also been considered in order to further underline the rationale for professionals such as EPs, whose role is focused on addressing children's wellbeing, to consider and address the context of the family as part of an holistic and integrated assessment which can lead to effective intervention strategies.

Examples from the literature of the ways in which EPs work with families have been highlighted, and some criticisms from within the profession around EP services' ability to meet the needs of children and families have been raised to provide a contextual background in which to place this research study. 
The review of the literature has clearly indicated that there is a strong rationale for EPs to work across a child's systems to address presenting difficulties. Both systemic and ecological systems theories provide approaches which can be utilised by EPs in joining a child's two most influential systems in order to promote their psychological well-being. Examples from the published literature of the ways in which EPs work with families using system theories approaches have been considered, but the published research of EP work in this area was found to be limited. Additionally, there was no research identified which specifically examined EPs' experiences of their work with families or their perceptions of the EP role in this area. The aim of this research study is to address this gap within the literature, and examine how EPs work with families within their practice and how they conceptualise their role within this. The aim is to also address the assertion of Dunsmuir et al. (2014) and identify factors that facilitate best practice, and which challenge barriers to collaboration, in order to inform EP practice in the area of family work.

The research questions formulated to meet those aims were:

1) What are EPs' experiences of their work with families?

2) What do EPs experience as barriers to this work?

3) What do EPs view as facilitators to this work?

4) What do EPs feel their role should be in family work?

Within the next chapter I will present the methodological considerations for the present study which aimed to gauge EPs' perceptions of their work with families. 


\section{CHAPTER THREE}

\section{METHODOLOGY}

\subsection{Overview}

In this chapter I will examine the theoretical underpinnings and assumptions of the research, including my epistemological and ontological positions, and the methodology used. I will include information on participant selection, and on the data collection method used; that of semi-structured interviews. I will review the analysis method of thematic analysis that was used, why this was identified as the appropriate methodology for this research, and how I utilised this. I will then consider the ethical implications of this research and how reliability, validity and generalisation were addressed within the research design.

\subsection{Epistemological and Ontological Assumptions of the Research}

Distinguishing between methodology as the philosophy behind research and methods in terms of techniques and practical application, is both constructive and necessary, as when opting to use particular research methods researchers are basing their decisions, implicitly or explicitly, on assumptions about the character of the social world (Cohen, Manion and Morrison, 2011).

Philosophical deliberations of research methodology cannot be separated from the practice of research, and are necessary in order for researchers to consider the assumptions underlying a research design (Pawson, 1991). All research is underpinned by assumptions which will have implications, and give direction to the applied methodology (Scott and Usher, 1999). A research methodology is required to 
make clear the basis of specific choices and decisions made within the research methods. A theoretical account of the ideas and assumptions embedded within the methodology should be provided. Methodology is defined by Gray (2009, p. 578) as "the analysis of and the broad philosophical and theoretical justification for a particular method used in research".

Ontology addresses the nature of being and of our existence (Gray, 2009) and concerns philosophical questions of whether knowledge is a truth which exists, or whether it is constructed.

Epistemology is the branch of philosophy that studies knowledge and attempts to distinguish what constitutes 'true' knowledge, considers the validity of knowledge, how it can be acquired, and how it can be communicated (Scott and Usher, 1999). Epistemology aims to address the question: how do we know what we think we know, and how do we distinguish between truth and falsehood?

Within any piece of research, it is important to reflect upon the epistemological and ontological assumptions implicit within the research, as without doing so can mean that the practice of research may be under-theorised (Scott and Usher, 1999). The assumptions contained within research are critical as they are embedded within the research process, and point to the researchers own suppositions.

The epistemological position of this research is within an interpretivist paradigm and is therefore underpinned by a constructivist philosophy, as it is primarily interested in exploring and interpreting the experiences of individuals in relation to the topic area of EPs' work with families. Interpretivism looks for "culturally derived and historically situated interpretations of the social life-world" (Crotty, 1998, p. 67). The basic tenet of this interpretivist paradigm is that reality is constructed by the people within the 
research process and that the researcher's role is to attempt to understand the "complex world of lived experience from the point of view of those who live it" (Schwandt, 1994, p. 118).

Within an interpretivist paradigm, a phenomenological philosophy is concerned with understanding how people experience and perceive the world around them (Bryman, 2004). Phenomenology directs that we put aside our expected understanding of 'phenomena' and instead consider our immediate experience in order that a new meaning may emerge (Gray, 2009), a reconsidered meaning or deeper understanding. Phenomenology is therefore not aiming to quantify, explain or generalise experiences, but rather it is concerned with exploring and understanding the way in which people perceive their own experiences (Bryman, 2004). There is a rejection of the positivist view that all knowledge and understanding comes from observable and measurable experience, and therefore that only a pure scientific method taken from the physical sciences and applied to people's experiences, will reveal 'the truth' and knowledge of those experiences.

Wilhelm Dilthey's study of interpretive understanding, hermeneutics, influenced the development of phenomenology (Eichelberger, 1989) and is the study of interpretive understanding or meaning which is concerned with the theory and method of the interpretation of human action (Bryman, 2004).

Hermeneutics views all social reality as being socially constructed and the focus should therefore be on interpretation of an individual's construction of their own personal and social experiences (Gray, 2009). Perception is considered an interpretation of context and experience and therefore represents an interpretivist ontology. An interpretivist ontological position views reality as being socially 
constructed, with multiple constructions possible. A constructionist approach rejects notions of an objective reality and tells us that "meaning is constructed not discovered" (Bryman, 2004 p. 18), viewing social reality as too multifarious to be comprehended through only observation and calibration, and viewing the aim of a researcher to be an interpreter of the multiple social constructions, in order to pursue a deeper level of knowledge and self-understanding (Gray, 2009). A positivist position, in contrast, views the world as existing independently from the thoughts which are held about it, and focuses on the search for objective knowledge through the causal relationships between phenomena.

The assumption within this study is that individual meaning results from the interaction between direct personal experience and the social context in which it occurs (Denzin, 1999; Chamberlayne, Bornat and Wengraf, 2000) and that individual narrations, whilst singular, can also be viewed as representative of group experiences (Erben, 1998; Kazmierska, 2004), and that contradictory positions, inconsistent themes within and between participants, and positions that do not fit with other themes identified, should be highlighted as an integral part of the research process (Josselson, 1995; Robson, 2011; Tierney, 2003).

My position as the researcher, and the proposal of this thesis, is one of discovering the experiences and perceptions of individual EPs' work with families. However, the structured methodological framework of thematic analysis which was used, and the structured context with external limitations in which EPs work, limits and constrains individual world views, and indicates that the philosophical stance adopted cannot be viewed as purely interpretivist. A critical realist position allows for exploration of meanings and experiences of participants, whilst relating this to the wider social structures which influence and constrain them (Robson, 2011). This stance aligns 
with the position of this research and influences the interpretivist perspective adopted within this study, which acknowledges that the ways individuals make meaning of their experiences and, in turn, the ways in which the context in which they operate, impinges on those meanings (Willig, 2001).

\subsection{Methodological Position}

\subsubsection{Qualitative Approaches}

This small scale study explores how a range of EPs perceive and construct their own experiences of working with families, and therefore takes an interpretivist/ constructivist stance, and applies a phenomenological approach aligned with social constructionist theory.

The interpretivist position of this research is identified with qualitative research methods. Qualitative research seeks to enrich our understanding of the phenomena in question (Elliot, Fischer and Rennie, 1999) which aligns with the purpose of this study to explore subjective, experiential accounts and perceptions of EPs' family work.

Tindall (1994) suggested that qualitative research is:

'... theory generating, inductive, aiming to gain valid knowledge and understanding by representing and illuminating the nature and quality of people's experiences' (Tindall, 1994, p. 142).

Qualitative methods of data analysis have increased in application in research areas more conventionally inclined towards more positivist methods, such as psychology, as it has been recognised that they allow for a richer understanding of phenomena and their dynamics (Attride-Stirling, 2001). 
Therefore, for this study, a qualitative research design was chosen which permitted an exploration of the participants' experiences, views and beliefs.

A quantitative methodology would have reflected a positivist ontology, and would not have provided the quality of meaning, and rich narratives of the individual experiences, that were required to meet the aims of this study.

Initially, Interpretative Phenomenological Analysis was identified as the most appropriate qualitative method to use in this research to explore EPs' own lived experiences of their family work, but following a pilot of the semi-structured interview it was recognised that the data which would emerge would reflect the personal lived experience of each EP, but also provide reflections on context and structures within which these occurred, so Thematic Analysis (TA) was then identified as the most appropriate method of analysis to use, which reflected the critical realist influence within the constructivist paradigm.

Other qualitative approaches which were considered, but did not meet the aims of this research study included Grounded Theory, which seeks to develop an explanatory theory from a range of participants' experiences, and adopts a "from the outside in" approach (Willig, 2008, p. 45). The purpose of this study was not to develop explanatory theories, but was to explore individual experience and perceptions. Discourse Analysis was also considered. This approach studies the ways in which discourse constructs subjectivity, self and power relations (Willig, 2008), but does not address the phenomenological study of individual experience that was the focus of this study. 


\subsubsection{Thematic Analysis}

Thematic Analysis (TA) was therefore selected as the most appropriate methodological approach for this study. TA is a qualitative approach which allows for a rich understanding of phenomena and dynamics to be co-constructed between the researcher and the participants in line with the constructivist paradigm within which this research is set (Braun and Clarke, 2006). As TA is not wedded to any preexisting theoretical frameworks, it is a method which can be utilised to reflect the constructionist approach of exploring EPs' experiences, aligned with a critical realist perspective which acknowledges the ways in which their context impinges on those meanings. Boyatzis (1998) argued that thematic analysis is not merely a tool for data analysis by researchers, but is in fact a fundamental human activity that constantly seeks meaning in social, cultural and political contexts. Utilising TA from a constructionist perspective ensures the focus is on the socio-cultural context in which the personal narratives take place. Therefore, TA can be a method which can work to reflect reality, and explore beneath the surface of reality (Braun and Clarke, 2006).

TA is possibly the most commonly used qualitative approach of the analysis of data in the social sciences (Holstein and Gubrium, 1994). However, it has also been considered poorly conceptualised, due to what has been regarded a poor demarcation (Boyatzis, 1998), with minimal guidance on the method of analysis of the data (Bryman and Burgess, 1994). Braun and Clarke (2006) and Attride-Stirling (2001) have directly acknowledged these criticisms, and addressed them through providing frameworks which can be used in a flexible, but rigorous, use of thematic analysis by researchers in the field of psychology (Braun and Clarke, 2006). 
The purpose of TA is to identify patterns of meaning across a data set to provide answers to the research questions set. This is achieved through a rigorous process of data familiarisation, coding and theme identification and revision. TA is theoretically flexible and suits questions related to people's experiences, views and perceptions (Braun and Clarke, 2006). TA can be approached inductively where themes are directed by the content of the data, or deductively where themes are linked to existing concepts or theories. The approach taken in this study was one of inductive TA, where the themes emerged directly from the data. A semantic approach to TA provides theme development which explicitly reflects the content of the data, as opposed to a latent approach where themes are linked to underlying concepts and theories underpinning the data (Braun and Clarke, 2006). Both a latent and a semantic approach to TA was adopted within this research as the themes identified directly reflect the content of the data, but analysis beyond the literal meaning was also considered to move beyond description, and identify beliefs and assumptions within the data.

There is some debate around whether TA is an experiential or a critical approach to qualitative research (Clarke and Braun, 2014). Experiential approaches aim to capture participants' experiences and perspectives and ground research in personal accounts, viewing language as reflective of internal understanding (Reicher, 2000). Critical approaches, however, view language as constitutive and a form of social action (Clarke and Braun, 2014). The approach adopted within this research reflects an experiential approach to TA, where the aim is to explore and capture EPs' experiences and perceptions on their work with families. 


\subsubsection{Semi-Structured Interviews}

Focused semi-structured interviews were used as the data collection method as this fitted within the epistemological orientation, and allowed for rich narratives of the experiences of the EPs to emerge within the open ended questioning techniques used. Semi-structured interviews can facilitate participants to express their individual experience in their own terms, and allows the researcher to establish rapport, and flexibly respond to particular issues as they are raised. This data collection methodology allows for recognition that EPs' interpretations are dynamic, fluid and will change over time and contexts (Cohen et al., 2011). The semi-structured interviews allowed for an exploration of the EPs' experiences within the context of their own work, and within wider contexts of their Educational Psychology Service, as well as wider legislative and professional contexts. Robson (2011) notes that an interview permits the exploration of multiple perspectives and this therefore offered the flexibility to explore the EPs' own individual experiences and interpretations.

The use of focus groups to collect data would not have provided the detailed exploration of personal experience that individual interviews are able to provide. Smith (2004) argued for caution around using focus groups where the aim of the research is to elicit detailed personal experiences, as focus groups do not allow for the detail and intimacy that an individual interview situation provides. The intimacy and detail of personal experience may be undermined within a group situation where there is less time for individual exploration of experiences, where there may be inhibition around personal disclosures which could affect standing within the group, and where the effect of potential group conformity could lead to a reduction in diversity of results (Smith, 2004). These considerations were particularly pertinent to this research given that all participants were EPs, some of whom were colleagues, or 
known to each other, who would be reflecting on their own professional practice; so the potential for group affect in both inhibition and conformity may have been significant.

Alexander and Clare (2004) described participants as the primary experts within research, and semi-structured interviews provided a data collection technique which allowed each participant the time and latitude to explore and reflect on their experiences, beliefs and opinions, which generated rich qualitative phenomenological data. The aim of the semi-structured interviews is not to form generalisations from responses but instead understand the experience as perceived by the participant (Livesey and Lawson, 2010). Robson (2011) notes that an interview allows for the exploration of multiple perspectives, fitting with the interpretivist and social construction theoretical perspectives of this study.

The strengths and weaknesses of semi-structured interviews are illustrated in Table 4 below. The strengths of this data collection technique are around its flexibility in allowing participants to respond to questions at length and lead the discussion in their own interpretations and perceptions of experiences. This gives high internal validity to the data collection process. The reliability of the data from semi-structured interviews, however, is less robust than that of a positivist methodology because exact replication of interview situations is not possible, as the interviewer is free to modify the interview. 
Table 4: The strengths and weaknesses of semi-structured interviews, adapted from Chris Livesey: Sociology Central, 1995-2017

(www.sociology.org.uk)

\begin{tabular}{|l|l|}
\hline Strengths and Uses & Weaknesses and Limitations \\
\hline $\begin{array}{l}\text { Positive rapport between interviewer } \\
\text { and interviewee. A simple, efficient and } \\
\text { practical way of obtaining information. }\end{array}$ & $\begin{array}{l}\text { Dependent on the skill of the interviewer } \\
\text { and articulacy of the respondent. }\end{array}$ \\
\hline $\begin{array}{l}\text { High validity as respondents are given } \\
\text { the opportunity to talk in depth and in } \\
\text { detail. Meanings behind actions may be } \\
\text { revealed through this dialogue, which is } \\
\text { non-directive. }\end{array}$ & $\begin{array}{l}\text { Validity: } \\
\text { - No real way of knowing if the } \\
\text { respondent is giving authentic } \\
\text { responses. } \\
\text { - The respondent may have imperfect } \\
\text { recall. } \\
\text { - Respondents may feel they have to } \\
\text { justify or rationalise their actions and so } \\
\text { their explanation may be different from } \\
\text { what they were thinking at the time. } \\
\text { - Interviewer may give unconscious } \\
\text { signals that influence the respondent }\end{array}$ \\
Time consuming/sometimes expensive \\
\hline $\begin{array}{l}\text { Complex questions can be discussed } \\
\text { and clarified. The interviewer can probe } \\
\text { areas suggested by answers, picking up } \\
\text { and responding to the information that } \\
\text { emerges. }\end{array}$ & $\begin{array}{l}\text { Not very reliable in the positivist sense } \\
\text { and they are difficult to replicate across } \\
\text { participants, as different questions are } \\
\text { likely to be asked and samples tend to be } \\
\text { small. }\end{array}$ \\
\hline $\begin{array}{l}\text { Reduces need for prior judgement. } \\
\text { The issue of pre-determining what will or } \\
\text { will not be discussed is resolved. The } \\
\text { interviewer is not pre-judging what is and } \\
\text { is not important information. } \\
\text { Easy to record. }\end{array}$ & $\begin{array}{l}\text { Analysing data may be difficult, in } \\
\text { terms of deciding what is and is not } \\
\text { relevant, and the subjectivity of those } \\
\text { analysing. } \\
\text { The personal nature of interviews means } \\
\text { that it may be difficult to generalise the } \\
\text { findings. }\end{array}$ \\
\hline
\end{tabular}

\subsection{Method}

Within this section I will provide an account of the systematic approach taken in the research to the collection and analysis of data (Gray, 2009). The selection of 
participants, the method of collection (semi-structured interviews), and the process of analysis (thematic analysis) will be described, with a consideration of the key issues in each area.

\subsubsection{Sampling}

Participants for the research were identified through a purposive sampling technique. In purposive sampling potential participants are identified through typicality or interest, as having experience or knowledge of the phenomena being studied (Robson, 2011). This study was researching the experiences of EPs in their work with families so a purposive sampling technique was appropriate as it allowed for identification of potential participants with a shared knowledge and experience in this area. Participants were all required to be practising EPs working within local authorities, who had at least three years' experience as a qualified EP.

Representative sampling which aims to reflect the general population would not have been valid in this study as the aims of the research are clearly based around a particular group with shared experience.

\subsubsection{Participants}

Phenomenological approaches such as thematic analysis and IPA tend to use small sample sizes, focusing on capturing rich, detailed data rather than large quantities of data from multiple sources.

Principal EPs (PEPs) from six LAs in the Midlands area were emailed with a request to contact all EPs within their service as potential participants in this study (see Appendix 1). The PEPs were given an overview of the research aims and design 
(see Appendix 2) and asked to pass on this information to all EPs in their service asking for any expression of interest in participating in the research to contact me directly. All principals agreed to allow EPs within their service to consider taking part and passed on the information.

I received ten expressions of interest from across four services. One participant was unable to take part in the study due to ill health at the time, so the number of participants interviewed was nine.

Some of the participants were known to me as current or previous work colleagues. They had been qualified as EPs for between 7 and 33 years, with six of the participants having more than 20 years' experience as practising EPs. Two participants had qualified as EPs since the introduction of the three year doctoral professional training programme and one had completed a post-qualification doctorate. One participant was male.

No attempt was made to sample EPs that would represent the profession as a whole, however, the gender imbalance and the length of time in practice as an EP, do reflect a trend nationally within the profession (Children's Workforce Development Council, 2008).

\subsubsection{Data Collection}

\subsubsection{Semi-Structured Interviews}

Each participant was interviewed once with interviews lasting approximately one and a half hours. The interviews took place at a location of the participant's choosing, which in all cases was at the office location of their respective EPS. Each interview 
was recorded for the purpose of transcribing, and each interview was numbered at the point of transcription.

Kvale (1996, p. 6) describes a semi-structured interview as "a conversation that has a structure and a purpose" as it is a dynamic and interactive method of data collection. In order to maximise the internal validity of the interview design the interviews followed a sequence of questions intended to increase cooperation, reduce feelings of anxiety and increase honesty and accuracy in the responses from participants.

The interview schedule was designed to allow for a flowing agenda where the discussion could be lead as necessary, or where discussion could develop spontaneously, mitigating against the imposition of an ordered set of questions, as noted by Smith, Flowers and Larkin (2009). Interview questions were open-ended in nature, and designed to elicit in-depth and considered replies that would allow participants to develop their thoughts and fully reflect their experiences (Coolican, 2014).

The interview questions were directly linked to the research questions to ensure data was relevant and valid, and the interviews began with a general question that allowed the participants to take the subject in the direction of their choosing, and to initially talk at length without lead (Smith et al., 2009). In order to increase reliability, the interviews followed a sequence of questions that were directly linked to my research aims (see Appendix 3 for an indicative interview schedule). The questions were designed as open ended questions to allow participants to determine how they might respond rather than applying a constraint, such as closed or scaled questions. 
Before the interviews, I considered the need for the development of rapport and trust with participants, and set out to achieve this through outlining objectives and boundaries clearly, and ensuring that I remained aware of verbal and non-verbal behaviours of participants within the interviews so that I was able to demonstrate sensitivity and empathy appropriately in response. Participants were provided with time to develop and build their responses, and I remained vigilant to my role as an active and inquiring listener.

It is also important to note that I was aware of my role as a fellow educational psychologist within the interview process and the effect that this may have had on the participants, and the possibility that this dynamic could lead to the creation of overt or covert power differentials between myself and the participants. To address these concerns I aimed to create a relaxed atmosphere through the use of limited self-disclosure, humour, and active listening techniques, to create a feeling of joint endeavour and trust. My role as a researcher and the ethical challenges that needed to be addressed are considered in more detail in section 3.4.7.

\subsubsection{Pilot}

The interview schedule was piloted with an EP peer, not participating in the study, to ensure that the questions and resultant data would be relevant to the research questions. This process resulted in the addition of questions to give more depth in the data around EPs' beliefs, feelings and experiences of their perceptions of the client groups they work with in the role of family work, and allowed for a more complex understanding of the EP experience within the systems and social contexts in which they operate. 
Following the pilot, it was also decided that a change in methodology, in terms of data analysis, would be required. Until this point the intention had been to use Interpretative Phenomenological Analysis to analyse the data, as the study was focused on EPs' personal lived experiences, and aimed to capture the meaning that participants assigned to their experiences in this area. However, the responses from the pilot indicated that the data set would not solely reflect an individual narrative of personal lived experience, and whilst this would be central to the data, it was likely to broaden out to comment on wider contextual issues, such as legislation and service delivery. It was therefore judged that the use of Thematic Analysis would allow for a reflection of the constructionist paradigm of this research, but would also reflect the critical realist influence within this.

\subsubsection{Data Analysis}

\subsubsection{Thematic Analysis and Thematic Networks}

Braun and Clarke's (2006) five-phase model of thematic analysis is a method for identifying, analysing and reporting themes and sub-themes within a data set, through a detailed organisation and description of the data. Thematic maps can be generated using thematic network analysis (Attride-Stirling, 2001) and are visual representations of the themes that have been generated. Thematic analysis of the transcriptions from the semi-structured interviews was the principal method of data analysis used in this study (Boyatzis, 1998; Braun and Clarke, 2006; Rubin and Rubin, 2005). This was completed as an inductive 'bottom up' process in which the development of themes emerged dependent on the contents of participants' comments, and not linked to pre-identified theories. 
Through the development of a framework for conducting thematic analysis, Braun and Clarke (2006) considered how theoretical and methodological issues relate to thematic analysis and explored the importance of 'thematising' meanings, using thematic coding. The framework has demarcated clear stages in the analytic process, to ensure that the analysis is an active decision-making process; Braun and Clarke (2006) provide a vocabulary and procedure for researchers to utilise in a way that is theoretically and methodologically sound (Braun and Clarke, 2006).

Applying thematic analysis from a constructionist perspective ensures the focus is on the socio-cultural context in which the personal narratives take place, instead of focusing on individual psychology.

Whilst historically, TA was poorly demarcated as an analytical tool (Boyatzis, 1998; Braun and Clarke, 2006), it is now widely regarded as a method in its own right (Joffe, 2012). Braun and Clarke (2006) formulated a step-by-step approach consisting of a 15-point checklist. This checklist was adhered to whilst conducting my research and is detailed below: 
Table 5: 15-point checklist of criteria for good Thematic Analysis

(Braun and Clarke, 2006)

\begin{tabular}{|c|c|c|}
\hline Process & Step & Criteria \\
\hline $\begin{array}{l}\text { Transcription and } \\
\text { familiarisation with } \\
\text { the data }\end{array}$ & 1 & $\begin{array}{l}\text { The data have been transcribed in detail, and the researcher } \\
\text { has familiarised themselves with the data through reading } \\
\text { and rereading of the transcripts, noting down initial ideas. }\end{array}$ \\
\hline $\begin{array}{l}\text { Generating codes } \\
\text { and searching for } \\
\text { themes }\end{array}$ & $\begin{array}{l}2 \\
3\end{array}$ & $\begin{array}{l}\text { The entire data set is given equal attention in the coding } \\
\text { process. } \\
\text { The coding process is thorough, inclusive and } \\
\text { comprehensive. } \\
\text { Examples from the entire data set are collated for each code. } \\
\text { (Themes have not been generated from a few vivid } \\
\text { examples.) } \\
\text { Codes are collated into potential themes. } \\
\text { Themes are checked against each other, and against the } \\
\text { original data-set. } \\
\text { Review themes to check if themes work in relation to the } \\
\text { coded extracts, and the entire data set, generating a } \\
\text { thematic map of the analysis. Themes are internally } \\
\text { coherent, consistent and distinctive. } \\
\text { Ongoing analysis to refine the specifics of each theme, and } \\
\text { the overall story the analysis tells, generating clear } \\
\text { definitions and names for each theme. }\end{array}$ \\
\hline Analysis & $\begin{array}{l}7 \\
8 \\
9 \\
10\end{array}$ & $\begin{array}{l}\text { Data have been analysed - interpreted, made sense of - } \\
\text { rather than just paraphrased or described. } \\
\text { Analysis and data match each other - selection of vivid, } \\
\text { compelling extracts, examples to support the analysis. } \\
\text { Analysis tells a convincing and well-organised story about } \\
\text { the data and the topic. } \\
\text { Analysis and extracts are linked to the research questions } \\
\text { and literature to produce a scholarly report of the analysis. }\end{array}$ \\
\hline Overall & 11 & $\begin{array}{l}\text { Enough time has been allocated to complete all phases of } \\
\text { the analysis adequately, without rushing a phase or giving it } \\
\text { a once-over lightly approach. }\end{array}$ \\
\hline Written report & $\begin{array}{l}12 \\
13\end{array}$ & $\begin{array}{l}\text { The assumptions about, and specific approach to thematic } \\
\text { analysis are clearly explicated. } \\
\text { There is a good fit between what you claim to do, and what } \\
\text { you show you have done - i.e. described method and } \\
\text { reported analysis are consistent. } \\
\text { The language and concepts used in the report are consistent } \\
\text { with the epistemological position of the analysis. } \\
\text { The researcher is positioned as 'active' in the research } \\
\text { process; themes do not just 'emerge'. }\end{array}$ \\
\hline
\end{tabular}




\section{Data familiarisation}

Braun and Clarke (2012) state this process of data immersion is actually the start of analysis - when one begins to look beyond surface meaning for more critical analysis. During this phase, notes were made on the printed transcripts, each interview transcript was read six times to ensure familiarisation and notes were made forming links and emerging themes within each interview. A key aspect of this phase was making links from the rough notes to the research question as a means of generating initial codes (see Appendix 4 for an example of notes made during data familiarisation).

\section{Generating codes}

Braun and Clarke (2006) state: "codes identify a feature of the data that appears interesting to the analyst" (p. 88). They also recommend coding as much data as possible, as it may prove useful later on. During this phase they also recommend using techniques for identifying potential 'patterns' in the data. I did this by utilising different coloured highlights and noting codes within the margins of the transcripts. This procedure was followed systematically on every transcript during this phase (see Appendix 5 for example pages of codes identified on a transcript).

\section{Searching for themes}

This phase is described by Braun and Clarke (2006) as "collating codes into potential themes, gathering all data relevant to each potential theme" (p. 87). All codes were categorised dependent upon general similarities to form an initial thematic 'map' (see Appendix 6). No codes were deleted or amalgamated during this phase. Braun and Clarke recommend not discarding anything during this phase as following further 
refinement some themes may need amalgamation, re-categorising or deleting, as indeed did occur within my analysis.

Braun and Clarke (2006) also require the researcher in thematic analysis to consider whether themes are identified with an inductive approach, or a deductive approach. When themes are identified inductively, they are strongly linked to the data themselves (Patton, 1990), providing a rich description of the data overall. The analysis for this study utilised an inductive approach. The inductive approach taken analysed the data to see what themes emerged. The coding was not linked to any specific theories identified in the literature review, but was guided only by the data itself and the themes which emerged through the process of listening, reading and re-reading the interviews. I remained open to any themes which emerged, linked directly to the data itself.

There are no firm boundaries to indicate the prevalence of data required across the data set in order to provide evidence for a theme; Braun and Clarke state that a researcher's judgment is required in defining the themes, but consistency of approach in doing so must be applied and demonstrated. Within this study, the consistency in identifying emerging themes was considered at steps 3 and 4 , particularly with regard to the prevalence within the data for each theme identified (see Appendix 6 for examples of codes grouped to form themes).

Within the analysis process, as themes begin to emerge, consideration of whether to provide a rich description of the whole data set, or focus on one particular aspect or group, needs to be taken. In this study, the data set represented a homogenous group (all EPs), so analysis of all data was appropriate. Additionally, there is no existing research on EPs' experiences of work with families, and it is advised that in 
studies where this is the case, it is important for the entire data corpus to be included in the analysis and reporting in order to achieve a rich encompassing account of the data.

At steps 4 and 5 of the Braun and Clarke analysis process, the data can be presented as 'thematic networks' (Attride-Stirling, 2001) which can be presented as visual, linked networks or 'maps' illustrating the main themes and the links between them. Attride-Stirling (2001) suggested that these networks provide an overarching picture of the structures and patterns within the themes from the data.

See Appendix 7 for Thematic Map 1 illustrating the initial themes which were identified at this stage.

\section{Reviewing and defining themes}

This phase is essentially one of quality checking (Braun and Clarke, 2012). Braun and Clarke (2006) warn of a potential pitfall at this stage by stating: "as coding data and generating themes could go on ad infinitum, it is important not to get overenthusiastic with endless re-coding" (p. 92). A review of the themes took place with an EP peer who was not a participant in the research, and this joint process of reviewing and refining allowed for identification of links across themes which produced some amalgamation and collapsing of themes to present a more coherent presentation of the patterns within the data.

This phase required interpretation of the data, beyond the semantic level, and involved identifying data extracts which allowed for the generation of clear definitions for each theme (Braun and Clarke, 2006, p. 92). Much of the deep analytic work connected with thematic analysis takes place here, where the specifics of each 
theme refine the overall story of the data corpus. Moreover, this phase requires coherence in that all themes not only require developing individually, but in relation to each other whilst considering the research question (Braun and Clarke, 2012).

See Appendix 8 for Thematic Map 2 which gives a coherent account of the overall data.

\subsubsection{Interpretations and Reporting of the Findings}

The interpretation component of thematic analysis takes place once a thematic map has been created, and Braun and Clarke (2006) advise considering questions within other studies using this method to guide the interpretation of the data from the themes generated. From this, I identified questions that explored the meanings of the data and which could provide more than a surface level interpretation, which would allow a narrative to form related to the initial research questions. Questions applied therefore included: 'What is the meaning underlying this theme?', 'What are the implications of the theme?', 'What assumptions and beliefs are submerged within this theme?', then more broadly 'What do the themes communicate about the topic?' and 'How do the themes inform the research questions?'.

The findings, and discussion of the findings, following this process of analysis will be presented in Chapter Four, with an overview of the overarching themes, main themes and subthemes identified, with evidence for each theme presented in the form of data extracts from the original data to strengthen the transparency and validity of the findings. 


\subsubsection{Reliability, Validity and Generalisation}

Cohen et al. (2011) assert that validity is key to effective research, and internal validity concerns the extent to which research findings can be sustained by the data, whilst external validity refers to the extent findings can be generalised. The constructs of reliability and validity taken from positive epistemologies, however, do not apply within a qualitative/interpretivist approach, and the standard for 'good' research differs from that accepted within traditional criteria (Miles and Huberman, 1994). Reliability and validity within qualitative research are in line with the aims, objectives and epistemological assumptions of the research project (Sparkes, 2001).

Yardley (2008) set out a framework of four principles for evaluating the validity of qualitative psychology: sensitivity to context, commitment and rigour, coherence and transparency and impact and importance. These four principles of validity will now be considered against the processes and structure of this research study:

i) Sensitivity to Context: Within this study sensitivity to context was demonstrated through addressing context within the literature review, considering the legislative, political and economic climate contexts for EP practice. Sensitivity to context was also demonstrated within the semi-structured interviews where individual EPs were given the opportunity, through open ended questioning, to outline, expand on and discuss their own contexts at the level of personal experience of EP practice, the organisations they work within and the impact of wider legislative and political frameworks.

Sensitivity to the context of the interview situations itself was also considered; the nature of the interviewer-interviewee relationships, 
where a social desirability response bias could occur, particularly as an EP was questioning other EPs on their practice which could be perceived as a threatening situation. Within this study reliability was increased through ensuring that the interview schedule was the same for each participant, questions were open ended and leading questions were avoided. The semi-structured nature of the interviews allowed for them to be 'interpersonal encounters' (Cohen et al. 2011, p. 124) in which a conversation could occur and allow the participants to feel at ease.

ii) Commitment and Rigour: In demonstrating commitment and rigour to the process of analysis, Braun and Clarke (2006) highlight the importance of avoiding pitfalls such as failing to move beyond description into making conceptual links, using the data collection question as the 'themes', being overly generic, and not providing a cogent analysis where themes are not clear or where they may overlap. They describe specific strategies that can be used to ensure rigour, including for instance: using a diary to track the ways in which the data has moved the researcher from initial assumptions, into new positions or perceptions, the use of extensive quotations in reporting, exploring convergence with other sources of data, independent checking of the data from a third party, and checking back with participants to see if hypotheses are accurate (Ratcliffe, 1995).

An attempt was made to apply all these strategies to some degree within this study. For instance, a research diary was used to track my thinking and the decisions I made during the research process, and to record 
discussions and questions arising during supervision sessions. I also ensured that a substantive extract of my research was independently checked by a peer to ensure that the findings of the analysis could be verified, and I used extensive quotations within the research report to provide evidence of themes and findings.

Commitment and rigour were also ensured through the development of knowledge and practice in the techniques of TA and interviewing.

iii) Coherence and Transparency: These were achieved through ensuring that analysis of the whole data set was coded and transparent within the analysis. There is extensive use of quotations from across the data to support identification of themes and subthemes, where they were identified and how they were generated, in order to maximise fidelity. Additionally, the presentation of a stage 1 thematic map and a stage 2 thematic map were used, to illustrate the emergence of the themes over the course of analysis. Again, this was independently verified by a third party peer. The reflexivity of myself as the researcher was discussed within supervision, reflections and shifts recorded within the research diary and made explicit within this paper.

iv) Impact and Importance: The impact and importance of this study was considered within the literature review where the paucity of research literature around EPs' experiences of their work with families was discussed, and the aims of the research to inform EP practice were considered. 
Perspectives on generalisation are predisposed by the epistemological and ontological orientations (Seale, 1999). The focus of this study was on the individual experiences of EPs within their personal and wider context. The aim of this study was to build a body of research in the area of EPs' work with families, through gaining a deeper understanding of individual EPs' experience. It is therefore my aim to build, through my findings, communicative generalisations, through providing contextualisation within individual narratives to allow readers to effectively judge similarity within their own settings, in order to stimulate community conversation about the study and its potential wider applications (Smaling, 2003)

\subsubsection{Reflexivity}

Reflexivity within qualitative research is an important component to ensure fidelity and validity throughout the research design and process. Personal reflexivity was applied throughout this study to ensure my awareness of my own constructions and experiences of the research area were surfaced and made explicit, and so that steps could be taken to address the difficulty of remaining neutral in the design, application and analysis of the study. Nightingale and Cromby (1999) described reflexivity as the researcher exploring how their involvements with their study inform their research.

These questions were addressed in relation to this study throughout the research process through the process of research supervision, which involved an exploration of my own role in this area from the start of the research proposal and throughout the research process. My own role as an EP with experience and perceptions on the subject area, and ways this may have limited the research design, and steps taken 
to address this is discussed more fully within Section 5.2 Methodological Reflections and Research Limitations in Chapter Five.

\subsubsection{Ethical Considerations}

In accordance with the ethical guidelines of the British Psychological Society (British Psychological Society, 2014) and the protocols of the ethics committee of the University of Cardiff, ethical considerations were attended to and followed (see Appendix 9 for the approved ethics committee information).

\begin{tabular}{|l|l|}
\hline $\begin{array}{l}\text { The principle of informed } \\
\text { consent }\end{array}$ & $\begin{array}{l}\text { Volunteers were provided with initial information on } \\
\text { the area of research, the time commitment, and the } \\
\text { method of data collection, at the point of seeking } \\
\text { participants before expressions of interest were } \\
\text { expressed. Identified participants were then given } \\
\text { further written information about the research topic } \\
\text { and the purpose and the scope of the research. }\end{array}$ \\
$\begin{array}{l}\text { Participants were informed of their right to withdraw } \\
\text { from the research at any point, up until the data } \\
\text { was transcribed and anonymised. }\end{array}$ \\
$\begin{array}{l}\text { An informed consent form was completed and } \\
\text { signed by each participant detailing their } \\
\text { understanding of the requirements of their } \\
\text { participation, the voluntary nature of their } \\
\text { participation, their ability to withdraw at any point } \\
\text { without giving a reason, their ability to ask } \\
\text { questions and discuss concerns with the research } \\
\text { supervisor, and their understanding of how the } \\
\text { issues of confidentiality, anonymity and data } \\
\text { handling would be addressed. }\end{array}$ \\
\hline Confidentiality and anonymity \\
& $\begin{array}{l}\text { Participants' names were not recorded during the } \\
\text { interview. Interviews were allocated a number for } \\
\text { data recording purposes. Recorded data was } \\
\text { transcribed for analysis within one month, and } \\
\text { transcribed data remained anonymous, and was } \\
\text { allocated a number for analysis purposes. } \\
\text { Participants were informed that data would be } \\
\text { anonymised but may be discussed anonymously } \\
\text { with research supervisors at the analysis stage. }\end{array}$ \\
\hline
\end{tabular}




\begin{tabular}{|l|l|}
\hline & $\begin{array}{l}\text { Participants were informed that the findings of the } \\
\text { research may be shared with interested parties } \\
\text { such as the University, or published at a later date } \\
\text { in an academic journal, however, the resulting data } \\
\text { would not be identifiable as theirs. } \\
\text { Care was taken to ensure identifying information } \\
\text { was removed from all quotes used within the } \\
\text { research paper. }\end{array}$ \\
\hline $\begin{array}{l}\text { Safe and appropriate storage } \\
\text { and handling of data }\end{array}$ & $\begin{array}{l}\text { Data was held securely in the form of recordings of } \\
\text { the interviews and written notes of the interview } \\
\text { made by myself. Recorded data was kept in a } \\
\text { locked cabinet at home until it was transcribed. } \\
\text { During transportation from the interview location } \\
\text { the data was in the possession of the researcher at } \\
\text { all times. No one else had access to the data. } \\
\text { Following transcription, data was held in a locked } \\
\text { cabinet at my home, and recorded data was } \\
\text { destroyed following transcription. The anonymous } \\
\text { transcribed data may be kept indefinitely by the } \\
\text { University. }\end{array}$ \\
\hline $\begin{array}{l}\text { Dissemination of research } \\
\text { findings }\end{array}$ & $\begin{array}{l}\text { Participants were advised they could request a } \\
\text { copy of the summary of the findings from the } \\
\text { researcher. They were advised that research } \\
\text { findings would be produced in the form of a } \\
\text { research report for the University of Cardiff, and } \\
\text { that the findings may be presented for publication } \\
\text { to a journal, such as Educational and Child } \\
\text { Psychology. }\end{array}$ \\
\hline
\end{tabular}

Chapter Four will be a presentation and discussion of my findings following the analysis described within the methodology. This report will present an overview of the overarching themes, main themes and subthemes found, with evidence for each theme presented in the form of data extracts from the original data to strengthen the transparency and validity of the findings. 


\section{CHAPTER FOUR \\ FINDINGS - RESULTS AND DISCUSSION}

\subsection{Introduction}

Within this chapter I will present the themes identified through the process of thematic analysis, as outlined in Table 5 in Chapter Three (Braun and Clarke, 2006). I will highlight the findings relevant to the research questions, discuss the individual themes analytically, and link these discussions to the literature presented in Chapter Two. The presentation of the four overarching themes identified will each be considered separately, with the main themes and the sub-themes within each main theme being presented as thematic diagrams. These will be supported by quotes from the data to provide evidence for the themes presented, and then move from the descriptive representation to an analytic discussion of the main theme and subthemes presented. In this way, the results and related discussion will be considered together to allow for a full examination and a coherent account of the data as presented.

The four overarching themes, the main themes, and sub-themes within those, presented in the first part of this chapter, have been inductively formulated through the thematic analysis stages, and address the research questions stated in Chapter Two. Within the final chapter I will summarise the key findings in relation to each research question, consider the implications for EP practice, research limitations and further questions arising from the findings.

A thematic map representing an overview of the inductively formulated overarching themes, main themes and sub-themes within each main theme is presented here 
(Figure 1) to provide an overview of the findings, and allow for orientation of the main themes and sub-themes, and for use as reference throughout this chapter. Main themes and sub-themes from these will be presented under each heading for discussion with the presentation of a thematic diagram to illustrate how these fit within the overarching themes.

It should be noted that this research focused on a deliberately broad area of EP practice as no previous research in this area had taken place. These broad parameters resulted in some limitations on the depth and complexity of the analysis, due to themes needing to be an accurate reflection of the data corpus and the word limit of the research paper. This limitation is reflected upon further within Chapter Five, Section 5.2 Methodological Reflections and Research Limitations.

Although the overarching themes, main themes and sub-themes are distinct from one another they are not wholly independent, but interrelate and overlap. The most significant interrelations and overlaps are indicated by the dotted pale orange lines on Figure 1 which maps out all of the overarching themes and main themes.

In all diagrams and headings the themes are presented as follows:

Overview:

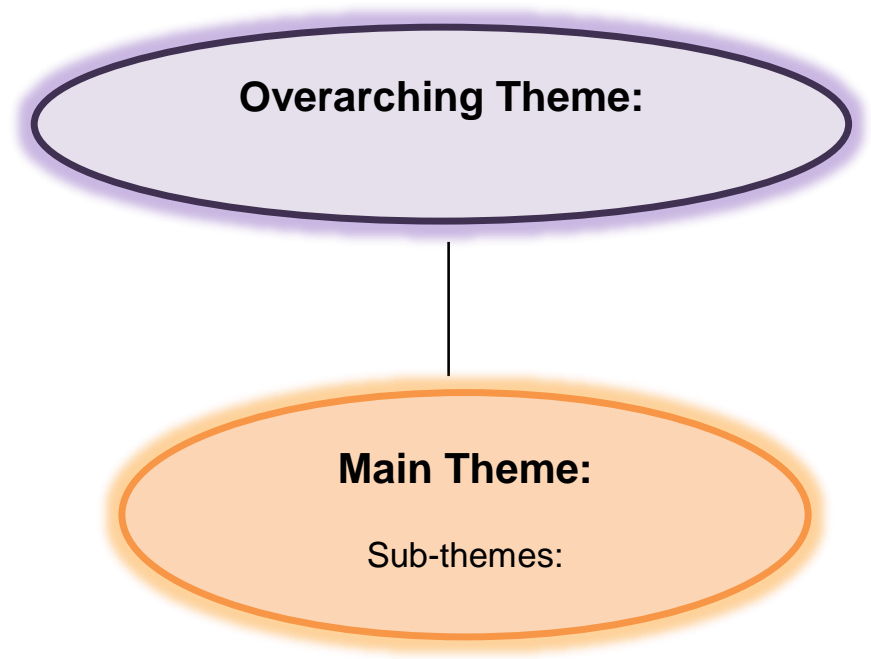


Figure 1: Thematic Map Overview

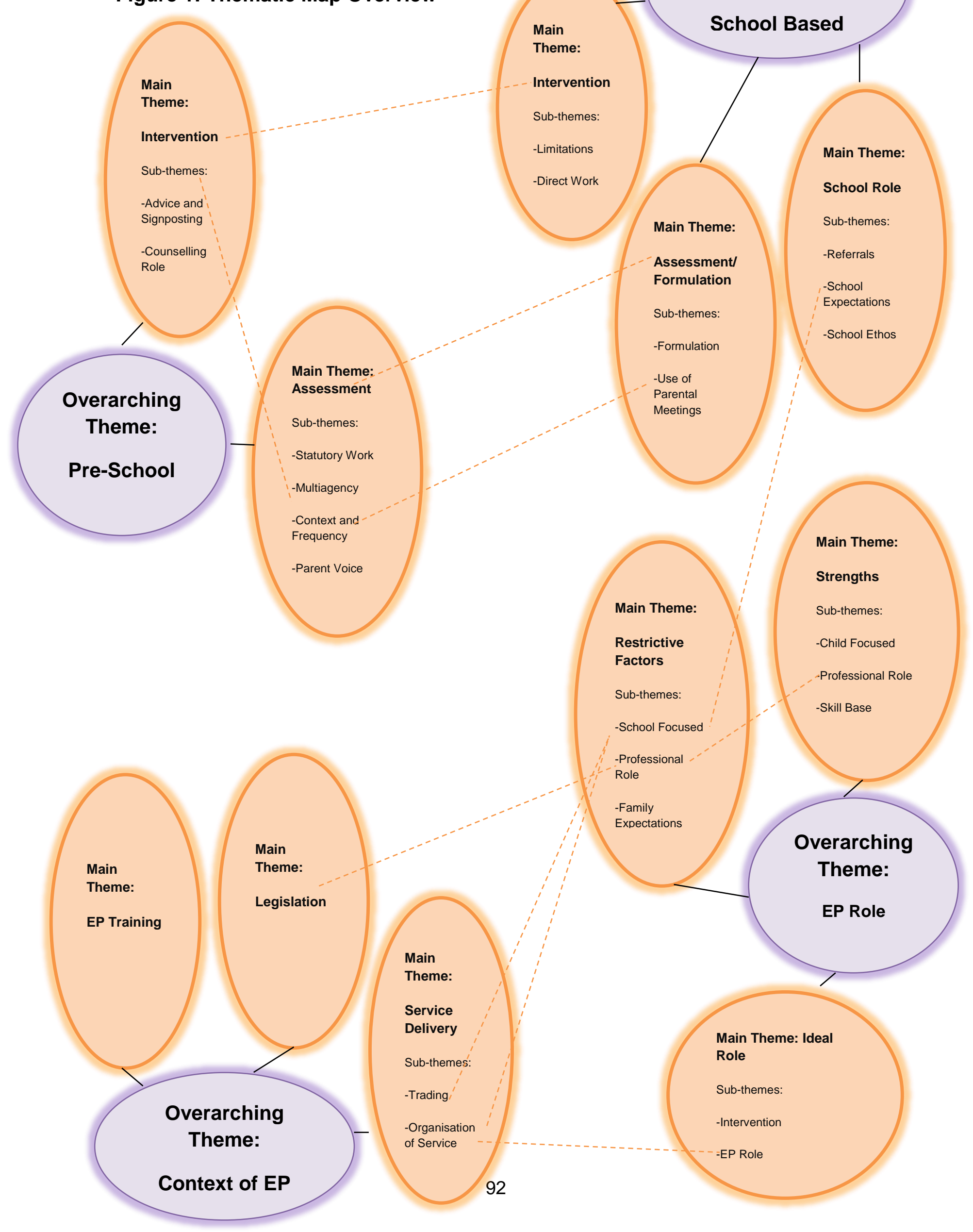




\subsubsection{Overview of Overarching Themes}

The main themes that emerged from the data set were organised under four overarching thematic areas:

- Pre-School Family Work

- School Based Family Work

- EP Role in Family Work

- Context

The overarching themes of pre-school work and school based work emerged from the spontaneous division of the participants' responses utilising these themes themselves, and were not related to direct questioning around these specific areas. Seven of the nine participants spontaneously divided their responses into these areas to describe their work with families, and all primarily focused on reflecting on their pre-school work before moving on to consider their family work in relation to school based work.

Two participants did not refer to pre-school work at all, and did not divide their EP family work into the pre-school/school based themes.

Themes organised under the overarching theme of 'EP Role' emerged both from direct questioning around participants' perspectives and views on this, as well as themes which emerged from their reflections and comments on their work throughout the interviews.

The overarching theme 'Context' emerged from questioning around barriers and facilitators to family work, as well as from reflections and comments on their work throughout the interviews. 


\subsection{Overarching Theme: Pre-School Family Work}

\subsubsection{Main Theme: Assessment}

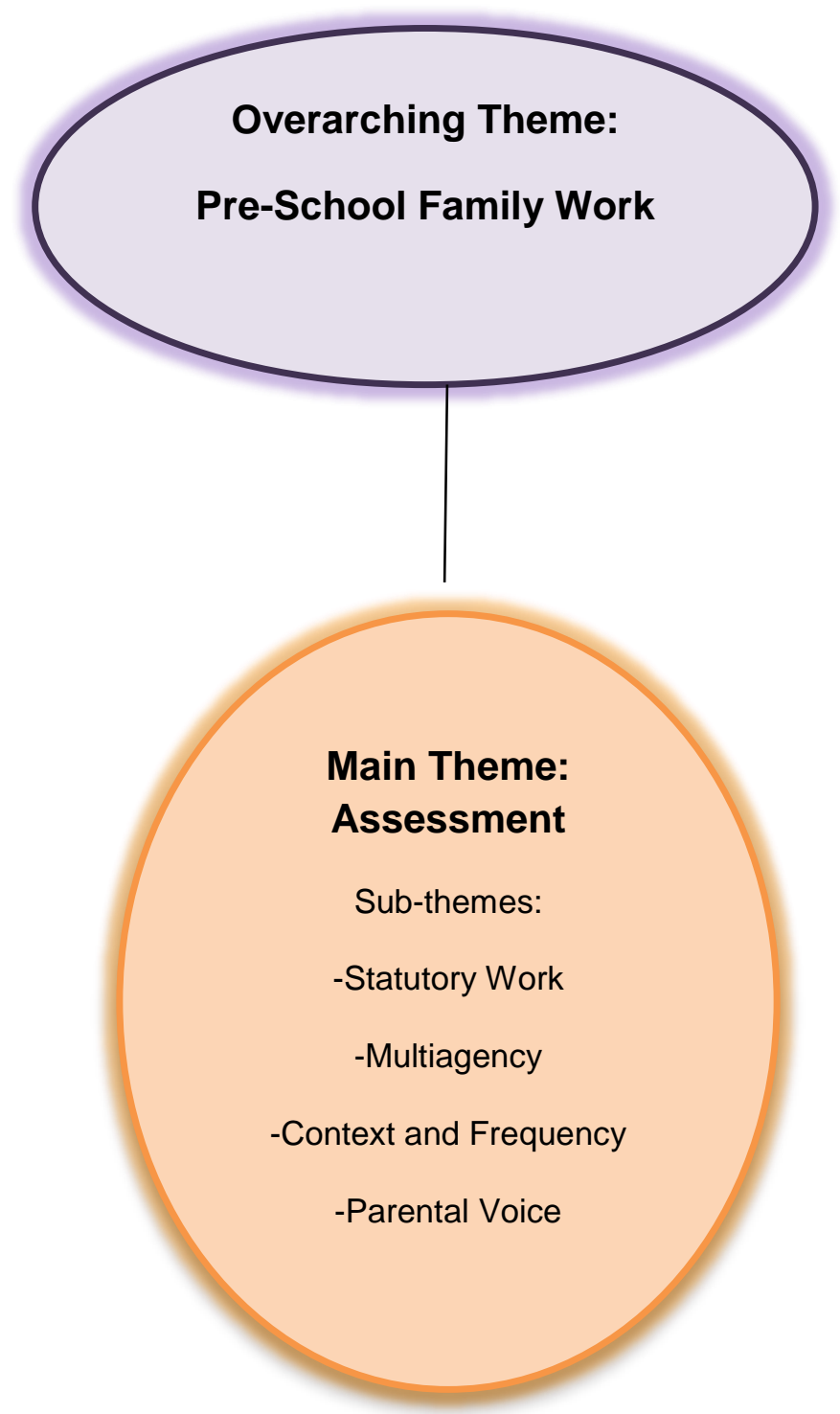

All EPs who referred to their pre-school work involved families in the assessment of pre-school children. EPs who referred to their pre-school work in relation to their work with families did so in the context of the work being primarily, or entirely, related to statutory assessment procedures. They identified their assessment work as having a number of interrelated factors, which formed the sub-themes: Statutory Work, Multiagency, Context and Frequency and Parental Voice. 


\subsubsection{Sub-theme: Statutory Work}

The role of statutory assessment in identifying SEN of pre-school children was the reported focus of this work, and this was linked to the role of identifying the provision which would be required in an educational setting to support these.

\section{e.g.:}

$\mathbf{P 1}$ "So my role with them is to undertake the assessment prior to them coming into an educational setting so they've got their education, health and care plan in place before they do that, and working with parents is a really important part of that because obviously the home environment is key isn't it?"

P3 “... our role is much more to get involved with parents in decisions about moving into school and what sort of educational provision do they want to look at, and helping them identify what the child's main needs are really."

P5 "Pre-school work with families is around statutory."

The role of an EP in working with families at a pre-school level was viewed overwhelmingly as a statutory role aimed at identifying SEN provision, and therefore all other descriptions of work in this area need to be viewed within this context. This finding would underline the assertions by MacKay (2006), Stringer et al. (2006) and Peake (1999) that EP work has become narrowly aligned with SEN procedures; identifying need and describing education provision. Buck (2015) suggested that EPs accept that casework linked to legal statutory obligations provides one of the main reasons for continued employment by LAs. Certainly, the data would indicate that within pre-school work, EPs accept and identify this as their distinctive role.

These findings are also consistent with those of Robinson and Dunsmuir (2010) who in a study to establish the role of the EP in work with children in the early years, identified that the potential of psychology to inform early years practice was not 
mentioned during focus group discussions. Moreover, a key issue that arose from the EPs' responses was that the requirements on them to provide psychological advice, as part of the statutory assessment process, inhibited wider practice.

Within the statutory role for EPs in working with families, alongside the assessment and identifying provision roles, a number of participants identified the role of explaining, and supporting parents through, the statutory assessment process.

\section{e.g.:}

P3 "And then there's quite a big role in explaining the whole process to parents of what happens next and trying to explain to them how it has to be a decision made by somebody else, and it's very complicated."

P4 "Some of it is definitely procedural stuff, like explaining the processes to them."

Although pre-school work was overwhelmingly identified as the primary way in which EPs work with families, the narrative which emerged from EPs' descriptions of this work, were that this work is mainly assessment based with a focus on identifying SEN provision and guiding parents through the statutory assessment processes. The outcome for EP involvement was to complete this process so that the child could enter school in the correctly identified provision type, with the correct level of support.

\section{e.g.:}

P5 "If the nursery want you to attend a review you attend a review, if the nursery don't want you to attend, they just want to keep it informal, then that's fine. But I would always go to anything statutory because I do believe we are the face of the authority, much more so than anything else." 
P6 "Once statutory was over, I would then work with them once a term like we're supposed to. It's in the lead up to statutory when the parents need so much help to wade through the paperwork and come to some realisations. If you've done your work properly when you produce your psych advice and the EHC plan is done, assuming that it goes down that route, then by that stage the parents, they've signed off on a document that says your child has got a problem so you kind of think 'please God I did my job properly and they've accepted it."

The focus on statutory assessment work in pre-school family work is likely to reflect the referral route to EP services, the perceived role of the EP within the LA and the role of other agencies in supporting families of pre-school children. One participant did comment that only pre-school children with severe and complex SEN were likely to be referred to EP services, and that this has changed over their time working as an EP.

e.g.:

P7 "Often the children who are referred to us now have severe and complex needs and therefore we're talking about a child who is, has got major learning difficulties. We try to target those as a group, we don't really give appointment time to children who have less than severe or complex needs."

There is therefore a likelihood of presumption that pre-school children referred to EP services require $\mathrm{EHC}$ plans, both on the part of the referrer and of the EP receiving a referral. Although Dowling and Osborne's (1985) assertion that the decision for an EP in how to proceed following a referral will in part depend on what the expectation of the EP involvement is, was in reference to school based referrals, the same influence can be seen to apply here in pre-school work, where referrals to EPs from 
other professionals or agencies indicate a high level of SEN with an assumption of requirement for statutory assessment.

The emphasis on special educational needs in EPs' work in the early years was recognised also by Dennis (2003) who suggested that early years practitioners envisaged a traditional role for EPs, based on assessment and individual intervention, which could mean that EPs replicate the statutory assessment role undertaken in schools in early years settings. Dennis (2003) called the growth of early years provision at that time a 'golden opportunity' for educational psychology services to work with the private, voluntary and independent sectors of early years provision, and proposed a broader model of service delivery by EPs in early years work. The results from this research would suggest that this move to a broader service model of delivery has not occurred.

Within the theme of involving families in assessment of pre-school children, the areas of identifying SEN, considering the child across settings and the importance of the family context within assessment were raised.

The process and aim of assessment had a high degree of agreement and consistency across responses, but the views and practice described around seeing the child and family across settings, and the degree of importance given to considering the family context within assessment varied between respondents. These variances will be considered in more depth within the Context and Frequency theme.

Identifying the child's abilities and difficulties was referred to as the focus for assessment. Some participants referred to adopting a strengths based approach in 
assessment with parents, and all participants acknowledged the need to involve preschool parents within the assessment process to varying degrees.

e.g.:

P1 (Question to P1: what do you think parents would see as your role in preschool work?) "Assessment. I think they think I'm coming in to say what their child can do and can't do, and what they need in school. Which of course I am." "But it's a bit more than that."

P6 "I keep that first chat quite chatty, and just, you know, what are you good at? It's all strengths based. I like strengths based work with families."

The legal responsibility of the LA to request individual assessment reports from EPs can support within-child approaches to assessment to fit the requirements of statutory educational psychology assessment reports (Buck, 2015), with the focus on the needs of the child pointing to the provision required. Buck (2015) also suggested that the move towards 'person-centred' rhetoric could easily be regarded as a rephrasing of 'within-child' conceptualisations, in contrast to 'family-centred', which would be more supportive of systemic approaches. The emphasis on 'strengths' when focusing on the child can still be seen as a within-child focus, which simply presents as the obverse of a deficit model. The data indicated that the statutory assessment role of EPs in their pre-school work does, perhaps inevitably, given LA requirements, place the assessment and report focus on the individual child and their strengths and needs, rather than on the child's systems.

These findings are consistent with those of Shannon and Posada (2007) whose study of EPs' involvement in pre-school work found that the volume and timescales associated with individual casework in the early years are perceived to be barriers to engaging more fully in other types of work with this age group, and that those 
pressures were associated with the need to complete the statutory assessment process in order for children to access provision.

\subsubsection{Sub-theme: Multiagency}

The involvement in multiagency work with pre-school families was consistent across participants who discussed their pre-school work specifically, and most acknowledged that they would usually work jointly with other agencies already involved with the family. Within the multiagency work with pre-school families most participants would work jointly with other agencies, through joint home visits and review meetings in nursery settings, and would utilise the prior knowledge and experience of those professionals within their assessment work. However, the role of the EP and other professionals remained separate with distinct expectations of each role, with the EP role again being defined through the statutory assessment role. The role of other agencies was viewed as distinct from the statutory role of the EP, and these agencies had a more supportive ongoing interventive role with families.

e.g.:

P3 "I might also visit families for pre-school work. That would probably be a joint visit with the early-years worker ... l'd go along with the key worker who knows the child best and sort of observe them working with the child."

P3 "Because we have a very good early-years service most of the pre-school children we work with already have a designated worker. So that support role in terms of the child's learning really comes from there, and our role is much more to get involved about decisions about moving into school."

Oakes (2010) found that early years work is one of the areas where EPs have an established multi-disciplinary role, but that paradoxically little had been written on how professional learning from this area of work can inform practice. Within Oakes' 
study on how EPs support early years children and their families, some EPs expressed concern at being brought in at too late a stage to 'rubber stamp' decisions made by other professionals. A rationale given for this structure was an avoidance of duplication of work between advisory teachers and the EPs, implying that an EP's skills/knowledge were in some way superior to those of an advisory teacher.

Within this research, the data indicated statutory assessment as the distinctive role for the EP within multidisciplinary work with pre-school children, but a clear rationale for this particular role for the EPs was not made. Several participants referred to the skills and experience of the early support services with whom they jointly worked, and how they were able to utilise their knowledge of the child and family within EPs' own assessments; the EPs all viewed their distinctive and additional role to be the leading on, and completion of, statutory assessment for provision purposes, as discussed above.

\subsubsection{Sub-theme: Context and Frequency}

The responses referring to the context and frequency of EP and parental contact within the assessment process for pre-school children are around home and nursery settings; the importance given to contact within both settings, and the frequency of contact indicated. These areas indicated variability in practice between participants, inferring differing beliefs around the value placed on home context and contact with parents.

A number of participants referred to their practice of seeing the child and family in both the home environment and the 'setting' (educational environment such as nursery or playgroup), whereas others reported that if a child was in a setting they 
would not visit the child and family at home. This difference in reported practice indicates differing assumptions about the role of the home and family in pre-school assessment, both in terms of establishing the child's abilities in differing settings, but also the value placed upon the family context in understanding the child, their experiences, and the family's needs in supporting their child.

\section{e.g.:}

P1 "Looking to what the child can do in the home environment as well as a setting."

P3 "If the child's in a nursery, or a different setting, I would go and see the child there to get that comparison."

P6 'Looking at how they've coped, trying to suss out their support networks, what's going on for the family, what situation are they in, are there any other stressors coming into the family."

Or

P5 "If the child was in a nursery then the parents would only see me at reviews, but if it was the child was at home, then the parents would see me."

P7 "Assessment work with pre-schoolers is almost exclusively in the nursery setting now. I can't remember the last time I visited a home."

P7 "Mostly I don't go home because it takes more time, and because it delineates the fact that my work is not really about how the child is managing at home."

These differing approaches to assessment infer a variance of attitude between the participants to the role of EPs in pre-school assessment, and the role of the child's family within this. Although all participants agreed that involvement of parents was a required and necessary component of pre-school assessment, those who indicated that they would see the child and family across both settings suppose that the assessment has a role in understanding the complete picture of the child which can only be achieved through an understanding of their functioning in the differing 
systems they exist within and through their experiences within those systems. Those who reported they would see the child and family at home also indicated that the purpose of this is not simply assessment of the within-child abilities in different settings, but to consider the environmental factors which may impact on this such as the family's own support networks and internal stressors. This approach to assessment supports the recommendations of Newland (2014) that practitioners should evaluate the context of the family system, and the contextual factors which may be barriers to family well-being, so that interventions that support family functioning, positive parenting approaches and resilience, can be made to bring about positive outcomes for the child.

The participants who indicated that if a child was in a nursery setting then their preschool assessment would be educationally focused, conducted with parents through the setting, and through meetings within this setting, indicated that the outcome of establishing the child's needs within an educational context was the primary focus of pre-school assessment work, and parents' views on this aspect of their child's needs were valued and part of that process, but consideration of the wider context of the family was not necessary to achieve the outcome required of the assessment.

One participant who had been an EP for nearly 30 years reported that this had changed significantly over the course of their career; early in their career home visits for pre-schoolers were standard, whereas now it is almost exclusively within nursery settings.

e.g.:

P7 "I try to keep my involvement with them purely about education ... partly because I don't have time and partly because it's not the EP role now, whereas I think when I started my career I could've done that if I wanted to." 
One participant indicated that if a child attends a nursery they will then be guided by that setting in their frequency of contact with the parents; this practice would suggest a shift from focusing on the family as the child's primary system within an assessment to one where the educational setting is perceived as the primary system within the assessment. As will be seen when the findings from school based family work are considered, the practice of the educational setting guiding or directing EPs' contact with parents is prevalent within school practice, but the data suggests may also have some relevance to pre-school family practice.

e.g.:

P5 'If they're in a nursery or any other kind of setting, you're really dependent on how much contact the nursery staff want you to have with the parents. If they feel you've got a useful role they ask you to attend every review, if they don't they just ask you to attend the statutory stuff. I'm always led by the nursery."

P5 "My assumption would be, always be at the first meeting in the nursery (to meet parents) and it would be after l'd seen the child, because parents ask us questions and you need to have something to say to them."

The practice reported here of seeing parents within an educational setting, and of the first contact being after seeing the child, so that the EP feels they have information to feedback to parents, is also consistent with some practice and views expressed within the school based themes, and indicates an assumption that the purpose in meeting parents is to allow the EP to impart their opinion and knowledge of the child to the parents, as well as collate information from the parents themselves. Oakes (2010) suggested that best practice for EPs working with parents of early years children would be that parents should be the first point of contact in gathering information about a child's needs, and that EPs would then provide regular feedback to parents according to the method of communication agreed between parents and 
EP. This suggested practice, which places the parents at the centre of the assessment process with their child, runs counter to that expressed by some EPs in this study, where once a child is in a nursery setting the educational placement is placed at the centre of the EP involvement, with the parents involved and informed, but as agreed between the EP and setting.

Other participants, however, viewed pre-school family work as very different and separate from school based family work, and felt that with pre-school families, home visits and frequent contact with parents was central to the assessment process the EP is involved with.

e.g.:

P6 "Pre-school work, lots of home visits!"

P6 "So a lot of, that's very close work with them (parents) actually, I meet with them a lot."

P4 "Always do a home visit. Several reasons to do a home visit. Number one it's less threatening, it's in their home, gives them a kind of balance and it gives a chance to see the family, and the child in the family environment."

P4 "I mean I do tend to see parents as knowing their child best, which is always my starting point."

These responses indicate that these participants view the role of parents as central to the assessment process, and therefore view frequent contact within the home setting as valuable. There is also an assumption here that meeting within a home setting allows for 'a kind of balance' within the EP and parent roles and status, and places the parents' expertise on their child above the EP's. Again, the relevance of the home environment to a pre-school child's experiences and development are also made explicit. 


\subsubsection{Sub-theme: Parental Voice}

The role of the EP in ensuring that parental views are expressed, understood and given weight, was acknowledged as part of the EP role in assessment when working with pre-school families.

e.g.:

P1 "One is the parents' perspective, 'cause that often is different from what the staffs' perspective is, isn't it, or from the professional perspective."

P3 "So I would see my role there as giving parents a voice, making sure they have their say and that their views are listened to."

The role of facilitating the parental voice is indicated both through ensuring the parents' perspective of their child is considered within the assessment, and acknowledging and considering the differing perspectives which may exist between staff, other outside agency professionals and parents, and also in terms of parental views about the type of SEN provision which parents may wish for their child.

These roles may be considered as part of an EP role, rather than that of other agencies who work with the family, due to the main task for EP involvement being statutory assessment, where the outcome will be the LA identification of SEN provision, and within this the EP's role as process facilitator, or LA officer. The parental perspective of the child's needs is necessary to these processes, and therefore becomes identified with the EP role. 


\subsubsection{Main Theme: Intervention}

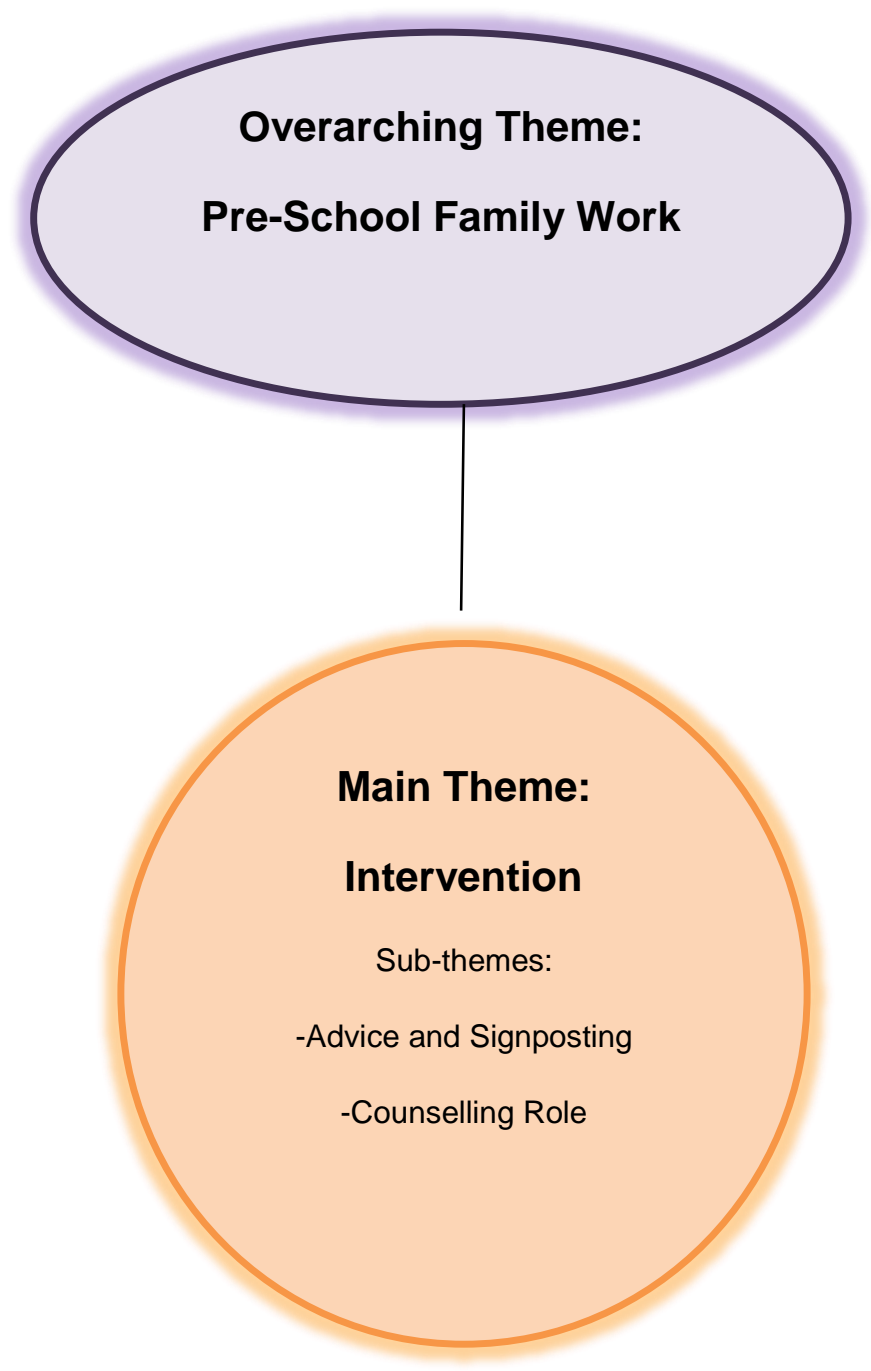

All participants who raised pre-school as an area in which they work with families, discussed their role being around assessment and this being linked to the statutory assessment process. None of the participants then spontaneously went on to report or reflect upon intervention work around those pre-school children and their families. In all cases where participants had discussed pre-schoolers and described their assessment work, but not reported any intervention type work, participants were subsequently asked specifically about their role and involvement with supporting intervention for those pre-school children and their families. The responses from this 
question generated the sub-themes: Advice and Signposting, and Counselling Role.

\subsubsection{Sub-theme: Advice and Signposting}

Most participants when asked about intervention work with pre-schoolers and their families responded that their role in this area was restricted and limited due to time constraints. The intervention work which was described was in terms of advice given in response to queries, but this was described as 'lacking in depth' and 'superficial'. One respondent explained that intervention was not a role for EPs in pre-school work; that it had been in the past but is no longer regarded as such. Other respondents did not clearly state that this was not an EP role but explained that they would expect other agencies to take on this role.

e.g.:

P3 "I mean there's potential to be talking about ways that they could be building relationships with their child, or managing behaviour but I don't do that work in depth really. It would be sort of superficial, one visit. I think if I was going to do that work in depth we'd need like weekly visits and I don't do that."

P3 "I wonder sometimes if parents expect that, and if it's something we could do, but we haven't really got the time."

P4 "Nurseries sometimes expect intervention and don't get it."

P7 "Now that (intervention work) doesn't even seem to be talked about anymore because I think it's recognised we don't really have time to go in and monitor programmes, because these children have got time allowed them and we want them sorted by the time they go to school."

The issue of intervention across settings, both at home and nursery, was referred to with reflections that often both parents and nurseries are expecting, and hoping, for 
this type of support from EPs, but no respondents indicated that they gave this type of support beyond the 'superficial' advice.

This finding is consistent with that of Robinson and Dunsmuir (2010) who argued that the potential for EPs to work with parents of early years children with problems, that can cause families and early years staff concern and distress (such as with sleeping, eating and toileting), is not fully realised within the practice of many EPS working with young children. This is despite the fact that psychological theory and research have made a significant contribution to the understanding of how these difficulties can be best understood and managed (Douglas, 1989, 2005; Herbert, 1996).

The responses around lack of substantial EP involvement in ongoing intervention work with pre-school children and their families indicated that this was primarily viewed as a role for other agencies rather than EPs, and that if intervention was required but no other agencies were currently involved, the EPs would then refer to an appropriate outside agency rather than offer support directly, due to the constraints of time. Although referring to other agencies for ongoing intervention support for children and families assumes that within the current systems this is not an EP role, but a role for other agencies, no respondents postulated any premise as to why this might be the case. No consideration was given to why assessment and identification of SEN provision would be the role of a psychologist, but the role of ongoing support to families with pre-school children would not be a role for a psychologist but would come under the remit of other agencies. 
e.g.:

P8 "Cases l've worked where they need more intervention, it's been early support services, I've found, usually offer that, or if they're at a setting it's been the SENCo or their key worker there."

P7 "If they're not coping then I always offer avenues of them getting referred to somebody whose job it is to support them at home."

An argument could be made that the task of intervening in family systems, to understand the interactional factors at play and flexibly build and adapt intervention models around this to support families and children, could be considered more of an obvious role for a psychologist, than the assessment of a child's functioning ability level and linking this to educational provision, which would be the more obvious role for educational based agencies. These assumptions can be linked to arguments made by Peake (1999) that the central tasks of EP work are largely social/political and administrative in nature, and whilst the legislative procedures have a useful role in clarifying and making equitable the support children with SEN can access in schools, this process needs educationalists not psychologists.

Participants' responses to their role in intervention in pre-school work would seem to indicate that the opposite remains largely true: EPs have taken on, and accepted the administrative educational procedures, but feel limited, to the point of a minimal superficial role in intervention work with pre-school children and their families or nurseries, and concede the arguably more complex intervention work across a child's systems, to other agencies and professionals.

This finding, that EPs perceive their role to be assessment and identification of provision, and other roles of family support fall to other agencies, is in line with the findings of Frederickson and Miller (2008) that members of a multiagency family 
support team perceived the role of the EP as an assessor of individual needs and a definer of resources.

\subsubsection{Sub-theme: Counselling Role}

Although not directly referred to by any participants as intervention work, a counselling type role was referred to by all participants who discussed their preschool work with families. Although only three participants directly referred to this as a 'counselling role', they all referred to a role for EPs with pre-school parents in providing emotional support, or helping them 'come to terms' with their child's difficulties. Some EPs framed this role as emotionally supporting parents in coming to terms with their child's difficulties, whilst others framed it as supporting parents to face, and understand the reality of their child's difficulties.

Those who viewed the role as emotionally supporting parents used emotive language such as: 'trauma', 'sensitive', 'needy', 'intense', and 'containing anxiety', to describe the parents' states and experiences, and their interactions with those parents.

e.g.:

P1 "They are still in the traumatic stage of their journey, aren't they? And I think we're well placed to understand that, and to let them feel they can talk about that as well. So it's, I suppose there's also a counselling element to it sometimes."

P7 "The parents are often very needy because they don't know what's wrong with their child."

P8 "In some ways it can be kind of be, containing anxieties that parents have." 
Other participants who focused more on the EP counselling role being in supporting parents to understand the reality of the child's situation, and to come to terms with this, used terms such as: 'reality check', 'open', and 'honest', to describe their interactions with parents.

\section{e.g.:}

P5 "Their grip on reality is so coloured by their need to not have a handicapped child. So part of our role with families like that is, in the nicest possible way, to talk about a reality check, but do it in the sense that the deficit is not necessarily a loss, there are things that can be joyful about it."

P5 "When you've got a child who is really massively disabled and the family are still hoping for that miracle, I think we come in and we, because we are less of a friend to the family than the first workers were and certainly the health visitors etc., the realisation that the child is probably going to have a handicapping condition from now on ... I think that's where we come in and we do pick up the pieces of parents who are desperately sad, because our input has made it possible for them to see that actually this miracle is not going to happen."

P6 "Also l'm the one who is quite honest with them and quite open and will say, you know, "I think this is quite significant, and I think that takes quite a skill to do that, to deliver sometimes unfortunate news."

P8 “Sometimes it's, our role is sometimes normalising, in some cases, what they're going through."

Both of these responses highlight a therapeutic role for an EP in working with preschool families that may be specific to this type of work due to the often severe and complex needs that the children have. Also, both approaches within this counselling role highlight the belief that this is a specific role for an EP in this type of work, that the other agencies involved may not have the skills to offer, or may not see as their role. 
The view of the counselling role being to support parents in facing the reality of their child's disability, can be viewed as facilitating change in the parents' constructs of the child through challenging the parents' view, but this approach does raise the dilemma of when it is appropriate for professionals working with parents to 'push' and 'when to hold back' (Cunningham and Davis, 1985). When a professional challenges parental views it indicates that the parent is not construing the child in the same way as the professional, and the aim should be to explore with the parents alternative ways of construing rather than moving them to adopt the 'definitive' construction of the professional.

The view that the EP is 'less of a friend' to the family, or less involved, suggests that not being emotionally enmeshed within the family system, as some other agencies may have become, allows for the EP to remain 'outside' the system and comment on what is observed to shift family perception of the situation. This perspective reflects that of first order cybernetics in systemic approaches where the 'therapist' remains 'outside' the family system and maintains a role in guiding and influencing the family system (Minuchin, 1974; Haley, 1976; Watzlawick et al., 1974).

The particular role supposed for EPs in the emotional support and containment role with pre-school families, may suggest that families seek this role from an EP, rather than from other agencies involved, as families may interpret this as the role of a psychologist, and that the EPs themselves view this role as something distinct to the EP role which other agencies involved do not offer.

The emergence of this counselling role may also be linked to the timing of EP involvement in the child's life; where the transition from the safety and acceptance within the family system, looking towards entering a wider educational system, with 
the associated discussions around SEN and provision, represent a time of great anxiety for parents, as well as the full consideration for families of the implications of their child's difficulties outside the family system.

Although EPs evidently see this as part of their role in pre-school family work, given that a number of participants made it clear that their assessment approach is educationally focused, primarily within educational settings, often at formal review meetings with other professionals, it is not clear in what way this approach is effective within those situations, and these types of interactions may be linked to the 'facing reality' approach around the child's educational needs, rather than the emotional containment approach.

\subsection{Overarching Theme: School Based Family Work}

\subsubsection{Main Theme: Assessment/Formulation}

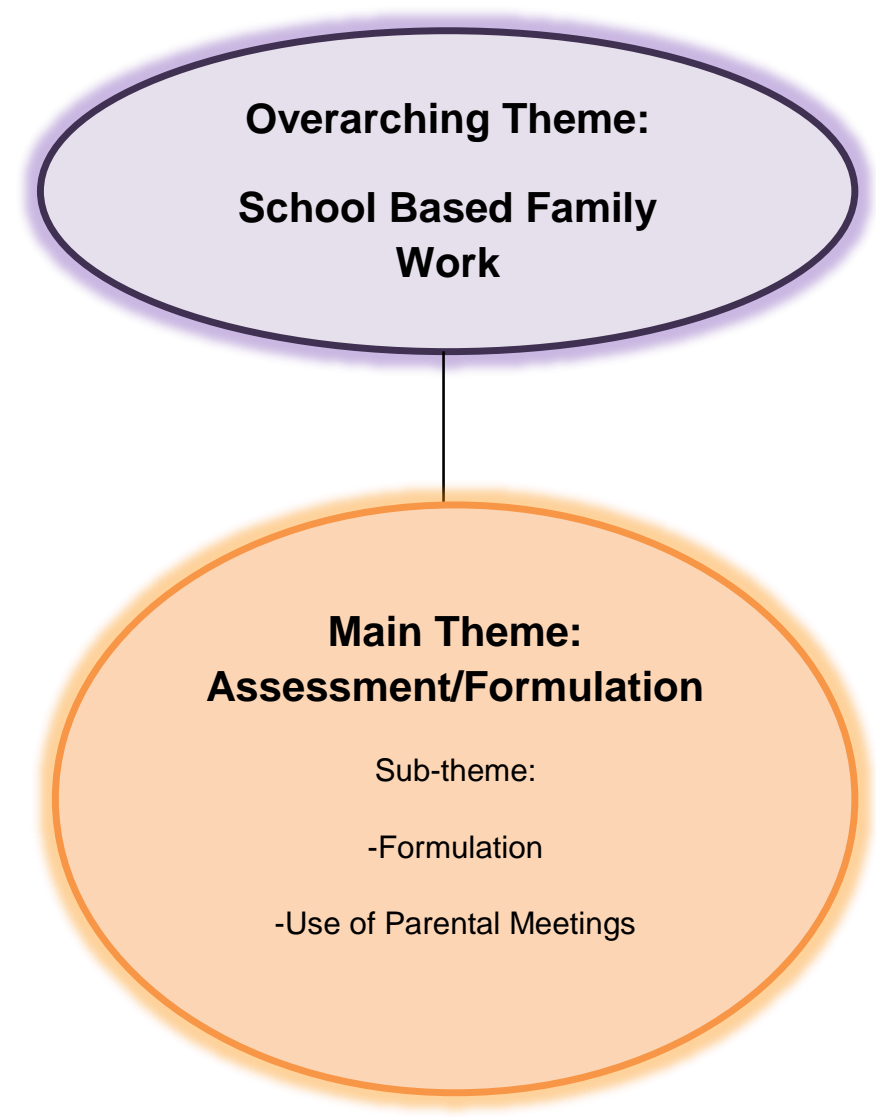


All participants discussed within their interviews their involvement with families through assessment within school based work, and from this emerged the themes of: Formulation and Use of Parental Meetings.

\subsubsection{Sub-theme: Formulation}

Most participants reported that they would utilise information from parents within their hypotheses formulation, although there was some variety in practice depending on the type of referral, with some participants being less likely to involve parents in cases referred with learning difficulties, but more likely to involve parents for referrals for social, emotional and mental health type difficulties.

e.g.:

P8 "Anything I think where there's more, maybe, mental health concerns or emotional and behavioural difficulties I think I'm more likely to meet parents."

P5 "I would certainly not expect to see a parent, and in fact to be honest with you, if the school asked me to do that I would actually not do the work." (In the case of referral for a numeracy difficulty)."

This finding is not consistent with that of Woods and Farrell (2006) who reported on the findings of a questionnaire survey of 142 EPs on their approach to assessment, and found that in cases of young people with learning difficulties, $22 \%$ of EPs viewed meeting with parents as the most useful assessment method, but $26 \%$ viewed meeting with parents of children with behavioural difficulties as the most useful assessment method. However, $91 \%$ reported commonly using parental interviews with parents where the referral is for a learning difficulty, but only $89 \%$ reported commonly using parental interviews for behavioural referrals despite a higher number indicating this would be most useful. 
Within this study, some participants indicated that in cases where children may have been referred for a learning difficulty they will often meet and work with parents to explore other hypotheses, and they reported that working in this way often revealed a wider more complex view beyond the initial reason for referral.

\section{e.g.:}

P4 "Again some of it is incidental. So they'd be referred by a school for something else. I don't know, they can't write the letter ' $H$ ' properly, or something crazy, and then actually you get to the bottom of it."

The participant quoted above described a referral for learning difficulties where through their work with foster carers identified that a child was unable to use a toilet through a fear from being previously beaten for making a noise, and the focus of the assessment and the formulation, and therefore the focus of the EP work in school, significantly altered.

e.g.:

P4 "But then, you know, thinking about 'oh cripes, if they're wearing a nappy in school, forget not writing the letter ' $H$ ', how does that make them feel?' How do they toilet with the rest of their peers? What about their independence? What about letting them grow? Which I think is more important than whether they can write the letter 'H' correctly."

Most participants indicated, through their descriptions of their assessment work, use of executive frameworks of practice within their assessment in schools, which included considering the family situation and parental views. These findings suggest that EPs have moved away from the more rigid, scientific and decontextualised approach that perhaps previously predominated in psychological practice, towards a more ecological approach such as the Woolfson Integrated Framework (2008), which was developed to support EPs with assessment and intervention work, and 
which incorporates Bronfenbrenner's (1979) social ecology model to ensure a holistic understanding of the child across multiple contexts (Woolfson, 2008). The use of eco-systemic perspectives such as this can support EPs to create a multilayered understanding of a problem situation (Cameron, 2006).

e.g.:

P1 'So I suppose it's when it's teasing out, it's part of our assessment process isn't it, that we're used to doing which is evaluating the different hypotheses, in this case donated by two different parts; the parents and the other professionals, and looking to see what would support the child best, or what fits best with the evidence."

P3 "I suppose it's got two functions really, one is to gather information from the parents about how they see the issues, how they find the child at home, is there a difference between how the child is at home and how they are in school, what are parents concerned about, what do parents do, do they have any strategies that would be useful at school, do they need strategies that would help them at home? So it's like a two way exchange of information, really, to build up a picture of the child."

P7 "It gave me another view on the child before I met the child, because you always have the school view on the child, and you have the school view on what they think parents think, and then you meet the parents and you really see what they think, and so it gave me another clear view as to what the idea of this child was by other people."

The quotes above indicate a use of an eco-systems approach to assessment and formulation and the responses suggest an information gathering approach by the EPs to allow them to consider the factors across the child's systems to inform their formulation process. Some responses, however, inferred that although using an ecosystems model of formulation the EP remains in an expert role, where following the collection of information from across systems the EP will donate their considered formulation with recommendations at the end of an assessment process. 
e.g.:

P2 "We are in a unique position to be able to value, weigh up and make a valued judgement over which course to pursue, we think there might be other explanations for it."

P2 "You get the early history so you can translate that into useful information for the school."

However, responses from other participants also adopting an eco-systems approach

to assessment and formulation, suggested that they view the families as

collaborators in the formulation process, where the EP and family work together

towards identifying hypotheses.

e.g.:

P9 "So having exploratory conversations around where the mental distress is coming from, you know. Sort of brainstorming in a very open and democratic way, and that can take hours, but it gets things out that are going to be very useful for the next period of work you know?"

P9 "The proper way of working with families is collaborative and looking at it as a holistic system."

P4 "Sometimes it's the odd questions isn't it? It's that odd curious question that seems 'why are you asking this?' that suddenly sheds all the light on something."

This approach to formulation is reflective of both an eco-systems model, but also a systemic approach to formulation where the EP utilises questioning techniques to allow families to view the difficulties from a different perspective, creating their own new hypotheses and thereby opening up potential for change.

This approach reflects that described by Ugazio (1985) and Pelligrini (2009) who looked at the ways in which questioning could be used by EPs to gather information, 
formulate and verify hypotheses as well as explore the beliefs of families, or staff, to facilitate healing and change.

Bowman and Goldberg (1983) described how school psychologists could use reframing to offer families alternative perspectives about children's difficulties that focus' on interactions and removes blame, and suggested that when used in this way the collaborative exploratory process of formulation can also be the process of intervention.

\subsubsection{Sub-theme: Use of Parental Meetings}

Although all participants reported that they would meet parents and families as part of their assessments within school based work, there was again a high degree of variability between the participants' descriptions of, and reflections on, their use of parental meetings.

One participant mentioned that in school based work, they would still make some home visits, but for most EPs, parent meetings for school based work would take place in school.

There was a variety of practice both within and between participants in who they would invite to be present when they meet parents. Several participants gave examples and reasons for adapting this dependent on the situation and the purpose of the meeting.

\section{e.g.:}

P2 "I've often got the class teacher and the parent to a consultation with myself to discuss what works." 
P5 "I would never meet a parent for the first time without a member of the school staff being in the room ... I don't put myself in a position where somebody can misquote me."

P3 "Sometimes they won't talk openly in front of the school in the same way, so often we might divide it and have some of the meeting just with the family, part of the meeting jointly. It varies."

P6 "Usually when I'm assessing I meet the parents on their own because I feel they're intimidated by school or wouldn't be as honest if they are not happy about things with school, so I like to meet them completely separately first."

There is one example above describing a joint systems approach where the aim of the EP is to facilitate a joint consultation between parents and school in order to find joint solutions. This model of working reflects the approach taken by Nolan and Moreland (2014) who reported the use of joint consultations with schools and families, which were collaborative in nature, where EPs were able to facilitate effective communication between the family and school to bring about a shift in the dynamic created through the collaboration of the consultation process. This is the approach which was first highlighted by Dowling and Pound (1994) who illustrated cases where joint family consultations brought about changes for children in school through building understanding of the position, experiences and feelings, between school and family.

One participant stated they would meet parents on their own in the first instance to allow for a full exploration of the family perspective without the influence of the school perspective. This position gives high value to the family system within parental meetings, and places a high priority on the family perspective as separate from that of the school as the referrer. This approach indicates respect for the 
parents communicated through the time the EP allocates to them indicating that they are valued and important in the process of assessment of their child. Cunningham and Davis (1985) suggested that respect can be communicated in a number of ways to families by professionals, but that the most powerful way is attending to them; listening, understanding, and trusting them to be competent and capable. Peake (1999) recommended that EPs should use their time to show that listening to parents is a priority and fundamental within their work.

Some participants described the purpose of meeting with parents within school based family work as being around exploratory dialogues.

$$
\text { e.g.: }
$$

P4 "So that opened up a whole hour and half of family consultation, looking at all of their different perceptions of it."

P4 "If you say to parents 'tell me what's happening, talk to me about it, you get a different perception of it."

These types of dialogues and consultations indicate a systemic approach to parental meetings where the perceptions of problems are shared and explored, and through this reframed. This approach is indicative of the Milan systemic approach which explores patterns of communication, relationship patterns, and how different family members might view these (Selvini-Palazzoli et al., 1980).

Some other participants, however, indicated that they viewed the purpose of meeting with parents to be school focused and set by the school. 
e.g.:

P5 "I would never see a parent without it being a formal meeting, like a review or an FCAF, or unless I knew what the school was asking me to meet the parent for."

P7 "Sometimes I will not see the parent, and if I do see the parent it's usually briefer and about educational need."

P8 "We meet with parents to explain our role, how we're supporting their child, feedback from any assessments or observations we've done."

P5 "I wouldn't meet with a parent if there was no purpose set by the school ... my time is too valuable to just spend waffling."

The purposes ascribed here to parental meetings are not focused on the parental perspective, or exploratory dialogue around the presenting issue, but are more focused on a specific outcome, set by the school, or within a formal meeting setting, with a specific purpose and agenda.

The focus on meeting parents to provide information from EP to parent is also evident where several participants reported that they would usually meet with parents only after seeing the child in order to have information to feedback. This indicates a very different purpose from those EPs who indicated that they would meet with parents before seeing a child in order to explore the parental perception.

In one situation the EP views themself as the receiver of rich information from parents and families, in the other the EP approaches parental meetings with a view to providing parents with information the EP has gained. Peake (1999) stated that in her view EPs frequently see the child, teachers, or other professional before they see the parents, so that 'we can tell them what we think', and suggested that the implicit message in this use of time is clear: we are there to tell not to listen. 
e.g.:

P2 "It's traditional to see them, to see them afterwards, after the assessment to keep them informed."

P3 "If it was a child l'd actually done some individual work with, I would see the parent mainly to feedback what l've found. And l'd have to say ideally I would love to do that in all cases but I can't say hand on heart that I do."

P7 "I did go through a phase of always seeing the parent first before I saw the child, now, if I'm not certain there's that need then, or if I think they might test higher than that school state, then I may get the parent to sign a form to say I can see their child and I simply see them for testing to think, 'where are they'?"

P7 "So it was very theoretical, whereas now when I see a parent, when l've already seen the child, like when I used to do it before when I was early in my career, I'd say 'well l've seen them, l've tested this, I've tested that, or 'we've spoken about this, I've got this information. I give a much clearer view of my opinion of the child."

Participants who reported seeing parents after seeing the child referred to 'feedback' and 'providing an opinion' to parents which indicates a more 'expert' model of practice, where through assessment of a child the EP forms hypotheses and feeds this back to school and parents. This approach supports the view of McQueen and Hobbs (2014) who argued that in their experience parents' conversations with professionals are often around information gathering, problem solving and solution finding with the expectation that the professional will offer some strategies or solutions (Annan et al., 2013; Todd, 2007).

This is in contrast to a systemic approach, indicated by other participants in the quotes below, where the aim is to explore different perspectives, to shift perceptions and encourage the setting up of alternative hypotheses and possibilities for intervention, rather than submitting to the pressure to give an expert opinion (Osborne, 1994). 
e.g.:

P4 "I mean I do tend to see parents as knowing their child best, which is always my starting point. And sometimes just exploring around the edges of things that don't immediately seem to be your brief."

P4 "Sometimes it might be perceived that I've stepped outside my role with questions and conversations but I think when you really get to work with families properly that's how you can do your best work."

P6 "So often I have quite a few members of the family at that meeting, and school staff, professional agencies, myself and it exploring the functions of behaviour and what this is saying to us. And it's quite interesting parents' perceptions of the behaviour as opposed to the school's perception and it's quite useful to have these conversations because school will, or parents will, suddenly see the behaviour in quite a different light."

These participants are not primarily viewing their meetings with parents as information gathering, or information giving, but are indicating that they are using curious questioning to explore 'around the edges', and explore differing perceptions, and doing this collaboratively with the family to allow them to be a part of the hypothesis formulation, thereby opening up the potential for change. This reflects the potential use of EP questioning as an intervention in EP consultation, which can be used to gather information, formulate and verify hypotheses collaboratively (Ugazio, 1985), and supports the assertion of Pellegrini (2009) that many EPs may be using systemic approaches without recognising, or labelling them, as such.

Although all participants reported that they did work with parents and families through meetings in school based work, it is evident that there are differing approaches and rationales for this work. 
It should also be considered that the evidence indicates that although all participants work with parents in school, it was far from the case that all the parents of children referred to, or seen by, EPs, will meet the EP.

\section{e.g.:}

P5 "I would certainly not expect to see a parent, and in fact to be honest with you, if the school asked me to do that I would actually not do the work." (In the case of referral for a numeracy difficulty).

P1 "My contact with parents in those cases is non-existent really because I wouldn't get to meet them at all, and my focus is really on what strategies the school is using to support the child and I would be expecting school to feedback to parents about what our conversations have been and the kinds of support they're going to offer."

This supports the findings of Woods and Farrell (2006) who in their survey of 142 EPs found that in cases referred for learning difficulties 9\% of EPs would not commonly meet with parents as part of their assessment, and $11 \%$ would not commonly meet with parents whose child was referred for behaviour difficulties. 


\subsubsection{Main Theme: Intervention}

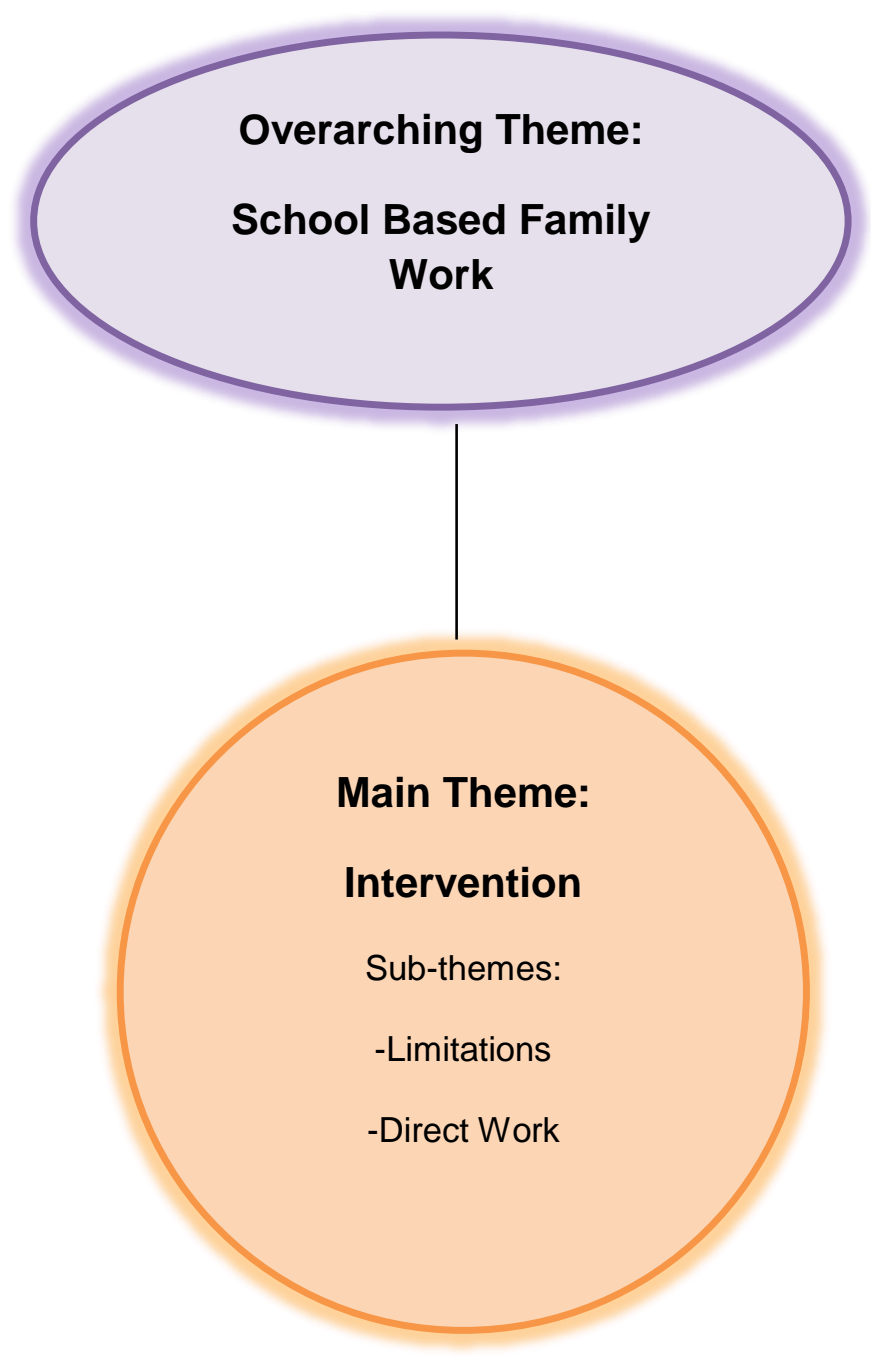

The main theme of intervention work with families in school based work generated two sub-themes: Limitations and Direct Work.

\subsubsection{Sub-theme: Limitations}

All participants discussed to varying degrees limitations upon their ability to conduct intervention work with families. Some participants expressed frustrations and raised questions around the limitations placed on family based intervention work, whereas 
others accepted these as limitations of the EP role. These varying perceptions of the EP role between participants will be discussed in more depth within the theme of EP role.

Several participants attributed the limitations on their intervention work with families as being linked to the traded model of service delivery within their own EPS, and the impact that schools as commissioners of EP work has on the ability to offer family based interventions.

\section{e.g.:}

P1 "Our work is negotiated with the people who fund us and in those cases we've talked about that's commissioned by schools, and it's not very often in my experience, that schools are asking for an extended piece of work with a family when they can get it for free from a family support worker."

P4 "I am desperate to get into that home and help her sort out her relationships and parenting and boundaries. But again, who funds that? Would that be school?"

The impact of a traded model of service on EPs' work with families will be considered further within the main theme of service delivery, but is raised here to highlight the specific impact it was felt to have on ability to conduct intervention work.

Participants also considered that intervention work with families would be both time consuming and intensive, and therefore the limitations on EP time to school placed a limitation on the ability to offer such interventions.

e.g.:

P1 "You know whether it's an intervention with a family or intervention with a child those pieces of work are very time intensive aren't they?" 
P7 "If they'd asked me (in the past) about their home difficulties at that time I probably would have offered them advice and support, and I might have gone back, and had more time to do that. I would have had more time not to just think about the child's needs at school but also the child's needs at home. I don't do that now because I haven't got time to work like that now."

One participant described working directly with families on identified issues at home, as a 'luxury' that is not available to EPs, but which trainee EPs may still find time to indulge in. The use of the term 'luxury' suggests this work with families is viewed as something which is desirable and indulgent but not essential.

e.g.:

P3 'I've got a trainee who's working with me at the moment and she's got a case where's she's identified attachment as an issue and she has the luxury of doing home visits and sort of exploring that much more with the mum, but I don't do that. Partly because the referral has come from the school and I suppose I'm focusing on what needs to be done in school because they've asked for support."

This participant clearly feels that their role is limited to school focused support as it is the school who have 'asked for support', and even in cases where family based issues have been identified, indicates that supporting the school is the priority for the EP, rather than addressing the issues identified across the child's systems holistically.

e.g.:

P3 "I would mainly focus under what was more under my control. So I would focus on, say it was around attachment and relationships, my main recommendations would focus on trying to build a stronger attachment and relationship in school, rather than doing work with the parents." 
Other participants also indicated that school based difficulties were the priority for EP intervention, and that intervention within a home, or family based difficulty, would not be considered as it would not necessarily have positive impact for the child in school which is the EPs' focus.

e.g.:

P7 "I never get involved with the parents in terms of what's the difficulty at home."

P7 "If for instance it's the kind of family who has had, always had a difficulty in looking after their child for a long time because of whatever reason, then I would take that as a fact, and not think particularly that some kind of intervention outside the school would necessarily have a huge impact on the school or the child's progress in school."

Although all participants when discussing assessment and formulation referred to the need to involve parents and to collect information about the child across the school and family systems, some participants' responses suggest that this information is used to formulate and understand why a child may present with difficulties within the school system, and utilise this to address the difficulties within that system alone. An eco-systems approach to both assessment and intervention would be looking to explore the interactions between the systems, and aim intervention approaches to where problems have been identified, and not simply using eco-systems assessment information to aim intervention in one priority system, namely the school.

An ecological systems perspective which integrates concepts and techniques from systems theory and ecological psychology, and underscores the systemic nature of a child's relationships within and across settings, widens the possibilities for interventions (Fine, 1985). However, the data would suggest that although EPs 
recognise and understand the need for an ecological systems perspective within the assessment process, at least in terms of information gathering, there is often not the recognition, or opportunity, to use this to widen the possibility for intervention, which often remains solely focused on the school system.

Fine (1985) stated that an ecological systems perspective could have particular usefulness for school psychologists whose work necessarily involves the relationships of home and school settings in the context of a child's 'problem', and that a systems-ecological approach is particularly useful for school based mental health consultants, as these professionals have a psychological orientation, and therefore an understanding of the many influences on behaviour. At the core of this approach is the understanding that a child exists in overlapping systems, and change in one system can influence change in another which opens up possibilities for a wide range of techniques and interventions that could be used selectively to bring about change across and between systems. However, the data suggests that EPs focus on intervention solely, or primarily, within the school system which limits the opportunity for wider interventions, and therefore for positive change to occur for referred children.

The understanding of the factors at play which are limiting EPs' work across the child's systems will be discussed further within the overarching theme of the EP Role, and the main theme of Restrictive Factors.

Many participants when considering the nature of the intervention work within the family system following the identification of need in this area, referred to the role of other outside agencies in conducting this work. As with pre-school work, direct intervention work with families was not seen as the role of an EP, but as the role of 
other agencies, or professionals, such as Family Support Workers (FSWs) or commissioned agencies, who an EP or school may refer to, if family intervention was considered.

\section{e.g.:}

P7 "I never get involved with intervention work with families, but I always make sure that they have the opportunity to be referred to somebody who can help them with that difficulty."

P3 "We now have a family support worker who can work with the family at home. They would work with the family."

P4 "A lot of mainstream schools subcontract out to places like $X Y Z$ and so whereas it would have been an EP they would bring on board, they pay for $X Y Z$ to come in who are cheaper than us."

The data suggests that schools, and some EPs, see the school system as the intervention focus for an EP, and intervention within the family system as the role of other agencies and professionals. This indicates that Peake's (1999) assertion that EPs do not offer interventions to families to help them understand their child, or provide detailed practical advice which they can use to improve their parenting and address problems within the family to support their children, has some validity within current EP practice as indicated by participants in this research.

This indicates a dichotomy in thinking about a child's systems, where different professionals are required across different systems rather than one professional holistically considering the child and interventions across systems.

One participant described this dichotomy in the thinking of the school which leads to different agencies for the school and family systems. 
P6 "Did you not think of telling me we have an FCAF? And that says, speaks volumes. That is like, this is the family, this is the child, and you are child agency, these agencies are family agency and you two don't go together. So yeah, each of those sends clear messages that there is no expectation of my work with families."

This finding resonates with the view of Gersch (2009) who argued that a move for EPs to a child psychologist role, would implicitly move to an expectation for work across the subsystems of the child, to focus on the needs and outcomes for the child, whilst an educational psychologist's role implicitly implies a focus, solely, or mainly on the school subsystem.

Several participants reported on the EP role in multiagency work, where they would work as part of a multidisciplinary team to support a family, and the EP role would be to offer advice and interventions strategies within review meetings to guide those professionals working directly with the family.

e.g.:

P2 "So we do have a multi-disciplinary approach here, where we work as a team, so agencies concerned will attend meetings and problem solve around the issues that might be presenting in schools. We're commonly part of those approaches, and obviously you carry on attending the reviews until there's progress."

There was also reference to other agencies being more available to schools to conduct intervention work with families both in terms of schools commissioning this work, and in free support to schools, which replaced the need for EPs to become directly involved in intervention work themselves. The professionals identified as most often picking up this work from schools were FSWs, and a few participants 
raised questions over the level of training and qualifications of FSWs for this role, and whether this work would in fact be best conducted by a psychologist.

e.g.:

P8 "A lot of my schools are quite good at identifying other resources and support within the community, for example, where a lot of them buy into family support, but like I say they may not be the best people, with the right skills, or the right understanding sometimes they need."

P4 "I feel an EP would be better placed to do that work. Experience, knowledge of child development, relationships, behaviour and stages and phases."

P6 "Family support workers are not very well trained. They have a very specific model and procedure and so they've only got one way of doing it, and that's it. And if that doesn't work ..."

P8 "Or I suggest family support get involved. But there's been times often where, I suppose l've felt the need to share where I think the work should be going and what strategies should be used, and what they should focus on, with other professionals, because sometimes I suppose I feel they're maybe not as qualified as we are maybe to do that work, but that they're the people who are around to do it."

The data suggests variance between schools, and individual EPs; some schools evidently view the EP as 'school system' focused and will therefore not always include the EP in family based agency meetings, whereas in other schools EPs have a clear role as part of a multidisciplinary team.

Within the multidisciplinary teams, however, some participants evidently feel constrained by their advisory only role, and believe that they may be the best placed professional to deliver some direct family intervention work. Hymans (2008) looked at how professionals in multiagency family support teams construe their role and the role of the team, and found that within an effective family support team everyone got 
involved with families and did what needed to be done, including activities outside their expected role. This contrasted with some other multi professional teams such as CAMHS, where professionals communicated but tended to 'stand on their own spot' with regard to working practices. Some of the frustrations of EPs in this study, suggested that they may feel constricted in their roles, or their 'own spots', within multidisciplinary teams, and believe that they have skills and positive interventions to offer families directly, but this is viewed as the 'spot' of other agencies or professionals, who in their view may be less skilled, or have a narrower scope of intervention strategies to offer than EPs.

\subsubsection{Sub-theme: Direct Work}

Advice and Strategies: Despite all participants discussing the limitations of their intervention work with families there were areas reported by most participants where they have been involved in intervention work with families.

Several participants referred to their role in giving advice to families, as part of their role in school based assessment and intervention. This was reported to be done through meetings held with parents in school and through the reports provided to schools which would also be provided to parents.

e.g.:

P2 "Where there are strategies needed that go across school and home settings, make it clear in the (written) advice that all adults working with that child need to take a certain approach, then even if you're stepping away because an assessment is complete then they know what they have to do to get on and support the child."

P3 "Yes, I think they'd just be part of the whole thing, recommendations for school and parents together. But then a copy of that would go to parents." 
P1 "I find parents often ask for opinion and advice, so even if we're not working with them in an ongoing way, it's not a long term intervention, then we're still in a position to give parents advice."

The concept of advice giving links back to the model adopted by some EPs in work with pre-school families, where following information gathering, and EP formulation, the EP is in a position to identify and inform parents and schools of strategies which may be effective, which forms the advice. This EP role reflects the findings of Ashton and Roberts (2006) who elicited the views of 28 SENCos and found that most SENCos saw advice giving, statutory assessment work and individual assessment as the unique contributions that EPs make to their schools. In adopting this 'advice giving' approach to intervention, EPs may therefore be fulfilling the expectations they feel is placed on them by the school. This suggests that it may be difficult for EPs to promote more systemic approaches in family work in school, as they may feel it will not be valued by SENCos, who are seeking individual child assessments and advice giving. The within-child focus of most EP reports as discussed previously (Buck, 2015), and the lack of eco-systemic perspectives within reports, would question the relevance and impact of this mode of advice giving to families.

One participant explained that they felt their role was often limited to formulation and recommendations, with an expectation that their input would then end at this point and there was no role for the EP beyond this. 
e.g.:

P6 "As much as we say we make decisions about case work, we then aren't allowed to continue the casework as we would want to quite often. In terms of the interventions in place and how they're done. Because we can formulate, we can work to whatever models we like, we've got autonomy to hypothesise and test our hypotheses and use different assessments to do that, and so we come up with our formulation. And from our formulation there needs to be action, so we come up with our recommendation, and that's often where it stops. And so that's kind of, we need the autonomy to then say 'and these are my recommendations so what I'm going to be doing is, I will be working with the family to do this, and I will continue this case in this direction.' Whereas it seems to me we are there to formulate the case, come up with recommendations, but not do them."

As well as advice given in consultation meetings and within reports, a number of participants also discussed ways in which they do, or have in the past, done more direct intervention work with families. These areas varied significantly between participants.

One participant had recently trained in Video Interactive Guidance (VIG), and identified this as being a way in which they were now working more directly with families, and through this were considering how this area of family work could be expanded.

e.g.:

P3 "So it involves visiting the parents at home, explain what VIG is and how it focuses on the relationship between them and their child which isn't always an easy conversation."

P3 "You are hoping perhaps to help the parent to help the child at home which might have spin offs into school, but obviously it's really important to help them anyway, even if it doesn't have spin offs into school, so that's a nice side of it really." 
This participant within the interview reported that they felt their work needed to be school focused because the referrals came through school and it is the school who is seeking support, but in discussing their VIG training and intervention they reflected that:

P3 "VIG, yeah, I don't know, I suppose it's reflecting like this has made me realise that underneath I would like to be working more closely with families."

This reflection suggests that this EP had been assuming a school based focus due to the referral system placing the school as the holder of the 'problem', but their training in, and use of VIG, and discussion of it within the interview, had surfaced a feeling that closer work with families was something they felt they would like to be part of the EP role.

A number of participants reported using parental 'drop-ins' for parental consultations; although all referred to this being something they had done in the past but were no longer offering. The reflections on this approach to working with parents was positive, with participants who used this approach noting that the location of these away from school and the nature of self-referral made them a more effective way to work with parents than through formal meetings in school where the school had identified their child had a problem.

e.g.:

P4 "I used to do drop-ins at a children's centre. Parental drop ins and they could bring any issue to that. They were very good. But you'd always have a follow up with them, so they'd go away with some actions, and they'd have a follow up." 
P4 "Those who are self-referrers were looking to develop parenting skills and family relationships definitely got more out of it on the whole. And with these drop-ins you think parents choose, they chose to come to them."

P5 "You were open to the community and you really did have an impact ... you would get families before they got to crisis."

The views expressed that this way of working with families was effective and valued as families could self-refer, supports Dowling and Osborne's (1985) assertion that the location of a problem within a particular context often determines who owns it, who is holding the problem, who is responsible for it, and therefore locating the 'problem' within school poses a number of barriers to effective work with families. Guishard (1998) described a project developed with the aim of evaluating the viability of time limited family work, and although this approach still took place within school, the project focused on self-referral by families, to address the issue that most parents who meet EPs in school are seen because of the school's needs, and their perceptions of the child's difficulties.

Therefore, a parental consultation model that allows for self-referral, and thereby ownership of the problem and responsibility for the resolution, and which takes place within a community setting, may be better placed to meet the needs of families who feel they require psychological support.

These parental 'drop-in' consultations would fit with the aspirations of Peake (1999) who called for psychological services to be made accessible to parents through providing an access route separate from school, through increasing the proportion of parental referrals to school referrals taken, and through being available to community groups who offer services directly to children and families. However, although all 
participants who described this type of 'drop-in' work explained that they felt this was positive and effective work, it was no longer ongoing due to a lack of commissioning, time constraints and the ending of projects with which the work was linked.

Therapeutic Approaches: Several participants also discussed a number of ways in which they worked directly with families using a number of therapeutic type approaches. Some participants referred directly to approaches such as 'family therapy' and 'solution focused' whilst others might not have named these approaches but work they described would fit within these parameters.

One participant had trained in family therapy, and described using this as the primary way in which they worked with families, both previously within a clear family therapy context, and more broadly through applying the systemic approaches from family therapy in consultations with families.

e.g.:

P9 “Sometime you've just got to give people new dance moves, and I think that's very optimistic that you can just, by talking about it, feeding back what people are doing, that you've see with your own eyes, you can give them something that helps them to radically change the way they function."

Other participants did not directly refer to family therapy but their descriptions of their work indicated that they were using systemic approaches within their consultation with families, through circular questions and reframing, to help alter perceptions of both the family and school. 
e.g.:

P6 "Whereas ours is all about relationships and the complexity of relationships and how they're impacting. You know, it's looking behind your problem. It's how everything is interplaying."

P4 "It was useful for the family to sit and talk to each other and for them to see that there were different perceptions of the same situation, which I think they thought they were all singing from the same hymn sheet, whereas that wasn't the case."

The premise of this type of approach is that people construct narratives around problems which then reinforce or confirm their responses to them, and therefore through collaborative exploration new perspectives, or narratives, can be formed and this allows people to change their 'dance moves' in response to the 'problem'.

Dawson and McHugh (1986) suggested that in historical terms, using systemic principles in educational contexts, such as those described by some EPs in this study, as a basis for thinking about problems, was a relatively recent phenomenon at that time. These ideas had started to have increasing influence in the psychiatric and social work fields, but the application of systemic principles to work with families and schools, particularly in an educational context, had been even more recent; a view supported by the relative literature in this area at that time. Sixteen years on from this, the literature around EPs' use of systemic approaches in schools remains scarce. Pellegrini (in 2009) reflected on the very limited literature published at that time on the use of systemic thinking within educational psychology, and he suggested that while EPs are often interested in applied systemic therapy, they are often unaware when approaches they are using are grounded in systemic thinking. The data from this study would suggest that this remains the case. 
Pellegrini suggested that EPs are often unaware when approaches they are using are grounded in systemic thinking such as solution focused brief therapy (SFBF), which has a more extensive literature on its use in educational psychology (Ajmal and Rhodes, 1995; Burns and Hulusi, 2005; Fogell, 1999; King and Kellock, 2002; Redpath and Harker, 1999; Rhodes, 1993; Stobie et al., 2005; Thorne and Ivens, 1999; Young and Holdorf, 2003). Pellegrini suggests that SFBT is favoured by EPs as it is easily incorporated into EP work due to the time limited nature of its approach and its application with individuals.

The data from this study would support Pellegrini's assertions, as two participants reported using a solution focused approach within their work with families whilst not clearly aligning this with a systemic perspective.

e.g.:

P2 "I will actively prompt partners around the table to summarise where they are with, in what they've done so far, what they think needs to happen, so that people feel they've had a chance to air their views on what's happened or not up to that point. But then try and elicit from that what's worked so far. It's a very solution focused approach really that I would tend to use. And try to get agreement, you know unanimous agreement around the table to work towards a new approach if it's been very negative and stuck."

P6 "I use a solution focused approach to try and get them to find their own solutions to the situation and empower them because at the end of the day I think that's what our role is about, empowering other people. I think, I'm always a great believer that if you've done your job well they won't think it's you that's done it."

One participant who had been trained in family therapy made the link between systemic family work and solution focused work explicit. 
e.g.:

P9 "You know, systemic family therapy and solution focused family therapy."

P9 "The model I use most in my work with anybody is solution focused. So you might have a discussion with a family in a kitchen, and I actually call that kitchen therapy. And you're having a cup of tea you know, you're dealing with the dog trying to bite your leg and all that stuff, and, but you're actually following a solution focused approach with them."

The approaches that this participant reported around intervention work with families, can be linked back to their reported approaches to assessment, which focused on collaborative exploratory dialogues with families.

e.g.:

P9 "... it's got to be a collaborative discussion, and open discussion, where that is just one of the aspects that you're using for your formulation."

P9 "The proper way of working with families is collaborative and looking at it as a holistic system."

The use of systemic approaches in both assessment and intervention utilises questioning by the EP in a collaborative framework to co-construct alternative understandings. When used in this way once again it is possible to see how the distinction between assessment and intervention becomes blurred, as the interventions occur during the collaborative exploration (Tomm, 1987a; Pellegrini, 2009), rather than being donated by the EP at the end of a data gathering process.

Family Based Training: Most of the participants reported involvement, at some time, in some type of family based training, as part of their intervention work with families. This included some specific parent training programmes such as Triple $\mathrm{P}$, Early Bird 
and Incredible Years, with some variance between participants' views of these. Three participants expressed some reservations about parenting programmes where parents are directed to attend and where the premise is that they are lacking in skills.

e.g.:

P2 "I think there's nothing more insulting than telling a parent you need to go on a parenting course."

P4 “Triple $P$ doesn't go down so well with families because it's a bit, professionals telling parents what to do, rather than working with what they've got."

P9 "There's things like Triple $P$, and all of them have the right, probably, content area. What's the intent, and whether you're giving any, again, negative messages about 'parents like you'. You've got to be very cautious about that."

Those participants who expressed some reservations about parental training programmes tended to be those who had expressed a preference for working collaboratively with parents rather than a more directive style. This view reflects the view of Todd (2007) that this model of intervention is based around 'upskilling' parents, which implies a judgement of a lack of knowledge, or lack of understanding or information.

One participant felt that the Incredible Years programme had a more positive collaborative approach to parent training, where parents learned from one another which was more influential.

e.g.:

P4 "Families prefer to learn from each other than they do from some professional telling them how to do it." 
Several participants expressed the view that they felt a more productive route for EPs to deliver training to families would be to tailor training towards particular groups or families.

\section{e.g.:}

P9 "I think group training, definitely has a place, but I think it would be more effective if it was individualised to a particular family, and a couple of workers went in and worked with the family, not necessarily in a family therapy way, but in a training way, you know deliver those principles."

P5 "I think if a school thinks it's worthwhile you can run courses for parents that makes them more tailor made to the specific parents that you're worried about. Actually I think that's a role ed psychs could do very well."

Once again, however, the onus is placed on the school's view that this work is worthwhile for EPs; the data indicating that no EPs were currently involved in this type of work, would suggest that schools are not prioritising this type of work, and therefore it is not taking place.

The following main theme of School Role will further explore how the role of the school impacts on EPs' work with families. 


\subsubsection{Main Theme: School Role}

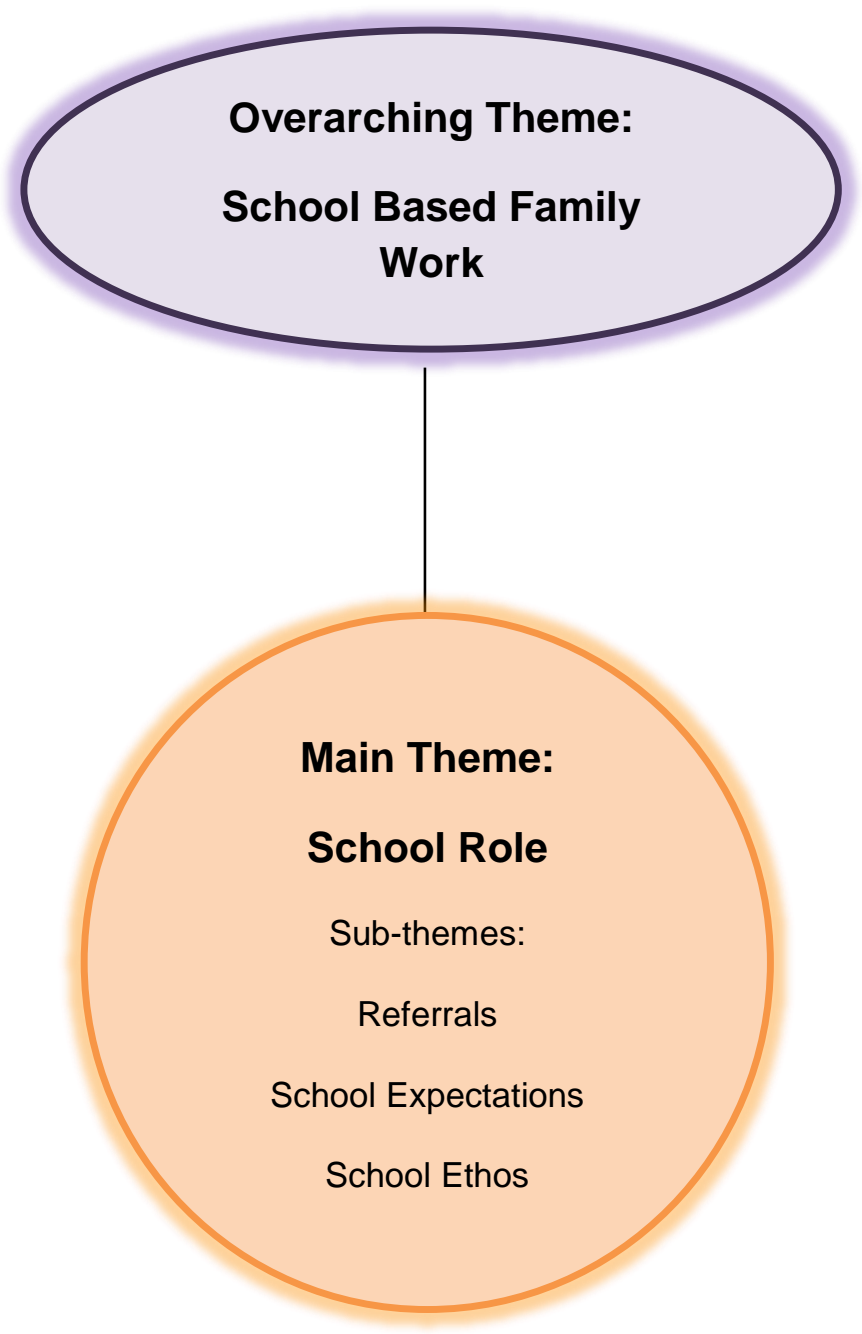

From the main theme of School Role emerged the sub-themes of: Referrals, School

\section{Expectations and School Ethos.}

\subsubsection{Sub-theme: Referrals}

Several participants raised the issue of referrals to the EP service as being an area which impacted on their work with families at a school based level. Those who reflected on referrals reported that schools were the source of referrals, and therefore had control over the referral route of children and families to EP services. 
e.g.:

P1 "It depends on how the referral comes in doesn't it, and if the school are saying we need some help to support this child, then the assumption immediately, the assumption to start off with is that I'm going to be working with the school."

An acknowledged consequence of the school controlling the EP referral route was that, as the school is making the referral it is the school who has 'the problem', not the child or the family, and therefore the school is 'the client' with whom the EP will be working. In this way, the referral route being controlled by schools subtly alters the EP's perceptions of the holder of the problem, and the focus of their work. This finding is consistent with Guishard's view (1998) that children are mainly referred to EPs because of school's concerns about a child and as a result most parents who meet EPs in school are seen because of the school's needs and not their own.

In the context of schools controlling referrals to EP services, the problem becomes very much located within school, owned by school and with the school responsible for its resolution with the support of the EP. The quote below illustrates the EPs view that as the referral comes from school, the school are asking for support, and therefore school 'hold' the problem, and the school is therefore the focus of the EP's work:

P3 "The referral has come from the school and I suppose I'm focusing on what needs to be done in school because they've asked for support."

Some participants were aware of the bias created within the referral system, and the assumptions created by this referral route, and considered some of the steps which might be required to address this issue. 
e.g.:

P3 "I think we need to look at how we take referrals because l'm aware of sort of inequality at the moment, some families get it, some families don't and it's just a bit ad hoc."

The referral routes, described by participants, and controlled by schools, underlines the lack of direct access that families have to psychological support; although there were some reports of schools agreeing to family access to EPs at the family's request, this would still have been controlled by school, at their discretion.

\section{e.g.:}

P3 "Sometimes parents might have asked for consultation, occasionally that would happen; the parents might have raised a concern and the SENCo doesn't necessarily think it's a concern but we say, well let's talk it through with the parents."

P4 "So, in xyz school the other day, for example, there'd been a family who'd kept saying 'can we have a chat with the psychologist? Can we have a chat with the psychologist? And school eventually set it up and said 'would you mind having a chat with these parents?"

Peake (1999) suggested that in order to redress the balance between school referrals and access for families to EP services, services should make it possible for parents to have ready access separate from the schools, with a referral system established for families to access EP services to meet their needs and not simply school's needs. The data would suggest that this has not occurred, and that the move to a traded model which has taken place since Peake made those challenges to the profession, may have strengthened the assumptions that schools as consumers control referrals, and are the EPs' clients, rather than children or families. 


\subsubsection{Sub-theme: School Expectations}

The expectations that a school has of an EP's role in working with families emerged through both direct questions about the participants' experience of this, and also through their descriptions of their work in school. Many responses suggested that schools have minimal expectations around EPs' work with families and that school's expectations are that the EP will focus on work with the school which may involve some limited contact with parents.

e.g.:

P3 "I don't think they'd really mind if we didn't involve parents in the discussion about how to help the child in school."

P3 "I guess sometimes they do find it helpful that l've got the time to find out a parent's opinion and help smooth the way or help the parent to see. So I think they do find that helpful. I don't think it's the first thing on their mind when they refer, I think they see it as a bit of a by-product."

P6 "Yeah they think we are school based, and that is what we do, we support them, we are not there to support the family."

Participants' awareness of this dynamic between EP and school, where the school expect the EP to be school focused, were evident in responses where EPs would seek agreement from schools before involving families.

e.g.:

P2 "You have to negotiate with the school, and where I'm careful not to commit the time I explain to the parent that I'm, you know, suggesting we do further work but I need to go back to the school to see how valuable that is first."

P6 "You are completely reliant on the importance they place on your work with families. If they don't want it, you don't do it." 
P2 "We have to make sure the school are happy to use their time in that way."

Two participants referred to discussions within their EP services where other EPs had reported that schools were restricting the contact of EPs with parents in order to focus on school work, although both reported that this had not arisen within their own schools.

e.g.:

P3 "I haven't had a problem with that. If I say I want to meet parents, then I've never had a school say 'oh you can't spend your time'. But I know other EPs in the service who have raised that as an issue, where they have been told that."

The role of EPs in statutory work was also reported by several participants to be the focus for school's expectations on their EP.

\section{e.g.:}

P1 "One of the big priorities for schools is to get a full report for them to request statutory assessment ... That's the main part of the work we do with schools, that they use their time for, and it takes a significant chunk of their days doesn't it, to do a full assessment like that."

P2 "Primarily work with families is through assessment work when schools refer a child for holistic assessment prior to requesting an Educational Health Care Assessment Plan."

The focus on statutory work in schools indicated in the data mirrors the focus on statutory work within pre-school work, where both have been cited as the primary role of the EP, and instrumental in dictating EP time, by the LA and the school, and in posing a barrier to more in depth work with families. Buck (2015) argued that the 
driver on psychological advice for statutory assessment purposes, is the LA decision making processes related to placement, and these support a 'within-child' approach to assessment and EP reports that do not promote or reflect systemic approaches to EP work. Imich (2013) noted that EP reports for SA procedures have become 'too long' and have 'little psychology' in them. Content analysis of professional reports found that EPs make maximum reference to 'ability', 'literacy' and 'cognitive' parameters, psychiatric statutory reports refer most frequently to 'child' and 'behaviour', whilst references to 'family' are most frequently cited in social service reports (Buck, 2015). The differing emphasis of professional statutory reports indicates professionals adopt responsibility for one system, or area of development of the child, with no single professional taking the role of considering the child within the wide ecological, social and family context. The emphasis in EP reports on ability, literacy and cognitive vocabulary, points to a predominantly within-child, deficit model of assessment, focusing on educational parameters to indicate provision and placement, and therefore not requiring a focus on family systems. Fox (2015) also suggested that whilst most EPs would agree that environmental and social factors form a central part of their role, EP reports still largely reflect a focus on the child and their problems.

Buck (2015) also suggested that EPs accept that casework linked to legal statutory obligations provides one of the main reasons for continued employment by LAs. The data would indicate that EPs also recognise that this additionally provides one of the main expectations of schools. 


\subsubsection{Sub-theme: School Ethos}

Four participants viewed the ethos of the school as an influencing factor on the degree to which the school would expect, and support, EP involvement with families.

e.g.:

P2 "I think it depends on the ethos of the school. I have had a school that's been trading that has really valued and has bought additional hours in because they've wanted me to do direct work with families, and another school might only want you to be spending time with families as part of the assessment. So it varies according to the ethos of the school."

Those who discussed the role of school ethos postulated that schools who had an inclusive ethos, and who viewed themselves as part of a wider community network, were more likely to value and support EP work with families. This was contrasted with schools who were primarily curriculum and attainment focused.

e.g.:

P2 "I think if a school is an inclusive school and values all members of the community, they are not threatened by parental involvement, and they see them as an essential part of the help process for the children, so I think there's a distinction between the sort of school that recognises the importance of measuring well-being, and you know, belonging to a happy and secure family for their achievement and success in school, and then the school that just wants to focus on standards, you know, and discipline."

P6 "Some schools understand they've got to get involved in the community and the families, and they see themselves well placed for doing that. Whereas some schools don't see it as their job. "We are here to educate the children as best we can given the circumstances the children come from, but we won't try to affect change on the circumstances the children come from, we will just do our best in school." 
Schools who attempt to work as closed systems, and who do not themselves adopt a systemic approach to joining a child's systems, will be unlikely to utilise EP time to work in this way.

Two participants suggested that special schools often adopt a more systemic approach to their involvement with pupils where they may have more of an ethos of family involvement. One participant viewed this as an opportunity for more EP family work whereas another participant felt that this placed on them a need to manage the school's expectation in this respect.

e.g.:

P7 "I think in special schools, there's more of a caring capacity and sometimes they do get involved with the child's home life in a special school. So I have to be more careful of my boundaries in that school, in that setting."

This participant's view of needing to 'protect boundaries' can be linked to their views about the EP role within assessment and intervention and the need for this to be exclusively educationally based. 
4.4 Overarching Theme: EP Role in Family Work

\subsubsection{Main Theme: Strengths}

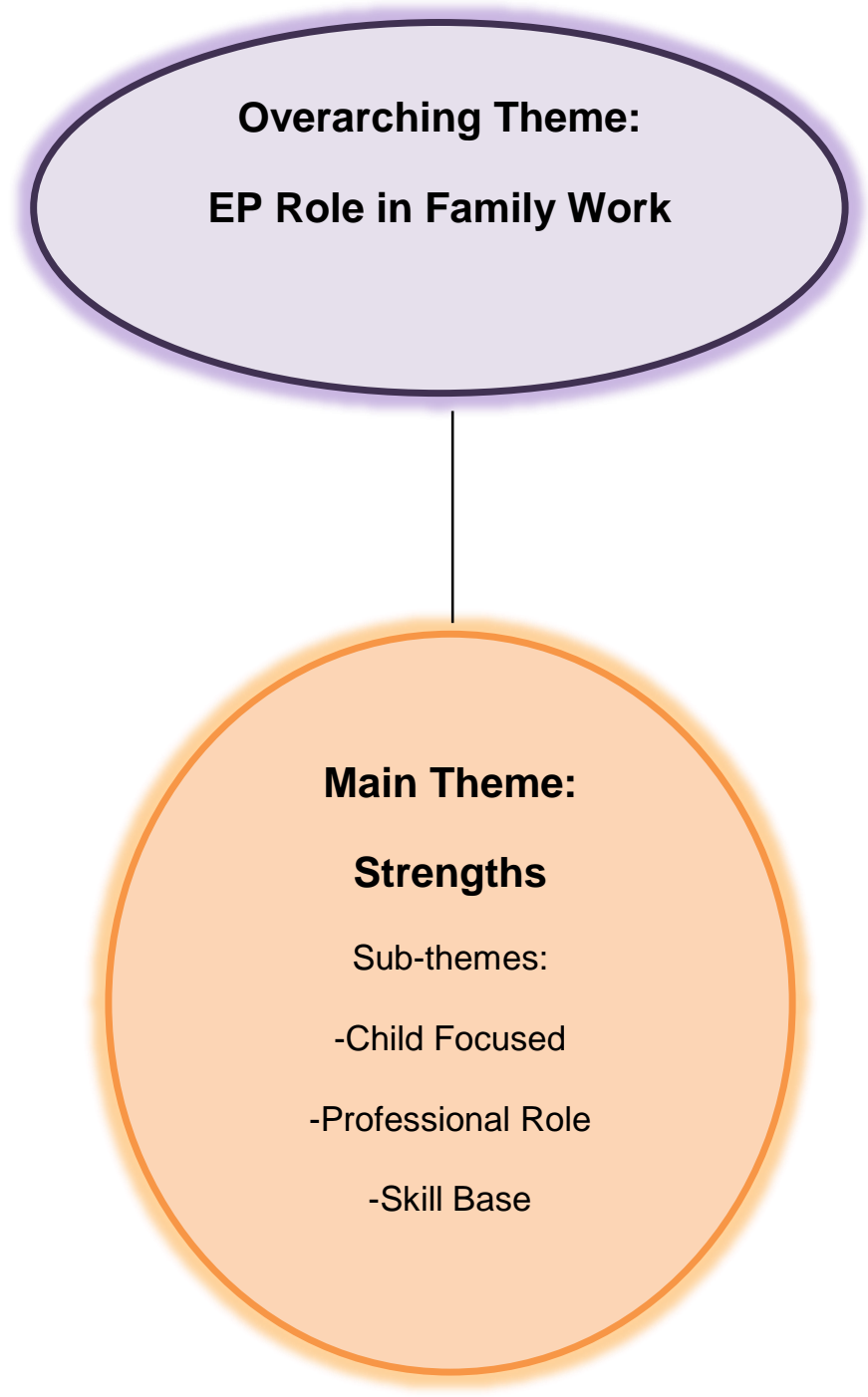

Within the overarching theme of EP Role in Family Work the main themes of Strengths, Restrictive Factors and Ideal Role emerged.

Within the main theme of Strengths the sub-themes of Child Focused, Professional Role and Skill Base emerged. 


\subsubsection{Sub-theme: Child Focused}

When discussing their practice in working with families across pre-school and school based settings, several participants indicated that the high value placed on the EP role in this work was due to the child being at the centre of EP work, and that with the child at the centre it is necessary to work beyond merely the educational setting and to work within and across all the child's systems to bring about the best outcomes for the child.

\section{e.g.:}

P6 "At the end of the day who is our client? Well the person at the middle of it is the young person and child, they are the most important person. That is who we are affecting change for. So therefore, yes, we should be working with families."

P9 "I think some psychologists wouldn't agree, but I think all of these things like sleep and diet, if they're impacting on a child's well-being then they're obviously part of the role."

One participant suggested that in their experience not all EPs share this view, and that this fundamental construct about the role of families, with the child at the centre, will effect the degree to which EPs will meet with parents and involve families.

$$
\text { e.g.: }
$$

P6 "I was listening to other EPs who said 'I never meet with parents, I never have time' and I think they hold the most fundamental role within their child's life."

Some responses supported the view that if an intervention which will support a child has been identified, and that involves the family, then this is the EP role, as the focus of an EP has to be the well-being of the child. 
e.g.:

P6 "If we've identified families, the family structure, as the difficulty impacting on the child and we feel skilled enough to put an intervention in place in the family, then yes that is our work."

P9 "For me the fundamental question is: is the proposed package, or the proposed strategy one that will bring down the level of mental distress? And if it answers that question l'd support a psychologist being involved."

The focus on the child and their well-being, and therefore the need to involve the family and consider the family well-being within this, was identified by Newland (2014) who found that Family Well-Being (FWB) is one of the strongest and most consistent predictors of child well-being and resilience. Aspects of FWB, including adult health and well-being, family self-sufficiency, and family resiliency, have been shown to impact child well-being through parent child interactions. Newland further argued that strategies for supporting FWB through building family resilience will impact positively on child well-being and resilience. She makes recommendations for practitioners involved in strengthening FWB, such as evaluating the context in which the family system is embedded and identifying their unique contextual factors, and in doing this evaluate the families' own well-being and create an individualised family prevention or intervention plan which builds upon strengths and mitigates risks for the family and the child.

Links in the data can be made between those participants who expressed a focus on child well-being being central to the EP role, frequent involvement with families, and a more collaborative systemic way of working with them, within their reported assessment and intervention practices. 
The child well-being focus expressed by these participants allows for a clear rationale for developing those systems of practice that support collaborative work with families to develop. Dunsmuir and Wolfe (2014) suggested that establishing this rationale for family work is necessary in order to identify the factors that facilitate best practice, and challenge the barriers to collaboration and delivery of effective interventions.

\subsubsection{Sub-theme: Professional Role}

The role of EPs as psychologists working outside the clinical setting was acknowledged by one participant as being a strength within the role. They felt that there was an overlap between the work of clinical psychologists and educational psychologists, but that EPs had an advantage in being able to be involved with a child across settings outside the clinic.

\section{e.g.:}

P4 "I think there is a big overlap (between EPs and Clin Psychs). Definitely a big overlap between the areas, I see are behaviour, kind of around anxiety and stress, toileting, parenting, routines, family dynamics to some extent, general development."

P4 "We're in the privileged position through of seeing the children across settings. I think that's a real strength for us."

Another participant highlighted the position of EPs to apply psychology to families, and the value that this could have to the family, the focus child within that family, and more widely to society. 
e.g.:

P9 "It's worth that investment of a high quality piece of work, and if the psychology can be beneficial, even at crisis points, then it's got huge value to families and society."

These strengths within the EP role, which would allow for positive cross systems work with schools and families, were recognised and stressed by MacKay (2006):

'The EP is uniquely placed, in collaboration with others, to provide generic child psychology services, and that it is time for the profession to claim its natural heartland of holistic services to children and young people across the settings of home, school and community' (MacKay, 2006, p. 14).

\subsubsection{Sub-theme: Skill Base}

Several participants referred to the wide skill base within EP practice, and available to them through training, that places them in a strong position to support families. It was felt that this skill set placed EPs in a better position to support families than some of the other agencies who currently do this work.

e.g.:

P4 "I feel an EP would be better placed to do that work. Experience knowledge of child development, relationships, behaviour and stages and phases."

The role of an EP as a 'problem solver' was also suggested by one participant to be a skill that EPs can transfer and utilise with families, as well as the ability to flexibly apply the wide range of therapeutic approaches and models with families, depending on need. 
e.g.:

P5 "When I explain my role I do use the word psychologist once, and then that's the last time I use it. I just say I'm a problem solver."

P6 "EPs have been trained in lots of different therapeutic tools, have a big toolkit. Basically that you go into a family and assess the situation, you asses what model you're going to use, and then intervention based on that."

Another participant suggested that the skill set that EPs use to work with teachers to support children can be applied to working with other adults, such as adults within the family system, and understanding this transferability of skills creates opportunities for family work. The use of consultation with school staff was referred to as a skill which translates directly to working with parents.

e.g.:

P6 "I think if you put the title 'families', you know people get worried, put off, like I was saying 'I'm not sure l've got the skills set for families'. But actually they're just individuals that you're working with, that are part of the child's system. So we work with teachers, so why wouldn't we work with families?" 


\subsubsection{Main Theme: Restrictive Factors}

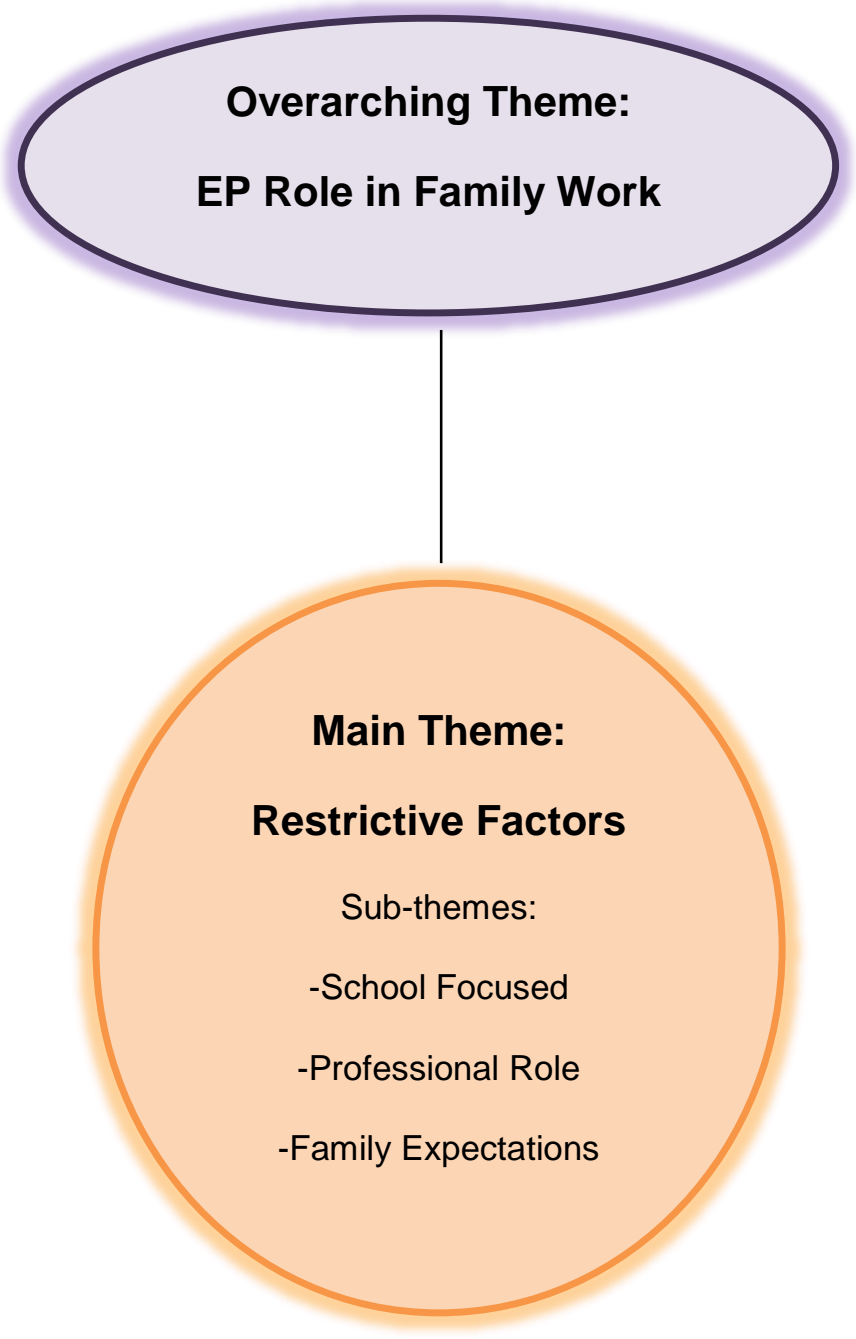

Within the main theme of Restrictive Factors of the EP Role in Family Work, the subthemes of School Focused, Professional Role and Family Expectations emerged.

\subsubsection{Sub-theme: School Focused}

Most participants reflected on the assumption that the EP role is a school focused role, but there were differences between participants who expressed some frustration with this, and a need to break out of this constriction, and those who 
accepted and valued this position for EPs. The data indicates an overlap between those EPs who question the school focused EP role and those who indicated a more child focused position and a systemic collaborative approach with families.

This participant clearly states that the EP position in their experience is one where the school 'holds' the problem and the problem is addressed through and within that setting.

e.g.:

P2 "If there were no problems in school, then I wouldn't be working with the family."

P3 "If it was just something about the child's behaviour at home and there wasn't an issue in school then we wouldn't get involved."

The participants quoted below, indicate that whilst they also recognise the school focus of the EP role, it is something which creates frustrations for them, and a position they seek to broaden when possible, whilst acknowledging the basis of these restrictions.

\section{e.g.:}

P4 "I am desperate to get into that home and help her sort out her relationships and parenting and boundaries. But again, who funds that? Would that be school?"

P6 "Cause there's only certain work, certain things you can get away with as an EP, you know and how you work. You've got a certain scope and you can push schools as much as you can to work how you think you should be working but at the end of the day if they've got another case and they want you to stop working you have to."

P4 "But that's a big frustration, that we sometimes can't follow through on family work." 
These quotes illustrate the level of control that EPs feel schools have over the EP role and the way in which the EP can work. The participants quoted above both indicate they would wish to work more broadly than the school setting to address the child's difficulties, but feel constrained in their ability to do so due to a lack of clarity on commissioning of this work outside the school setting; the knowledge that schools have purchased the EPs' services to address the school's needs, and that the position allows the school some implicit control over how, and where, EPs spend their time.

The quote below illustrates one participant's belief that the EPs' role can be viewed by schools, and some EPs, as having a 'cut off' between home and school, where the school is the setting where an EP can have impact, but home and family are separate and divided from this, and a setting where EPs cannot have impact.

e.g.:

P6 "There's seen to be a kind of cut off isn't there? That we can affect change here but look at home, we can't do anything there."

The participant quoted below, continues this theme of separate home and school 'realms', and the premise that EPs can have control or impact within the school, but not within the home.

e.g.:

P7 "So I do try to know what's going on, but still try to keep them very separate in terms of what's going on at school, that's going on at home. And although they're obviously intimately connected I feel I have absolutely no control over what goes on for children at home, or very little control, and therefore I just focus on where I have a little bit of control, in the school setting." 
P7 "It's not that EPs couldn't do that, but we'd be more, crossing over there into the home realm, and that is, that is something that's a big, a big thing, and I think it's good to keep home and school separate but connected."

The language used by the participant above to describe a 'crossing over' assumes, and reinforces, the position of the EP firmly within the school realm, and therefore a change of position and movement would be required by EPs for family based work. Furthermore the emphasis on this being a 'big, big thing' infers a danger and a caution in approaching this cross over.

The continuing focus of the EP role as being school based and school focused found within the data, could suggest that Prilleltensky and Nelson's (2000) vision whereby school psychologists could promote child and family well-being, and develop strong community infrastructures for children and families, has not yet come to fruition, and that their premise that in order to achieve this, a shift in the paradigms of 'school psychology' would be required, is equally slow to evolve.

\subsubsection{Sub-theme: Professional Role}

Within participants' reflections on the role of the EP in family work, some tensions within the area between professional practising psychologists' boundaries arose. 
e.g.:

P3 "I don't know if this is relevant but in the XYZ school where I work there's a clinical psychologist working with the children with disabilities team and she's involved with some of the same families, and when she first came into this work she said 'I can't understand why you educational psychologists don't work with families. Because when you look at it, it doesn't make sense. Why is she coming in, she's working with the family and then coming into school to see what's going on, but I'm only working in school with the issues that are presenting in school. It doesn't make sense but I think it's to do with caseload ... It doesn't make sense does it? We're not working with the whole picture ... Almost casting aspersions on "why didn't you think of that, you know."

This participant was reflecting upon their interaction with a clinical psychologist, who had directly commented on the school focus of EP work and questioned why EPs did not work with families. The participant evidently felt there was some criticism within this discourse between psychologists, but acknowledged that the school focused role of an EP would not 'make sense' to the clinical psychologist, as they were not 'working with the whole picture'. The EP describing this encounter believed that the clinical psychologist had greater flexibility in this scenario to work across both the family and school systems, whereas the EP was restricted to the school system.

Other participants also reflected on the differing approaches taken by clinical psychologists and educational psychologists.

e.g.:

P4 "The referral routes are different (for EPs and CPS) the time allocation per case is different. They have the opportunity to come back and see them time and time again, whereas ours feels like a bit hit and run. Volume, the sheer volume of our caseload and the expectations of us often prevents us from doing a good family job." 
The above two quotes indicate that those participants perceived clinical psychologists as having both more time and flexibility within their professional role and work structure, allowing them to work across systems and in more depth, more easily than EPs.

These views would support those of Jones (2003) that as EPs moved out of child and family guidance type services, health provision has expanded, and clinical psychologists have moved to occupy this space, while EPs have become solely school focused.

The participant quoted below, however, viewed clinical psychologists as working equally as 'remotely' from families as EPs.

e.g.:

P7 "Even if they saw a clinical psychologist they wouldn't go into the home and see them. People like me and other qualified psychologists tend to work, usually, at a fairly remote level from clients, and that's different from when I started definitely."

Two participants considered that the professional title of 'Educational Psychologist' in itself limited the expectations of the role both within and outside the profession.

e.g.:

P6 "Do families see us as the people who could support them? Depends if we change our title 'Educational'. That doesn't strike 'families'. It says we're school based ... educational limits us, it tells you exactly. We do what it says on the tin."

P3 "Yeah we've got the skills to do it but because we don't do it, because we haven't got the capacity, and because our focus is on educational, and that's in our title." 
One participant felt that the title of 'Educational and Child Psychologist' allowed for wider expectations of the role, and that the use of a Community Educational Psychologist title could be more encompassing, but may possibly have little meaning, or a clear shared understanding of that role. This supports the view of Gersch (2009) who argued that the name of a profession should offer immediate and accurate information about the nature of the business and services it offers, as inappropriately named professions risk being overlooked in favour of other professions.

Some participants raised the issue of a lack of confidence within the EP profession in working with families, both due to the lack of opportunity they may have had to practice in this area, and due to some viewing this work as fundamentally different to school based work, and being outside an EPs' role.

e.g.:

P3 "I think there would be some EPs who would be uncomfortable doing it because, they are more comfortable working in schools with systems and delivering training."

P6 "The way l've been trained we have done family work and we can turn our skills to that, but also because I haven't practised it my confidence level as an EP is low going into that setting. So if there are professionals out there where that is their sole job, l'd much rather refer to them."

The link between EPs and statutory assessment was viewed by some participants to have come to define the EP role. The participant quoted below described the EP role as now mainly administrative, and this as a 'tedious' role. 


\section{e.g.:}

P5 "I think we're massively administrators now, but it's because nobody else actually seems to understand it. So I think we have to do it because we're the people who understand it and we're the people parents see. Before, your role was not there to make sure the statementing process worked, it was conducted by somebody out there, and you worked with the family ... it's a very tedious role, it's not a role that when you become an ed psych you think you're going to be helping parents to work through procedures."

However, another participant described feeling 'happy' that their expertise could be utilised within the statutory role they provided.

e.g.:

P7 "I have to say EHC planning, that we are intimately tied up with that system, and I'm happy that my expertise is there. I could've offered other things but that's, I don't think that's ever going to happen."

This participant also again sounded a cautionary note around EPs working outside the school system, directly with parents, and assumed a pragmatic position in accepting the constraints on the EP role and focusing the expertise available within these.

e.g.:

P7 "I think you'd have to be careful once you start intervening with children at home because you're not dealing with professionals, you're dealing with parents and you've got to be careful, and offer enormous amounts of support, so I can't see EPs will ever have the time to do that. So, I don't think that's an EP role. Not to say it couldn't be, but it's not." 
The data which emerged around the restrictive factors of the EP role in family work, both around boundaries between practising psychologists' roles, and the statutory assessment role, would support those assertions by MacKay (2006) that educational psychology has developed into a profession focused overwhelming on 'narrow' educational issues, which has almost been 'crippled' by bureaucracy, education legislation and restrictive departmental boundaries. MacKay's emotive language of 'narrow' and 'crippled' evidently reveals his position that the educational and legislative focus is negative for the profession, but the data would indicate that not all EPs would necessarily agree with this.

\subsubsection{Sub-theme: Family Expectations}

All participants reflected on their views and experiences of the family's expectations of the role of an EP once their child had been referred. A few participants commented that the family's expectations will be set by the school's expectations, as it will usually be the school who explains the EP role to parents. This raised the question of informed consent by parents in those situations where they may not meet the EP until after they have seen the child, or where they may not meet the EP at all.

e.g.:

P1 "I would explain the first time I meet them, we'd talk about my role, which does beg the question doesn't it, for the cases where I'm not directly involved with the parents, the extent to which their consent is informed doesn't it?"

P6 "It shows that they are not coming in with information, and therefore aren't giving informed consent to anything, because they don't know what we're about and what the process is." 
The issue of informed consent is raised within the AEP Code of Professional Conduct (AEP, 2012), the BPS Code of Ethics and Conduct (BPS, 2009) and the relevant HCPC documents (HCPC, 2008, 2009) which all state that EPs should ensure informed consent is obtained before their involvement with any individual. The data would indicate that this cannot always be regarded as taking place, and thereby raises significant ethical implications for individual practice and EP services.

The concept of 'respect' for parents, and this being an expectation of a family, of a professional in working with their child, arose within several interviews.

The participant quoted below reflected on a time within their service when meeting parents before seeing a child was expected as part of the service delivery, but where this is no longer the case, and meeting after an assessment to feedback to parents is now the model widely used.

\section{e.g.:}

P7 "It was almost like, it felt like I had permission to wallow in a parent interview. So that was lovely, and the more I wallowed in it, I thought, 'yeah this is lovely'. To even talk to me before I see your child, that feels respectful that I'm introducing myself to you, and it's more like l'm saying: This is what could happen. Do you want that to happen? So it was like giving them major consent before I even saw their child."

The emotive language this participant uses to describe this previous way of working: 'wallow', 'lovely' and 'respectful', creates a positive image of these encounters both for the EP and the parents, and clearly established a consensus that informed consent had been granted. 
Several participants acknowledge that this basic level of respect and consent would be expected by families.

\section{e.g.:}

P1 "I think most parents would want to meet with someone who's working with their child."

P6 "As a parent myself, if someone tried to see my child without seeing me first I would feel very cross about it. It's not only a respect thing, it's the information."

In consideration of the findings within the parental meetings sub-theme, that several participants do not always meet parents before seeing the child, the family expectations of respect and consent may not be being met in all circumstances when EPs are involved. The issue of time constraint was again postulated for this practice, and change in practice, for some EPs.

\section{e.g.:}

P7 "The advantages of not having to see parents first, is that there's more time, a lot more time." 


\subsubsection{Main Theme: Ideal Role}

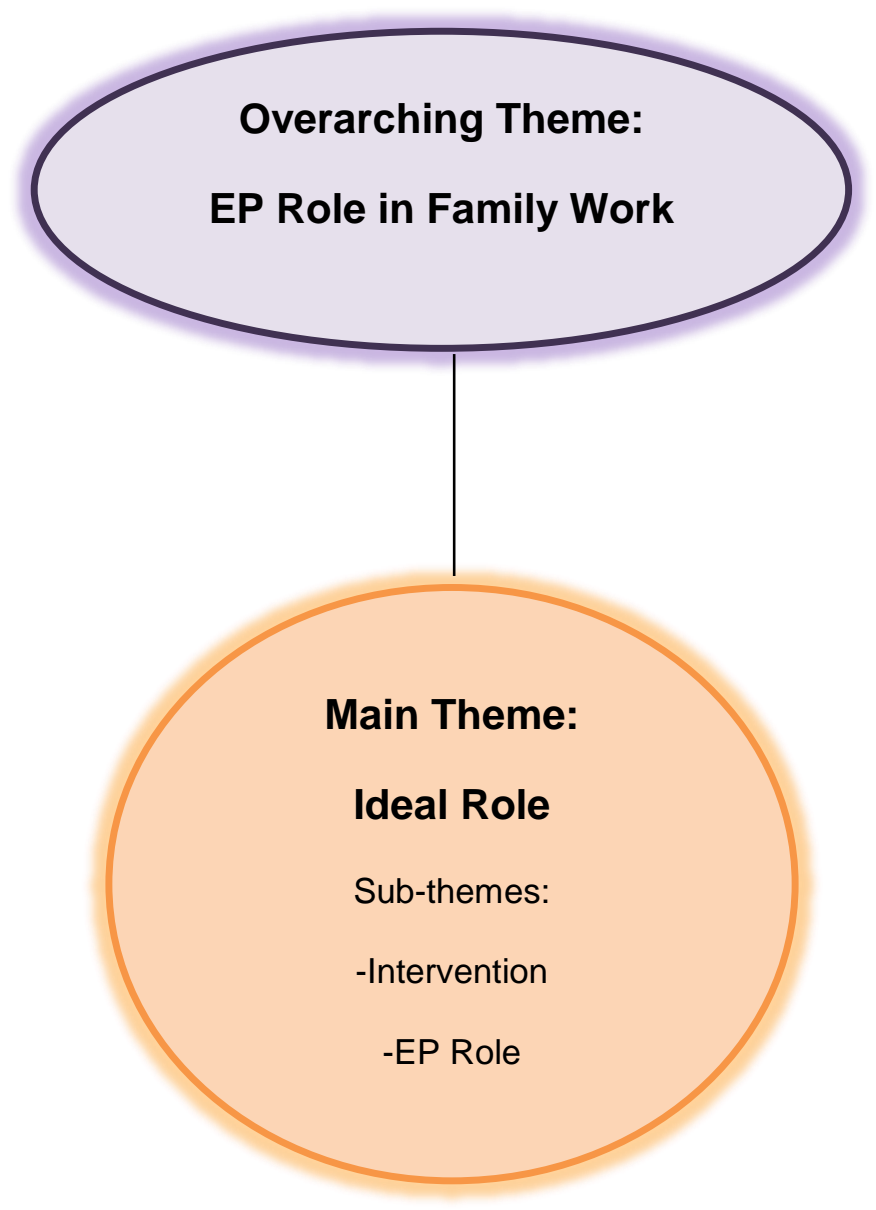

The main theme of the ideal role for EPs in family work emerged from both a direct question towards the end of the interview around their perceptions of this, but also from their comments and reflections on their professional practice throughout the interviews. The concept of the 'ideal role', of the best ways that EPs could work with families, if some of the restrictions and constraints, which had been discussed earlier in the interview, were removed was discussed. From this, two sub-themes emerged: Intervention and EP Role. 


\subsubsection{Sub-theme: Intervention}

Several participants described a number of ways in which they would like to offer intervention and ongoing support to families if the constraints around time and workload were not present. Factors most consistently highlighted included: time that would allow for direct work with families and thus more in-depth work.

\section{e.g.:}

P1 "If they're experiencing difficulties in managing the children's behaviour, working with them over time to do that, not just a one off type thing, but actually seeing how that's gone, and how they feel about that and what their priorities are next."

P4 "I'd like to visit more often, some families where I think there is a need or where I could be of benefit. I just think it would promote the children's skills in so many areas - language, communication, behaviour, parenting skills and confidence, relationships between the children and the parents, the family's perception of themselves, dynamic within the family, their relationship with school. Just everything, I think it's huge."

The focus on supporting relationships within the home environment was consistent, and in the quote below emerged as a 'wish':

P1 "I wish I could do that. Work with parents on developing their relationships with the children and engaging in shared activities, that kind of thing."

Again the subject of increased capacity to allow more thorough work arose:

P9 "A low caseload and to do things properly, you know, and incredibly thoroughly." 
The desire of participants to ideally be able to extend their intervention work with families indicates the will to move beyond the school setting and fully embrace an eco-systemic approach to identifying and creating sources of support for children, as suggested by Annan (2005), if the constraints and restrictions on achieving this could be removed.

\subsubsection{Sub-theme: EP Role}

Within the reflections by participants on the way in which the role of the EP could change, if the current restrictions were not in place, the subjects of a more community based role, and of having more autonomy in their role, arose.

$$
\text { e.g.: }
$$

P3 "I think you could create a different role, maybe more of a community psychologist role where you had far fewer schools and much lower case load and then you could. But not on the numbers we have at the moment."

P5 "Address environmental, community issues. We used to have a cluster model ... and it wasn't only education, but schools were seen as resources places. It was absolutely fantastic. We really did become a community resource."

P5 "So being a community ed psych, being a community resource I think was a really good plan ... you were open to the community and you really did have an impact ... if six parents turned up in a week you would just give six parents advice and then hopefully they would go home and tell $x y x$ about the advice and whatever. So there was like a drip feed. It didn't take over the work, but it was just something available to the community."

One participant quoted above was reflecting upon a previous cluster model in which they had worked, which had been designed to create a more community based role 
for a patch EP. This model was no longer in practice in that authority, but the EP reflected upon the effectiveness of this approach.

The reflections on a community psychologist role support those of Stringer et al. (2006) who argued that a community educational psychology orientation could provide a sound basis for ensuring the future strength and health of the profession, and in particular ensure the effective application of psychology to improve outcomes for children and families.

One participant strongly felt that more professional autonomy would be the key for them in creating the ideal EP role in supporting families, as this would allow the flexibility for the EP to make the judgements about working within and across systems. They identified that in order for this to take place, a shift in power away from schools would need to occur, and that this was rooted in the current funding structure.

e.g.:

P6 "That we'd have autonomy in how we work and should be able to make professional judgements about the way we need to work. To enable us to work with families we need to have that autonomy and people need to understand we have it and why we have it. Because we are professionals that can make those judgements on where our time is best used to affect change for the young person."

P6 "We get more autonomy and more time. Take the power away from schools. So a change in funding would be needed." 


\subsection{Overarching Theme: Context of EP Role in Family Work}

\subsubsection{Main Theme: Service Delivery}

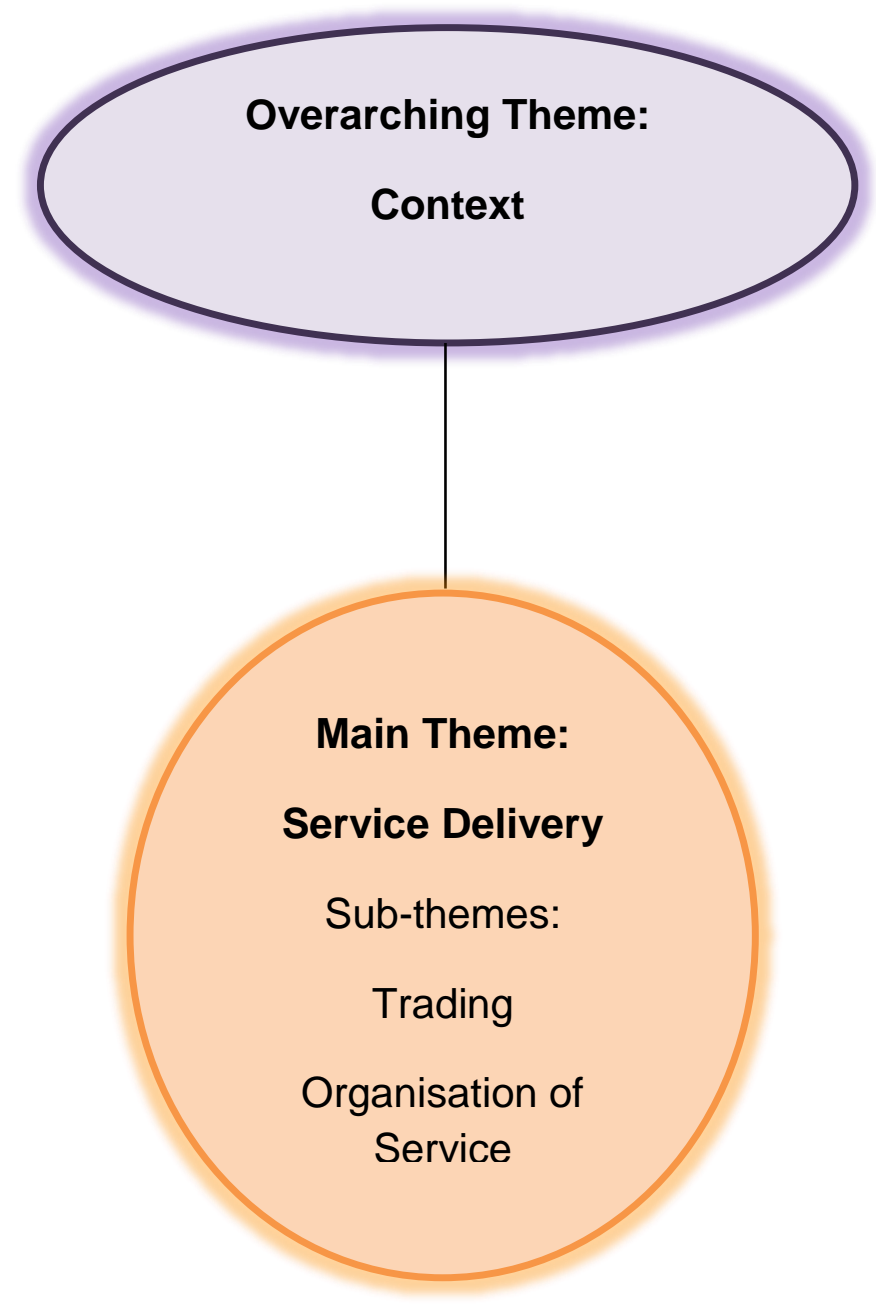

\subsubsection{Sub-theme: Trading}

Seven out of the nine participants worked in Local Authorities where the EPS was operating a traded model of service to schools, to varying degrees. Some were several years into a purely traded model where schools did not get any allocation of EP time but purchased packages of EP time annually, and others were operating a mixed model, or newly embarking on a traded model. 
Of the seven participants working within a traded model of service, six discussed and reflected upon the effects this had had on EP work with families.

Most viewed the traded model as restricting their flexibility and autonomy in working with families due to the consumer model dynamic that existed within the traded model. Several responses used language such as 'ownership' and 'possession' to describe the relationship between schools and EPs within a traded model.

e.g.:

P4 "It's difficult within the traded model. I think in the past it's been easier to allocate time as you best see fit. Within the traded model schools have some ownership over how they think you should use your time and to some extent you have to kind of go along with that 'cause they're paying for a service."

P6 "So (in the past), if then I said 'well, I think we should use three hours of this to work ...' You could negotiate more easily ... you weren't their possession almost."

P6 "Because they buy us, and therefore that is our role, we are kind of a good aren't we? We're an entity to them, they have bought us in and therefore do what they need."

Although participants described still negotiating their work with schools, there was a very strong and recurrent image of 'ownership' and 'possession', with schools holding the power within the EP school relationship in a traded model.

e.g.:

P5 "You can make a case for it. If they say yes that's great, if they say no then because they've paid for you, you can't insist."

P6 "It is a consumer market you are entering into. There are different forces at play you can't battle with. You can, as much as you try, you trade ethically to ensure no group is kind of left out, but actually families do suffer I think because of that."

P8 "It's how they want to use their hours that they buy in from our service." 
These concerns echo those raised by Stringer et al. (2006) where they described the time allocation system they used at that time as creating an 'illusion' among head teachers that they 'owned' the EPS, and could demand of it what they would. They described what they saw as some ethical dilemmas for EPs in the time allocation model, such as challenges to an EP's requirements to see parents if the school thought it unnecessary, potential disputes over work with excluded pupils, and potential disputes over requests from parents for EP involvement. They were writing at a time before a traded model had been widely introduced and the data from this study would suggest that the concerns they raised at that time may have been exacerbated by the traded model.

This finding also supports that of Islam (2013) who found in a study of EPs' perceptions of working within a traded service, that participants perceived that they had less autonomy and control over their work since moving to a traded model, and they felt that schools had greater control and power in terms of directing EPs' work. The EPs in this study emphasised the importance of keeping schools happy, which is consistent with the suggestion made by Ashton and Roberts (2006) that providing a service that schools value and want, is favoured above trying to radically change the types of activities that the EP service can offer to schools.

Participants referred to feeling that the control that schools had gained over EPs through the traded model had restricted their ability to work with families in a number of ways, such as schools not valuing this type of work, reducing flexibility and professional autonomy, and less time being within the EPs' control. 
e.g.:

P1 "I do think trading's had a significant impact because the opportunities aren't there just to do that because you think it's the necessary thing to do. Although of course, there have always been time constraints."

P4 "A lot of it is dictated by the traded model which has been a ... it doesn't allow you to have the same flexibility that you had before to make your own decisions like you could before."

P6 "I think traded really restricts the families model."

These findings raise further potential ethical issues for consideration; the DECP in their professional practice guidelines, states that professional EPs need to be aware of the extent to which those with more power may seek to determine their actions, and they should be prepared to maintain their professional perspective. Within this they include potential paying clients who may assert a position of power within the EP/client relationship. The BPS (2013) Ethical Trading guidelines additionally consider the ethical implications for LA EPs, who it is assumed have a duty to the entire population of children and young people (particularly those who are vulnerable) in the LA; the issue of what happens to those who are not identified by clients as needing EP support has always been a concern but becomes more so in a traded environment. The BPS (2013) recommends that EP services acknowledge the implicit power relationships in any traded situation, which may impact on the access to EP services of certain sections of the community. The impact on parents and families must be considered within this.

One participant did feel that the traded model potentially provided more time and opportunity for schools to use their EP time in work with families, because they now had the capacity to buy additional packages of EP time for this if they wished. 
e.g.:

P5 "Now that schools have to pay for us and they can choose to have, you know, twelve hours, eighteen hours, or however long they want, in the olden days when every school got a basic six hours a term, seeing parents was a nightmare. There's more time available. Much more. I hated the idea of schools having to pay for us but actually it's been the best thing possible because the quality of the work we can do in schools now is just a zillion times better than it used to be."

This participant, however, had not found that their schools had been choosing to use additional time for work with families, but was acknowledging that the possibility was there within a traded model.

Another participant considered that on reflection, encouraging schools to buy additional time for work with families was not something that had been raised or considered within their service.

e.g.:

P3 "We tend to talk about training or group work or some sort of organisational work. I don't think it's something (additional family work) we've ever put to them. Yeah it's quite thought provoking."

These responses indicate that the traded model itself may not be restricting family work, but the school's limited understanding of the EP role, and the EPS's lack of focus in marketing, or promoting this area of work in schools, has led to schools seeking other types of work from EPs.

\subsubsection{Sub-theme: Organisation of Service}

Several participants discussed the issue of time, workload and capacity in restricting their ability to work with families. 
e.g.:

P3 "Everything feels a bit more rushed. I don't have that time to take with each case, to look at the whole situation and think about the child's perspective. It's more about advise the school try this programme, try that programme."

A number of factors were attributed to the feeling that there was not sufficient time to give to more work with families. One was that pressure of statutory work within schools; both the priority that schools give this and the need for the EP to balance the demands of that work.

e.g.:

P8 "I suppose with us it's managing. Knowing the work we have in school, we have to be realistic about how we use our time. A lot of my schools are needy when it comes to EHCP, so I could offer to do this but I know that l'd be asked to still do the TACs, that wouldn't go away, so it's about me managing my workload as well."

A few participants suggested alternative models of organising service delivery which would allow for more focus on family work, such as a community psychology model and a specialist team for family work within a service, but the issues of time and capacity were acknowledged as still being constraints even within these alternative models.

e.g.:

P3 "I think you could create a different role, maybe more of a community psychologist role where you had far fewer schools and much lower case load and then you could. But not on the numbers we have at the moment."

P6 'It's equality of offer isn't it? Because if you're offering it in one school it's got to be open to every school. So actually your whole service needs to be able to offer that work, so you've got to ensure that the CPD of the service is up to scratch to deliver that." 
P6 "Unless you set up a different service model in which case you have a group of EPs, and therefore as a school EP I wouldn't be doing that work, it would be another group of EPs that, as part of their school's hours say, it comes from a different EP and that EPs job is just to deliver families work within xyx."

The Hampshire Psychology Service (HPS) moved to a community psychology orientation, as considered by some participants within this study. This reorganisation took place because of the drive to view themselves as a service for the community of Hampshire and not just the community as defined by a school. Stringer et al. (2006) provided examples within their paper of EP work arising from this reorganisation which relates to work with families and it included: the use of Video Interaction Guidance (VIG) with parents in their homes, intervention work with parents whose children were at risk of exclusion, parents' problem solving sessions held in community centres, workshops for parents of children in the early years, and those with adolescents, and informal discussion groups for parents on aspects of child development, work with health colleagues on contributions to antenatal sessions on communication, play and attachment. These principles and values align with those of Peake (1999) where she called for psychology services for children and families and not just for schools, and made recommendations about how EPSs could reorganise to ensure this access.

Both Peake (1999) and Stringer et al. (2006) wrote at a time before the move to traded models of service delivery, and before the impact of austerity measures on local authorities, which, as can be seen from the data evidenced within this study, has had a further impact on embedding EP practice firmly within the school system, and even further from a child and family orientation than was in place at that time. 
The data indicates that the focus on educational issues remains core to EP work and role, and organisation of services under a traded model of service delivery has placed EPs even more firmly within the control of schools, with the 'ideal' of working at the heart of communities being even more remote. Burton and Kagan (2003) noted that community psychology had developed in other parts of the world but not in Britain, and proposed a number of reasons for this, including the lack of a favourable policy context. The political and legislative agendas that have impacted on LAs and EPSs since this time may well be viewed as having further stifled this community orientation development.

\subsubsection{Main Theme: Legislation}

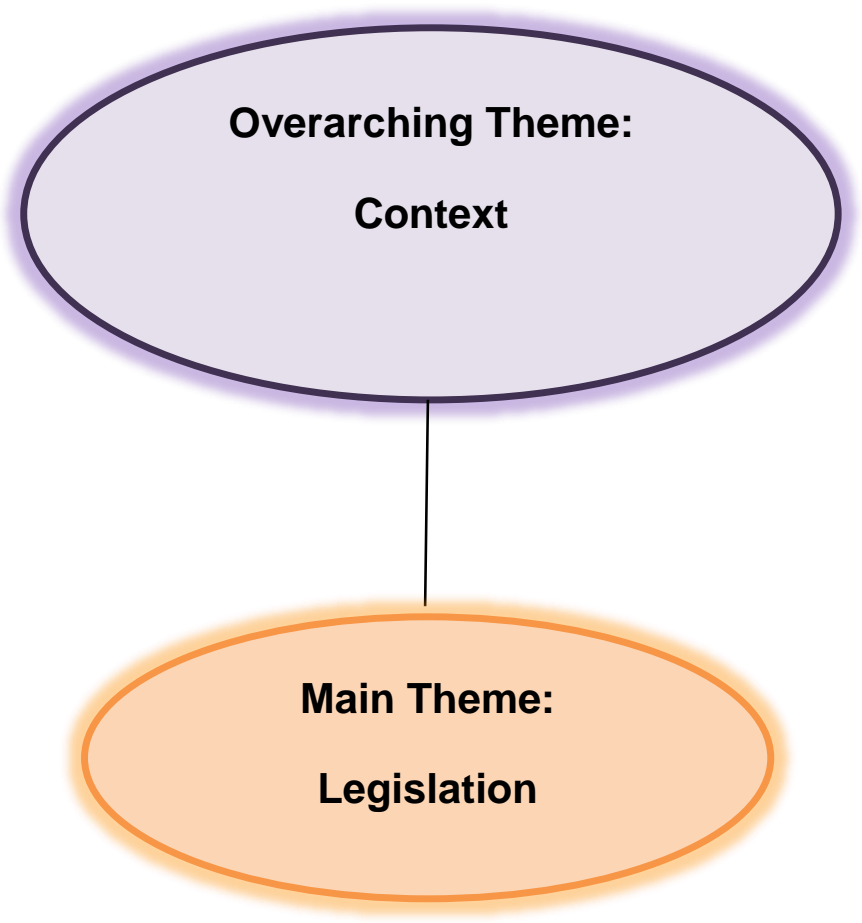

All participants commented to varying degrees on the Children and Families Act (2014) and the impact of this on their work with families. 
The data suggests a wide variance in the responses around this issue.

Some respondents commented positively on the ways in which the legislation had increased schools' understanding of the need to involve parents more fully in the statutory processes, and that parents' involvement had led to them feeling more valued within the process.

e.g.:

P1 "It's probably been beneficial as part of schools seeing, involving the parents, have to be part of the process."

P3 "I think the person centred approach that's come in with the new EHCP process, I think that has helped a lot, and I think parents have felt really valued through that. I think that has been a positive move."

However, other responses indicated opinions that, whilst the legislation had 'good intentions' of involving families, the process itself was 'unwieldy' and 'cumbersome' and this in itself created additional stress and anxiety for some families.

e.g.:

P4 "On paper it looks like it should have changed the way we work. In practice it's the same people sitting around the table, and in fact, I think it bewilders some parents ... for ninety percent of the families I work with they preferred that route, I think, as opposed to a bunch of people, if you can get them, sitting around a table having a two and a half hour meeting that's beyond them half the time. No, I think the intention was good, in practice I don't think it's good for families."

P5 "My work has not changed much at all. I think the EHC paperwork is really good, but I think the whole process is cumbersome."

P6 “I think that's more lip service to what's going on. I don't think it's fundamentally changed anything at all. You know, the twelve week meeting is nice, but pointless for families to come in again, it just heightens their anxiety: 'why are we meeting?' 'Might it still not get through?'” 
Some responses also indicated that participants felt that the workload had increased within the new procedures, with additional meetings and the extension of the EP role to twenty-five years, and this had in fact restricted their ability to fully engage with the new processes.

\subsubsection{Main Theme: EP Training}

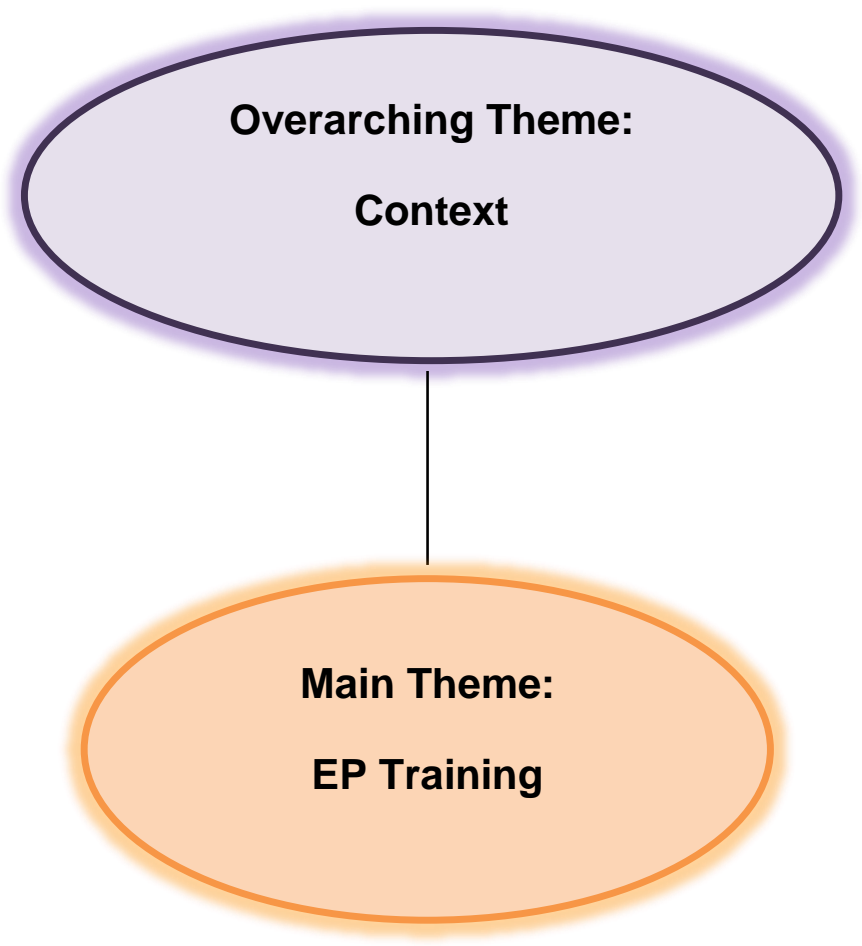

All participants were asked to provide reflections on the degree to which their training had impacted on their practice in their work with families. Of the nine participants, seven had completed their training before the Doctoral training was introduced. One had gone on to complete a top up Doctorate, two had completed the three year Doctoral training. The participants represented four different EP training courses.

Those who had completed the Master's level EP training overwhelmingly commented that there had been minimal focus on family work within their training, 
but a number did comment that through the supervision of trainees they had become aware this had changed and that trainees were now being much better equipped to work in this area than they themselves had been.

e.g.:

P2 "These days having supervised trainee EPs, you know, family work is embedded in, in that approach and certainly things like attachment, and the impact on neurological development. So that lends itself to making a rationale for involving families in your assessment work. It's strengthened over the years I think."

P5 "We were taught to be school psychologists."

P5 "The training now is much broader."

However, this contrasted with the comments from those participants who had trained more recently on the Doctoral training who reported that the focus on family work had been minimal.

e.g.:

P6 "I don't think there was enough. If that is a set role for us to go into, there wasn't a lot around family work."

P8 "I don't think we did a lot about working with families I have to say. It wasn't something particularly focused on."

Those who did refer to family work input from both their Master's level training and the Doctoral training linked this to the consultation models which were used and which provided an eco-systemic approach to consultation. 
e.g.:

P1 "I can't remember doing a lot of work with parents specifically. More as part of, you know, sort of systemic type approaches really, where the family is obviously one of the systems that the child operates within. One thing that we did quite a bit on was eco-systemic consultation. I still think back to that, in terms of what I'm doing in my role really."

P6 "Although then you can say that, but we got taught loads of consultation methods so that's families work right there, and all the obviously, all the working with adults stuff. It translates directly to families."

The findings from this research have been rich, highlighting many important aspects of current EP practice with families. These have been presented within this chapter as a broad picture in order to reflect the data corpus and the breadth of findings. They have also been discussed in relation to the findings of the wider literature. Within Chapter Five I will summarise the findings and discussion directly in relation to the four stated research questions, and from this make links to implications emanating from the findings, in the areas of: EP practice, service delivery and EP training. Within this chapter I will also consider the methodological limitations of the research, areas of future research and the generalisability of the findings. 


\section{CHAPTER FIVE}

\section{CONCLUSION}

This chapter provides a conclusion to the research study. Within this chapter I will consider the findings in relation to the four research questions. Key findings in relation to each research question will be summarised, and the implication for EP practice, service delivery and EP training will be considered in light of the key findings of the research study. Questions arising from the findings will be raised and posed as discussion points, which may indicate areas of further research, or from which a platform for community discussion within the profession can arise. Methodological reflections and limitations of the research, and areas for future research, will then be discussed.

\subsection{Key Findings}

\subsubsection{Research Question 1: What are EPs' experiences of their work with families? Pre-School Based Findings:}

\begin{tabular}{|c|c|}
\hline & EPs' Reported Experiences: \\
\hline $\begin{array}{l}\text { Pre-School } \\
\text { Family Work }\end{array}$ & $\begin{array}{l}\text { EPs' pre-school work is primarily, or solely, statutory } \\
\text { assessment work. } \\
\text { * The EP's role is assessment, in order to identify SEN } \\
\text { provision. } \\
\text { EP pre-school work is only with children with significant } \\
\text { SEN. } \\
\text { EPs have a role in explaining statutory assessment } \\
\text { processes to families, and supporting them with the process. } \\
\text { EPs often work with other agencies already involved with the } \\
\text { families. } \\
\text { All EPs involve parents in the statutory assessment process, } \\
\text { but EP practice varies: }\end{array}$ \\
\hline
\end{tabular}




\begin{tabular}{|l|l|}
\hline i) If a child is in a nursery setting, some EPs focus their \\
assessment within the nursery; contact with parents will \\
be within that setting often at education focused review \\
meetings. \\
ii) Some EPs view home visits and home based \\
assessments, which consider family context factors, as \\
an important part of pre-school work, and involve \\
meeting/consulting with families outside of the nursery \\
setting even if the child attends a nursery setting. \\
EPs do not view intervention work with pre-school families \\
as part of the EP role; views on whether this should be part \\
of the EP role varied. \\
Intervention work with pre-school families is viewed by EPs \\
as the role of other agencies: education agencies such as \\
Early Support Services/Pre-School Services, or Social Care \\
agencies. \\
\hline Analysis and Conclusions: \\
Pre-school referrals to EPs have an assumption of a high \\
level of SEN and a likelihood of requirement for statutory \\
assessment. This is assumed by the referrer and the EP. \\
Variance in EP practice reflects differing attitudes towards \\
the EP's role in assessment: \\
i) Some EPs view the EP role as educationally focused; \\
with the need to establish educational provision as the \\
key EP role. The involvement with parents through the \\
nursery setting at formal review meetings reflects this \\
focus. \\
ii) EPs who involve families outside of the nursery setting, \\
and include home based assessment, and family context \\
factors within their assessments, view understanding the \\
child within the home and educational setting as key to \\
the EP role, signifying a 'child within their systems' \\
centred focus, rather than a 'child within education' \\
centred focus to assessment. \\
*ariance in EP practice signifies differing assumptions about \\
the role of families in assessments: \\
i) Some EP practice places the family at the centre of pre- \\
school work thereby giving a high status and value to the \\
family's role in the assessment of their child. \\
based interventions, and support families, is not utilised, and \\
this role is viewed as primarily the role of education based \\
agencies. \\
ii) Some EP practice places the nursery setting at the \\
fontre of their pre-school work, signifying the educational \\
\end{tabular}




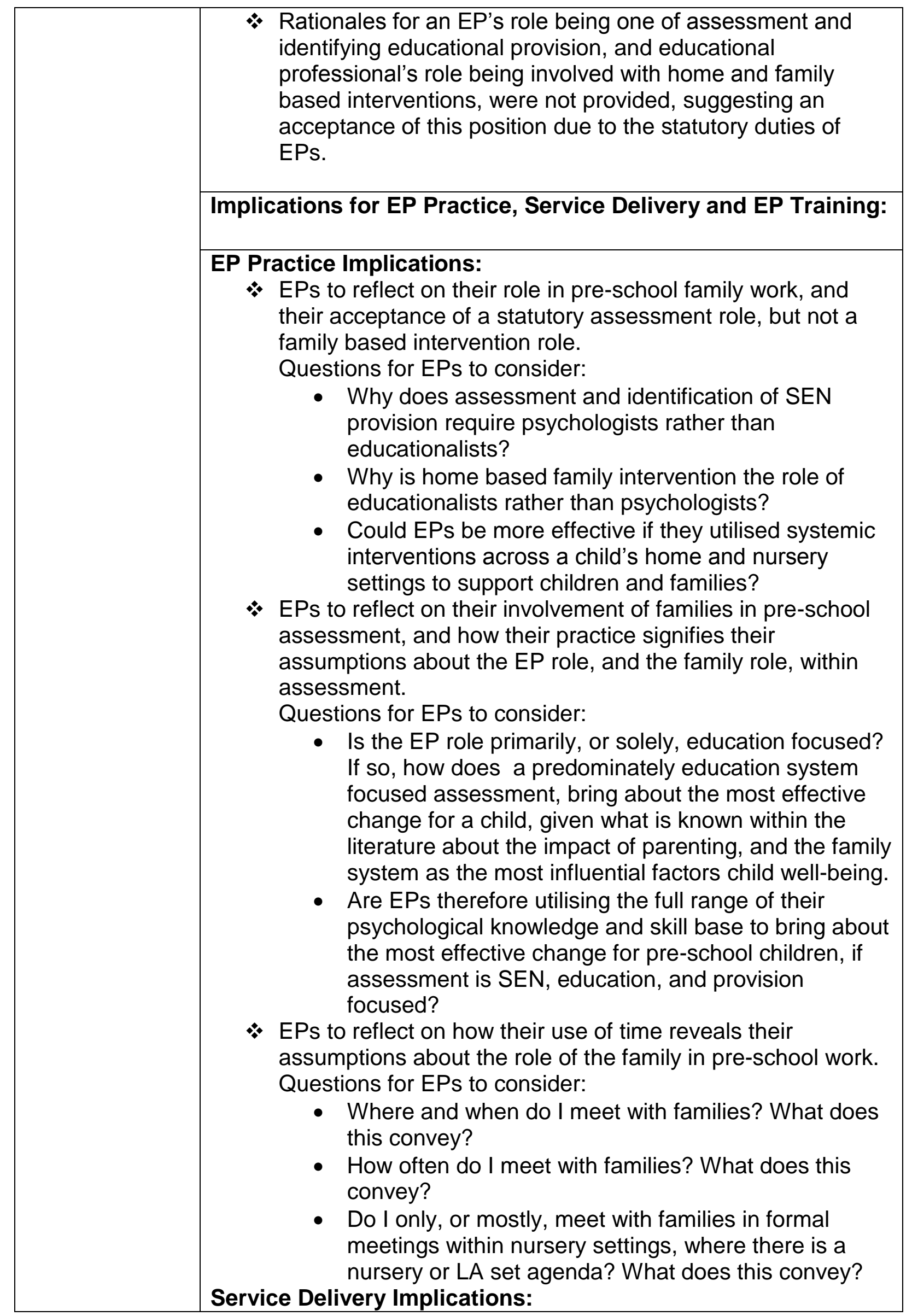




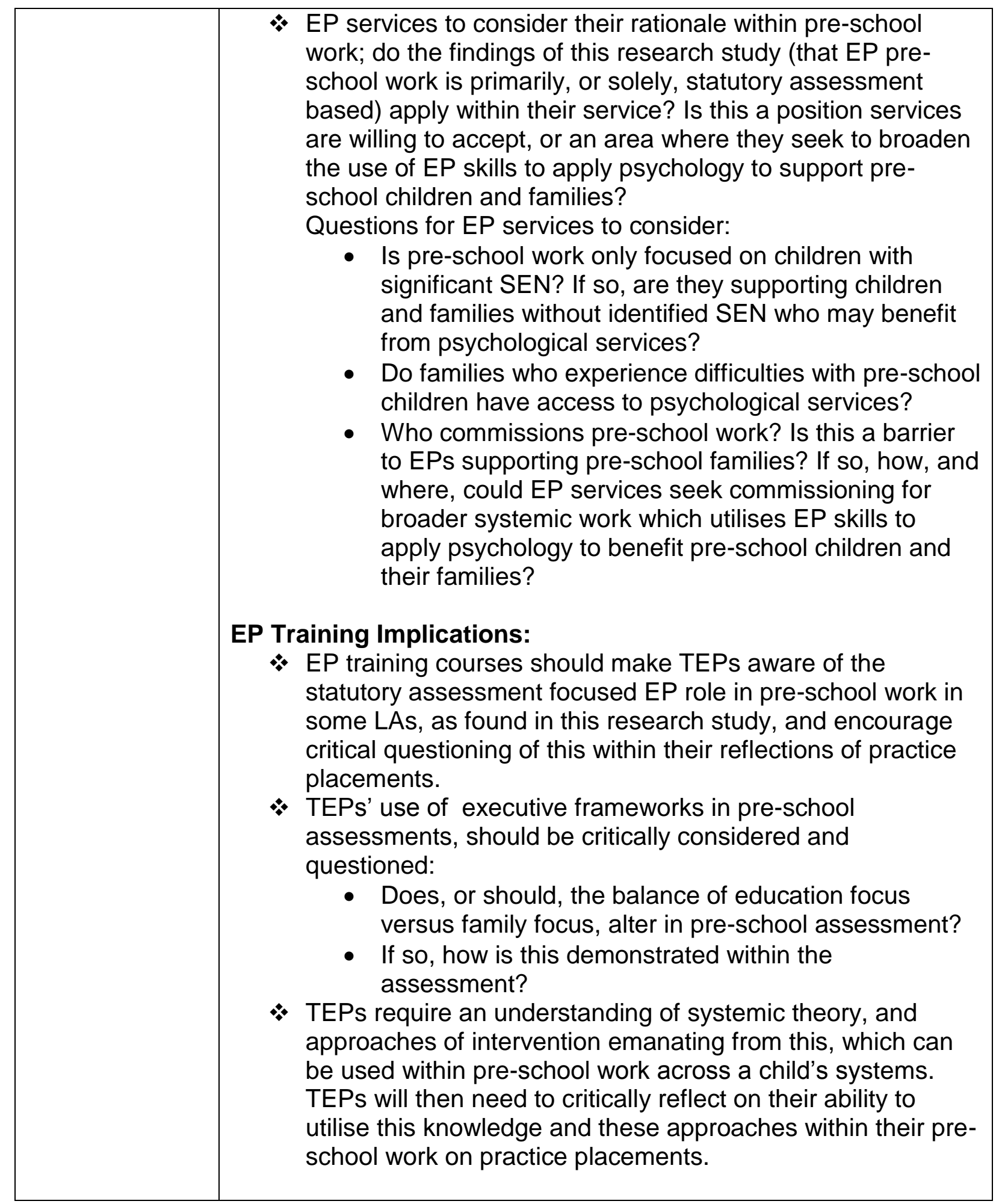




\subsubsection{Research Question 1: What are EPs' experiences of their work with families? School Based Findings:}

\begin{tabular}{|c|c|}
\hline & EPs' Reported Experiences: \\
\hline $\begin{array}{l}\text { School Based } \\
\text { Family Work }\end{array}$ & 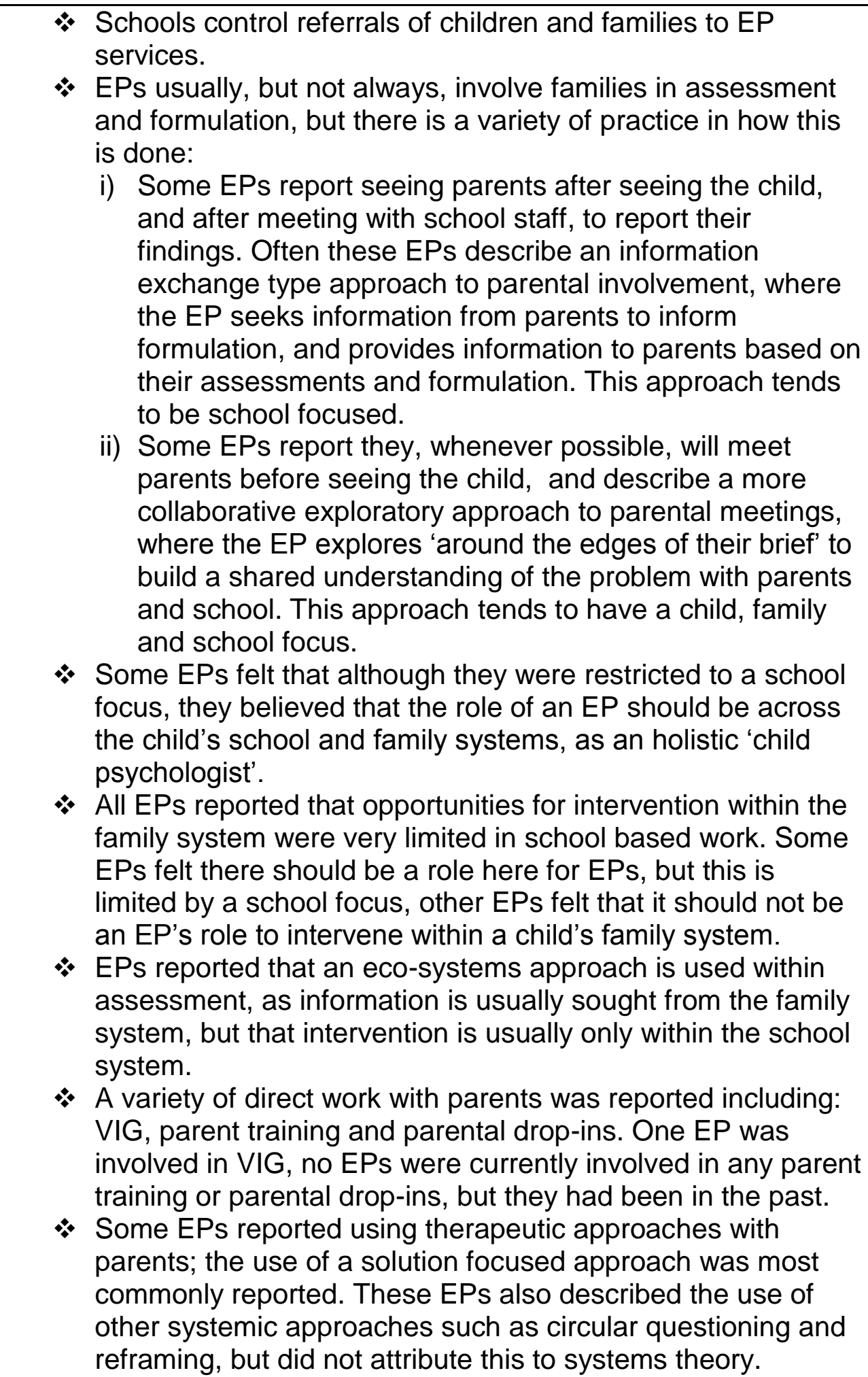 \\
\hline
\end{tabular}




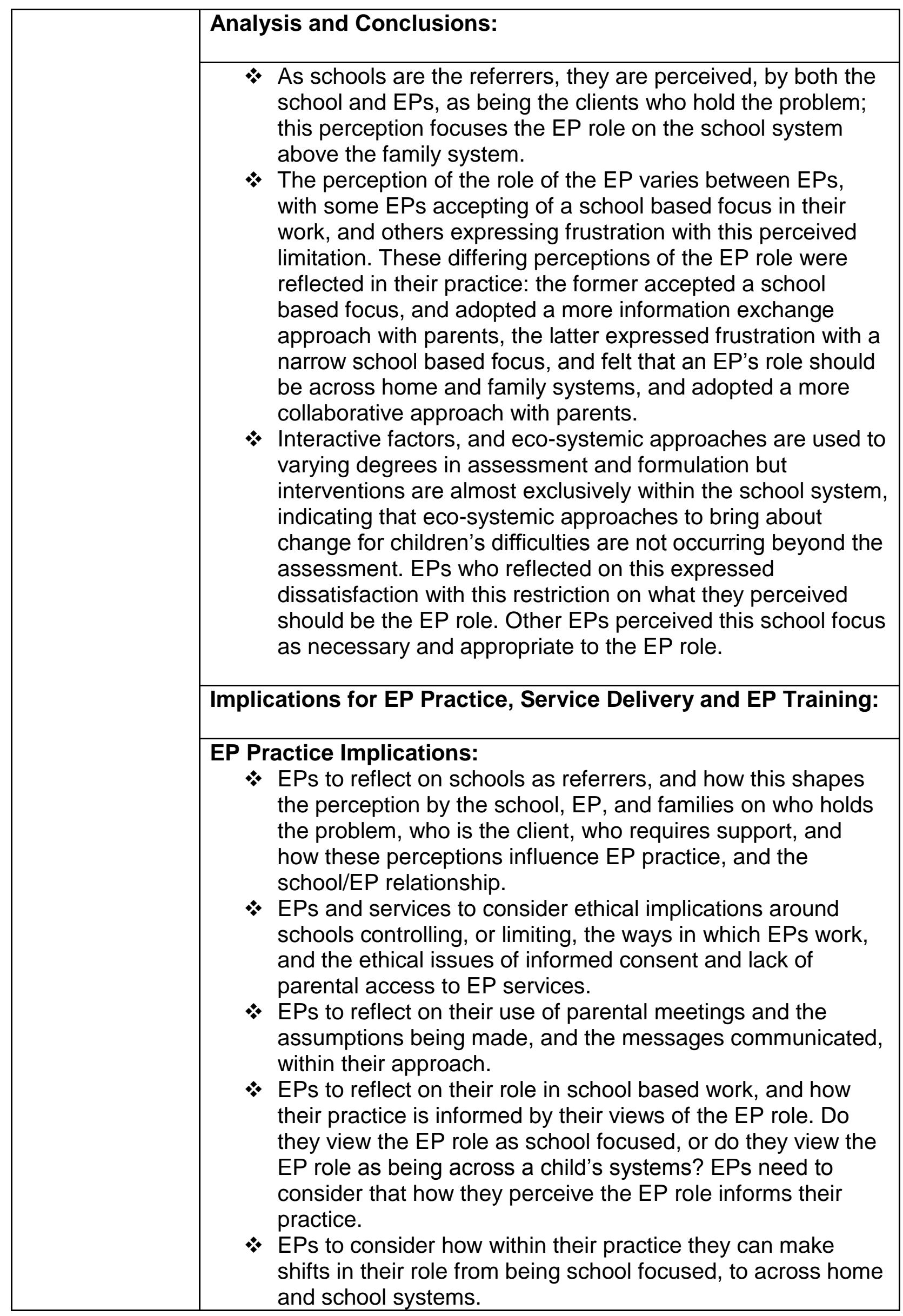




\begin{tabular}{|l|l|}
\hline EPs to become more aware of when they are using systemic \\
theories within family and school consultations so that they \\
can make this approach more explicit and central within their \\
practice. \\
Service Delivery Implications: \\
EP services to consider their referral systems. \\
Questions for EP services to consider: \\
- Who is able to refer to the service? Does a referral \\
from a school represent a problem for a child, a family \\
or for the school? How does this impact on EP \\
practice? \\
- Are they a psychological service for schools, or a \\
psychological service for children and families? \\
- Are children and families with difficulties able to \\
access EP services? Should they be able to? How \\
could this be achieved? How could this work be \\
commissioned? \\
- What are the needs of children and families within the \\
area they serve? What interventions can they develop \\
and offer within the community to address these \\
needs and support children and families? How could \\
this work be commissioned? \\
- How would they need to structure/restructure the EP \\
service to ensure they are meeting the needs of \\
children and families, as well as schools? What steps \\
would they need to take to achieve this?
\end{tabular}




\subsubsection{Research Questions 2 and 3: What do EPs experience as the barriers and facilitators to their work with families?}

\begin{tabular}{|c|c|c|}
\hline $\begin{array}{l}\text { EPs' Experiences } \\
\text { of the Barriers to } \\
\text { their Work with } \\
\text { Families: }\end{array}$ & *. & $\begin{array}{l}\text { A traded model of service creates a consumer/ provider } \\
\text { dynamic between school and EP; EPs reported that } \\
\text { they felt that schools had an 'ownership' of EP time } \\
\text { within this model, and could be more directive of EPs. } \\
\text { Family based work is time intensive, and traded service } \\
\text { delivery does not allow EPs autonomy to direct their } \\
\text { time to family work when they feel it is required, or they } \\
\text { have a role. } \\
\text { School Ethos: Schools which have a curriculum and } \\
\text { attainment focus are less likely to view family support } \\
\text { as a school role, and are therefore less likely to use EP } \\
\text { time for family work. } \\
\text { A dichotomy exists in the thinking of schools, and other } \\
\text { professionals, between the child's home and school } \\
\text { systems and therefore between the professionals they } \\
\text { involve in those systems. The EP is not perceived as } \\
\text { the professional who is involved in the home/family } \\
\text { system. This leads to the involvement of other } \\
\text { professionals and agencies for this system. } \\
\text { A proliferation of other agencies and professionals exist } \\
\text { which schools can refer families with difficulties to. } \\
\text { These agencies are often cheaper than EP services, or } \\
\text { free to schools, therefore schools do not use EP time } \\
\text { for family work. } \\
\text { Schools prioritise statutory assessment work for EP } \\
\text { work, and EPs reported this taking up a large } \\
\text { proportion of their time to schools, leaving minimal } \\
\text { available time for family based work. EPs reported } \\
\text { needing to manage their own workloads given the } \\
\text { pressures of statutory work. }\end{array}$ \\
\hline
\end{tabular}




\begin{tabular}{|c|c|}
\hline $\begin{array}{l}\text { EPs' Experiences } \\
\text { of Facilitators to } \\
\text { their Work with } \\
\text { Families: }\end{array}$ & $\begin{array}{l}\text { A child and family centred orientation in practice rather } \\
\text { than a school-centred orientation in practice: with the } \\
\text { child at the centre it is necessary to work beyond } \\
\text { merely the educational setting, and to work within and } \\
\text { across all the child's systems to bring about the best } \\
\text { outcomes for the child. This then provides a clear } \\
\text { rationale for EP involvement in family work. } \\
\text { * School Ethos: schools that have a strong community } \\
\text { focus, and view their role as supporting families, will be } \\
\text { more likely to use EP time in family work. } \\
\text { * EPs are not based within clinical settings, which } \\
\text { provide the potential to work flexibly and apply } \\
\text { psychology within school, family and community } \\
\text { settings. } \\
\text { * EPs have the skill base to work with families: they are } \\
\text { able to apply the psychological theories of child } \\
\text { development, attachment and relationships, behaviour, } \\
\text { and mental health, and utilise a variety of models of } \\
\text { assessment and intervention alongside using } \\
\text { therapeutic approaches. EPs' use of consultation } \\
\text { models with adults in schools to address the needs of } \\
\text { children can be utilised within the family system. } \\
\text { * Traded models of service delivery could provide the } \\
\text { opportunity for schools to buy additional time for family } \\
\text { work, or specific packages of time for this work. }\end{array}$ \\
\hline \multicolumn{2}{|c|}{ Implications for EP Practice, Service Delivery and EP Training: } \\
\hline \multicolumn{2}{|c|}{$\begin{array}{l}\text { EPs to reflect on their practice: are they school orientated, or child, family } \\
\text { and school orientated? How does this influence their practice within and } \\
\text { across a child's systems? }\end{array}$} \\
\hline \multicolumn{2}{|c|}{$\begin{array}{l}\text { EPs to be aware of a school focused practice not providing a rationale for } \\
\text { work across a child's systems, and of the implicit pressure on EPs within a } \\
\text { traded model of service delivery to be school focused. }\end{array}$} \\
\hline \multicolumn{2}{|c|}{$\begin{array}{l}\text { EPs to be aware of their wide and varied skill set, and how these skills can } \\
\text { be transferred to family work to bring about positive changes for children who } \\
\text { are referred to EP services. }\end{array}$} \\
\hline
\end{tabular}


* EPs need to consider how through their work with schools, and with other professionals, they can shift the perception of the EP role as being solely school focused, and ensure that schools view working with families as part of the EP role.

\section{Service Delivery Implications:}

* EP services need to reflect on their priorities, aims and values. How can they ensure values such as equality of opportunity and social justice apply within a traded model of service, where they need to balance the need to meet the expectations of schools, with the aim of providing psychological services that meet the needs of children and families as well as schools?

* EP services need to consider how their traded model of service delivery, or time allocation model, impacts on family focused work. Has a traded model restricted EPs' ability to engage in family work in their service, as indicated within this research study?

* EP services need to consider how they can market and promote family work within a traded model of service, e.g. could specific packages of time for family based work, such as VIG, parent training, or parental drop-ins be purchased by schools or other settings within the community?

\section{EP Training Implications:}

* TEPs need to be aware that the consultation approaches, therapeutic approaches and systemic theories and approaches they are developing and implementing, can be used with families as well as school staff, and they should be encouraged to find opportunities for extending these skills into family based work on practice placements.

* TEPs need to consider, as they develop their practice, how the role of the EP can be extended to community settings beyond the school, and critically consider the limitations they may experience in this on practice placements.

* EP training courses should consider to what extent their curriculum promotes a school based focus, and whether a minimal focus within the curriculum on family based work creates a perception of the EP role not being within the family system, which is then reinforced on practice placements. Training courses need to consider to what extent they promote the role of EP as an holistic child psychologist working across all the child's systems, and whether changes to the course curriculum to focus more on systemic family work would bring about a shift in TEPs', and future EPs', view of the EP role. 


\subsubsection{Research Question 4: What do EPs feel their role should be in family work?}

\begin{tabular}{|c|c|c|}
\hline $\begin{array}{l}\text { EPs' views on what } \\
\text { the EP role should } \\
\text { be in family work: }\end{array}$ & * & $\begin{array}{l}\text { All EPs reflected on the constraints on the EP role } \\
\text { leading to a school based focus, but there was a } \\
\text { variance between how EPs viewed this limitation of } \\
\text { their role: } \\
\text { i) Some EPs adopted a more pragmatic } \\
\text { acceptance position: that these limitations were } \\
\text { inevitable and immovable, and therefore EPs } \\
\text { should focus on how they could best apply } \\
\text { psychology within the school system to bring } \\
\text { about the best outcomes for children. } \\
\text { ii) Other EPs adopted a more idealistic resistance } \\
\text { position: where they were seeking ways in which } \\
\text { the EP role could be extended across a child's } \\
\text { systems, as they believed that EPs should apply } \\
\text { psychology where it is required to support } \\
\text { children, families and schools. } \\
\text { Some EPs felt the role of an EP should be to apply } \\
\text { psychology directly to the family system when } \\
\text { required; a particular focus on supporting and } \\
\text { building family relationships was made by several } \\
\text { EPs. } \\
\text { Some EPs felt that the EP role should involve more } \\
\text { direct intensive work with families when EPs judged } \\
\text { this as appropriate and beneficial for the child. EPs } \\
\text { commented this would require a greater degree of } \\
\text { professional autonomy and flexibility to make these } \\
\text { decisions. } \\
\text { Some EPs felt that a community educational } \\
\text { psychologist role should be the role that EPs adopt, } \\
\text { with families able to access support through EPs } \\
\text { within school and community settings. }\end{array}$ \\
\hline
\end{tabular}


Implications for EP Practice, Service Delivery and EP Training:

\section{EP Practice Implications:}

* EPs to reflect on the ways in which they can extend their role beyond the school, into the family and community settings when this would provide the best outcomes for the child.

* EPs to consider how they can use the skill base they have to support family relationships and family well-being, in order to promote child well-being.

\section{Service Delivery Implications:}

* EP services to consider how their service could be restructured to provide a more community educational psychologist orientation which supports children, families and schools.

- EP services reflect on their current commissioning structures and how these may limit EP practice, and open up dialogues with current, and potentially new, commissioners to ensure that service delivery is ethical and meets the needs of children and families in the local area.

* EP service managers to consider how the structures within their service could support those EPs who are seeking to extend their role beyond the constraints of the school system.

\section{EP Training Implications:}

* TEPs should be encouraged to consider a community educational psychology orientation within the course curriculum, and reflect on the relevance of this within their practice placements, and how this impacts on EP family work.

\subsection{Methodological Reflections and Research Limitations}

As a researcher, it is important to reflect on the limitations of a research design and to consider how these may have impacted on the findings. This study focused on the experiences of EPs, and adopted a social constructionist paradigm to consider their perceptions and experiences through semi-structured interviews and a thematic analysis. My own identity as an EP with 20 years of practice, and with my own 
experiences of family work within a number of EPS LA contexts, provided a strong practitioner orientation to this study, which provided both strengths and limitations to the design and consideration of the findings.

My own knowledge, understanding and experience of EP family work, and the context in which EPs work, assisted in ensuring that sensitivity to context, and impact and importance, crucial principles in establishing validity and reliability in qualitative research (Yardley, 2000), were met. However, my own experiences of the research area also inevitably means that I have my own constructs, perceptions and understanding of the EP role in family work, which could influence my approach to the study design, and application of the methodology and analysis. I was aware of this potential influence within the research from the time that I identified this research area, due to my own professional interest and experience in family work. This was explicitly discussed within tutorials at the time of the research proposal, and continued to be actively discussed and reflected upon throughout the research process, within tutorials and within my research diary. I took steps to ensure that the influence of my own experiences and perceptions were limited within the design, and explicitly reflected upon at each stage of the process. This was achieved through establishing open research questions which allowed a full exploration of each individual's personal experience, reflections on interview recordings to ensure I did not unduly influence, guide or reinforce participants' responses, careful checking and rechecking of emerging themes against the transcripts' codes to ensure evidence for the themes, and extensive use of quotations within the results and discussion to provide evidence of the themes identified and discussed.

Additionally, my role as an EP interviewing other EPs, some of whom were current and past colleagues, could be considered to present a potentially threatening 
interaction where EPs could have felt judged when sharing their own practice. Steps taken to minimise this influence were: request for volunteers from across five different services, volunteers provided with information on the study area and research questions before the interviews, and participants given explicit information on how their data would be anonymised, stored and used.

This research study focused on a deliberately broad area of EP practice. The area of study was deliberately broad because no previous research in this area had taken place, and therefore it was important to allow participants to define for themselves the scope and meaning of EP family work, and for this to emerge within the findings. The impact, however, of broad research questions, was some limitations on the depth and complexity of the themes and the analysis, due to themes needing to be an accurate reflection of the data corpus and the word limit of the research paper.

This research studies the perceptions of nine EPs from four EPSs within the Midlands. Although the four EP services represented do reflect different service delivery models and organisation, they are unlikely to reflect the wider variance in EP service delivery and organisation which may exist nationally. Through providing rich accounts from the data, I aimed to aid the reader to make informed judgements about the applicability of my findings to other EP contexts. Morse (1999) argues that knowledge gained from qualitative data derived from small scale, subjectivist studies is not limited to demographic variables; it is the fit to the topic or the comparability of the problem that is of concern. It is therefore my aim to build, through my findings, communicative generalisations, through providing contextualisation within individual narratives to allow readers to effectively judge similarity within their own settings, in order to stimulate community conversation about the study and its potential wider applications (Smaling, 2003). 


\subsection{Future Research}

Due to the lack of any previous research on EPs' perceptions of family work, and the paucity of research in the area of EPs and family work more generally, and given that this research study adopted a qualitative approach to a broad area of EP work, there are a variety of future research paths which this study could point to.

It may be useful to the EP profession, given the findings of this research, for further quantitative research to be conducted into some of the findings of this study. For example:

- Around the numbers of EPs reporting the use of systemic theories and approaches within their practice, and the utilisation of these with families.

- On EPs' use of parental meetings (e.g. before or after seeing a child, informed consent, purpose of meeting etc).

- Numbers of EPs reporting current involvement in family based intervention work, e.g. parent training, parent drop-in, VIG or other family based interventions etc.

A large scale national quantitative research study, around these types of research questions, would increase the generalisability of the findings of this study in light of other findings, and inform the national picture of the EP role in this area.

Other areas of more qualitative research which would add to the findings from this study could be a discourse analysis of EP meetings with parents to explore the EP role within these, or interviews with families, schools and other agencies to explore their perceptions of the EP role in family work. 
Another profitable area of research leading from this study could be to consider in more depth the extent to which differing models of service delivery and organisation impact on EP family work. Principal EPs from a number of LAs, identified due to their differing models of service delivery and organisation, could be interviewed to consider if/how their model of service delivery supports EPs in meeting the needs of children and families, rather than just meeting the needs or demands of schools or LAs.

\subsection{Concluding Comments}

Within the literature review, Peake's (1999) sharp critique of the EP profession's 'desertion' of families, and her assertion that EP services had become schools' psychological services which were increasingly inaccessible to families, alluded to the aims of this research study: to establish the experiences of family work of EPs currently in practice. Her challenge posed to the profession to restructure and reorganise services to ensure they were meeting the needs of children and families, and not just schools and LAs, can be considered here in concluding comments, given the findings of this study, and the extent to which the challenges posed by Peake in 1999, may have been met.

She challenged the EP profession to ensure that they were meeting the needs of children and families, and not just schools, through ensuring:

- Parents have access to EP services; with a proportion of EP time available for parental, and not just school, referral. 
The findings of this study would suggest that schools tightly control EP referrals through the traded model, which was not in place in 1999. No EPs reported a route for parental referral outside statutory assessment.

- EPs use their time to demonstrate that listening to parents is a priority and fundamental to their practice.

EP practice in the use of time in meeting with parents varied between EPS, and reflected underlying assumptions about the EP role.

- EPs provide detailed advice and intervention for parents, to empower them to solve their own problems, such as use of parental consultation services, and parent groups.

All EPs reported a lack of opportunity for family based interventions. No EPS were currently involved in parental consultation groups, parent groups or training programmes. One EP was using VIG with families.

- EP services should ensure a balance of statutory work with children and families work.

None of the EPs reported that their service had structures in place to ensure and protect children and families work.

- EP services should create, and offer, intervention services for families to meet local need.

None of the EPS reported their services had created and offered intervention services for families in line with local needs. Some EPs discussed how this could be done, and felt it was a role EPS should be involved in. 
- EP services need to prioritise offering psychological services to vulnerable children and families such as LAC, homeless families, those who have experienced domestic violence, women who live in poverty, those who have experienced abuse, and those where addiction and mental health needs exist within the family.

None of the EPs reported any steps taken by their services to ensure that psychological services were available to children and families within these vulnerable groups.

Given these findings, and the significant changes in the service delivery context since Peake asserted her challenge, it may be time once again for the challenge to be posed to the EP profession:

Are we meeting the needs of children and families, and not just schools, or do we need to restructure services within the traded context, to ensure that we are? 


\section{REFERENCES}

Ajmal, Y., \& Rees, I. (2001). Solutions in schools. Creative applications of solution focused brief therapy with young people and adults. London: BT Press.

Ajmal, Y., \& Rhodes, J. (1995). Solution focused brief therapy, EPs and school. Educational and Child Psychology in Practice, 22(2), 111-123.

Alexander, N., \& Clare, L. (2004). You still feel different: the experiences and meaning of women's self-injury in the context of a lesbian or bisexual identity. Journal of Community and Applied Social Psychology, 14(2), 78-84.

Allely, C., Puckering, C., Mills, M., Cox, A.D., Janneke, E., \& Maddox, H. (2014). The impact of the Mellow parenting programme on later measures of childhood verbal IQ. Educational and Child Psychology, Working with Families: Collaboration and Intervention, 31(4), 30-39.

Anderson, C. (1983). An ecological developmental model for a family orientation in school psychology. Journal of School Psychology, 21, 179-189.

Anderson, H., \& Goolishian, H. (1992). The client is the expert: a not-knowing approach to therapy. In S. McNamee \& K. Gergen (Eds.), Therapy as a social construction (chapter 2). London: Sage.

Annan, J. (2005). Ecological practice: illustrations from educational psychology in New Zealand. Kairaranga, 6(2), 10-18.

Annan, M., Chua, J., Cole, R., Kennedy, E., James, R., Markusdottir, I., Monsen, J., Robertson, L., \& Shah, S. (2013). Further iterations on using problem-analysis framework. Educational Psychology in Practice, 29(1), 79-95.

Aponte, H.J. (1976). The family-school interview: an eco-structural approach. Family Process, 15, 303-313.

Ashton, R., \& Roberts, E. (2006). What is valuable and unique about the educational psychologist? Educational Psychology in Practice, 22(2), 111-123.

Association of Educational Psychologists, Manifesto. Retrieved from:

http://www.aep.org.uk/news/aep-manifesto-please-bring-it-to-the-attention-of-yourlocal-p/

Association of Educational Psychologists (2012). Code of Professional Conduct Members' Handbook. Durham: AEP.

Attride-Stirling, J. (2001). Thematic networks: an analytic tool for qualitative research. Qualitative Research, 1(3), 385-405. 
Bandura, A., Caprara, G.V., Barbaranelli, C., Regalia, C., \& Scabini, E. (2011). Impact of family efficacy beliefs on quality of family functioning and satisfaction with family life. Applied Psychology: An International Review, 60, 421-448.

Barlow, J., Coren, E., \& Stewart-Brown, S. (2002). Meta-analysis of parenting programmes in improving maternal psychosocial health. British Journal of General Practice, 52, 223-233.

Barrett, M., \& Trevitt, J. (1991). Attachment behaviour and the schoolchild: an introduction to educational therapy. London and New York: Tavistock/Routledge.

Bateson, G. (1979). Mind and nature: a necessary unity. London: Wildwood House.

Belsky, J., Vandell, D.L., Burchinal, M., Clarke-Stewart, K.A., McCartney, K., \& Owen, M.T. (2007). Are there long term effects of early child care? Child Development, 78(2), 681-701.

Bertalanffy, L. von (1968). General systems theory. New York: Braziller.

Bevington, S. (2013). Home-school relationships: the communication and engagement practices of schools and the role of the community educational psychologist. (Doctoral thesis). University of Exeter, UK.

Bickford-Smith, A. (2003). Joint working with child and adolescent mental health services. Association of Educational Psychologists News and Information Circular, 12 March 2003.

Binns, K.A., Steinberg, A., \& Amorosi, S. (1997). The metropolitan life survey of the American teacher: building family-school partnerships: views of teachers and students. New York: Lewis Harris and Associates.

Bowlby, J. (1969). Attachment and loss, vol.1, Attachment. London: Hogarth Press and Institute of Psychoanalysis, New York: Basic Books.

Bowlby, J. (1973). Attachment and loss, vol.2, Separation anxiety and anger. London: Hogarth Press and Institute of Psychoanalysis, New York: Basic Books.

Bowlby, J. (1980). Attachment and loss, vol. 3, Loss: sadness and depression. London: Hogarth Press and Institute of Psychoanalysis, New York: Basic Books.

Bowlby, J. (1994). The family and the school: a joint systems approach to problems with children. Foreword p. xi. London: Routledge.

Bowman, P., \& Goldberg, M. (1983). "Reframing": a tool for the school psychologist. Psychology in the Schools, 20, 210-214.

Boyatzis, R. (1998). Transforming qualitative information: thematic analysis and code development. London: Sage. 
Braun, V., \& Clarke, V. (2006). Using thematic analysis in psychology. Qualitative Research in Psychology, 3(2), 77-101.

Braun, V., \& Clarke, V. (2012). Thematic analysis. In H. Cooper, P.M. Camic, D.L. Long, A.T. Panter, D. Rindskopf \& K.J. Sher (Eds.), APA handbook of research methods in psychology, vol 2: research designs: quantitative, qualitative, neuropsychological, and biological (pp. 57-71). Washington, DC: American Psychological Association.

Brestan, E.V., \& Eyberg, S.M. (1998). Effective psychosocial treatments of conduct disordered children and adolescents: 29 years, 82 studies and 5272 kids. Journal of Clinical Child Psychology, 27, 180-189.

British Psychological Society (2014). Code of human research ethics. Leicester: BPS Publications.

Bronfenbrenner, U. (1979). The ecology of human development: experiments by nature and design. Cambridge, MA: Harvard University Press.

Bronfenbrenner, U. (2001). The bioecological theory of human development. In U. Bronfenbrenner (Ed.), Making human beings human: bioecological perspectives on human development (pp. 3-15). Thousand Oaks, California: Sage.

Bryman, A. (2004). Social research methods (2nd ed.). Oxford: Oxford University Press.

Bryman, A., \& Burgess, R. (1994). Analyzing qualitative data. London: Routledge.

Buck, D. (2015). Reconstructing educational psychology reports: an historic opportunity to change educational psychologists' advice? Educational Psychology in Practice, 31(3), 221-234.

Buehler, C., \& O'Brien, M. (2011). Mothers' part-time employment: associations with mother and family well-being. Journal of Family Psychology, 25(6), 895-906.

Burden, R. (1978a). Schools systems analysis: a project approach. In W. Gillham (Ed.), Reconstructing educational psychology. London: Croom.

Burden, R. (1978b). Developing the curriculum at a residential school for the physically handicapped. AEP Journal, 4(8), 40-43.

Burden, B. (1981a). The educational psychologist as instigator and agent of change in schools: some guidelines for successful practice. In A. McPherson \& A. Sutton (Eds.), Reconstructing psychological practice. London: Croom Helm.

Burden, B. (1981b). Systems theory and the relevance to schools. In B. Gillham (Ed.), Problem behaviour in the secondary school. London: Croom Helm. 
Burden, R. (1982). Even trainees can do it! Applying educational psychology in secondary schools. AEP Journal, 5(10), 24-27.

Burden, R. (1999). We're on the road to nowhere: twenty-one years of reconstructing educational psychology. Educational Psychology in Practice, 14(4), 228-231.

Burns, K.M., \& Hulusi, H.M. (2005). Bridging the gap between a learning support centre and school: a solution focused group approach. Educational Psychology in Practice, 21(2), 123-130.

Burton, M., \& Kagan, C. (2003). Community psychology; why this gap in Britain? History and Philosophy of Psychology, 4(2), 10-23.

Byng-Hall, J. (1991). The application of attachment theory to understanding and treatment in family therapy. In C. Murray Parkes and J. Stevenson-Hinde (Eds.), The place of attachment in human behaviour. London: Tavistock Publications.

Byng-Hall, J. (1995). Rewriting family scripts. Improvisation and change. New York: Guildford.

Cameron, R.J. (2006). Educational psychology: the distinctive contribution. Educational Psychology in Practice, 22(4), 289-304.

Cameron, S., \& Maginn, C. (2009). Achieving positive outcomes for children and young people in public care. London: Sage.

Campion, J. (1984). Psychological services for children using family therapy in the setting of a school psychological service. Journal of Family Therapy, 6(1), 47-62.

Cannon, W. (1939). The wisdom of the body. New York: W.W. Norton.

Carlson, D.S., Kacmar, K.M., \& Williams, L.J. (2000). Construction and initial validation of a multidimensional measure of work-family conflict. Journal of Vocational Behaviour, 56(2), 249-276.

Carr, A. (2006). Chapter 10: Conduct problems. In The handbook of child and adolescent clinical psychology, a contextual approach (2nd ed.) (pp. 362-420). London \& New York: Routledge.

Carr, E.R. (2013). Parental leadership roles and conflict management: developing family resiliency through parent-child reconciliation. University of South Dakota, $\mathrm{p}$. 85.

Casanova, P.F., Garcia-Linares, M.C., de la Torre, M.J., \& de la Villa Carpio, M. (2005). Influence of family and socio-demographic variables on students with low academic achievement. Educational Psychology, 25(4), 423-435.

Cecchin, G. (1987). Hypothesising, circularity, and neutrality revisited: an invitation to curiosity. Family Process, 26, 405-413. 
Chamberlayne, P., Bornat, J., \& Wengraf, T. (2000). The turn to biological methods in social science - comparative issues and examples. London: Routledge.

Chien, N.C., \& Mistry, R.S. (2013). Geographical variations in the cost of living: associations with family and child well-being. Child Development, 84(1), 209-225.

Children's Workforce Development Council (2008). Children's Workforce Development Council consultation final report: Building a sustainable system of entry training for educational psychologists. Retrieved from

http://www.cwdcouncil.org.uk/educational-psychology/consultaion-final-report.

Children and Families Act (2014). Published by TSO (The Stationery Office):

London. Retrieved from:

http://www.legislation.gov.uk/ukpga/2014/6/pdfs/ukpga 20140006 en.pdf

Christenson, S.L., Hurley, C.M., Sheridan, S.M., \& Fenstermachor, K. (1997). Parents' and school psychologists' perspectives on parental involvement activities. School Psychology Review, 26, 111-130.

Clarke, V., \& Braun, V. (2014). Thematic analysis. In A.C. Michalos (Ed.), Encyclopaedia of quality of life and well-being research (pp. 6626-6628). Dordrecht, Netherlands: Springer.

Cohen, L., Manion, L., \& Morrison, K. (2011). Research methods in education (7th ed.). London: Routledge.

Coleman, J.S. (1966). Equality of educational opportunity. Washington: US Government Printing Office.

Confucius, \& Whaley, A. (1938). The analects of Confucius. New York: Random House.

Conoley, J.C., \& Conoley, C.W. (1982). School consultation: a guide to practice and training. New York and Oxford: Pergamon Press.

Coolican, H. (2014). Research methods and statistics in psychology. London: Hodder \& Stoughton.

Cottrell, D., \& Boston, P. (2002). Practitioner review: the effectiveness of systemic family therapy for children and adolescents. Journal of Child Psychology and Psychiatry, 43(5), 573-586.

Cox, D.D. (2005). Evidence-based interventions using home school collaboration. School Psychology Quarterly, 20(4), 473-497.

Crotty, M (1998). The foundations of social research: meaning and perspective in the research process. London: Sage. 
Cunningham, L. (2016). Maintaining an interactionist perspective of undesirable behaviour: what is the role of the educational psychologist? Educational Psychology Research and Practice, 2(1), 49-58.

Cunningham, C., \& Davis, H. (1985). Working with parents: frameworks for collaboration. Milton Keynes: Open University Press.

Dallos, R., \& Draper, R. (2005). An introduction to family therapy: systemic theory and practice. Maidenhead: Open University Press.

Dawson, N.K., \& McHugh, B.M. (1986). Families as partners. Pastoral Care in Education, 4(2), 102-109.

de Shazer, S. (1985). Keys to solution in brief therapy. New York: Norton.

Dell, P.F. (1982). Beyond homeostasis: towards a concert of coherence. Family Process, 21(1), 21-41.

Dennis, R. (2003). Starting to make a difference: responding to the challenges of recent developments in the early years. Educational Psychology in Practice, 19(4), 259-270.

Denzin, N. (1999). Biological research methods. In J.P. Keeves \& G. Lakonski (Eds.), Issues in educational research. Oxford: Pergamon.

Department for Education (DfE) (2015). Special educational needs and disability code of practice: 0 to 25 years. Retrieved from https://www.gov.uk/government/publications/send-code-of-practice-0-to-25

Department of Education and Science (DES) (1967). Children and their primary schools (The Plowden Report). London: HMSO.

Desforges, C., \& Abouchaar, A. (2003). The impact of parental involvement, parental support and family education on pupil attainment and adjustment. London: Department for Education and Skills, Research Report.

Deslandes, R., Potvin, P., \& Leclerc, D. (1999). Family characteristics a predictor of school achievement: parental involvement as a mediator. McGill Journal of Education, 34, 135-153.

DfEE (2000). Educational psychology services (England): current role, good practice and future directions. Report of the Working Group. Nottingham: Department for Education and Employment.

DfES (2005a). Trainers for users of the common assessment framework. Retrieved from www.everychildmatters.gov.uk

DfES (2005b). Children's workforce strategy. Annesley, Nott: DfES Publications. 
Douglas, J. (1989). Training parents to manage their child's sleep problems. In C. Schaefer \& J. Briesmeister (Eds.), Handbook of parent training (pp. 13-37). New York: Wiley.

Douglas, J. (2005). Behavioural approaches to eating and sleeping problems in young children. In P.J. Graham (Ed.), Cognitive behaviour therapy for children and families (pp. 187-206). Cambridge: Cambridge University Press.

Dowling, E., \& Osborne, E. (1985). The family and the school: a joint systems approach to problems with children. London: Routledge.

Dowling, E., \& Osborne, E. (1994). The family and the school: a joint systems approach to problems with children. London: Routledge.

Dowling, J., \& Pound, A. (1994). Joint interventions with teachers, children and parents in the school setting. In E. Dowling \& E. Osborne (Eds.), The family and the school. London: Routledge.

Dunsmuir, S., Cole, R., \& Wolfe, V. (2014). Guest Editorial: Working with families: collaboration and intervention. Educational and Child Psychology: Working with Families: Collaboration and Intervention, 31(4), 6-8.

Eccles, J.S., \& Harold, R.D. (1993). Parent-school involvement during the early adolescent years. Teachers College Record, 94(3), 568-587.

Edwards, J.R., \& Rothbard, N.P. (1999). Work and family stress and well-being: an examination of person environment fit in the work and family domains. Organizational Behavior and Human Decision Processes, 77(2), 85-129.

Egan, G. (1990). The skilled helper: a systemic approach to effective helping (4th ed.). California: Brooks-Cole.

Eichelberger, T (1989). Disciplined inquiry: understanding and doing educational research. UK: Longman Publishing Group.

Elliot, R., Fischer, C., \& Rennie, D.L. (1999). Evolving guidelines for publication of qualitative research studies in psychology and related fields. British Journal of Clinical Psychology, 38, 215-229.

Eodanable, M., \& Lauchlan, F. (2009). The advance of research and evaluation skills by EPs: implications for training and professional development. Educational Psychology in Practice, 25(2), 113-124.

Epstein, J.L. (2001). School, family and community partnerships. Boulder, CO: Westview Press.

Erben, M. (Ed.) (1998). Biography and education - a reader. London: Falmer Press. 
Fallon, K., Woods, K., \& Rooney, S. (2010). A discussion of the developing role of educational psychologists within children's services. Educational Psychology in Practice, 26(1), 1-23.

Fan, X., \& Chen, M. (2001). Parental involvement and students' academic achievement: a meta-analysis. Educational Psychology Review, 13(1), 1-22.

Farrell, P. (2010). School psychology: learning lessons from history and moving forward. School Psychology International, 31(6), 581-598.

Fernández, J. (2011). The specificity of the educational psychologist. Papeles del Psicólogo, 32(3), 247-253.

Fine, M. (1979). Parents versus children: making the relationship work. Englewood Cliffs, NJ: Prentice-Hall.

Fine, M.J. (1985). Intervention from a systems-ecological perspective. Professional Psychology: Research and Practice, 16(2), 262-270.

Fine, M.J., \& Holt, P. (1983). Intervening with school problems: a family systems perspective. Psychology in the Schools, 20(1), 59-66.

Fine, M.J., \& Pitt, R. (1980). Intervention with underachieving gifted children: rationale and strategies. Gifted Child Quarterly, 24, 51-55.

Fogell, J. (1999). Working miracles. Special Children, March, 30-33.

Fox, M. (2009). Working with systems and thinking systemically - disentangling the crossed wires. Educational Psychology in Practice, 25(3), 247-258.

Fox, M. (2015). What sort of person ought I to be? - Repositioning EPs in light of the Children and Families Bill (2013). Educational Psychology in Practice, 31(4), 382396.

Frederickson, N. (1990). Systems approaches in educational psychology practice: a re-evaluation. In N. Jones \& N. Frederickson (Eds.), Refocusing Educational Psychology. London: Falmer Press.

Frederickson, N., \& Miller, A. (2008). What do educational psychologists do? In N. Frederickson, A. Miller \& T. Cline (Eds.), Educational psychology: topics in applied psychology (pp. 1-27). London: Hodder Education.

Frederickson, N., \& Cline, T. (2009). Special educational needs, inclusion and diversity: a textbook (2nd ed.). 648 pp. Maidenhead: Open University Press.

Freund, J.C., \& Cardwell, G.F. (1977). A multi-faceted response to an adolescent's school failure. Journal of Marriage and Family Counselling, 3(2), 49-57. 
Frome, P., \& Eccles, J. (1998). Parents' influence on children's achievement related perceptions. Journal of Personality and Social Psychology, 74, 435-452.

Fukkink, R.G. (2008). Video feedback in widescreen: a meta-analysis of family programs. Clinical Psychology Review, 28(6), 904-916.

George, E., Iveson, C., \& Ratner, H. (1990). Problems to solutions, brief therapy with individuals and families. London: BT Press.

Georgiades, N., \& Phillimore, L. (1975). The myth of the hero-innovator and alternative strategies for organisational change. In C. Kiernan \& F. Woodford (Eds.), Behaviour modification with the severely retarded. Amsterdam: North-Holland Elsevier/Excerpta medica.

Gersch, I. (2009). A positive future for educational psychology - if the profession gets it right. Educational Psychology in Practice, 25(1), 9-19.

Gersch, I., \& Noble, J. (1991). A systems project involving student and staff in a secondary school. Educational Psychology in Practice, 7(3), 140-147.

Gillham, B. (Ed.) (1978). Reconstructing educational psychology. London: Croom Helm.

Gillham, B. (Ed.) (1981). Problem behaviour in the secondary school. London: Croom Helm.

Gilmore, G. (1974). School psychologist-parent contact: an alternative model. Psychology in the Schools, 11, 170-173.

Gray, D. (2009). Doing research in the real world (2nd ed.). California: Sage Publications.

Guishard, J. (1998). The parents' support service brief family work in a school context. Educational Psychology in Practice, 14(2), 135-139.

Haley, J. (1976). Problem solving therapy. San Francisco: Jossey-Bass.

Hames, A., Rollings, C., \& Janes, E. (2009). Confident parenting: a guide for group facilitators. Newcastle: HEADS.

Hancock, R. (1998). Building home school liaison into classroom practice: a need to understand the nature of a teacher's working day. British Educational Research Journal, 24(4), 399-414.

Hart, D. (1979). More business as usual: implications of an individual referral. AEP Journal, 4(10), 30-33. 
Hay, D.F., Pawlby, S., Sharp, D., Asten, P., Mills, A., \& Kumar, R. (2001). Intellectual problems shown by 11-year old children whose mothers had postnatal depression. Journal of Child Psychology and Psychiatry, 42(7), 871-889.

Health and Care Professions Council (2008). Standards of conduct, performance and ethics. London: HCPC.

Health and Care Professions Council (2009). Standards of proficiency: practitioner psychologists. The Stationery Office (2005).

Hearnshaw, L. (1979). Cyril Burt, psychologist. London: Hodder \& Stoughton.

Henderson. A.T., \& Mapp, K.L. (2002). A new wave of evidence: the impact of school, family and community connections on student achievement. Austin, TX: Southwest Educational Development Laboratory.

Herbert, M. (1996). Toilet training, bedwetting and soiling. Leicester: British Psychological Society.

HM Treasury (2010). Spending Review. Crown Copyright Ref: cm7942.

Ho, B.S. (1997). The school psychologist's role based on an ecological approach to family-school-community collaborations. The California School Psychologist, 2(1), 31-38.

Hobbs, N. (Ed.) (1975). The futures of children. San Francisco: Jossey-Bass.

Hoffman, L. (1981). Foundations of family therapy. New York: Basic Books.

Holstein, J.A., \& Gubrium, J.F. (1994). Phenomenology, ethnomethodology and interpretive practice. In N.K. Denzin \& Y.S. Lincoln (Eds.), Handbook of qualitative research (pp. 262-272). Thousand Oaks, California: Sage.

Hornby, G., \& Lafaele, R. (2011). Barriers to parental involvement in education: an exploratory model. Educational Review, 63(1), 37-52.

Hutchings, J., Bywater, T., Daley, D., Gardner, F., Whitaker, C., Jones, K., Eames, C., \& Edwards, R.T. (2007). Parenting intervention in Sure Start services for children at risk of developing conduct disorder: pragmatic randomised controlled trial. British Medical Journal, 334, 678-682.

Hymans, M. (2008). How personal constructs about 'professional identity' might act as a barrier to multiagency working. Educational Psychology in Practice, 24(4), 279288.

Imich, A. (2013). National Association of Principal Educational Psychologists NAPEP Conference - presentations in the role as SEN and Disability Professional Advisor Department for Education (DfE). 
Islam, S.N. (2013). An investigation into educational psychologists' perceptions of traded service delivery, using soft systems methodology. (Unpublished doctoral thesis). University of Birmingham, UK.

Jencks, C., Smith, M., Acland, H., Bane, M.J., Cohen, D., Gintis, H., Hayns, B., \& Michelson, S. (1972). Inequality: a reassessment of the effect of family and schooling in America. New York: Basic Books.

Jenkins, G.M. (1969). The systems approach. Journal of Systems Engineering, 1(1), 19-27.

Jenkins, H. (1995). Systemic work with individuals. In H. Jenkins, (English ed.), The Dictionary of Family Therapy. Oxford: Blackwell Reference.

Jeynes, W.H. (2005). A meta-analysis of the relation of parental involvement to urban elementary school student academic achievement. Urban Education, 40(3), 237-269.

Jeynes, W.H. (2007). The relation between parental involvement and urban secondary school student academic achievement: a meta-analysis. Urban Education, 42(1), 82-110.

Joffe, H. (2012). Thematic analysis. In D. Harper \& A. Thompson (Eds.), Qualitative research methods in mental health and psychotherapy: a guide for students and practitioners (pp. 209-223). Chichester: Wiley-Blackwell.

Jones, E. (1993). Working with individuals. In H. Jenkins (Ed.), Family systems therapy: developments in Milan-systemic therapies. Chichester: Wiley.

Jones, P.R. (2003). Child and family guidance: a phoenix from the ashes? A personal account. Educational Psychology in Practice, 19(4), 317-324.

Josselson, R. (1995). Imagining the real - empathy narrative and the dialogic self. In R. Josselson \& A. Lieblich (Eds.), The narrative study of lives - interpreting experience. London: Sage.

Kaplan, L. (1971). Education and mental health. New York: Harper and Row.

Katz, D., \& Kahn, R.L. (1969). Common characteristics of open systems. In F.E. Emery (Ed.), Systems Thinking. Harmondsworth: Penguin Books, Allen Lane.

Kazmierska, K. (2004). Ethical aspects of biological interviewing and analysis. In P. Chamberlayne, et al. (Eds.), Biographical methods and professional practice - an international perspective. Bristol: The Policy Press.

Kelly, B. (2008). Frameworks for practice in educational psychology: coherent perspectives for a developing profession. In B. Kelly, L. Woolfson \& J. Boyle (Eds.), Frameworks for practice in educational psychology. London: Jessica Kingsley Publishers. 
Kennedy, E.K., Cameron, R.J., \& Monsen, J. (2009). Effective consultation in educational and child psychology practice professional training for both competence and capability. School Psychology International, 30(6), 603-625.

Kennedy, H., Landor, M., \& Todd, L. (2011). Video Interaction Guidance: a relationship based intervention to promote attunement, empathy and well-being. London: Jessica Kingsley Publishers.

King, E., \& Kellock, I. (2002). Creating a solution focused counselling team, Educational Psychology in Practice, 18(2), 103-111.

Kvale, S. (1996). Interviews. London: Sage.

Landry, S.H., Smith, K.E., Millar-Loncar, C.L., \& Swank, P.R. (1997). Predicting cognitive language and social growth curves from early maternal behaviours in children at varying degrees of biological risk. Developmental Psychology, 33(6), 1040-1053.

Livesey, C., \& Lawson, T. (2010). The application of sociological research methods in education. London: AQA.

Lombard, T. (1979). Family-oriented emphasis for school psychologists: a needed orientation for training and practice. Professional Psychology, 10(5), 687-696.

MacKay, T. (2006). The educational psychologist as community psychologist: holistic child psychology across home, school and community. Educational and Child Psychology: Community Psychology: Theoretical and Practical Implications for Educational Psychologists, 23(1), 7-15.

Maturana, H., \& Varela, F. (1980). Autopoiesis and cognitions: the realisation of the living. Dordrecht: D. Reidel.

McKeown, K., Pratschke, J., \& Haase, T. (2003). Family well-being what makes a difference? Shannon: Report to Ceifin Centre.

McQueen, C., \& Hobbs, C. (2014). Working with parents: using narrative therapy to work towards genuine partnership. Educational and Child Psychology: Working with Families Collaboration and Intervention, 31(4), 9-17.

Miles, M.B., \& Huberman, A.M. (1994). Qualitative data analysis: an expanded sourcebook (2nd ed.). London and Thousand Oaks, California: Sage.

Miller, A. (1980). Systems theory applied to the work of an educational psychologist. AEP Journal, 5(3), 11-16.

Minuchin, S. (1974). Families and family therapy. London: Tavistock Press.

Moran, P., Ghate, D., \& ver der Merwe, A. (2004). What works in parenting support? $A$ review of international evidence. London: Department for Education and Skills. 
Morgan, A. (2000). What is narrative therapy? An easy to read introduction. Adelaide: Dulwich Centre Publications.

Morse J.M. (1999). Qualitative generalizability. Qualitative Health Research, 9(1), 5-6.

Murray, L. (1992). The impact of postnatal depression on infant development. Journal of Child Psychology and Psychiatry, 33, 543-561.

Murray, A.D., \& Hornbaker, A.V. (1997). Maternal directive and facilitative interaction styles: associations with language and cognitive development of low-risk and high risk toddlers. Developmental Psychology, 20(1), 166-179.

Murray, L., Halligan, S., \& Cooper, P. (2010). Effects of postnatal depression on mother-infant interactions, and child development. In J.C. Bremner and T.D. Wachs (Eds.), The Wiley-Blackwell handbook of infant development volume II: applied and policy issues (2nd ed.), (pp.192-220). Oxford: John Wiley.

Murray, L., Arteche, A., Fearon, P., Halligan, S., Goodyer, I., \& Cooper, P. (2011). Maternal postnatal depression and the development of depression in offspring up to 16 years of age. Journal of the American Academy of Child and Adolescent Psychiatry, 50(5), 460-470.

National Institute for Clinical Excellence (NICE) (2013). Antisocial behaviour and conduct disorders in children and young people: Recognition, intervention and management.

Newland, L. (2014). Supportive family contexts: promoting child well-being and resilience. Early Child Development and Care, 184(9-10), 1336-1346.

Newland, L.A., Chen, H.H., Coyl-Shepherd, D.D., Liang, Y., Carr, E.R., Dykstra, E., \& Gapp, S.C. (2013). Parent and child perspectives on mothering and fathering: the influence of eco cultural niches. Early Child Development and Care, 183(3-4), 534552.

Nightingale, D.J., \& Cromby, J. (1999). Social constructionist psychology: a critical analysis of theory and practice. Buckingham: Open University Press.

Nolan, A., \& Moreland, N. (2014). The process of psychological consultation. Educational Psychology in Practice, 30(1), 63-77.

Oakes, E. (2010). What drives us to give of our best? - An appreciative inquiry into how educational psychologists support early years children and their families. (Doctoral thesis). University of Manchester, UK.

Osborne, E. (1994). Some Implications of the theoretical framework: an educational psychologist perspective. In E. Dowling \& E. Osborne (Eds.), The family and the school: a joint systems approach to problems with children. London: Routledge. 
Patton, M.Q. (1990). Qualitative evaluation and research methods. London: Sage.

Pawson, R. (1991). Approaches to teaching social research methods. In J. Gubbay (Ed.), Teaching methods in social research: report of a conference at City University. Norwich: University of East Anglia.

Peake, A. (1999). Psychology services for children and families. Keynote presentation to the annual conference of the DECP, Bournemouth 1999. Unpublished.

Pellegrini, D.W. (2009). Applied systemic theory and educational psychology: can the twain ever meet? Educational Psychology in Practice, 25(3), 271-286.

Pfeiffer, S., \& Tittler, B. (1983). Utilising the multidisciplinary team to facilitate a school-family systems orientation. School Psychology Review, 12, 168-173.

Plas, J. (1986). Systems psychology in the schools. New York: Pergamon Press.

Plato, \& Jowett, B. (2000). The Republic. New York: Dover Publications.

Plowden Report (1967). Children and their primary schools. Central Advisory Council for Education, London: HMSO.

Pomerantz, E.M., Moorman, E.A., \& Litwack, S.D. (2007). The how, whom and why of parents' involvement in children's academic lives: more is not always better. Review of Educational Research, 77(3), 373-410.

Prilleltensky, I., \& Nelson, G. (2000). Promoting child and family wellness: priorities for psychological and social intervention. Journal of Community and Applied Social Psychology, 10(2), 85-105.

Puckering, C., Connolly, B., Werner, C., Toms-Whittle, L., Thompson, L., Lennox, J., \& Minnis, H. (2011). Rebuilding relationships: a pilot study of the effectiveness of the Mellow parenting programme for children with Reactive Attachment Disorder. Clinical Child Psychology and Psychiatry, 16(1), 73-87.

Pugh, G., De'Ath, E., \& Smith, C. (1994). Confident parents, confident children. Policy and practice in parent education and support. London: National Children's Bureau.

Rackett, P., \& Macdonald, B. (2014). 'Fun with Mum': using video interaction guidance to enhance early relationships and diminish maternal postnatal depression. Educational and Child Psychology, Working with Families: Collaboration and Intervention, 31(4), 82-92.

Ratcliffe, D. (1995). Qualitative evaluation and research methods. Newbury Park, CA: Sage.

Redpath, R., \& Harker, M.E. (1999). Becoming solution focused in practice. Educational Psychology in Practice, 15(2), 116-121. 
Reicher, S. (2000). Against methodolatory: some comments on Elliot, Fischer and Rennie. British Journal of Clinical Psychology, 39(1), 1-6.

Rhodes, J. (1993). The use of solution focused brief therapy in schools. London: BT Press.

Robinson, M., \& Dunsmuir, S. (2010). Multi-professional assessment and intervention of children with special educational needs in their early years: the contribution of educational psychology. Educational and Child Psychology, 27(4), 1021.

Robson, C. (2011). Real world research: a resource for users of social research methods in applied settings (3rd ed.). Chichester: John Wiley \& Sons Ltd.

Rubin, H.J., \& Rubin, I.S. (2005). Qualitative interviewing: the art of hearing data (2nd ed.). London: Sage.

Rutter, M., Maughan, B., Mortimore, P., \& Ouston, J. (1979). Fifteen thousand hours: secondary schools and their effects on children. London: Open Books.

Sanders, M.R., Mazzucchelli, T.G., \& Studman, L.J. (2003). Practitioner's manual for standard stepping stones Triple P. Brisbane, Australia: Triple P International.

Sawyer, D., Gale, J., \& Lambert, D. (2006). Rural frontier mental and behavioural health care: barriers, effective policy strategies, best practice. National Association for Rural Mental Health.

Scott, D., \& Usher, R. (1999). Researching education. London: Cassell.

Schwandt, T.A. (1994). Constructivist, interpretivist approaches to human inquiry. In N.K. Denzin \& Y.S. Lincoln (Eds.), Handbook of qualitative research (pp. 118-137). Thousand Oaks, California: Sage Publications.

Seale, C. (1999). The quality of qualitative research. London: Sage Publications.

Selvini-Palazzoli, M., Boscolo, L. Cecchin, G., \& Prata, G. (1980). Hypothesizingcircularity-neutrality: three guidelines for the conductor of the session. Family Process, 19(1), 3-12.

Shannon, D., \& Posada, S. (2007). The educational psychologist in the early years: current practice and future directions. Educational Psychology in Practice, 23(3), 257-272.

Shapiro, E.S., \& Cole, C.L. (1994). Behaviour change in the classroom: selfmanagement interventions. New York: Guildford Press.

Singh, K., Bickley, P.G., Keith, P.B., Trivette, P., \& Anderson, E. (1995). The effects of four components of parental involvement on eighth-grade student achievement: structural analysis of nels-88 data. School Psychology Review, 24, 299-317. 
Smaling, A. (2003). Inductive, analogical, and communicative generalization. International Journal of Qualitative Method, 2(1), 52-67.

Smith, J. (2004). Reflecting on the development of interpretative phenomenological analysis and its contribution to qualitative research in psychology. Qualitative Research in Psychology, 1, 39-54.

Smith, P.K., Cowie, H., \& Blades, M. (2004). Understanding children's development. Oxford: Blackwell.

Smith, J.A., Flowers, P., \& Larkin, M. (2009). Interpretative phenomenological analysis: theory, method and research. London: Sage.

Sparkes, A. (2001). Myth 94: qualitative health researchers will agree about validity. Qualitative Health Research, 11, 538-552.

Steinberg, L., Lamborn, S.D., Dornbusch, S.M., \& Darling, N. (1992). Impact of parenting practices on adolescent achievement: authoritative parenting, school involvement and encouragement to succeed. Child Development, 63, 1266-1281.

Stevenson-Hinde, J. (1990). Attachment within family systems: an overview. Infant Mental Health Journal, 11, 218-227.

Stobie, I., Boyle, J., \& Woolfson, L. (2005). Solution focused approaches in the practice of UK educational psychologist: a study of the nature of their application and evidence of their effectiveness. School Psychology International, 26(1), 5-28.

Stoker, R. (1987). Systems intervention in schools - the ripple effect. Educational Psychology in Practice, 3(1), 44-50.

Stoker, R. (1992). Working at the level of the institution and the organisation. Educational Psychology in Practice, 8(1), 15-24.

Stratford, R. (1990). Creating a positive school ethos. Educational Psychology in Practice, 5(4), 183-191.

Stringer, P., Powell, J., \& Burton, S. (2006). Developing a community psychology orientation in an educational psychology service. Educational and Child Psychology, Community Psychology: Theoretical and Practical Implications for Educational Psychologists, 23(1), 59-67.

Sung, J.H., \& Hsu, H.C. (2009). Korean mother's attention regulation and referential speech: associations with language and play in 1-year olds. International Journal of Behavioural Development, 33(5), 430-439.

Taylor, D. (1982). Family consultation in a school setting. Journal of Adolescence, 5, 3367-3377. 
Taylor, H.B., Anthony, J.I. Aghara, R., Smith, K.F., \& Landry, S.H. (2008). The interaction of early maternal responsiveness and children's cognitive abilities on later decoding and reading comprehension skills. Early Education and Development, 19(1), 188-207.

The British Psychological Society (2013). Ethical trading guidelines for practice for educational psychologists. Division of Educational and Child Psychology.

The British Psychological Society, Professional Practice Guidelines, The Division of Educational and Child Psychology. Retrieved from:

http://www.bps.org.uk/sites/default/files/documents/professional practice guidelines - division of educational and child psychology.pdf

The British Psychological Society, Scottish Division of Educational Psychology, Role of the Educational Psychologist. Retrieved from:

http://www.bps.org.uk/networks-and-communities/member-microsite/scottish-

division-educational-psychology/role-educational-psychologist

Thomas, G. (1987). Quality control in educational psychology. Educational Psychology in Practice, 3(1), 13-16.

Thorne, H., \& Ivens, J. (1999). Brief interventions with students with emotional and behavioural difficulties. Educational Psychology in Practice, 15(2), 122-125.

Tierney, W.G. (2003). Undaunted courage - life history and the postmodern challenge. In N.K. Denzin \& Y.S. Lincoln (Eds.), Strategies of qualitative inquiry. London: Sage.

Tindall, C. (1994). Issues of evaluation. In P. Banister, E. Burman, I. Parker, M. Taylor \& C. Tindall, C. (Eds.) Qualitative methods in psychology. Buckingham: Open University Press.

Todd, L. (2007). Partnerships for inclusive education: a critical approach to collaborative working. London: Routledge.

Tomm, K. (1985). Circular interviewing: a multifaceted clinical tool. In D. Campbell \& R. Draper (Eds.), Applications of systemic family therapy (pp. 33-45). London: Grune \& Stratton.

Tomm, K. (1987a). Interventive interviewing: part I. Strategising as a fourth guideline for the therapist. Family Process, 26(1), 3-13.

Tomm, K. (1987b). Interventive interviewing: part II. Reflexive questioning as a means to enable self-healing. Family Process, 26(2), 167-183.

Tomm, K. (1988). Interventive interviewing: part III. Intending to ask linear, circular, strategic or reflexive questions? Family Process, 27(1), 1-15. 
Topping, K. (1979). The psychology of organisations - polemics and sources. AEP Journal, 5(1), 2-4.

Trotter, H., \& Rafferty, H. (2014). A follow-up to the incredible years parenting programme: the reflections of mothers one to two years later. Educational and Child Psychology, Working with Families: Collaboration and Intervention, 31(4), 40-57.

Tucker, B.Z., \& Dyson, E. (1976). The family and the school: utilizing human resources to promote learning. Family Process, 15, 125-141.

Turner, S., Randall, L., \& Mohammed, A. (2010). Doing an effective job? Measuring the impact of casework. Educational Psychology in Practice, 26(4), 313-329.

Ugazio, V. (1985). Hypothesis making: the Milan approach revisited. In D. Campbell \& R. Draper (Eds.), Applications of systemic family therapy (pp. 23-32). London: Grune \& Stratton.

Wagner, P. (2000). Consultation: developing a comprehensive approach to service delivery. Educational Psychology in Practice, 16(1), 9-18.

Walsh, F. (2003). Family resilience: a framework for clinical practice. Family Process, 43(1), 1-18.

Wang, J., \& Wildman, L. (1995). An examination of effects of family commitment in education on student achievement in seventh grade science. Journal of Research in Science Teaching, 32, 833-837.

Watzlawick, P. (1978). The language of change. New York: Basic Books.

Watzlawick, P., Weakland, J., \& Fisch, R. (1974). Change: principles of problem formulation and problem resolution. New York: Norton.

Weakland, J. (1982). Family therapy with individuals. Journal of Strategic and Systemic Therapies, 2(4).

Webster-Stratton, C. (2006). The incredible years: a trouble shooting guide for parents of children aged 2-8 years. Incredible Years.

White, M., \& Epson, D. (1990). Narrative means to therapeutic ends. New York: Norton.

Williams, B., Williams, J., \& Ullman, A. (2002). Parental involvement in education: research report 332. London: Department for Education and Skills.

Willig, C. (2001). Introducing qualitative research in psychology: adventures in theory and method. Buckingham: Open University Press.

Willig, C. (2008). Introducing qualitative research in psychology (2nd ed.). Maidenhead: McGraw Hill/Open University Press. 
Wolfendale, S. (1983). Parental participation in children's development and education. London: Gordon and Breach.

Wolfendale, S., \& Topping, K. (Eds.) (1996). Family involvement in literacy: effective partnerships in Education. London: Cassell.

Wolfendale, S., \& Cook, G. (1997). Evaluation of special educational needs parent partnership schemes. University of East London (Research Report RR 34), DfEE.

Wolfendale, S. (1999). Parents as partners in research and evaluation: methodological and ethical issues and solutions. British Journal of Special Education, 26(3), 164-169.

Wolfendale, S., \& Bastiani, J. (Eds.) (2000). The contribution of parents to school effectiveness. London: David Fulton Publishers.

Wood, J. (2015). Best practice in the psychological assessment of early years children with differences. Educational Psychology Research and Practice, 1(1), 2329.

Woods, K., \& Farrell, P. (2006). Approaches to psychological assessment by educational psychologists in England and Wales. School Psychology International, 27(4), 387-404.

Woolfson, L. (2008). The Woolfson et al. integrated framework: an executive framework for service-wide delivery. In B. Kelly, L. Woolfson \& J. Boyle (Eds.), Frameworks for practice in educational psychology. London: Jessica Kingsley Publishers.

Yardley, L. (2000). Dilemmas in qualitative health research. Psychology and Health, 13, 215-228.

Yardley, L. (2008). Demonstrating validity in qualitative psychology. In J.A. Smith (Ed.), Qualitative psychology: a practical guide to methods (2nd ed.), (pp. 235-251). London: Sage.

Young, S., \& Holdorf, G. (2003). Using solution focused brief therapy in individual referrals for bullying. Educational Psychology in Practice, 19(4), 271-282. 


\section{APPENDIX 1 \\ Gatekeeper Letter to Principal EPs}

Address

Date

Dear Principal Educational Psychologist,

I am a post graduate student in the School of Psychology, Cardiff University. As part of my doctoral research I am carrying out a study on educational psychologists' (EPs) experiences of working with families. I am writing to enquire whether you would be willing to allow me to approach the EPs within your service, seeking volunteers to be participants in this study.

I would require two EPs from your service to participate in individual semi-structured interviews around their experiences of family work, and perceptions of the EP role in this area. All data will be anonymous, and no names of EPs or educational psychology services will be recorded.

If you were in agreement to me seeking volunteers from your service I would provide some details of the study and what would be required of participants, for you to email to all EPs in your service, requesting that any interested volunteers contact me directly by email or phone, to discuss further and make arrangements.

Many thanks in advance for your consideration of this project. Please let me know if you require further information.

Regards,

Claire McGuiggan

Educational Psychologist

School of Psychology

Cardiff University

Tower Building

70 Park Place

Cardiff

CF10 3AT

McGuiggabCL@cardiff.ac.uk
Andrea Higgins

$\underline{\text { Research Supervisor }}$

School of Psychology

Cardiff University

Tower Building

70 Park Place

Cardiff

CF10 3AT

HigginsA2@cardiff.ac.uk 


\title{
APPENDIX 2 \\ Overview of Research Aims and Design Provided to Participants
}

\author{
Information for Participants
}

\section{PLEASE READ THE FOLLOWING INFORMATION CAREFULLY BEFORE PROCEEDING}

\section{Research Study Information}

I am an educational psychologist working for Birmingham LA and I am undertaking doctoral research in the School of Psychology at Cardiff University. As part of my doctoral research I am carrying out a study on educational psychologists' (EPs) experiences of working with families. The purpose of this research is to inform the role of EPs in work with families as part of a child's system to address presenting difficulties.

The title of the research project is:

'Using an ecological systems theory framework to explore educational psychologists' experiences of working with families: an interpretative phenomenological analysis'.

You will be asked about your own experiences, as an LA EP, of working with families and your views and opinions on the EP role in this area.

\section{Interview information}

You are invited to take part in an individual interview session with the researcher, taking approximately 90 minutes, to explore your views on educational psychologists' work with families. All EPs within your own, and several other services, have been invited to take part. No individuals have been specifically targeted to participate. Interviews will be recorded and notes taken. The findings will form the basis for a research report for the University of Cardiff which is exploring EPs' experiences of their work with families.

You have the right to decline to answer any questions, or to withdraw from completing the interview at any time.

\section{How will I be protected?}

Participants' names will not be recorded during the interview. Interviews will be allocated a number for data recording purposes. Recorded data will be transcribed for analysis within one month of recording. Transcribed data will be anonymous, and allocated a number for analysis purposes.

Data will be anonymous but may be discussed anonymously with research supervisors at the analysis stage. Findings of the research may be shared with interested parties such as the University, however, the resulting data will not be identifiable. 


\section{What will happen to my data?}

Data will be held securely by myself in the form of a recording of the interview and written notes of the interview made by myself. Recorded data will be kept in a locked cabinet at my home until it has been transcribed. During transportation from the interview location the data will be in the possession of the researcher at all times. No one else will have access to the data.

Following transcription data will be held in a locked cabinet at home.

Recorded data will be destroyed at the end of the research project.

Anonymised transcriptions may be held indefinitely by the University.

The findings will be published in a Cardiff University doctoral research publication.

\section{How will I find out about the results?}

A summary of the findings can be sought from the researcher following completion of the research paper.

Researcher: Claire McGuiggan

Cardiff University, School of Psychology, 6th Floor Tower Building, 30 Park Place, Cardiff CF10 3AT

MCGUIGGANCL@cardiff.ac.uk

For further information, queries or complaints, you can contact:

Researcher's Supervisor: Andrea Higgins (Professional Tutor)

Cardiff University, School of Psychology, 6th Floor Tower Building, 30 Park Place, Cardiff CF10 3AT

HIGGINSA2@cardiff.ac.uk

Ethics Committee at the School of Psychology, Cardiff University, Tower Building, 70 Park Place, Cardiff CF10 3AT

psychethics@cardiff.ac.uk 


\section{APPENDIX 3 \\ Indicative Interview Schedule}

\section{Indicative interview schedule for semi-structured interviews - EPs' experiences and views of family work:}

- In what ways do you as an EP work with families?

$>$ Tell me more about your role in $\mathrm{x} / \mathrm{y}$ work.

$>$ What was significant about your role in that work?

$>$ Why do you feel that is important?

$>$ In what ways do you involve families in psychological formulation?

$>$ In what ways do you involve families in intervention?

- What do you feel an EP's role is in work with families?

$>$ Why is that an EP's role/why isn't that an EP's role?

$>$ Whose role is that?

$>$ What is not an EP's role in work with families?

- What are school's expectations of EPs' work with families?

- What are parent's expectations of an EP's role with the family?

- What do you experience as barriers to your role in working with families?

- What do you experience as facilitators in your work with families?

> Tell me more about $\mathrm{x} / \mathrm{y}$ barrier/facilitator.

$>$ Is this something new or something which has always existed in your role?

$>$ What has changed?

$>$ Do you feel a move towards more traded models of EP services has changed your role in work with families?

$>$ In what ways?

$>$ Do you feel the recent legislation, Children and Families Act 2014, has changed your role in work with families? In what ways?

$>$ How has your training informed or influenced your work with families?

- What would you ideally like an EP's role to be in work with families? 


\section{APPENDIX 4}

Examples of Notes Made During Data Familiarisation 
Analysis

Codes lat reading: $14 / 1 / 17$.

(01) Themes emerging:

Early tears-pre-schod

Home enviramet key tome of eary yearts.

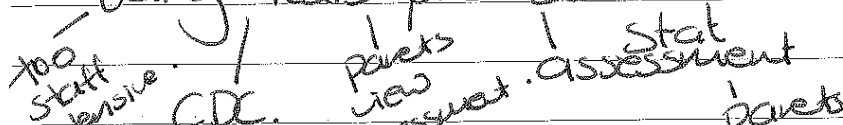

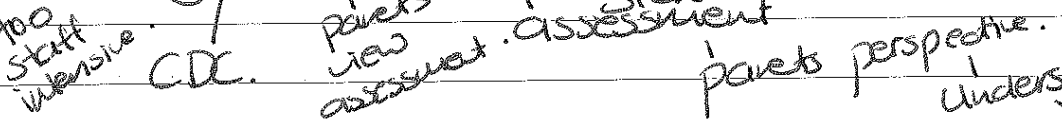
School based work - consultation lcanselvis.

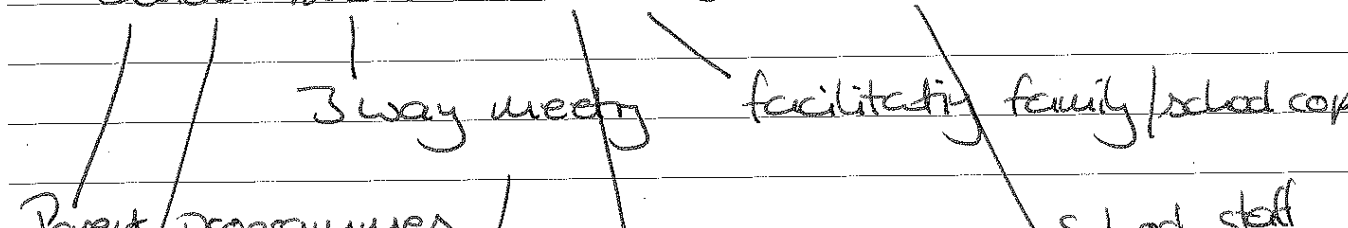

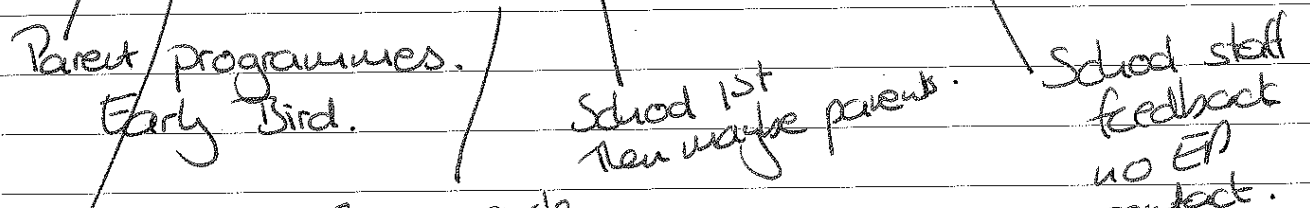

Meet parent vim pareste.

at hane 40\%\%.J supports schat decisia

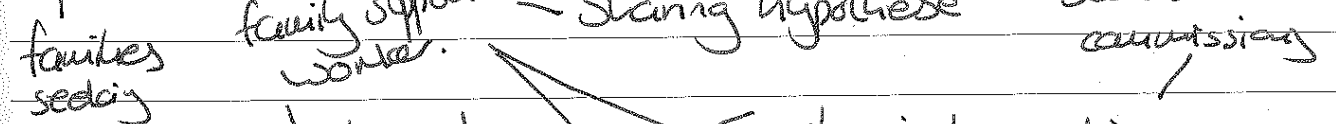
diagnosis. attadumet paret Farily intenention Equalise pene indxake het paeb /schods.

- Médiation polo

parinar Not now in the

Extenat to sclood \& family. numbuings 1 past 
(Pi) Cout.

Not to led

Undestand familes

favily whot to do.

position.

Improve quarily of life for family.

Relationskips in fanilies - driblveis behaviour.

famities movally open - Sametimes familie doit engage.

Schools waut EP to - Schoods dictatonial wor

direct families.

Eplfaming wok Sduods set up pasens

Need to manage Train's. Novents.

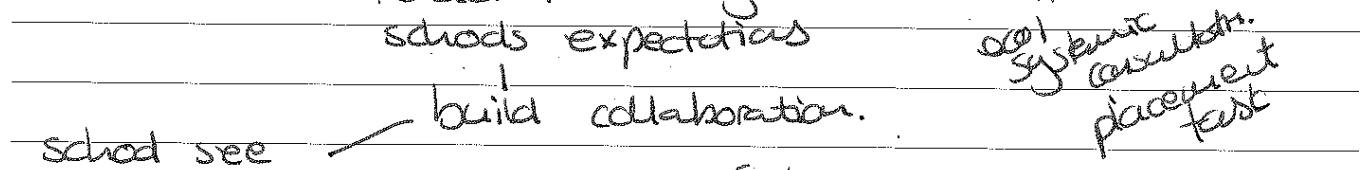

for ass tor

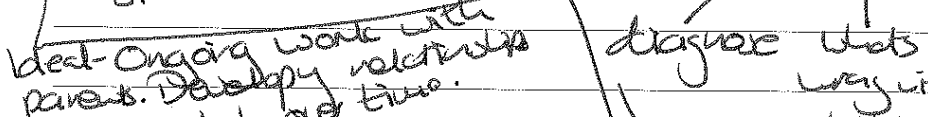

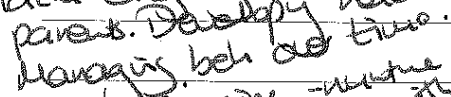

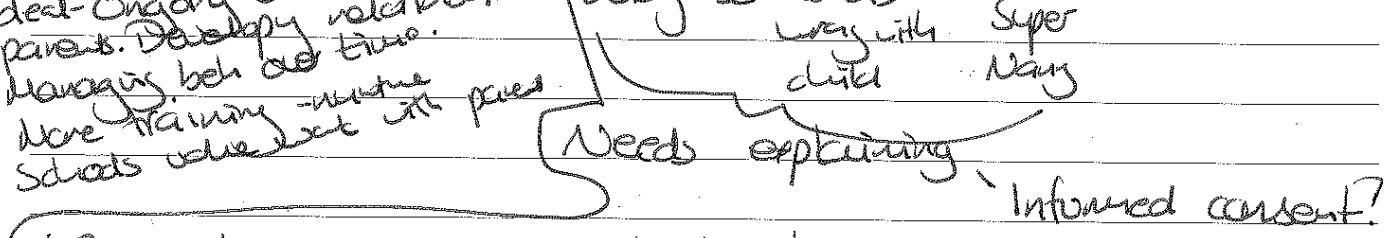

EP rde to suppout schod \& faming THS t tida.

2 years trading, previcusy time allocation. parets bor.

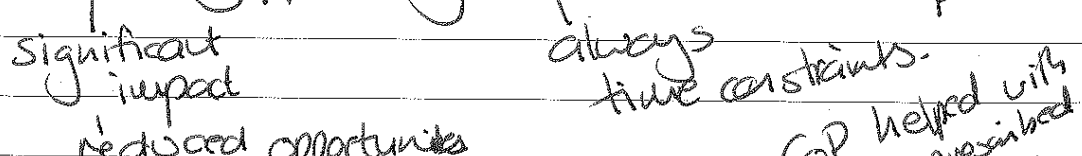

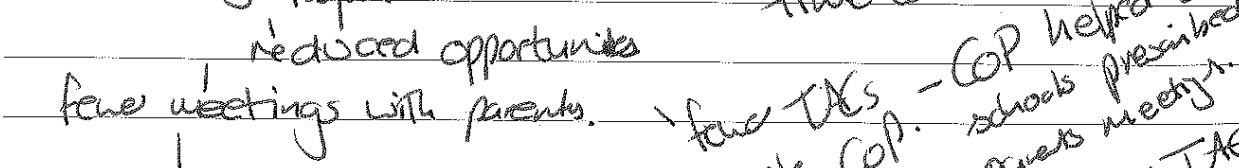
less fleribilitg. depite col pidect TA's 


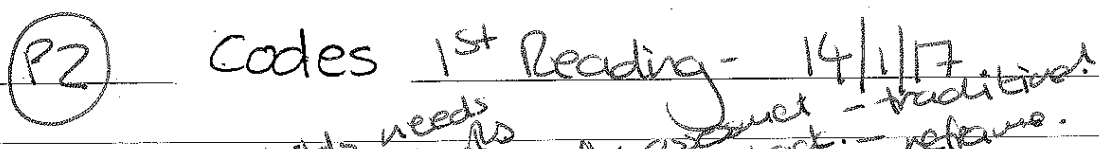

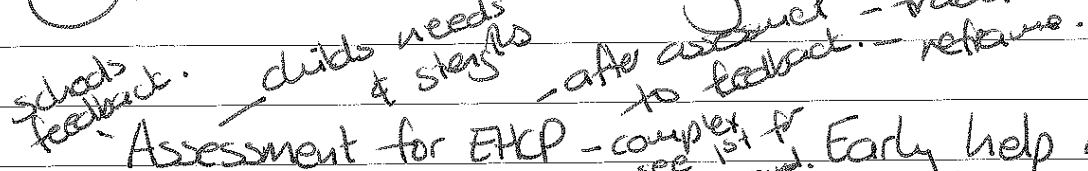
Assessment for ENCP - complext Early help meeting

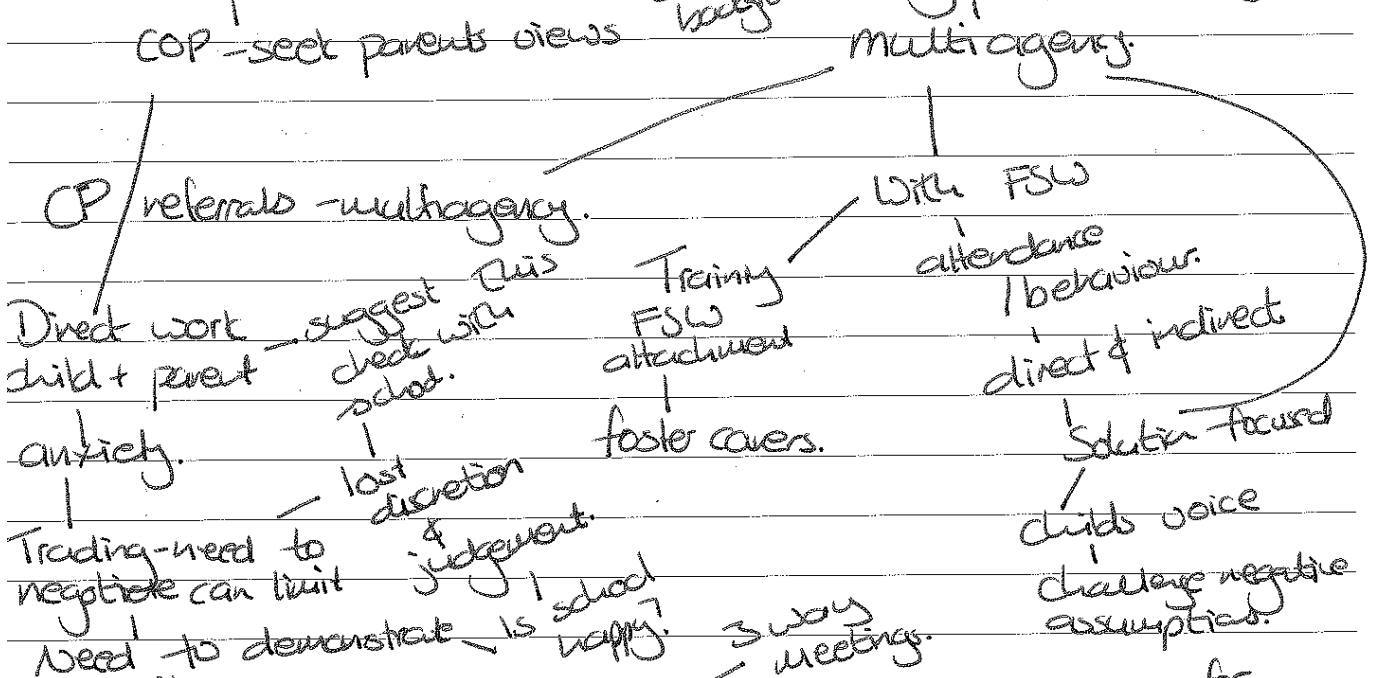

- benent Dependent as adiools lack of tive for

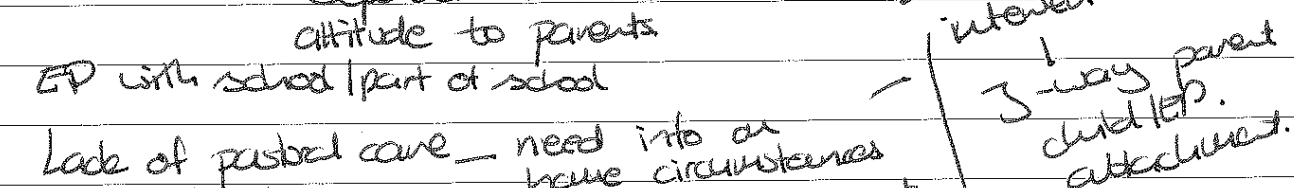

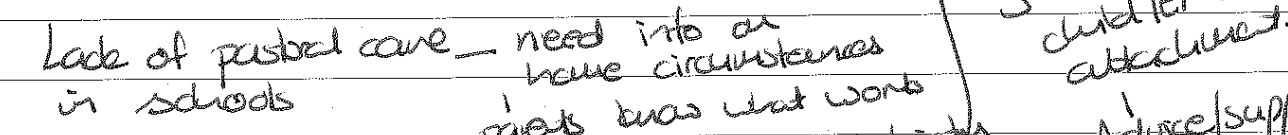

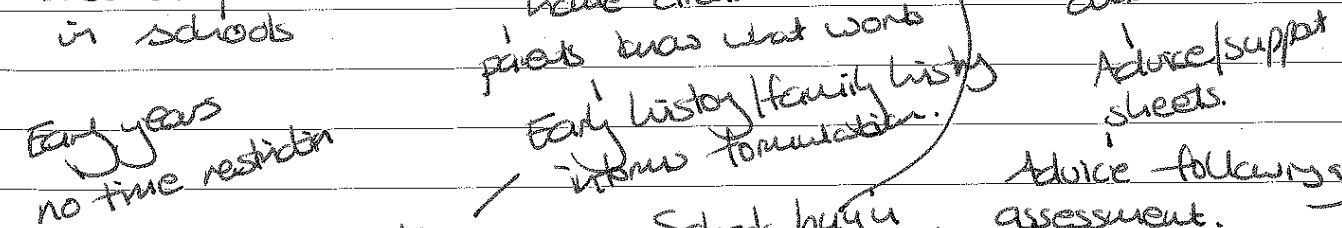

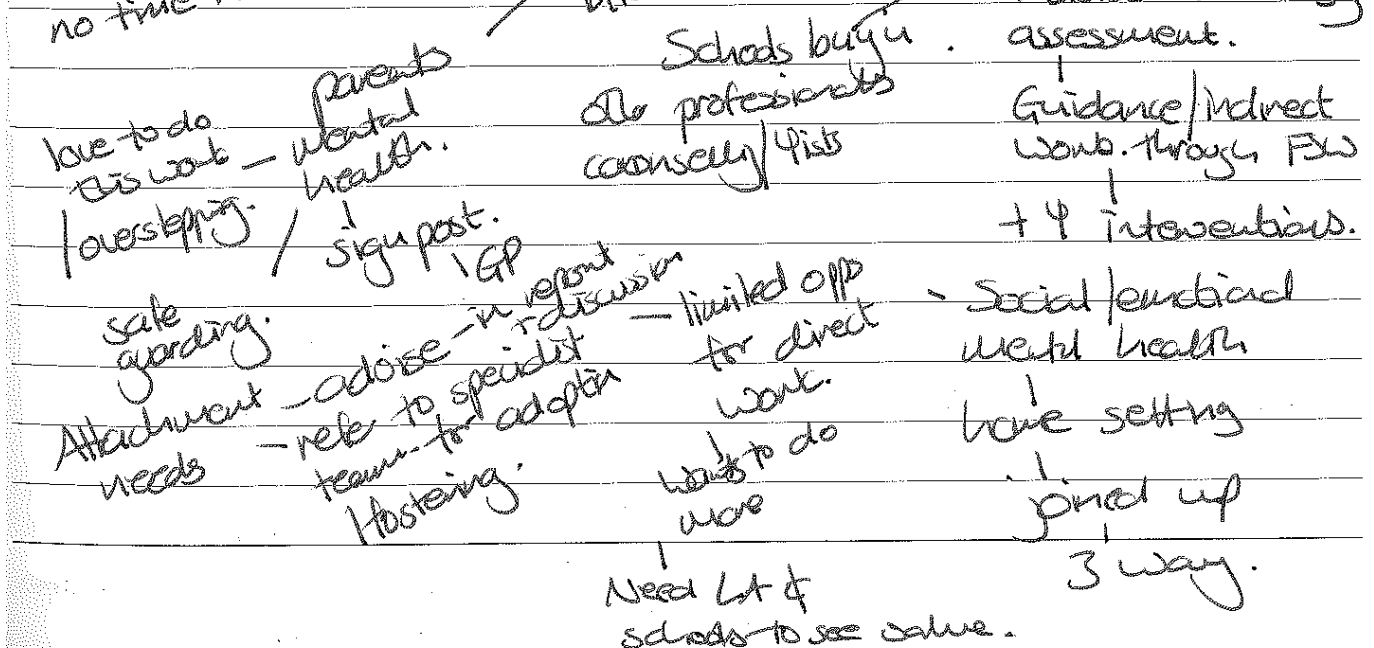




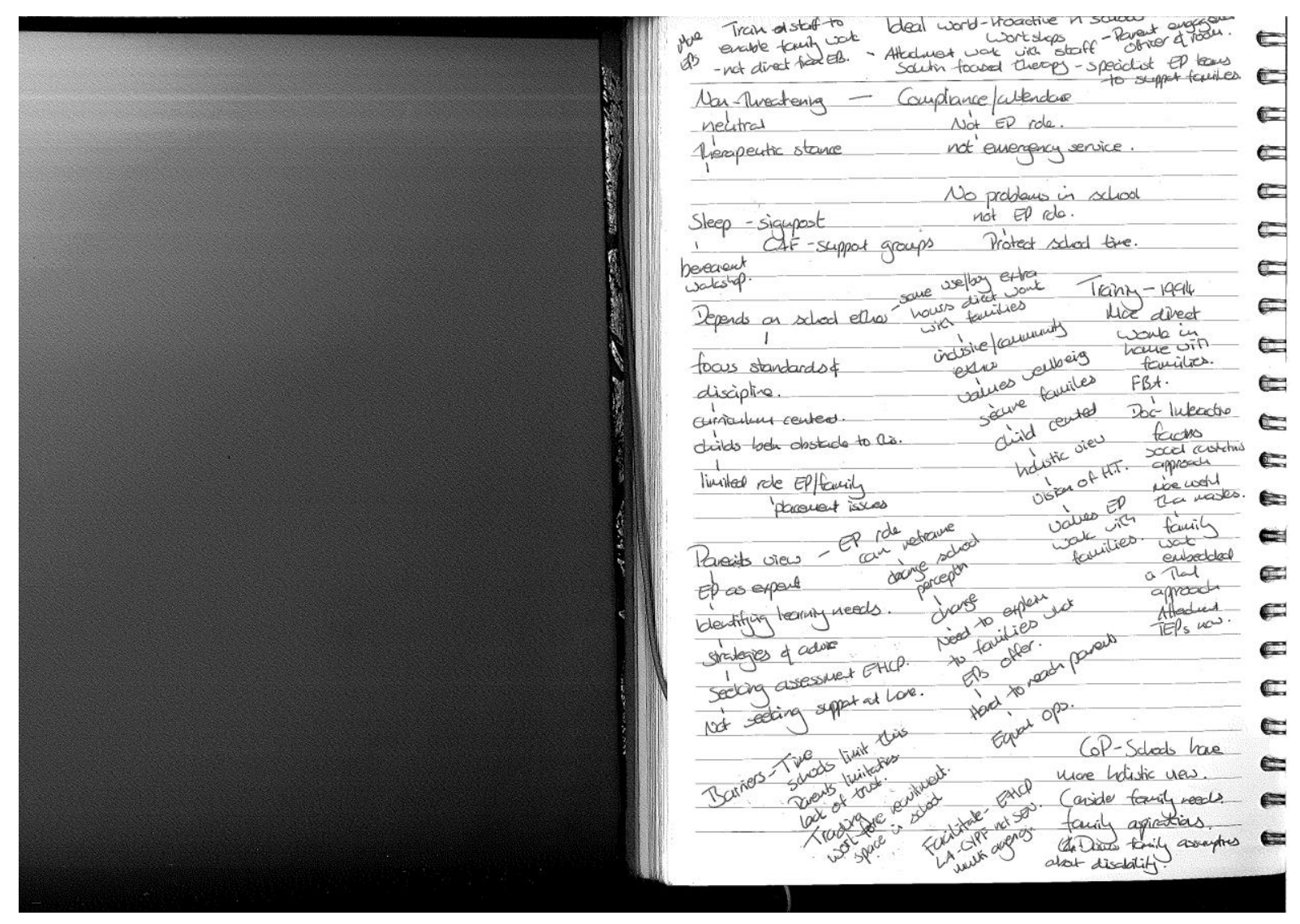




\section{APPENDIX 5}

Examples of Codes Identified on a Transcript 
1. It's the $29^{\text {th }}$ June 2016 . Ok, l'm going to make notes as well, is

2. that ok?

3. Yep.

4. Ok, so if we just start off, erm, looking at, erm, the way that

5. you work with families as an educational psychologist at the

6. moment. So if you could tell me a little bit about the different

7. ways that you feel you work with....

8. Ok, erm, one of the ways which springs to mind is working with pre-school families. I think we do a lot of kind of home-visits

10. with them, erm, a lot of time, probably with families is preschool work. Also, I tend to get involved with families through

12. my work in special schools.

13. Ok.

14. Where either the schools have suggested it or the parents

15. have asked for it. That's another area. Erm, previously l've worked with families

18. Ok.

19. I'm qualified to do the

20.

m qualified to do the

21. the main ways I work with families.

That's probably

22. Ok. Erm, so if we look at each of those areas in a little bit more

23. depth, so if you can tell me a little bit more about those. So

24. shall we start with the pre-school work? You said that's one of

25. the main ways you work with families. You mentioned home

26. visits. Can you tell me a little bit about, erm, what you'd

27. actually do on home visits, what, erm, that, what that would

28. involve in that work with families in pre-school work?

29. Erm, some of it is definitely procedural stuff, like explaining the

30. processes to them, checking the right people are involved,

31. asking their opinions. Erm, I mean I do tend to see parents as

32. knowing their child best, which is always my starting point. And

33. sometimes just exploring around the edges of things that don't

34. immediately seem to be your brief..

35. Ok.

36. ....can give quite rich information.

37. Can you give me some kind of examples of that? What do you

38. mean, what would be your brief and what would you see as

39. kind of the edges of your brief?

40. Yeah, I think you, your brief is to, to go out as I see it, assess

Stat ass procedures

Exploratory

conversations 
Parent advice

SEN provision identification

Counselling role

Acceptance

Reassurance

Non judgemental
41. the child, make some decisions, erm, support the family with

42. the process of, particularly if it's statutory assessment. Erm,

43. but then quite often I expand a little bit and talk about, you

44. know, feeding and parenting and behaviours and family
45. dynamics and look at that as well. Foster, working with foster

46. parents is another area that I quite often work with.

47. Oh, ok. So, with pre-schoolers, you said that your brief would

48. usually be around assessment and kind of decisions following

49. assessments. So, what you would do would be involving the

50. family in that assessment?

51. Yeah, erm, explaining things to them, dealing with their queries, erm, supporting them through the process

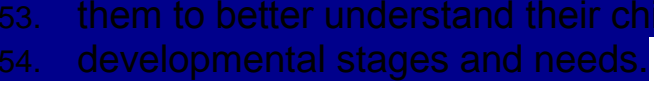

55. Ok.

56. Often providing reassurance, supporting them with school

57. placement, erm, provision that's needed. That kind of thing.

58. Ok. You mentioned that sometimes you would kind of, erm, 59. explore more around the areas we described as the 'edges of

60. your brief', around maybe some things like the family dynamic

61. and sleep and behaviour, erm, if you were, if they weren't

62. necessarily directly related to maybe school placement, that

63. was your brief, what would you see as your role there, when

64. you were exploring those areas?

65. Erm, to help them better understand and build relationships

66. with their children. Erm, often to help them accept their child as

67. they are, erm, and reassurance. And often I think it give

68. information, I'm just thinking of a child who's not at pre-school,

69. slightly off-task, who I worked with at a special school, and it

70. was around the child being quite tired during the day and bits

71. and pieces and nobody could unravel it and I met with the

72. mum and I kind of completely off kilter said 'oh, you know, how

73. does he sleep?' and it turned out that he could only go to sleep

74. with the dummy. He was nine years old and could only get to

75. sleep with a dummy. When he woke in the night he had a

76. bottle, he slept in mum's bed and at 3 o'clock every morning

77. he'd wake up and insist that she made him a Sunday dinner -

78. which she did! And, erm, so I was kind of not making

judgements about how they run their family,

82.

83. But that's how she'd always done it and that was kind of

84. normal for her and she wouldn't have thought to volunteer that

85. information unless l'd have delved a little bit deeper. But that

86. did kind of create a bigger picture other than this child's in a

87. special school and not learning very well.

88. Yeah, yeah.
Support process

Family

context/dynamics

Support stat

process

Support family

relationships

Exploratory

conversations

Formulation 


\section{Exploratory}

conversations

Reframing

Traded Model restrictive

School Values

(mainstream and special)
89. So I, yeah I think sometimes it might be perceived that I've

90. stepped outside my role with questions and conversations but

91. think when you really get to work with the families properly

92. that's how you can do your best work.

93. Yeah. So the example you've given there, so if we go onto,

94. that was a, working with parents in a special school?

95. Yes.

96. Ok.

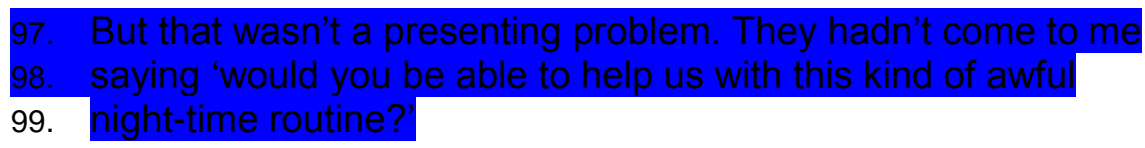

100. Ok.

101. Because they didn't perceive it to be that way, however it was

102. impacting just the same in different facets.

103. Ok. And you were saying that, they, that's kind of stepping

104. slightly outside the brief because it's not directly related to the

105. presenting difficulty?

106. Yeah.

107. Do you find in most cases where you're involved with a child 108. that schools referred to you, would you investigate those kinds 109. of family areas?

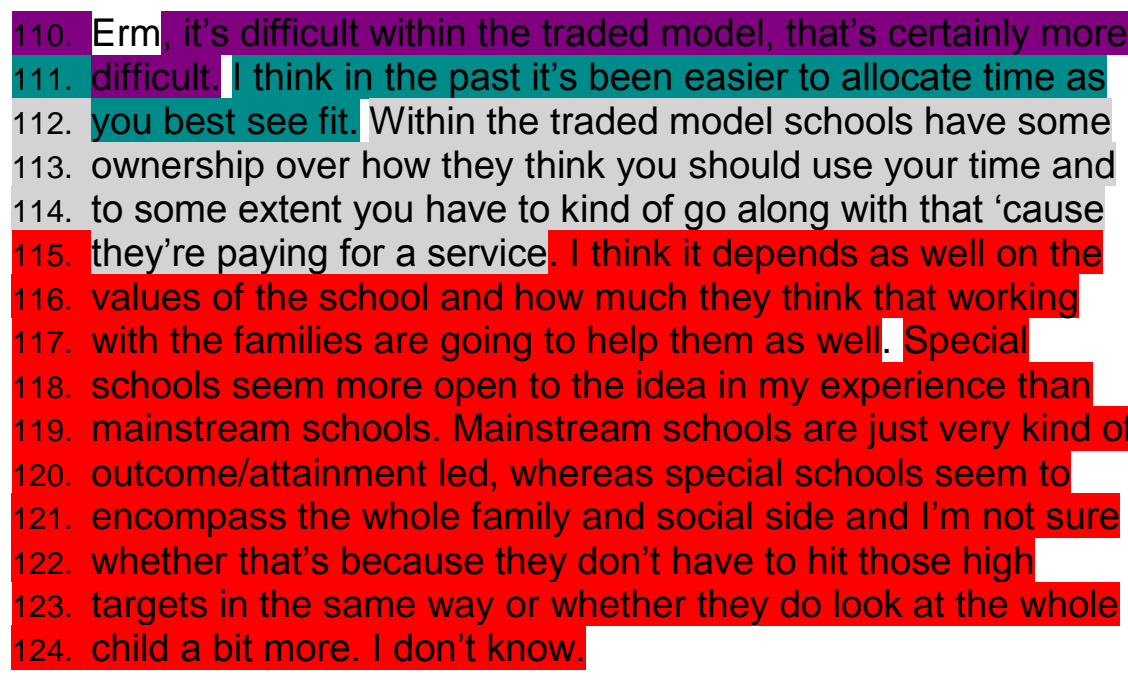

125. Ok.

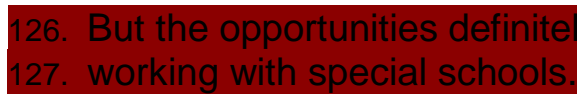

128. Ok. They're more open to... The special schools have the
Stepping over boundary

Formulation

Stepping over

Formulation

Exploratory

conversations

Autonomy

Traded model school control

Special schools 
School

values/traded

model

Parent access

referral

Advice

Positive emotion

Consultation

Refer on/sign post

Positive emotion
129. same traded model?

130. They do but they're more open to buying additional hours for it

131. to using their hours in that way for it, erm, definitely.

132. So tell me a little bit more about more generally then, special

133. schools, how you tend to, erm, work with the families in special 134. schools.

135. Sometimes it can be planned. So, erm, in $X Y Z$ the other day, for example, there'd been a family who'd kept

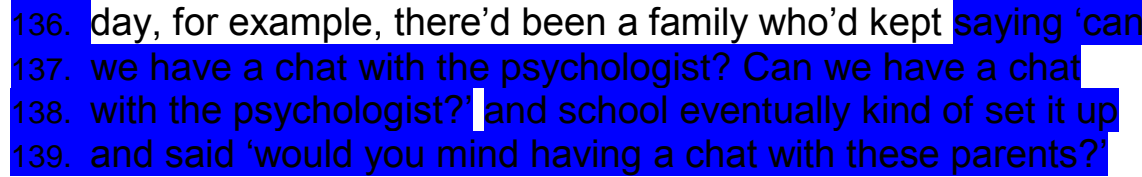

140. and I said 'no that's fine'. Didn't really know what it was about 141. and it ended up being around the, erm, child having significant 142. anxiety around moving vehicles at home. So it could be a 143. lawnmower, it could be a helicopter circling, it could be, erm, a 144. bike riding past and the little boy would absolutely flip out. Erm, 145. and that opened up a whole hour and a half probably of family

146. consultation, looking at all of their different perceptions of it. It

147. transpired that mum, mum was kind of fuelling it a little bit in

148. that she was telling him how he felt rather than asking him how

149. he felt. We looked at explaining it a bit more so he was having. you know,

151. explained to mum she could kind of see it more clearly. But

152. then, that was a great piece of work, lovely, enjoyed doing it,

153. erm, didn't involve seeing the child in school at all but things

154. were impacting on the child in school.

155. Ok.

156. Because every time they got off the school bus he was

157. panicking a lawnmower was going to be there and kind

158. of... but the difficulty with work like that is 'where next'? So I

159. said to the school 'either you can pay me to come in and work

160. with him and the family or, erm, my trainee might be able to do

161. some, or I can leave you some resources or you can refer

162. back into CAMHS. This is the area of need, this is what needs

163. to happen in my opinion'. But financially, that is the big barrier

164. of, do school, you know, pay for me to do six sessions with him which is, and as a piece of work I would love to do, I would

166. love to do it. And they might well take me up on it.

167. Do you find that generally, so you have to give the school a

168. choice there you would say?

169. I did and that's what happened at the end.

170. This is a piece of work that could be done....

171. That's it.

172. .... But you would need to fund it, or we would need to 173. signpost it somewhere else where you might or might not get
Consultation

Exploratory

conversations

Formulation

Systemic

Traded model restrictive 
174. it. Do you know what, in that situation what's chosen?

175. I'm waiting for them to get back to me.

176. Ok.

Flexibility

177. But they have in the past had a piece of similar-ish work where

178. my trainees done it because she's in her second year and

179. she's got a bit more flexibility and it comes under her gaining experience hat. But that's

Systemic

consultation

Intervention

Limitations

Frustration

Home school

linking

Other agencies
181. sometimes can't follow through on family work and for that

182. example, yes it was useful for the family to kind of sit and talk

183. to each other and for them to see that there was different

184. perceptions of the same situation which I think they thought

185. they were all singing from the same hymn sheet, whereas that

186. wasn't the case. And me sharing with them that it was the

187. gnats that were causing the problem and possible solutions for

188. that. So I think it was useful, I think they got something out of

189. it, but they do need that next step now.

190. Yeah, yeah. Is that a situation that you find, quite frequently

191. find yourself in? Where you can see there's work that needs to

192. be done with a family...

193. Yes, yes.

194. ....work you'd like to do but you can't?

195. Yes. There's another family that, erm, I'm working with, a

196. single mum. How many kids? Maybe three or four kids? Erm,

197. and she just can't get the children out of the house in the

198. morning, she's struggling. The older child is only about seven,

199. hits her, throws things - he's completely lost respect for her

200. and, erm, I am desperate to get into that home and help her to

201. sort out her relationships and parenting and boundaries. But

202. again, who funds that? Would that be the school?

203. Right.

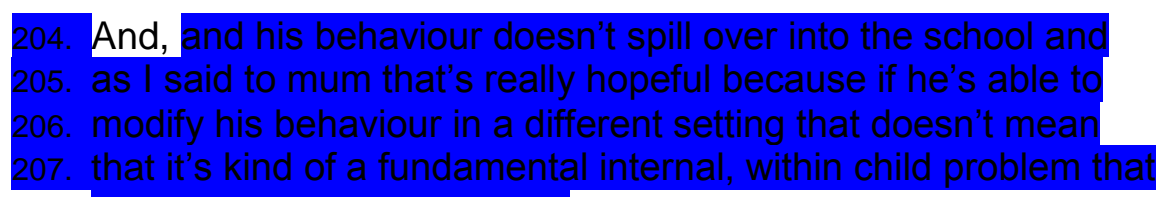

208. you can't do anything about. It's about getting him to replicate

209. that. What's different? What could you do that's the same?

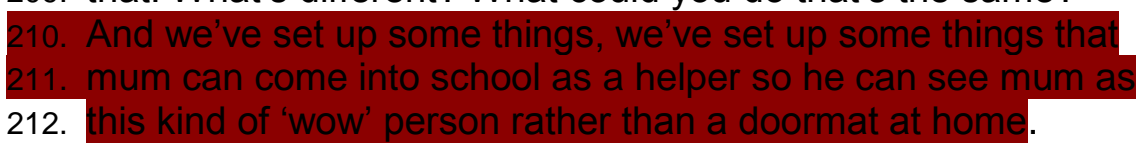

213. Ok.

214. We've set up that he has to do this kind of reward chart things

215. at home that's shared with school so he can't then be this kind

216. of baddie at home and goodie at school without any

217. communication. But I desperately want to spend six or eight
Intervention

Intervention

Limitations

Frustration

Formulation

Eco-systemic

Limitations 
218. sessions with her and we can't. And I think Think Family did

219. work with her for a while. 


\section{APPENDIX 6}

Examples of Codes Grouped to Form Themes 


\begin{tabular}{|c|c|}
\hline $\begin{array}{l}\text { Overarching } \\
\text { Theme }\end{array}$ & School Based Family Work \\
\hline Sub Theme & Intervention \\
\hline $\begin{array}{l}\text { Quotes from } \\
\text { data to } \\
\text { evidence this } \\
\text { theme }\end{array}$ & $\begin{array}{l}\text { P1 "It then becomes a review cycle that includes the parents as well." } \\
\text { P1 "My contact with parents in those cases is non-existent really because I } \\
\text { wouldn't get to meet them at all, and my focus is really on what strategies the } \\
\text { school is using to support the child and I would be expecting school to feedback } \\
\text { to parents about what our conversations have been and the kinds of support } \\
\text { they're going to offer." } \\
\text { P1 "We don't really do intervention with the family and I think that's probably for } \\
\text { a couple of reasons; partly we have a family support worker, so the early help, } \\
\text { as it was, is a team of family support workers who work with families pre child in } \\
\text { need, child protection level, so families who need support to prevent them } \\
\text { getting to that stage. And partly because of our position as a traded service } \\
\text { now." } \\
\text { P1 "Our work is negotiated with the people who fund us and in those cases } \\
\text { we've talked about that's commissioned by schools, and it's not very often in my } \\
\text { experience, that schools are asking for an extended piece of work with a family } \\
\text { when they can get it for free from a family support worker." } \\
\text { P1 "With limited resources, that's the side of our work that we might have got } \\
\text { involved with in the past because we thought it was the right thing to do, } \\
\text { perhaps we don't now." } \\
\text { P1 "You know whether it's an intervention with a family or intervention with a } \\
\text { child those pieces of work are very time intensive aren't they?" } \\
\text { P1 "I don't think they see it as outside our role, but they have a lot of priorities." } \\
\text { P1 "I find parents often ask for opinion and advice, so even if we're not working } \\
\text { with them in an ongoing way, it's not a long term intervention, then we're still in } \\
\text { a position to give parents advice." } \\
\text { P2 "We might do direct work sometimes where anxiety management is needed, } \\
\text { then I would organise appointments to teach a skills like progressive relaxation } \\
\text { techniques with the parent and child directly. " } \\
\text { and strategies and sharing that with other professionals working with the family." } \\
\text { P2 "It's a very solution focused approach I would tend to use." } \\
\text { construct intervention over time." } \\
\text { P2 "Giving guidance and following up with reports or consultation suggestions }\end{array}$ \\
\hline
\end{tabular}




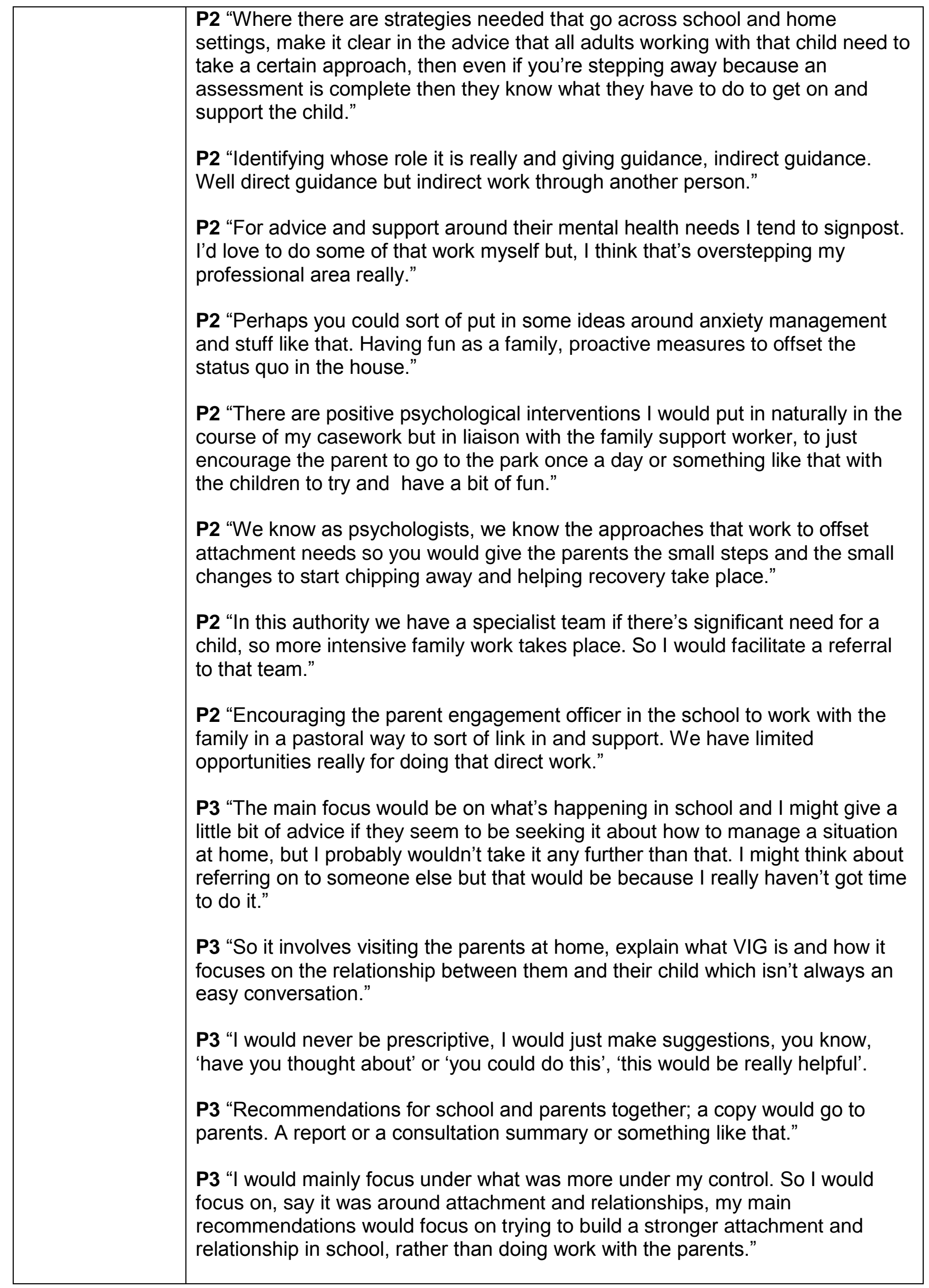




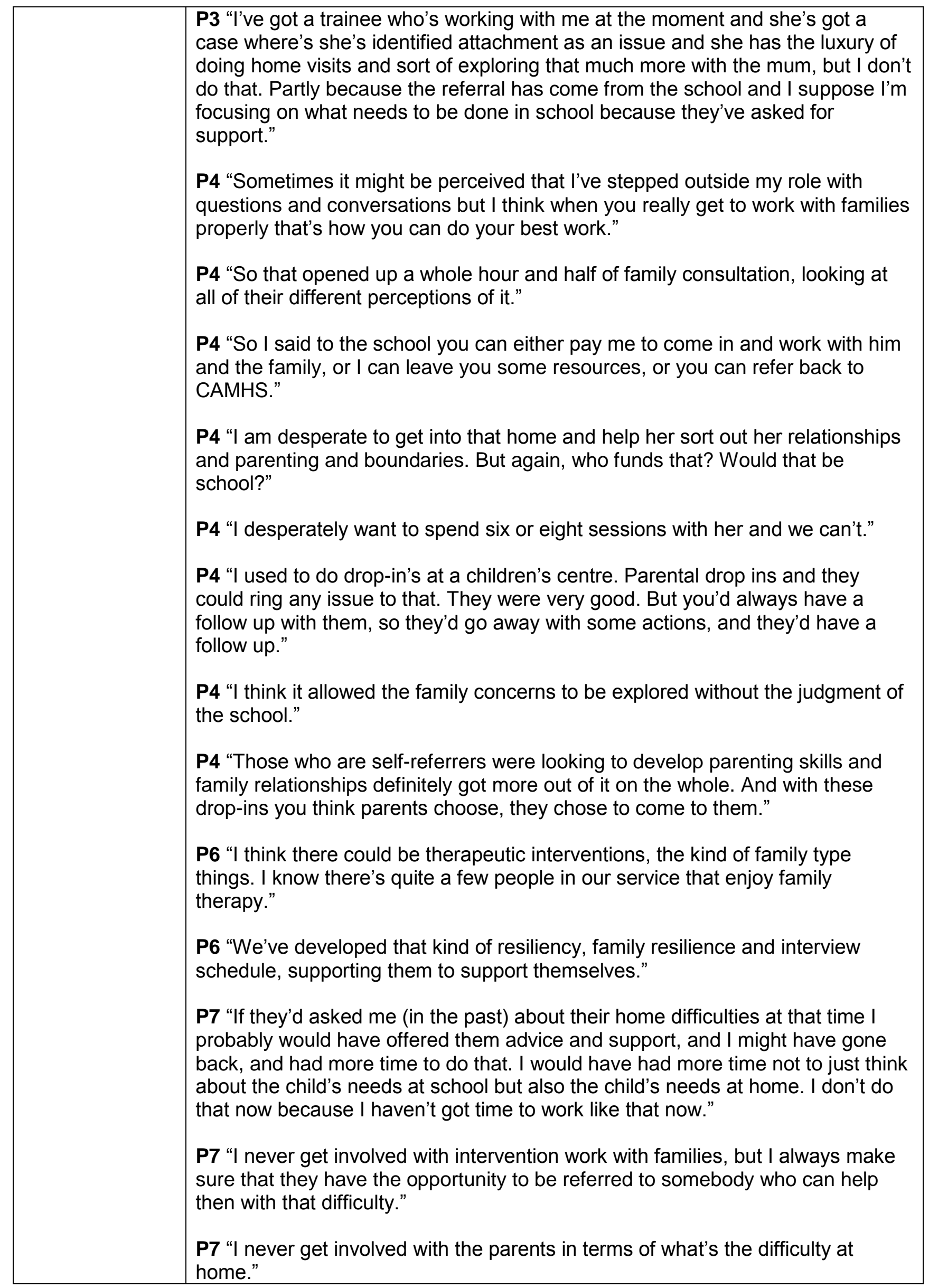




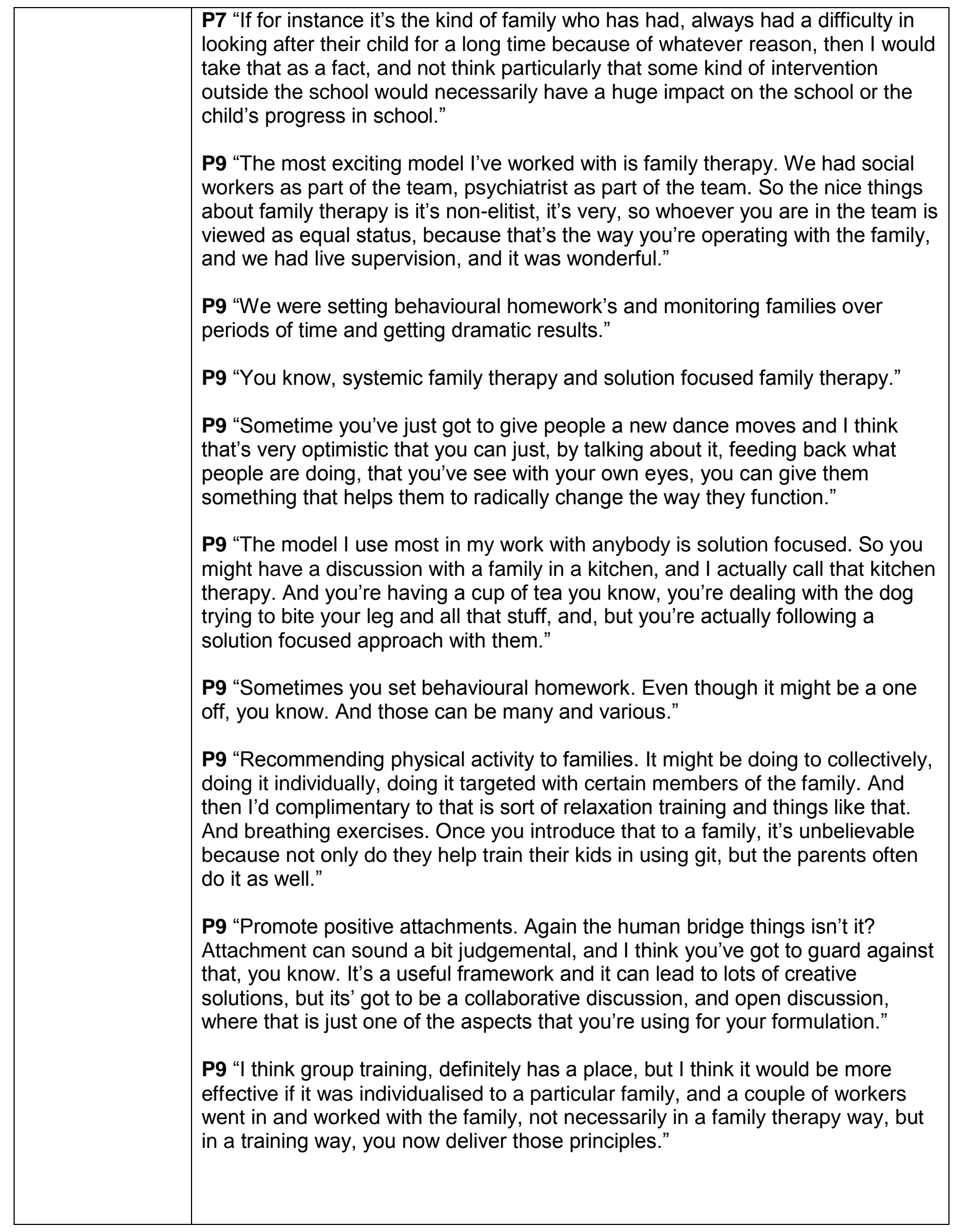




\begin{tabular}{|c|c|}
\hline $\begin{array}{l}\text { Overarching } \\
\text { Theme }\end{array}$ & School Based Family Work \\
\hline Sub Theme & Referrals \\
\hline $\begin{array}{l}\text { Quotes from } \\
\text { data to } \\
\text { evidence this } \\
\text { theme }\end{array}$ & $\begin{array}{l}\text { P1 "It depends on how the referral comes in doesn't it, and if the school are } \\
\text { saying we need some help to support this child, then the assumption } \\
\text { immediately, the assumption to start off with is that I'm going to be working with } \\
\text { the school." } \\
\text { P3 "Sometimes parents might have asked for consultation, occasionally that } \\
\text { would happen; the parents might have raised a concern and the SENCo doesn't } \\
\text { necessarily think it's a concern but we say well let's talk it through with the } \\
\text { parents." } \\
\text { P3 "I think we need to look at how we take referrals because I'm aware of sort of } \\
\text { inequality at the moment, some families get it, some families don't and it's just a } \\
\text { bit ad hoc." } \\
\text { P3 "I guess part of our pathway would be for schools to be able to identify } \\
\text { families in that way, but we'd have to come up with some sort of criteria." } \\
\text { P3 "The referral has come from the school and I suppose I'm focusing on what } \\
\text { needs to be done in school because they've asked for support." } \\
\text { P3 "Because they have an allocation of time they make the decisions about who } \\
\text { they want to refer." } \\
\text { P4 "When schools refer children it's very, and possibly that's how it is, their } \\
\text { perception of the situation, and they make quite valued judgements about } \\
\text { families and parents." } \\
\text { P4 "We have a bit of an ad hoc referral route, which can mean that we're a bit } \\
\text { all-encompassing with no breaks on it ever, and you kind of feel that you can't } \\
\text { often say no." } \\
\text { P8 "Any child gong towards EHCP you would see the parents, but I think it } \\
\text { depends on the information you receive from school, whether they say 'I think } \\
\text { it's important to meet the parents', or whether you say 'I think it's important to } \\
\text { meet the parents, or whether the school prioritise that as something they think is } \\
\text { important." }\end{array}$ \\
\hline
\end{tabular}




\begin{tabular}{|c|c|}
\hline $\begin{array}{l}\text { Overarching } \\
\text { Theme }\end{array}$ & School Based Family Work \\
\hline Sub Theme & Statutory Work \\
\hline $\begin{array}{l}\text { Quotes from } \\
\text { data to } \\
\text { evidence this } \\
\text { theme }\end{array}$ & $\begin{array}{l}\text { P1 "One of the big priorities for schools is to get a full report for them to request } \\
\text { statutory assessment." } \\
\text { P1 "That's the main part of the work we do with schools, that they use their time } \\
\text { for, and it takes a significant chunk of their days doesn't it, to do a full } \\
\text { assessment like that." } \\
\text { P1 "Schools know have to include some information from home and family in } \\
\text { order to complete that piece of work. They know it's something I would need to } \\
\text { include." } \\
\text { P1 "I don't attend as many of the team around the child meetings as I used to, } \\
\text { which is ironic really, isn't it, because the code of practise has changed to make } \\
\text { those team around the child meetings more important, and yet I feel like I have } \\
\text { less capacity to attend them." } \\
\text { P2 "Primarily work with families is through assessment work when schools } \\
\text { referee child for holistic assessment prior to requesting an Educational Health } \\
\text { Care Assessment Plan." } \\
\text { P2 "If it's purely for statutory assessment that's straight forward, I'd probably see } \\
\text { them after I've done the assessment work to feedback." } \\
\text { P7 "The reason I've changed that now is that I feel like I'm working differently } \\
\text { with my schools, I feel like I'm implementing EHC procedures." } \\
\text { P7 "The workload is huge. So } 30 \text { EHC advices last year, pro-rate means a } \\
\text { report every week or so, and a very detailed report. So I just feel like I've got to } \\
\text { keep my work in balance in all reason and actually that gets easier because I } \\
\text { see more clearly what I've got time to do." } \\
\text { P7 "It's unrealistic in the days of very complex and efficient in XYX, EHC } \\
\text { planning, that we are intimately tied up with that system, and l'm happy that my } \\
\text { expertise is there. I could've offered other things, but I don't think that's ever } \\
\text { going to happen." } \\
\text { P8 "Any child gong towards EHCP you would see the parents, but I think it } \\
\text { depends on the information you receive from school, whether they say 'I think } \\
\text { it's important to meet the parents', or whether you say 'I think it's important to } \\
\text { meet the parents, or whether the school prioritise that as something they think is } \\
\text { important." }\end{array}$ \\
\hline
\end{tabular}




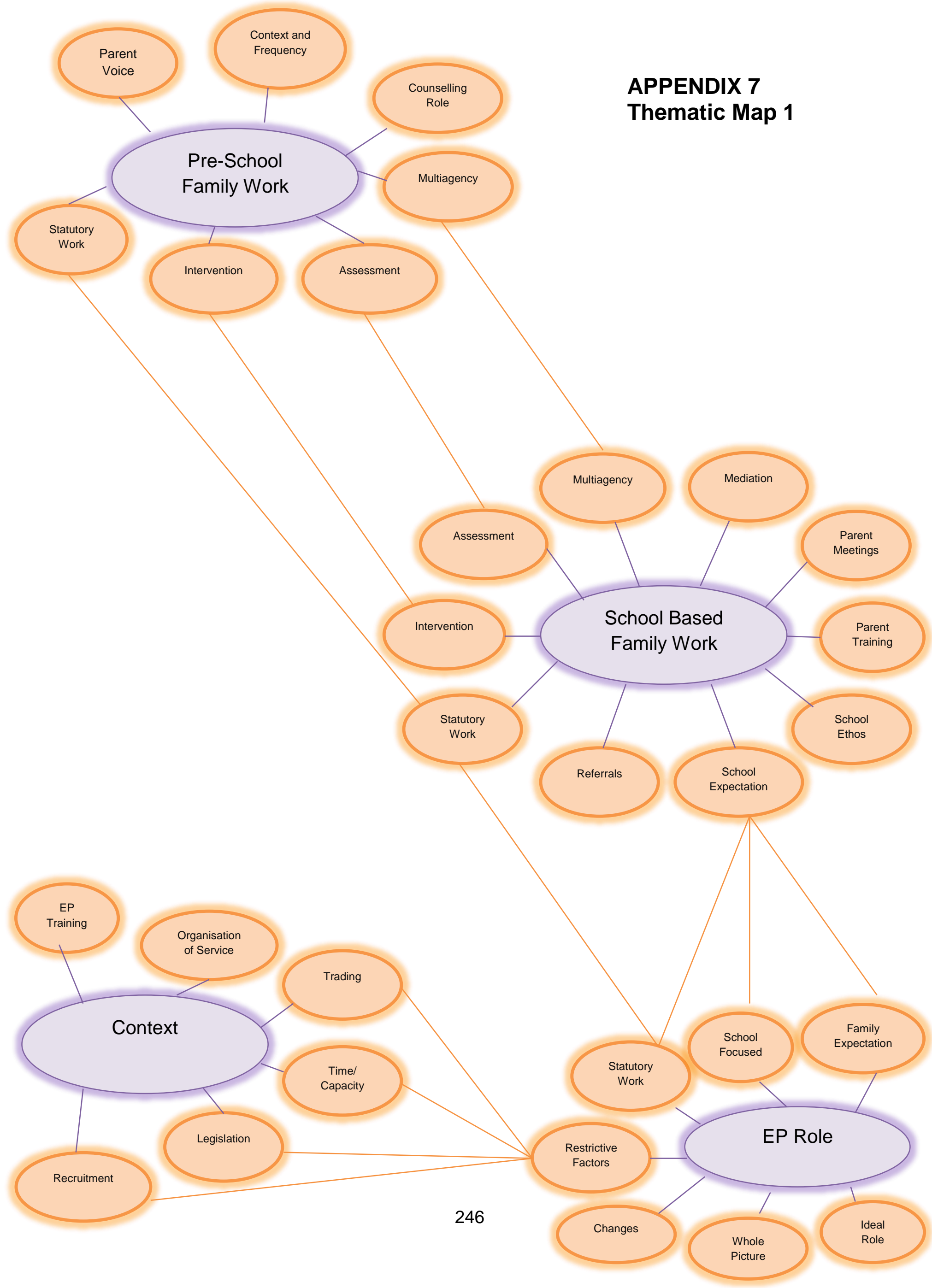


APPENDIX 8: Thematic Map 2

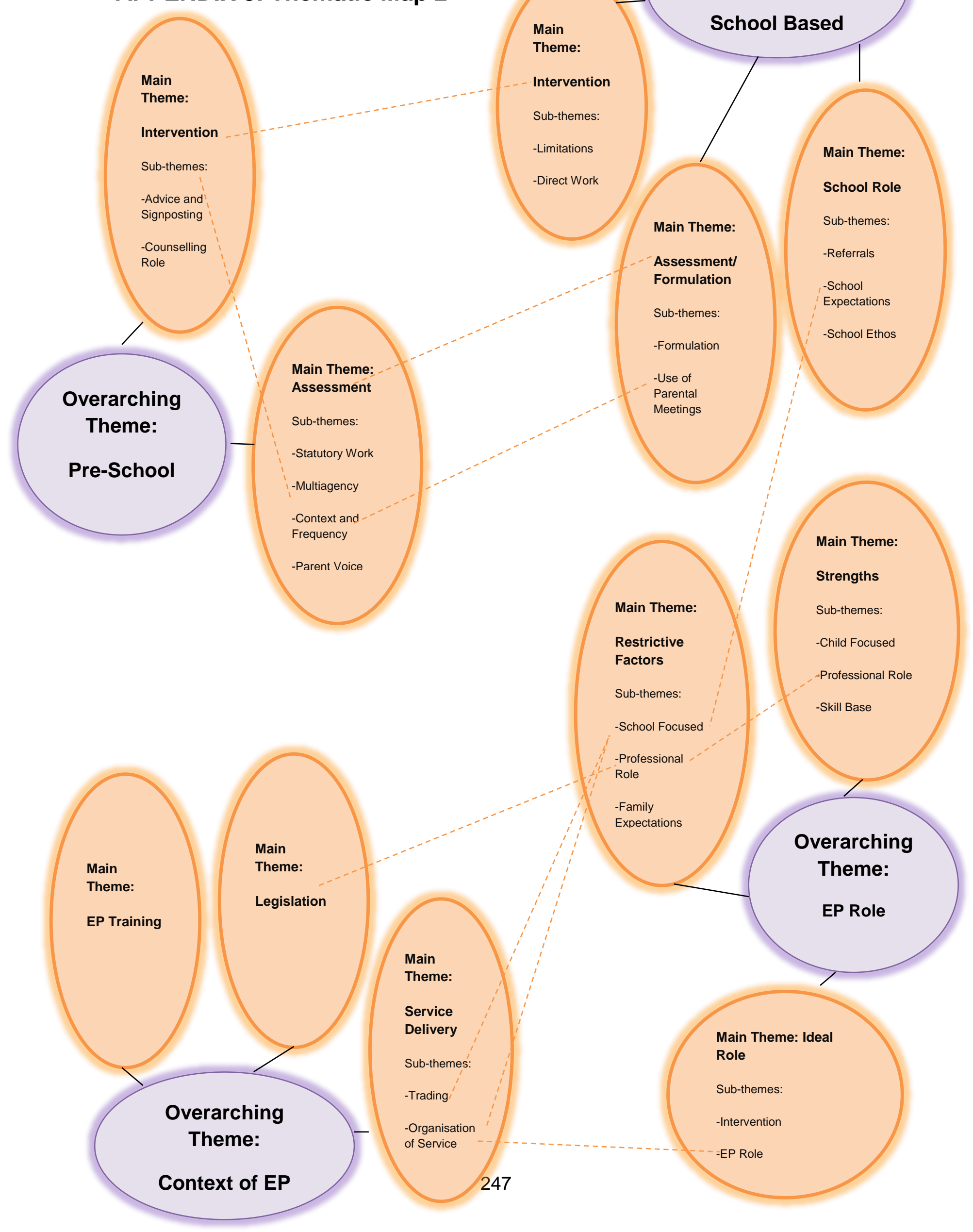




\section{APPENDIX 9}

Approved Ethics Committee Information

$\underline{\text { Research and Ethics Proposal }}$

Using an ecological systems theory framework to explore educational psychologists' experiences of working with families: an interpretative phenomenological analysis

By Claire McGuiggan 


\section{Introduction and rationale for research}

This is a proposed research project to explore educational psychologists' (EPs) experiences of working with families. It aims to explore their perceptions and feelings around their experiences and capture the meaning that participants assign to their experiences, and their thinking and opinions around those experiences.

An ecological systems theory framework, Bronfenbrenner (1986) will be used to explore the EPs' work with families at the level of the child's, families' and EPs' own system. Participants' views on the role of EPs in family work, informed through their own experiences, will be explored looking at facilitators and barriers for this role.

EPs work at multiple levels within a variety of ecological systems surrounding a child. The family system is recognised as one of most influential systems on a child's development, alongside school (Dowling and Osborne, 1985), yet there is relatively little research around EPs' role in family work and how, or whether, they bring the two systems together as a strategy to deal with problems experienced by children.

EPs often work with the school as the primary system for a child (Dowling and Osborne, 1985), and although the importance of the family system is acknowledged it is unclear how, or whether, EPs integrate these systems together within their work, and how they view their role in work with families. EPs' views and experiences of working with the school system are clear and well documented (Farrell et al., 2006), but EPs' experiences of working with family systems, equally important to a child's development and problems, still present as opaque and lacking in evidence through research.

The importance of EPs' role in working with family systems has been acknowledged widely and for some time (Wolfendale, 2005; Jones, 2006) but the way in which EPs do this and how they individually perceive their role has not been addressed.

The literature review of this proposed study will consider an overview of the nature of an ecological system perspective and how this can be used for school based consultants such as EPs, and why this may be considered an important aspect of EP work. EPs' work can be involved across systems working with systemic interventions to modify the system which is supportive of 'problem' behaviours (Fine, 1984).

The evidence for the effects of home, school and home-school relationships on the life of a child will be considered, and in light of this the call for greater parental involvement in education and the assumptions often made that there should be a family orientation in the role of educators (Anderson, 1983; Gilmore, 1974; Lombard, 1979) and the implications of this for the role of the EP.

An ecological systems approach will be considered as a framework for understanding that a child's development, or problems, exist in overlapping systems and that changes in one system can influence other systems. Whether EPs feel this frame work is useful in their work for psychological formulation, and in interventions, 
will be explored. The use of an ecological systems approach within a consultative model of EP work will be considered, and how this can take into account a broad spectrum of interactions that influence a child (Aponte, 1976; Fine and Holt, 1983).

The role of the EP will be explored, the views of the participants on the role of the EP within work with families, and how this impacts on the use of systemic and ecological problem solving methods.

A preliminary literature review in this area has indicated that relatively little research exists, specifically around the views of EPs in supporting and working with families, despite the significant literature around the importance of the home and school connections; this paper will consider the literature available and the reasons and implications for a lack of research in this area around EP work.

\section{Research questions}

Research questions will be:

1) What are EPs' experiences of their work with families?

2) What do EPs experience as barriers to this work?

3) What do they view as facilitators to this work?

4) What do EPs feel their role should be in family work?

\section{Research design and measures}

This will be a small scale study. There will be 8-10 participants: all EPs working within a Local Authority (LA), with at least three years' experience working as an EP. Five Principal EPs from LAs will be approached for permission to seek volunteers for participants from the educational psychology service. All EPs in each service will then receive an email providing initial details of the research and volunteers will be asked to make contact with me by email or phone.

Data collection will be through individual semi-structured interviews followed by a thematic analysis of each interview.

Interviews will be recorded and notes taken. Participants' names will not be recorded; they will be informed that data will be stored confidentially until recordings have been transcribed.

Questions within the semi-structured interview will aim to explore the individual EP's experiences of working with families, their constructions of their role in this as an EP, their feelings about working with family and school systems, what they see as an EP's role in family work, what they experience as the barriers and facilitators to EP's work with families. 


\section{Methods of analysis}

Thematic Analysis will be used to analyse the semi-structured interview data. The interviews will be recorded, transcribed and analysis of the verbatim data developed.

Analysis of the participants' responses will aim to interpret their experiences and views and the sense they make of them, firstly for themselves and then secondly for myself as the researcher.

The analysis will focus upon what is distinct for each participant (ideographic) but will also attempt to identify commonalities across the group of participants. Part of the analysis will also reflect my own role in the interpretative and collaborative nature of the interviews and data analysis.

From the analysis and evaluative process will emerge a set of themes, which will represent commonalities across participants' accounts but also accommodate variations in the data, and these will provide the focus for the analytic commentary for the research paper.

\section{Ethical considerations}

The principle of informed consent: Volunteers will be sought and initial information provided on the area of research, the time commitment, and the method of data collection. Identified participants will then be given further written information about the research topic and the purpose and the scope of the research. Participants will be informed of their right to withdraw from the research up until the data is transcribed and anonymised.

An informed consent form will be completed and signed by each participant detailing: their understanding of the requirements of their participation, the voluntary nature of their participation, their ability to withdraw at any point without giving a reason, their ability to ask questions and discuss concerns with the research supervisor, and their understanding of how the issues of confidentiality, anonymity and data handling will be addressed.

Confidentiality and anonymity: Participants' names will not be recorded during the interview. Interviews will be allocated a number for data recording purposes. Recorded data will be transcribed for analysis within one month. Transcribed data will be anonymous, and allocated a number for analysis purposes.

Participants will be informed that data will be anonymous but may be discussed anonymously with research supervisors at the analysis stage. Participants will be informed that the findings of the research may be shared with interested parties such as the University, or published at a later date in an academic journal, however, the resulting data will not be identifiable as theirs. 
Safe and appropriate storage and handling of data: Data will be held securely by myself in the form of a recording of the interview and written notes of the interview made by myself. Recorded data will be kept in a locked cabinet at home until it has been transcribed. During transportation from the interview location the data will be in the possession of the researcher at all times. No one else will have access to the data.

Recorded data will be transcribed within one month.

Following transcription data will be held in a locked cabinet at home.

Recorded data will be destroyed following transcription.

Anonymous transcribed data may be kept indefinitely by the University.

Dissemination of research findings: Participants will be advised they can request a copy of the summary of the findings from the researcher. They will be advised that research findings will be produced in the form of a research report for the University of Cardiff. The findings may be presented for publication to a journal such as Educational and Child Psychology.

\section{Estimated start date and duration of project}

I aim to begin collecting data in April 2016 and to submit the research report by September 2016.

\section{References}

Anderson, C. (1983). An ecological developmental model for a family orientation in school psychology. Journal of School Psychology, 21, 179-189.

Aponte, H. (1976). The family-school interview: an eco-structural approach. Family Process, 15, 303-313.

Bronfenbrenner, U. (1986). Ecology of the family as a context for human development: research perspectives. Developmental Psychology, 22(6), 723.

Dowling, E., \& Osborne, E. (1985). The family and the school: a joint systems approach to problems with children. London: Routledge.

Farrell, P., Woods, K., Lewis, S., Rooney, S., Squires, G., \& O'Connor, M. (2006). A review of the function and contribution of educational psychologists in England and Wales in light of "Every Child Matters: Change for Children". DfES, Research Report 792.

Fine, M. (1984). Integrating structural and strategic components in school based consultation. Techniques, 1, 44-52. 
Fine, M.J., \& Holt, P. (1983). Intervening with school problems: a family systems perspective. Psychology in the Schools, 20(1), 59-66.

Gilmore, G. (1974). School psychologist-parents contact: an alternative model. Psychology in the Schools, 11, 170-173.

Jones, P. (2006). Every child's parent matters: community educational psychology and the Plymouth parent partnership project. Educational and Child Psychology, 23(1), 16-26.

Lombard, T. (1979). Family-oriented emphasis for school psychologists: a needed orientation for training and practice. Professional Psychology, 10(5), 687-696.

Mackay, T. (2006). The educational psychologist as community psychologist: holistic child psychology across home, school and community. Educational and Child Psychology, 23(1), 7-15.

Wolfendale, S. (2013). Parent partnership services for special educational needs: celebrations and challenges. Routledge.

Wolfendale, S., \& Einzig, H. (2013). Parenting education and support: new opportunities. Routledge.

\section{Appendices}

(1) Gatekeeper Letter

(2) Volunteer Information Email

(3) Informed Consent Form

(4) Participant Information Sheet

(5) Debrief Form

(6) Indicative Questions for Semi-Structured Interviews 


\section{Appendix 1: Gatekeeper Letter}

Address

Date

Dear Principal Educational Psychologist,

I am an educational psychologist working for XXXX LA and I am undertaking doctoral research in the School of Psychology at Cardiff University. As part of my doctoral research I am carrying out a study on educational psychologists' (EPs) experiences of working with families. The purpose of this research is to inform the role of EPs' work with families as part of a child's system to address presenting difficulties. I am writing to enquire whether you would be willing to allow me to approach the EPs within your service, seeking volunteers to be participants in this study.

I would require two EPs from your service to participate in individual semi-structured interviews around their experiences of family work, and their perceptions of the EP role in this area. Interviews will last for approximately 90 minutes, they will be recorded and then transcribed. All data will be anonymised at the point of recording, stored securely, and not identifiable within the final research paper.

If you were in agreement to me seeking volunteers from your service I will provide a formatted email containing some details of the study, and what would be required of participants, for you to email to all EPs in your service, requesting that any interested volunteers contact me directly by email or phone, to discuss further and make arrangements. I have attached a formatted email which can be used for this purpose if you are in agreement.

Many thanks in advance for your consideration of this project. Please let me know if you require further information.

Regards,

Claire McGuiggan

Educational Psychologist

School of Psychology

Cardiff University

Tower Building

70 Park Place

Cardiff

CF10 3AT

McGuigganCL@cardiff.ac.uk
Andrea Higgins

Research Supervisor

School of Psychology

Cardiff University

Tower Building

70 Park Place

Cardiff

CF10 3AT

HigginsA2@cardiff.ac.uk 


\section{Appendix 2: Volunteer Information Email}

Dear EPs in xxx LA Educational Psychology Service,

I am an educational psychologist working for XXXX LA and I am undertaking doctoral research in the School of Psychology at Cardiff University. As part of my doctoral research I am carrying out a study on educational psychologists' (EPs) experiences of working with families. The purpose of this research is to inform the role of EPs in work with families as part of a child's system to address presenting difficulties.

I am writing to enquire whether you would be willing to participate within this study.

Participation would involve completing an individual semi-structured interview around your experiences of working with families within your LA EP role, and your perceptions of the EP role in this area. Any EP who has been in practice for at least three years is eligible to take part in this study.

Interviews will last for approximately 90 minutes, they will be recorded and then transcribed. All data will be anonymised at the point of recording, stored securely, and not identifiable within the final research paper. I would be able to travel to you to complete the interview.

If you would consider taking part in this research, or require more information, please contact me at:

\section{MCGUIGGANCL@cardiff.ac.uk}

Or on:

07761489724

Further information can also be obtained from my research supervisor:

Andrea Higgins, School of Psychology, Cardiff University, Tower Building, 70 Park Place, Cardiff CF10 3AT

HigginsA2@cardiff.ac.uk

Thank you for considering this proposal, I look forward to working with some of you on this study.

Kind Regards,

Claire McGuiggan

Educational Psychologist. 


\section{Appendix 3: Informed Consent Form}

\section{School of Psychology, Cardiff University \\ Consent Form - Confidential data}

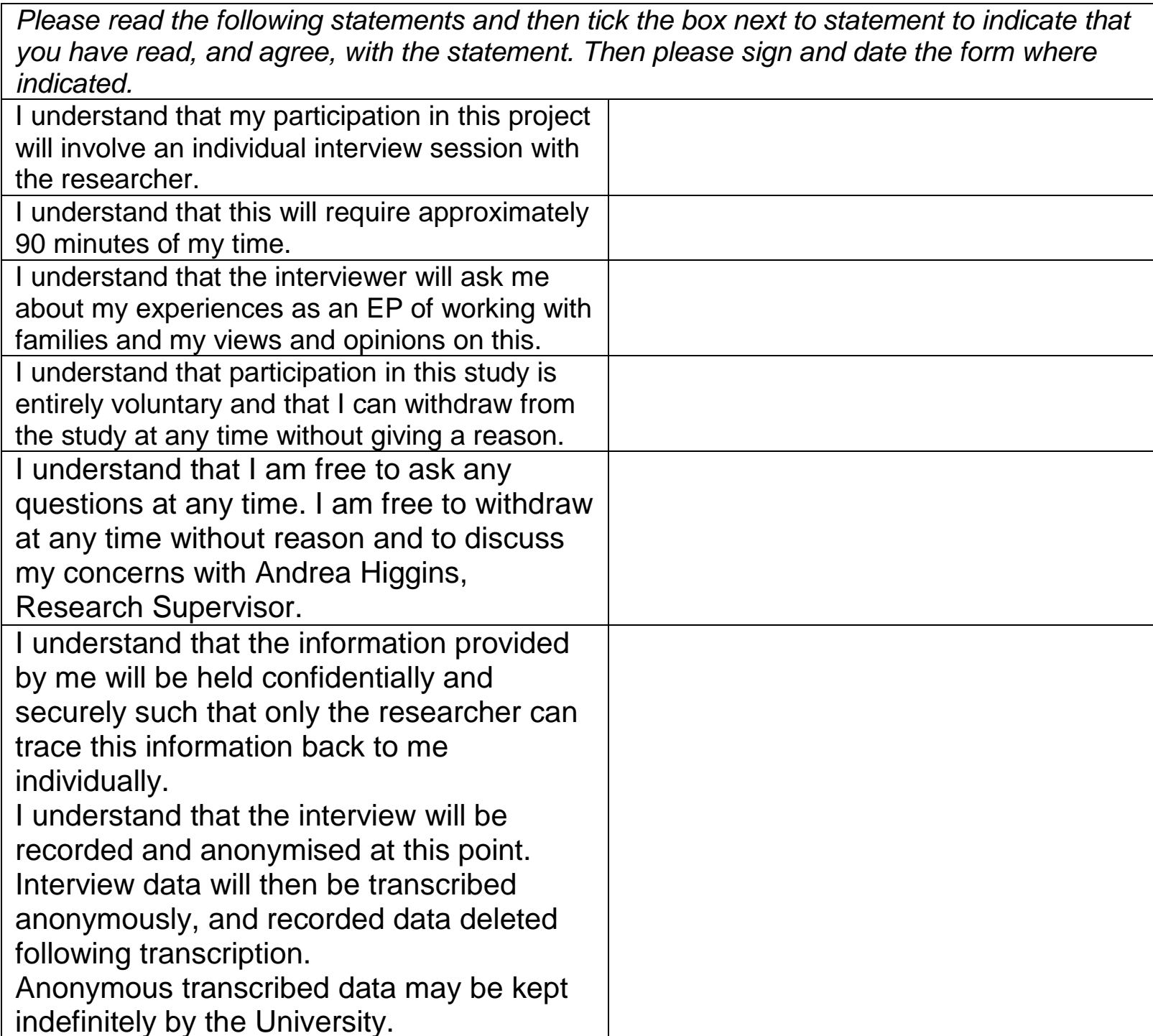

I, (NAME) consent to participate in the study conducted by Claire McGuiggan, School of Psychology, Cardiff University, with the supervision of Andrea Higgins.

Signed:

Date: 
For further information, queries or complaints, you can contact:

Andrea Higgins

Research Supervisor

School of Psychology

Cardiff University

Tower Building

70 Park Place

Cardiff

CF10 3AT

HigginsA2@cardiff.ac.uk

Ethics Committee at the School of Psychology, Cardiff University, Tower Building, 70 Park Place, Cardiff CF10 3AT

psychethics@cardiff.ac.uk 


\title{
Appendix 4: Participant Information Sheet
}

\author{
Information for Participants
}

\section{PLEASE READ THE FOLLOWING INFORMATION CAREFULLY BEFORE PROCEEDING Research Study Information}

I am an educational psychologist working for XXXX LA and I am undertaking doctoral research in the School of Psychology at Cardiff University. As part of my doctoral research I am carrying out a study on educational psychologists' (EPs) experiences of working with families. The purpose of this research is to inform the role of EPs in work with families as part of a child's system to address presenting difficulties.

The title of the research project is:

'Using an ecological systems theory framework to explore educational psychologists' experiences of working with families: an interpretative phenomenological analysis'.

You will be asked about your own experiences, as an LA EP, of working with families and your views and opinions on the EP role in this area.

\section{Interview information}

You are invited to take part in an individual interview session with the researcher, taking approximately 90 minutes, to explore your views on educational psychologists' work with families. All EPs within your own, and several other services, are invited to take part. № individuals have been specifically targeted to participate. Interviews will be recorded and notes taken. The findings will form the basis for a research report for the University of Cardiff which is exploring EPs' experiences of their work with families.

You have the right to decline to answer any questions, or to withdraw from completing the interview at any time.

\section{How will I be protected?}

Participants' names will not be recorded during the interview. Interviews will be allocated a number for data recording purposes. Recorded data will be transcribed for analysis within one month of recording. Transcribed data will be anonymous, and allocated a number for analysis purposes.

Data will be anonymous but may be discussed anonymously with research supervisors at the analysis stage. Findings of the research may be shared with interested parties such as the University however the resulting data will not be identifiable.

\section{What will happen to my data?}

Data will be held securely by myself in the form of a recording of the interview and written notes of the interview made by myself. Recorded data will be kept in a locked cabinet at my home until it has been transcribed. During transportation from the interview location the data 
will be in the possession of the researcher at all times. No one else will have access to the data.

Following transcription data will be held in a locked cabinet at home.

Recorded data will be destroyed at the end of the research project.

Anonymised transcriptions may be held indefinitely by the University.

The findings will be published in a Cardiff University doctoral research publication.

\section{How will I find out about the results?}

A summary of the findings can be sought from the researcher following completion of the research paper.

Researcher: Claire McGuiggan

Cardiff University, School of Psychology, 6th Floor Tower Building, 30 Park Place, Cardiff CF10 3AT

MCGUIGGANCL@cardiff.ac.uk

For further information, queries or complaints, you can contact:

Researcher's Supervisor: Andrea Higgins (Professional Tutor)

Cardiff University, School of Psychology, 6th Floor Tower Building, 30 Park Place, Cardiff CF10 3AT

HIGGINSA2@cardiff.ac.uk

Ethics Committee at the School of Psychology, Cardiff University, Tower Building, 70 Park Place, Cardiff CF10 3AT

psychethics@cardiff.ac.uk 


\section{Appendix 5: Debrief Form}

\section{'Using an ecological systems theory framework to explore educational psychologists' experiences of working with families: an interpretative phenomenological analysis'.}

Thank you very much for taking part in this study.

This study aims to explore educational psychologists' experiences of working with families. The purpose of the research is to inform the role of EPs in their work with families as part of a child's system to address presenting difficulties.

A summary of the findings can be sought from the researcher following completion of the research paper.

All data will be held confidentially in a safe storage unit until the data is transcribed. The data will be entirely anonymous and it will not be identifiable back to any individual. Recorded data will be transcribed within one month and will then be destroyed. Anonymous transcripts may be held indefinitely by the University.

If you would like further information on this research project, or are interested in the outcomes of this project, please contact the researcher.

For any other concerns please contact Andrea Higgins, Research Supervisor, at the School of Psychology, Cardiff University, or the Ethics Committee at the School of Psychology, Cardiff University, Tower Building, 70 Park Place, Cardiff CF10 3AT, psychethics@cardiff.ac.uk

Thank you for your time.

\section{Claire McGuiggan}

Educational Psychologist

School of Psychology

Tower Building

Park Place

Cardiff University

CF10 3AT

MCGUIGGANCL@cardiff.ac.uk

\author{
Andrea Higgins \\ Research Supervisor \\ School of Psychology \\ Tower Building \\ Park Place \\ Cardiff University \\ CF10 3AT
}

HigginsA2@cardiff.ac.uk 


\section{Appendix 6: Indicative Questions for Semi-Structured Interviews}

- What do you feel an EP's role is in work with families?

$>$ Why is that an EP's role/why isn't that an EP's role?

$>$ Whose role is that?

- In what ways do you as an EP work with families?

$>$ Tell me more about your role in $x / y$ work.

$>$ What was significant about your role in that work?

$>$ Why do you feel that is important?

$>$ In what ways do you involve families in psychological formulation?

$>$ In what ways do you involve families in intervention?

- What do you experience as barriers to your role in working with families?

- What do you experience as facilitators in your work with families?

$>$ Tell me more about $x / y$ barrier/facilitator.

$>$ Is this something new or something which has always existed in your role?

$>$ What has changed?

$>$ How would you like it to be?

$>$ Do you feel a move towards more traded models of EP services has changed your role in work with families?

$>$ In what ways?

$>$ Do you feel the recent legislation, Children and Families Act 2014, has changed your role in work with families? In what ways?

$>$ How has your training informed or influenced your work with families? 